Portland State University

PDXScholar

Environmental Science and Management

Professional Master's Project Reports

Spring 2006

\title{
Estuarine Habitat Mitigation in Oregon: Policy Review, Analysis, and Recommended Improvements
}

Anna Buckley

Portland State University

Follow this and additional works at: https://pdxscholar.library.pdx.edu/mem_gradprojects

Part of the Environmental Health and Protection Commons, and the Natural Resources Management and Policy Commons Let us know how access to this document benefits you.

\section{Recommended Citation}

Buckley, Anna, "Estuarine Habitat Mitigation in Oregon: Policy Review, Analysis, and Recommended Improvements" (2006). Environmental Science and Management Professional Master's Project Reports. 5 .

https://pdxscholar.library.pdx.edu/mem_gradprojects/5

https://doi.org/10.15760/mem.33

This Project is brought to you for free and open access. It has been accepted for inclusion in Environmental Science and Management Professional Master's Project Reports by an authorized administrator of PDXScholar. Please contact us if we can make this document more accessible: pdxscholar@pdx.edu. 


\title{
Estuarine Habitat Mitigation in Oregon: \\ Policy Review, Analysis, and Recommended Improvements
}

\author{
By Anna Buckley
}

In partial fulfillment for the Master Degree of Environmental Management

Environmental Science and Resources Program

Portland State University

Portland, Oregon

June 2006

Prepared for the Oregon Department of State Lands 


\section{ACKNOWLEDGEMENTS}

I would like to acknowledge Melissa Feldberg and Oregon Sea Grant for awarding me with the 2005-2006 Natural Resource Policy Fellowship that provided me with the opportunity to embark on this project. Likewise, I would like to extend my appreciation to Janet Morlan and the Department of State Lands for the topic idea and willingness to host me and mentor me through this endeavor. Also, I'd like to thank my graduate committee: Dr. Joe Maser from Portland State's Environmental Science and Resources Graduate Program, Janet Morlan from the Department of State Lands Wetlands Program, and Dr. James Good from Oregon State University’s Marine Resource Management Program for greatly improving this report with their expertise, encouragement, and editing suggestions. Finally, I'd like to thank my friends and family for their enduring support throughout my graduate studies. 


\section{TABLE OF CONTENTS}

ACKNOWLEDGEMENTS

LIST OF FIGURES $\quad$ v

LIST OF TABLES vi

LIST OF ACRONYMS viii

1 INTRODUCTION 1

2 POLICY AND REGULATORY BACKGROUND 5

2.1 Mitigation 5

2.2 Oregon Coastal Management Program 7

2.3 Removal-Fill Law and Wetlands Law 9

2.3.1 Wetlands policy and regulations 10

2.3.2 Salmon policy and regulation $\quad 15$

2.3.3 Mitigation rules $\quad 15$

2.3.4 Estuarine resource replacement (ERR) 17

2.3.5 Estuarine boundaries for ERR 17

2.3.6 Estuarine habitat relative values system 18

2.3.7 Replacement requirements $\quad 21$

3 PERMIT INVENTORY 23

3.1 Introduction and Methodology 23

3.2 Results 25

3.2.1 Development activity 25

3.2.2 Permit description 26

3.2.3 Impacts and mitigation 28

3.2.4 Mitigation method 29

3.2.5 Impacts per estuary 31

3.2.6 Compensation ratios $\quad 32$

$\begin{array}{ll}3.2 .7 \text { Success criteria } & 35\end{array}$

3.3 Summary of Permit Inventory 38

4 ESTUARINE ECOLOGY AND RESTORATION 40

4.1 Introduction 40

4.2 Estuarine Habitat Inventory $\quad 42$

4.3 Primary Productivity 43

4.4 Pacific Northwest Estuarine Fisheries 44

4.5 Invasive Species $\quad 45$

4.6 Water Quality 46

4.7 Estuarine Subhabitats $\quad 48$

4.7.1 Unvegetated flats $\quad 50$

4.7.2 Tidal marshes $\quad 51$

4.7.3 Eelgrass beds $\quad 52$

4.8 New Tidal Datum $\quad 54$

4.9 Estuary and Estuarine Wetland Changes $\quad 56$

4.10 Status of the Science of Tidal Wetland Restoration 58

4.10.1 Introduction 58

4.10.2 Successes 60

4.10.3 Defining success 61

4.10.4 Causes of failure 63

4.10.5 Regulatory compliance $\quad 64$

4.10.6 Need to incorporate adaptive management 65 
4.10.7 Performance criteria 66

4.10.8 Tidal marsh restoration technique 73

4.10.9 Seagrass restoration technique $\quad 75$

$\begin{array}{ll}\text { 4.11 Summary } & 76\end{array}$

5 WETLAND ASSESSMENT TOOLS AND COMPENSATION 78 METHODS

5.1 Introduction $\quad 78$

$\begin{array}{ll}\text { 5.2 HGM Functional Assessment } & 79\end{array}$

5.3 Oregon's HGM Functional Assessments 80

5.3.1 ERR compared to HGM functional assessment $\quad 75$

5.3.2 HGM potential application 83

5.3.3 Estimating ecological lift 83

5.3.4 Calculating enhancement credit 85

5.3.5 Additional enhancement ideas 86

5.3.6 HGM shortcomings 88

5.3.7 Oregon Wetland Rapid Assessment Program 89

5.4 Compensation $\quad 89$

5.4.1 Incorporation of functional assessments into ratios $\quad 89$

5.4.2 Temporal loss and habitat maturation 93

5.4.3 Offsite compensation 96

5.4.4 In-kind vs. out-of-kind compensation 97

5.4.5 Out-of-kind as applied to Oregon's estuarine wetlands99

5.4.6 Mitigation banking 101

5.4.7 Conservation in lieu 109

5.4.8 Payment to provide $\quad 110$

5.5 Summary 111

6 TAKING A WATERSHED APPROACH TO ESTUARINE 113

MITIGATION

6.1 Introduction 113

6.2 Call for a Watershed Approach 113

6.2.1 Mitigation Action Plan 116

6.2.2 North Carolina's watershed approach $\quad 117$

6.2.3 San Francisco Bay 122

6.2.4 Alabama 122

6.3 Oregon's Resources for Implementing a Watershed Approach 122

6.3.1 Wetland Conservation Plans 123

6.3.2 GIS Permit Database 124

6.3.3 Data 126

6.3.4 Estuarine Habitat Inventory 128

6.3.5 Estuarine and Watershed Restoration Priorities 132

6.3.6 Oregon Coast Ecoregions 135

6.3.7 Other Coastal Priorities 137

6.4 Summary 143

7 RECOMMENDATIONS 146

7.1 Introduction 146

7.2 Statutory Changes $\quad 146$

$\begin{array}{ll}7.3 \text { Rule Changes } & 147\end{array}$

7.4 Standard Operating Procedures $\quad 150$

7.5 Other Areas 153 
REFERENCES

158 


\section{LIST OF FIGURES}

FIGURE

Figure 1: Oregon's estuaries (Cortright et al. 1987).

Figure 2: Statewide classification for Oregon’s estuaries (Cortright et al. 1987).

Figure 3: Classification hierarchy of wetlands and deepwater habitats

(Cowardin et al. 1979).

Figure 4: Oregon’s Estuarine habitats (Hamilton 1984).

Figure 5: Estuarine Habitat Types and Relative Values (Hamilton 1984).

Figure 6: Number of removal-fill permits per development activity in estuaries from 1989-2005.

Figure 7: Acres of impact per development activity from 1989-2005.

Figure 8: Net change per habitat type 1989-Oct 2005.

Figure 9: Number of permits per mitigation method, 1989-2005.

Figure 10: Acres of impact versus mitigation activity for permits during 1989-2005.

Figure 11: Estuarine Impacts in acreage per estuary during 1989-2005.

Figure 12: Permitted acres of mitigation per acres of impact compared to hypothetical 34 acres of mitigation if freshwater ratios and/or estuarine relative values used.

Figure 13: Acres of mitigation per acre of impact for the 12 in-kind permits.

Figure 14: Restoration Consideration Areas (RCA) in yellow within proposed Siuslaw 105 Bank (Scranton 2004).

Figure 15: Distribution of estuarine habitat in Oregon (Scranton 2004).

Figure 16: Restoration Consideration Area's as a percent of Estuary Area (source: Scranton 2004).

Figure 17: Oregon Coastal Tidal HGM classification (source: Scranton 2004).

Figure 18: Breakdown of estuary tidal HGM class per estuary (source: Scranton 2004). 131 
Figure 19: Oregon Coast Level IV Ecoregions (Thorson et al. 2003). 


\section{LIST OF TABLES}

TABLE

\section{PAGE}

Table 1: Development Activity associated with Removal Fill Permits in Oregon Estuaries. 25

Table 2: Permitted impacts and mitigated acres per Cowardin class for 1989-2005 29 for permits involving estuarine impacts and/or estuarine mitigation.

Table 3: Ratios of mitigation acres to impact acres for permits involving estuarine mitigation 33 during 1989 to 2005.

Table 4: Summary of success criteria used in estuarine resource replacement associated 36 with removal fill permits from 1989-2005 inventory.

Table 5: Status of mitigation projects meeting success criteria. 37

Table 6: Average productivity value based upon estuarine mitigation rules (Hamilton 1984). 41

Table 7: Habitat type per estuary (Good 1999).

42

Table 8: Net primary production estimates (gC/m2-yr) per habitat type in Oregon's estuaries. 43

(source: Emmett et al. 2000).

Table 9: Ecological functions identified for select estuarine subhabitats 49

(Short et al. 2000; Adamus 2005).

Table 10: Submersed aquatic vegetation habitat requirements developed for 54

Chesapeake Bay (Fonseca et al. 1998).

Table 11: New tidal elevations based upon 1983-2001 epoch and NAVD 1988. 55

(source: NOAA 2006).

Table 12: Changes in estuarine wetlands from 1870 to 1970 (Good 2000). 57 
Table 13: Wetlands and tidal elevation surface area for Coos Bay (source: Borde et al. 2003). 58

Table 14: Changes in acres of existing tidal wetlands in Oregon's estuaries 59 between 1970 \& 2002 (source: Scranton 2004).

Table 15: Recommended structural and functional attributes for monitoring restoration projects 72 (Pinnitt et al. 1998).

Table 16: Functions of Oregon's estuarine wetlands identified by relative values 82 (Hamilton 1984) and the tidal HGM tool (Adamus 2005).

Table 17: Summary statistics of the estuarine resource replacement rules 'natural biological productivity and species diversity' of habitat types (source: Hamilton 1984) and function capacity scores for the 120 wetlands surveyed for tidal HGM method (source: Adamus 2005).

Table 18: Washington’s compensatory wetland mitigation ratios (DOE et al. 2006). 93

Table 19: Estuarine habit and tidal marsh habitat zoned for development and acres zoned for 98 mitigation in Oregon's estuaries (Cortright et al. 1987).

Table 20: Coastal communities with approved or pending Local Wetland Inventories 126 (DSL 2006).

Table 21: List of Watershed-based assessments and restoration priorities for 133 Oregon's Coastal Watersheds and Estuaries.

Table 22: Priority habitats established by Oregon Watershed Enhancement Board 139

(OWEB 2004). 


\section{LIST OF ACRONYMS}

CM-Compensatory Mitigation

CWA-Clean Water Act

CWM-Compensatory Wetland Mitigation

DCM-Division of Coastal Management

DEQ-Oregon Department of Environmental Quality

DLCD-Oregon Department of Land Conservation and Development

DOE-Washington Department of Ecology

DSL-Department of State Lands

E1UB-Estuarine Subtidal Unconsolidated Bottom

E2AB-Estuarine Intertidal Aquatic Bed

E2EM- Estuarine Intertidal Emergent

E2EM/SS- Estuarine Intertidal Emergent Scrub-shrub

E2FO- Estuarine Intertidal Forested

E2RS- Estuarine Intertidal Rocky Shore

E2SB- Estuarine Intertidal Strean Bed

E2SS- Estuarine Intertidal Scrub-shrub

E2US- Estuarine Intertidal Unconsolidated Sand

ELI-Environmental Law Institute

EPA-Environmental Protection Agency

ERR-Estuarine Resource Replacement

ESA-Endangered Species Act

ESH-Essential Salmon Habitat

FCI-Functional Capacity Index

FCU-Functional Capacity Units

FCZMA-Federal Coastal Zone Management Act

FWCA-Fish and Wildlife Coordination Act

FWPCA-Federal Water Pollution Control Act

GIS-Geographic Information Systems

HEA-Habitat Equivalency Analysis

HGM-Hydrogeomorphic

HGM WP-Hydrogeomorphic Wetland Profile

HMT-Highest Measured Tide

HUC-Hydrologic Unit Code

IMST-Independent Multi-disciplinary Science Team

LAS-Land Administrative System

LCREP-Lower Columbia River Estuary Partnership

LWD-Large Woody Debris

LWI-Local Wetland Inventory

MAP-Mitigation Action Plan

MBRT-Mitigation Bank Review Team

MHW-Mean High Water

MHHW-Mean Higher High Water

MLW-Mean Low Water

MLLW-Mean Lower Low Water

MSH-Marine Sourced High

MSL-Marine Sourced Low 
NC-CREWS-North Carolina Coastal Region Evaluation of Wetland Significance

NCEEP-North Carolina's Ecosystem Enhancement Program

NEPA-National Environmental Policy Act

NGVD-National Geodetic Vertical Datum

NMFS-National Marine Fisheries Service

NOAA-National Oceanic and Atmospheric Administration

NRC-National Research Counsel

NRCS-Natural Resource Conservation Service

NTDE-National Tidal Datum Epoch

NWI-National Wetland Inventory

OAR-Oregon Administrative Rules

ODFW-Oregon Department of Fish and Wildlife

ODOT-Oregon Department of Transportation

OEP-Oregon Estuary Plan

OHJV-Oregon Habitat Joint Venture

ORNHIC-Oregon Natural Heritage Information Center

ORS-Oregon Revised Statues

OWEB-Oregon Watershed Enhancement Board

OWRAP-Oregon Wetland Rapid Assessment Program

OWRD-Oregon Water Resources Department

PAB-Palustrine Aquatic Bed

PAR-Photosynthetically Available Radiation

PEM-Palustrine Emergent

PEM/SS- Palustrine Emergent Scrub-shrub

PF-Forested Tidal Wetland

PFO-Palustrine Forested

PFO/SS- Palustrine Forested Scrub-shrub

PSS- Palustrine Scrub-shrub

PTP-Payment to Provide

RAE-Restore American Estuaries

RCA-Restoration Consideration Area

R/PSS- Riverine/Palustrine Scrub-shrub

RS-River-sourced

SPGP-State Programmatic General Permit

SSNERR-South Slough National Estuarine Research Reserve

SWI-Statewide Wetlands Inventories

USACE- United States Army Corps of Engineers

USFWS-United States Fish and Wildlife Service

USGS-United States Geological Survey 


\section{CHAPTER 1}

\section{INTRODUCTION}

Estuaries are "partially enclosed tidal inlets of the sea in which sea water and river water mix to some degree” (Little 2000). As a transitional area between freshwater and marine ecosystems, estuaries are biological hotspots that provide important habitat for fish and wildlife including numerous migratory and resident shorebirds and waterfowl, marine mammals including Stellar sea lions, Dungeness crab, flounder, and juvenile salmon (Thom 1987).

Oregon’s estuaries are geologically young and exist along the North American-Juan de Fuca Plate subduction zone (Emmett et al. 2000). This subduction zone has produced mountain ranges that include the Coast Range, the Klamath, and Cascade Mountain ranges and is also responsible for the large earthquakes that occur every 300-500 years.

There are 22 major estuaries along Oregon’s 300-mile coastline (Figure 1), each with varying characteristics of salinity, river flow inputs, mixing, morphology, and substrate composition (Bottom et al. 1979). Mean elevation differences between low and high tide in Oregon's estuaries are considered mesotidal with ranges greater than six feet (Emmett et al. 2000). With the exception of the Columbia River, most of Oregon's estuaries are smaller than $100 \mathrm{~km}^{2}$

At the end of the last ice age (10,000-15,000 years ago), rising sea levels flooded coastal river valleys, which created Oregon's estuaries. Most west coast estuaries are drowned-river valley estuarine systems with small watersheds from adjacent coastal mountains with little to zero annual snowfall. However, the Umpqua, Rogue, and Columbia rivers drain interior basins and thus snowmelt contributes to the freshwater input to these estuaries. Estuaries with small watersheds are generally well mixed, but those with larger riverine inputs such as the Columbia tend to be seasonally stratified (Good 1999). As a bar-built estuary, Netarts Bay is an exception to drowned-river valley estuaries commonly found along Oregon's coast. Bar-built estuaries are generally shallow and occur at river mouths where sand accumulates offshore (Little 2000).

Oregon’s Mediterranean climate with mild wet winters and hot dry summers results in seasonal variations of riverine and marine influence. Highest freshwater inflows occur during winter with very little freshwater input during summer and early fall. During spring and summer, high-pressure northwesterly winds drive ocean upwelling of cooler, nutrient-rich water to the near shore ocean (Colbert \& McManus 2003; Sigleo et al. 2005) surface resulting in 
phytoplankton (mostly diatoms) blooms. The tides carry the nutrient-rich water and phytoplankton into estuaries providing the basis of the food chain for free-swimming organisms such as fish, known as 'nekton'.

Oregon’s commercial fisheries are dependent upon estuaries as spawning, rearing, and resting habitat for numerous species of salmonids, clams, oysters, herring, and crab. Additionally, among other functions, estuaries can filter pollutants, stabilize the shoreline against erosion, and provide recreation opportunities such as bird watching and kayaking (Good 1987). Due to their relatively small area, Oregon's estuaries provide little floodwater storage compared to other regions in the United States such as the Gulf Coast (Adamus 2005).

From 1870 to 1970, two-thirds to 80\% of Oregon’s estuarine wetlands were impacted (Good 2000; Scranton 2004). In the early twentieth century, the wetland impacts were mainly due to draining and diking tidal wetlands to allow for agriculture and livestock grazing. Agricultural impacts were later followed by impacts associated with urban development, port growth, and navigation channel dredging for deep and shallow water navigation. While important to the economic and social vitality of coastal and inland communities, these anthropogenic impacts can also have deleterious impacts on the functions and values provided by estuaries (Good 2000; Adamus 2005; DeLuca et al. 2003; Long 2000)

Due to the ecological, social, and economic importance of estuaries, federal and state policies were developed to research and manage Oregon's estuarine ecosystems starting in the 1970’s. For instance, the Columbia River Estuary was designated as a Land Margin Ecosystem study area by the National Science Foundation and is included in the EPA National Estuary Program, as is the Nehalem, Tillamook, Nestucca, Sand Lake and Netarts Bay in the Tillamook Estuary Partnership. The South Slough, a branch of Coos Bay, is part of the National Oceanic and Atmospheric Administration's (NOAA) National Estuarine Research Reserve program and sponsored locally by the Oregon Department of State Lands. National Wildlife Refuges are located in the Coquille, Nestucca, and Siletz Bays. The comprehensive state policy for managing Oregon's coastlands is the Coastal Management Program, which is a networked program implemented by several state, regional, and local agencies.

With extensive protection afforded by Oregon’s Coastal Management Program, estuarine impacts are now rare, with over $98 \%$ of the remaining estuary protected from development. One regulatory element of this program is the Estuarine Resource Replacement statute (ORS 196.830) and associated rules (OAR 141-085-0240 to 0266) that require compensatory mitigation for permitted estuarine removal/fill impacts. Although impacts are rare, it has been 
over two decades since a major evaluation of the estuarine resource replacement program has been undertaken. During this time period, concepts of landscape ecology and salmon recovery efforts have broadened and deepened our understanding of estuaries. Furthermore, methods for classifying wetlands and tools for estuarine wetland functional assessment have expanded. At the state level with the passage of the Wetlands Conservation Act, wetland protection has expanded to protect all wetland types, not just estuarine. Additionally, more recent rules have been written and adopted for freshwater wetland compensatory mitigation that require different compensation requirements and have different definitions of restoration and enhancement. Finally, there is a body of scientific literature documenting the limitations of compensatory mitigation and suggestions for improving this practice. In response, a federal interagency group has been working to implement suggestions for improving the policy of compensatory mitigation. The goal of this project was to analyze Oregon's estuarine mitigation statute and rules in the context of scientific and political developments that have emerged over the past two decades and to identify areas for improvement.

The report is organized in the following manner. After the introductory chapter (Chapter 1), Chapter Two describes Oregon’s current estuarine policy and related state and federal policies. Chapter Three provides an inventory of recent permitted impacts and associated estuarine resource replacement. Chapter Four consists of a brief summary of the status of estuarine ecology and restoration/mitigation, with knowledge gaps identified. Chapter Five discusses wetland functional assessment tools and options for compensatory mitigation. This chapter begins with a description of the tidal Hydrogeomorphic (HGM) assessment method, how it compares to the estuarine resource replacement rules' relative values table, and the utility of the tidal HGM in estuarine mitigation. Chapter Five, then, explores alternative mitigation options such as out-of-kind, banking, payment-in-lieu, and conservation in lieu. Chapter Six introduces the concept of incorporating compensatory mitigation into a watershed approach. Based upon the information gathered from the ecological and restoration/mitigation literature and the permit inventory, Chapter Seven outlines recommendations to change the statute, the rules, the standard operating procedures, and other aspects of Oregon's estuarine resource replacement program. 


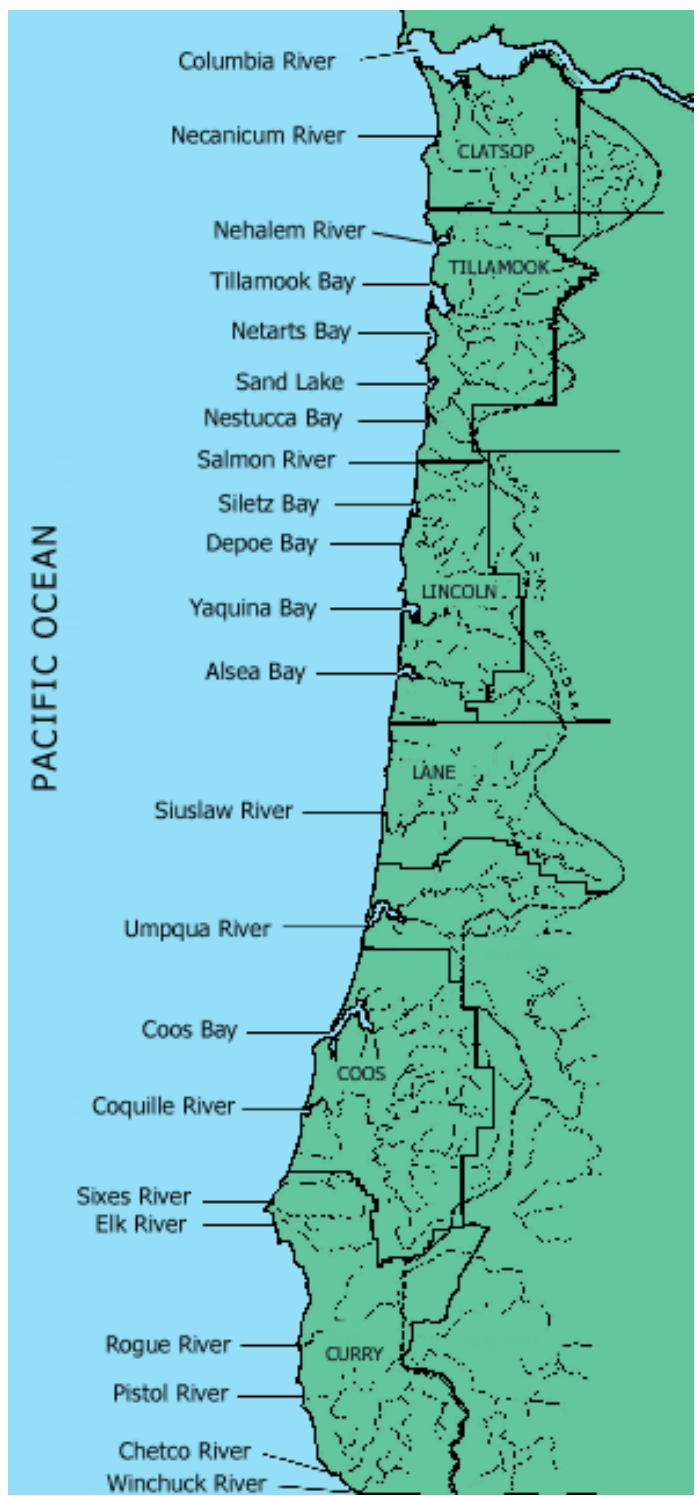

Figure 1: Oregon's estuaries (Cortright et al. 1987). 


\section{CHAPTER 2}

\section{POLICY AND REGULATORY BACKGROUND}

\subsection{Mitigation}

A number of federal regulations require mitigation for environmental impacts. As described by Blomberg (1987), these regulations include the Fish and Wildlife Coordination Act (FWCA) of 1958, the National Environmental Policy Act (NEPA) of 1969, The Federal Water Pollution Control Act, now known as the Clean Water Act (CWA) of 1972, the Endangered Species Act (ESA) of 1973, and the Federal Coastal Zone Management Act (CZMA) of 1972. The FWCA provides the authority to regulate activities that affect or modify any stream or body of water, to minimize the adverse impacts on fish and wildlife resources and habitat. NEPA was enacted by Congress in 1969 to establish a national environmental protection policy. This policy requires the preparation of an environmental assessment (EA) to determine if a proposed federally-funded action will have a significant effect on the quality of the human environment. The CWA governs pollution control and water quality of the Nation's water bodies. Section 404 of the CWA provides the authority for a permit program that regulates the disposal of dredged or fill material into navigable waters, as defined by the CWA. Section 401 of the CWA requires states to develop water quality standards and water quality certification for dredge or filled activities in navigable waters. The ESA requires the conservation of endangered and threatened species and their habitats. Under the ESA, the National Marine Fisheries Service (NMFS) and the U.S. Fish and Wildlife Service (USFWS) publish lists of endangered and threatened species. The CZMA's objective is to preserve, protect, develop, and restore the nation's coastal resources.

While all of these regulations require mitigation to reduce adverse impacts and to compensate for permitted estuarine impacts, the FWCA was the first regulation to introduce contemporary mitigation as a tool for managing environmental impacts associated with development. The federal agencies responsible for implementing these aforementioned regulations include the US Fish and Wildlife Service, the US Environmental Protection Agency, the US Army Corps of Engineers, the National Oceanic and Atmospheric Administration, and the National Marine Fisheries Service. The FWCA requires the US Fish and Wildlife Service (USFWS) to evaluate development proposals for estuarine impacts in relation to potential damage to wildlife. Such proposals must discuss efforts for mitigating and compensating for damages. The USFWS mitigation requirements have four levels of habitat value based on 
scarcity and importance to groups of species. Estuarine habitats generally fall under the high value category for scarce resources in which the mitigation goal is "no loss of in-kind habitat value”.

Similarly, but in a broader sense, NEPA requires federal agencies to evaluate environmental impacts of proposed development through a project alternatives analysis which includes the mitigation sequence: avoiding impacts, minimizing impacts, rectifying impacts, reducing the impact over time, and compensating for impacts (Blomberg 1987). Section 404 of the CWA requires that the US Army Corps of Engineers (USACE) and the Environmental Protection Agency (EPA) regulate the discharge of materials in waters of the United States, which include tidelands and many wetlands. As with NEPA, the 404 program requires the same mitigation sequence for projects that have the potential to adversely affect water supplies, shellfish beds, and fishing areas. As outlined in the Memorandum of Agreement between the USACE and the EPA entitled "The determination of mitigation under the Clean Water Act Section 404(b)(1) guidelines”, the policy goal is to strive for no overall net loss of values and functions for wetlands and in-kind aquatic site replacement in close proximity to the impact site is preferred (USACE 1990). In addition to section 404 of the CWA, the USACE is responsible for implementing Section 10 of the Rivers and Harbors Act, which regulates certain activities in navigable rivers, including tidal waters to mean high water. Impacts to navigable rivers require mitigation.

Originally developed recommended by the National Wetlands Policy Forum in 1988 (The Conservation Foundation 1988), an administrative policy of “no-net-loss” of wetlands was adopted by the EPA under the presidential leadership of President George H.W. Bush in January of 1989. The goal applied to both wetland acreage and associated functions and values. In the Clean Water Action Plan of 1998, President Clinton expanded the goal of 'no net loss' to a goal of 'net gain' of 100,000 acres per year by 2005 (EPA 2006). At the state level, Oregon has also adopted a goal of 'no net loss of freshwater wetlands' and, due to their significant historical losses, a 'net gain of 250 acres of estuarine wetlands per year' by the Oregon Progress Board (DSL 2004). Compensatory wetland mitigation plays an important role in meeting 'no net loss' of wetlands at both the state and federal level.

In Oregon, state agencies are involved in implementing aspects of federal regulations, but also have to implement state regulations. The Oregon Department of Fish and Wildlife works with the US Fish and Wildlife Service and National Marine Fisheries Service to implement the Fish and Wildlife Coordination Act. The Oregon Department of Fish and Wildlife is also 
responsible for implementing the State’s Endangered Species Act. The Oregon Department of Environmental Quality implements the CWA's Section 401 certification program, while the Department of Land Conservation and Development’s Coastal Management Program ensures activities are consistent with the federal Coastal Zone Management Act. The state regulations that give Oregon legal authority to manage removal and fill activity and require compensation for impacts in Oregon's estuaries are the Removal-fill Law and Estuarine Resource Replacement Law, implemented by the Oregon Department of State Lands (DSL).

\subsection{Oregon Coastal Management Program}

Although federal legislation, the Coastal Zone Management Act of 1972 (FCZMA) used the incentive of financial support to encourage states to develop coastal management plans. Aiming to balance ecological, cultural, historical, and aesthetic values, these plans were designed to protect wetlands, floodplains, estuaries, fish and wildlife and their habitat within the coastal zone (Good et al. 1999). In response to this federal act, Oregon networked the Comprehensive Land Use Planning Program (DLCD 2001) with other state laws such as the Beach Bill and the Removal-fill Law to establish Oregon’s Coastal Management Program, which was approved in 1977. During 1971-1976, 19 planning goals were developed under Oregon’s Land Use Law to provide specific planning objectives for land use in Oregon (Cortright et al. 1987). Local governments are required to develop comprehensive plans and land use regulations that meet the requirements in the statewide goals. Those plans and regulations are then reviewed and “acknowledged’ by the Department of Land Conservation and Development (DLCD). Goals 16 and 17 relate to estuarine land use. DLCD is responsible for overseeing the implementation of all land use goals and, more to the point, is the state agency that manages Oregon's Coastal Management Program ensuring the program is consistent with the CZMA.

\footnotetext{
Adopted in December 1976, Goal 16: Estuarine Resources (OAR 660-015-0010(1)) set out to achieve long-term environmental, economic, and social sustainability within Oregon's estuaries. This goal required the classification of all estuaries as natural, conservation or development (shallow draft and deep draft development), which would dictate land use activity ranging from the most to the least protective. Figure 2 depicts the classification for each estuary in Oregon. Additionally, cities and counties were required to cooperatively develop estuary plans that subdivided each estuary into natural, conservation, and development management units. Each estuary can subdivide only to the least restrictive management level. For example, a 'conservation' estuary may only have 'natural' and 'conservation' subunits, whereas as a 'development' estuary can have all three subunits (Cortright et al. 1987). Goal 16 includes specific permitted or unpermitted land use activities for each type of management unit that must be adopted as regulations by the cities and counties.
}

As the nation's first statewide mandatory estuarine mitigation program (Quarterman 1985), Goal 16 included the provision: “When dredge or fill activities are permitted in intertidal 
or tidal marsh areas, their effects shall be mitigated by creation, restoration, or enhancement of another area to insure that the integrity of the estuarine ecosystem is maintained” (DLCD 2006a). Impacts to subtidal habitat below lowest measured tide do not require mitigation (Smith 1983). Additionally, the goal required estuary plans to identify and to protect potential land for mitigation sites. These mitigation sites were usually areas of heavy erosion or sedimentation, degraded fish and wildlife habitat, abandoned diked estuarine marshes, and areas of poor water quality (Smith 1983). Comprehensive estuary plans designated 98\% of remaining intertidal lands as natural or conservation management units (Good et al. 1999). Remaining intertidal areas zoned for development are predominantly in the deep draft development estuaries of the Columbia River, Tillamook Bay, Yaquina Bay, and Coos Bay. Thus, the estuary plans provide a high level of protection to Oregon's estuaries.

The other comprehensive land use goal related to estuaries is Goal 17: Coastal Shorelands (OAR 660-015-0010(2)) (DLCD 2006b). This goal requires cities and counties to designate shore lands, including estuary shore lands, into resource protection, rural, and waterdependent development use categories (Good 1981). Major marshes are one of the significant habitats that receive some protection under Goal 17.

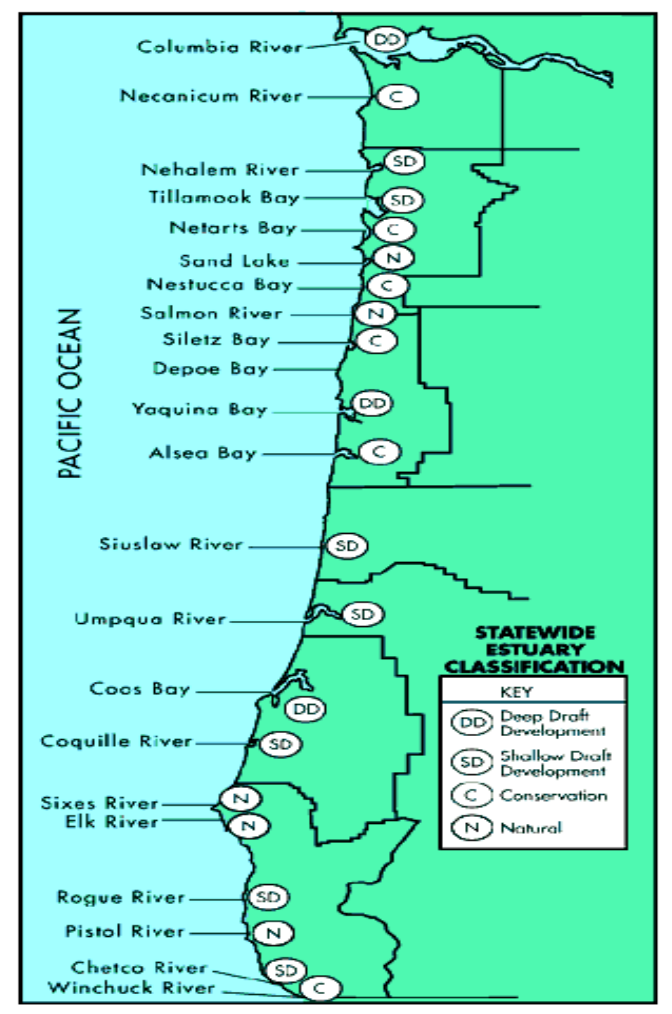

Figure 2: Statewide classification for Oregon's estuaries (Cortright et al. 1987). 
Oregon's Removal Law of 1967 (amended to include Fill in 1971) is administered by the Department of State Lands (DSL). This law is designed to protect, conserve, and allow the best use of the state's water resources (DSL 2006). "Waters of the State" are defined as " natural waterways including all tidal and non-tidal bays, intermittent and perennial streams, lakes, wetlands and other bodies of water in this state, navigable and nonnavigable, including that portion of the Pacific Ocean, which is in the boundaries of this state.” (DSL 2006).

A state Removal-fill permit is required if an activity involves the removal or fill of more than 50 cubic yards of material within the bed or banks of waters of the state, which includes bays and estuaries to the head of tide including land less than or equal to the elevation line of nonaquatic vegetation, if discernible, or the highest measured tide (HMT). In 1979, House Bill 2619 revised the Removal-fill Law to require estuarine resource replacement, the Oregon Mitigation Law, with the issuance of a Removal-fill permit. The Oregon Mitigation Law (ORS 541.626) is now called the Estuarine Resource Replacement statute (ORS 196.830). In addition to DLCD’s Coastal Management Program mandatory consistency review, the Oregon Department of Fish and Wildlife (ODFW) and the Oregon Department of Environmental Quality (DEQ) provide review comments related to fish and wildlife and water quality impacts on Removal-fill Permit applications submitted to DSL for proposed projects in Oregon's estuaries (Blomberg 1987).

\subsubsection{Wetlands policy and regulations}

Estimates have been made that the United States has lost more than half of its wetlands habitat since European colonization; and wetland loss in Oregon is estimated to be 38\% (Dahl 1990). Due to this great loss and increased understanding of the various goods and services provided by wetlands, a national policy of “no net loss” of wetlands was adopted in 1988. Introduced initially by the National Wetlands Policy Forum in 1988 (The Conservation Foundation 1988), this policy has been embraced by each United States President since that time and has been incorporated into many federal agency requirements. The general concept for achieving this goal was to compensate for unavoidable wetland impacts by restoring or creating an area of equal size elsewhere. This practice is commonly called 'wetland compensatory mitigation'. Due to the recognition that not all wetlands provide the same functions, goods, and services, no net loss in terms of area has been expanded to include no net loss of ecosystem function, compensating not only for the area of impact but also for the loss of function related to 
that impact (i.e., water storage, water filtration, wildlife habitat, etc.). This provided impetus for the development of tools to assess wetland function (Bartoldus 1999). To compensate for historical losses, natural resource management nonprofits and agencies began to restore degraded aquatic habitat outside of the regulatory framework, resulting in the extension of the "no net loss” to "net gain” of wetlands acres. Nonregulatory or voluntary ecosystem restoration efforts are undertaken for their own sake and value, not to lessen or mitigate development impacts.

\section{Wetland definitions and classifications}

Different definitions and classifications exist for wetlands depending upon their purpose. Wetland definitions (and related criteria) are used to determine if an area is or is not a wetland, and to delineate wetland boundaries. Once wetlands are identified, they are often "classified” by type based upon various characteristics. In the regulatory context, DSL uses the same wetland definition as the U.S. Army Corps of Engineers: "wetlands are those areas that are inundated or saturated by surface or ground water at a frequency and duration sufficient to support, and that under normal circumstances do support, a prevalence of vegetation typically adapted for life in saturated soil conditions.” (ORS 196.800(17)).

DSL’s Wetlands Regulatory Program requires use of both the Cowardin classification (Cowardin et al. 1979) and, more recently, the Hydrogeomorphic (HGM) classification (Brinson 1993; Adamus 2001; 2005) in wetland permit applications and compensatory wetland mitigation plans. According to Cowardin, wetlands occurring in estuaries include tidal waters of coastal rivers and embayments, salty tidal marshes, mangrove swamps, and tidal flats. Cowardin's Estuarine System has two subsystems: subtidal and intertidal (Figure 3) and 12 classes. The ‘Aquatic bed’ class includes macroalgal beds and seagrass (eelgrass) beds.

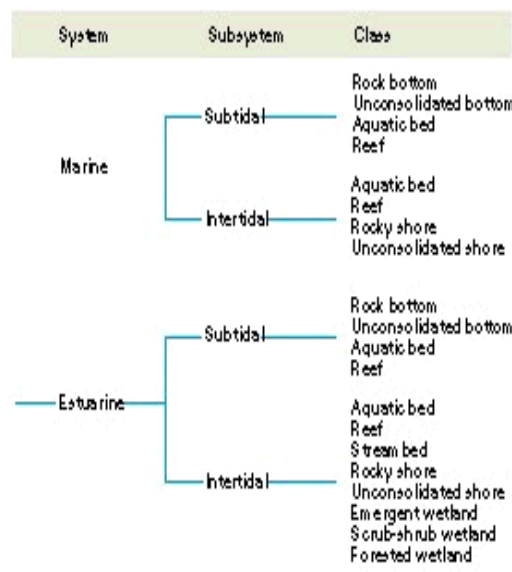

Figure 3: Marine and Estuarine classification hierarchy of wetlands and deepwater habitats (Cowardin et al. 1979). 
While the Cowardin classification "class” level classified wetlands primarily on vegetation or substrate type, the Hydrogeomorphic (HGM) classification system was developed in recognition of the importance of abiotic or physical characteristics in dictating the occurrence and types of wetlands across the landscape (Brinson 1993). This classification system recognizes that wetlands can be distinguished from one other by their position in the landscape, source of hydrology, and direction of water flow. Generally speaking, wetlands in similar landscape positions with similar hydrology will function similarly. Examples of HGM classes are Estuarine Fringe, Riverine, Depression, and Slope wetlands. A significant characteristic of the HGM is that the classification system is developed regionally and provides a framework for functional assessment methodology. Oregon has developed a statewide HGM classification (Adamus 2001) and related functional assessment guidebooks for two regions - the Willamette Valley and for Coastal Estuarine Fringe or tidal wetlands. A distinction is made between wetland functions and values. While functions are inherent to the habitat, a value is societal based, which can change over time and is more subjective. For example, wetland function include nutrient cycling, water storage, and wildlife habitat. Societal values attached to wetland functions could include less treatment needed for drinking water source, reduced property damage due to reduced flooding, and recreational activities such as bird watching. The HGM classification system classifies wetlands found in estuaries as Estuarine Fringe (Brinson 1993). HGM classes can be further divided into subclasses. Adamus (2005) named three subclasses for Oregon's Estuarine Fringe class: River-sourced, Marine-sourced High Marsh, and Marinesourced Low Marsh, which are described in more detail in Chapter 5.3, Oregon’s HGM Functional Assessments.

Bottom et al. (1979) provided the classification basis for DSL's estuarine rules. Modeled after Cowardin, the classes include both intertidal and subtidal tidal regimes found in Oregon. These classes are vegetated/unvegetated flats and tidal marsh. Subclasses exist for each of these classes depending upon subsystem in the estuary (marine, bay, slough \& riverine), substrate type, and vegetation type (Figure 4).

The HGM Estuarine Fringe classification system (Adamus 2005) classifies tidal forested and emergent marsh habitats based upon tidal inundation regimes and water source, but does not include algal or eelgrass beds or unvegetated estuarine habitats. The vegetated estuarine subclasses meet the state wetland definition, while the unvegetated estuarine subclasses such as rock bottom, streambed, rocky shore and unconsolidated shores are included as waters of the state as defined by the Removal-fill Law. 


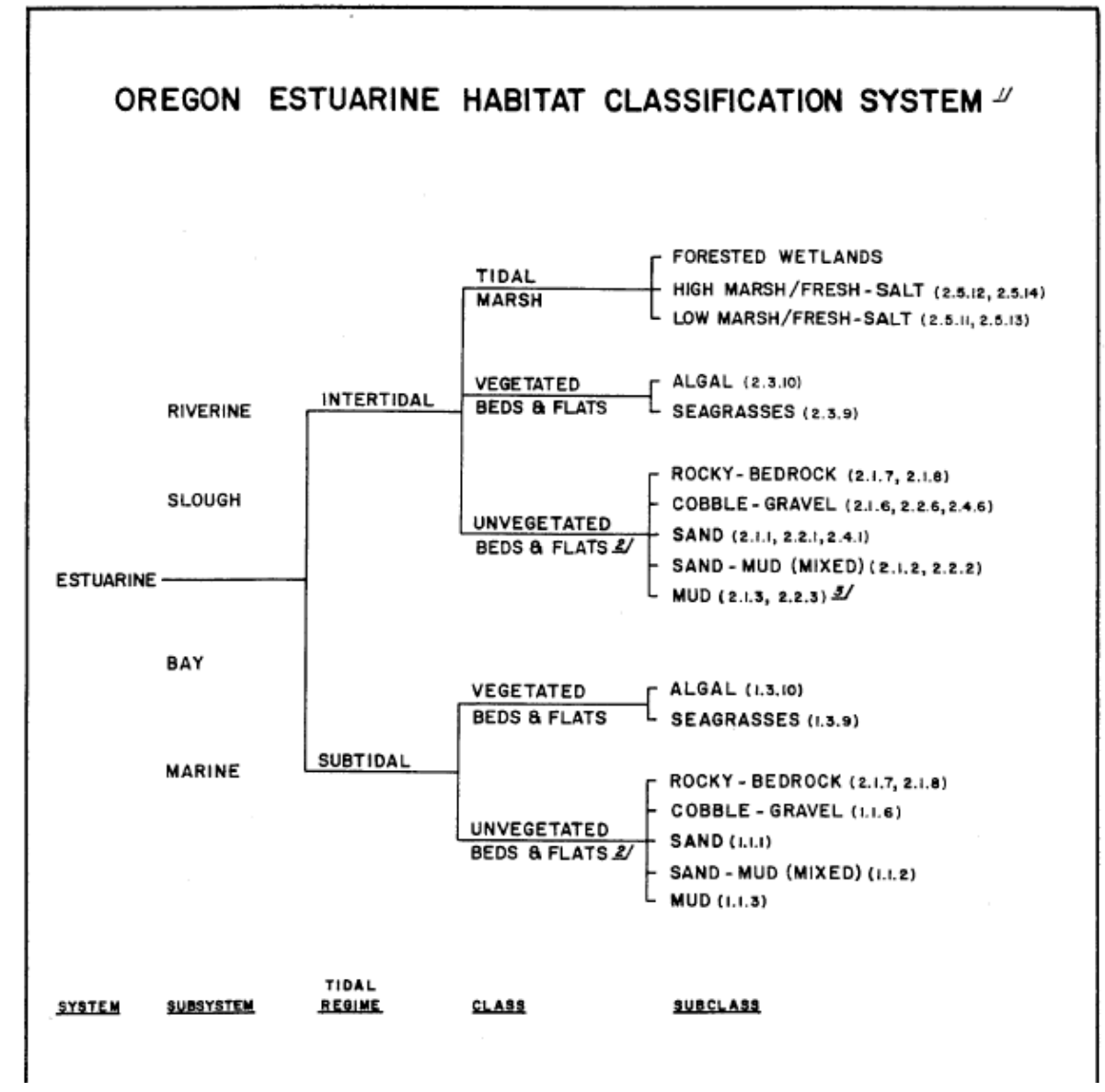

Figure 4: Oregon’s Estuarine habitats (Hamilton 1984).

\section{DSL wetland policies and regulations}

DSL's Wetlands Program implements the state’s 1989 Wetlands Conservation Act (ORS 196.668-196.692) (DSL 2006). The program's main responsibilities include developing and maintaining a statewide wetlands inventory (SWI), providing wetlands technical guidance to the public, and bridging Oregon's land use planning and state and federal wetland regulations. The SWI consists of a combination of the National Wetlands Inventory (NWI) and finer resolution, more informative Local Wetlands Inventories (LWIs) for local communities. NWI maps were developed using high altitude aerial photography with a minimum wetland resolution of two acres. However, they do not include agricultural wetlands, most wetlands less than two acres, or many hard to identify seasonal wetlands. Adopted in 1990 and updated in 2001, state administrative rules for LWIs (OAR 141-86-180 et seq.) were developed to provide guidance and standards to local governments for LWIs. DSL works with local governments and private consultants to develop LWIs, which include wetlands that are at least 0.5 acres in area and also document the condition and functions of mapped wetlands. LWIs are also used to help implement state planning Goal 5 (Natural Resources) and Goal 17 (Coastal Shorelands) providing the basis for identifying “significant” wetlands. Designed to protect Oregon's natural resources, Goal 5 and Goal 17 require local governments to inventory natural resources including riparian areas, wildlife habitat, and wetlands and then prioritize resources for protection. Due to the finer level of detail compared to NWIs, LWIs can help local governments to limit the potential wetland impacts as they develop and implement their plans. Where completed, mostly in urban areas, LWIs replace the NWI in urban areas. However, not all local governments have developed LWIs. 
Another related element is the Wetland Land Use Notification process (ORS 215.418), also implemented by the DSL Wetlands Program, requires local governments to notify DSL of development activities that may impact mapped wetlands. The Wetlands Program determines if there are jurisdictional wetlands or other waters on the property and provides guidance on whether a Removal-fill permit is required. LWIs, as opposed to the coarser resolution NWI, facilitate this process. Additionally, the Wetlands Program assists in implementing the Removal-fill law by conducting wetland determination and providing quality control for wetland delineations submitted by permit applicants.

The state has adopted a no net loss of wetlands policy for wetlands and, due to the degree of historical loss of estuarine wetlands, has adopted a goal of an annual net gain goal of 250 acres of estuarine wetlands per year. Through the Removal-fill permit requirements that include mitigation sequencing and compensatory wetland mitigation, DSL can work directly to achieve the no net loss of freshwater wetlands goal; however, a state permit is not required for all wetland impacts, such as for those impacts that are less than 50 cubic yards and for those activities that are exempt. Also the Removal-fill Law has no direct control over whether the state achieves a 250 net gain acres per year of estuarine wetlands, without sacrificing the 'no net loss' of freshwater wetlands. Often times, formerly estuarine wetlands will meet wetland criteria, thus reintroducing tidal flushing in to these formerly estuarine wetlands to mitigate for freshwater wetland impacts will result in a net gain of estuarine wetlands but a net loss of wetland acreage.

However, through its partnership with the South Slough National Estuarine Research Reserve's restoration efforts and other entities and programs, DSL can help make some progress towards this goal. Other restoration efforts such as the Oregon Habitat Joint Venture, the Tillamook Bay Estuary Partnership, the Lower Columbia River Estuary Partnership, the USFWS Refuge Program, and the US Forest Service’s work in the Salmon River Estuary that are being undertaken will help to achieve this state benchmark (OHJV 2006; Morlan 1991; Cornu \& Sadro 2002; LCREP 2005). The Oregon Habitat Joint Venture is made up of coalition of private conservation organizations working with government agencies to protect and restore important bird habitat.

\subsubsection{Salmon policy and regulation}

Declining salmon populations have been the impetus for much of the science and policy focus on Pacific Northwest estuaries. In response to declining salmon populations in 1993, DSL was required to work with ODFW to designate riverine and estuarine waterways important to salmon life histories as Essential Salmon Habitat (ESH). Instead of the 50 cubic yard permit threshold, any amount of Removal-fill activity in these waters requires a DSL permit. All estuaries are designated as ESH. Another statewide policy response to declining salmon runs was the creation of the Oregon Plan for Salmon and Watersheds, developed in 1997. The 
Oregon Plan brings together government agencies, land owners, and nonprofits to conserve salmon populations. Because estuaries provide important rearing habitat to juvenile salmon, there has been a renewed interest in understanding and restoring estuarine habitat.

\subsubsection{Mitigation rules}

Relative to wetlands and waterways impacts, generally, the Removal-fill Law requires the three-step mitigation sequence approach of (1) avoiding impacts, (2) minimizing impacts, and (3) if no other practicable alternatives exist, compensation for unavoidable impacts. At the compensatory mitigation stage, there are three different programs depending upon the type of aquatic habitat to be impacted: compensatory mitigation for non-wetland waters of the state (CM), compensatory wetland mitigation for impacts to freshwater wetlands (CWM), and estuarine resource replacement for impacts to intertidal area of estuaries (ERR). While CM and CWM will be described briefly, ERR will be described in detail.

$\mathrm{CM}$ is required for permitted impacts to waters of the state (other than wetlands or estuaries) below ordinary high water and usually involves enhancement activities such as riparian planting or seeding.

CWM is required for all permitted freshwater wetland impacts. OAR 141-085-01210151 describes the regulatory requirements for CWM. Any impacts less than 0.2 acres may automatically be mitigated for off the site through the Payment to Provide (PTP) program or through a mitigation bank credit purchase. For larger impacts, onsite mitigation at the impact site is preferred. If impracticable, the mitigation project can be done away from the wetland impact site (offsite) at another location or by purchasing credits through a mitigation bank if it serves the area where the impact is located and the bank will replace similar wetland type(s) and functions. Bank service areas are generally defined by watershed boundaries, but are decided upon on a case-by-case basis between the mitigation banker and regulatory agencies when the mitigation bank instrument is developed. However, as of winter 2006, no mitigation banks are selling credits in the Coast Ecoregion. An ecoregion is a geographic unit with similar climate, subsurface geology, physiography, hydrology, soils, and vegetation and the Coast Ecoregion extends along the coast from the Columbia River south to California and east to the crest of the Coast Range and Klamath Mountains (Omenrik \& Gallant 1986).

The CWM rules require the restoration, creation, or enhancement of wetlands using area of mitigation to area of impact ratios of 1:1, 1.5:1, and 3:1, respectively. Restoration means to reestablish wetland hydrology to a former wetland sufficient to support wetland characteristics. Creation means to convert an area that has never been a wetland to a jurisdictional wetland. 
Enhancement refers to a human activity that increases the function of an existing degraded wetland. An assessment of wetland functions must be completed at the proposed impact site and at the proposed CWM site, if this site is currently a wetland. Wetland functions and values to be assessed include, at a minimum, water quality and quantity, fish and wildlife habitat, native plant community and species diversity, and recreational and educational values. The Hydrogeomorphic functional assessment method (HGM) is the preferred method, although other methods including best professional judgment may be used. In Oregon, regional HGM methods have been developed for tidal wetlands (except those found in the Columbia River Estuary) and for some wetland classes in the Willamette Valley ecoregion.

The CWM rules require the mitigation to replace the impacted Cowardin class and HGM class/subclass (in-kind mitigation). However, 'out-of-kind' CWM may be approved if the Cowardin class and HGM class is deemed environmentally preferable; if the replacement wetland addresses watershed management priorities such as flooding; if the replacement wetland type (Cowardin/HGM class) and functions have experienced significant historical losses; or the replacement wetland supports rare plant communities, as identified by the Oregon Natural Heritage Information Center. Purchasing credits from a Mitigation Bank, paying into the Payment To Provide fund, or Conservation in lieu for rare or difficult-to-replace wetland types (bogs, fens, vernal pools) are acceptable CWM alternatives and specific requirements are delineated in OAR 141-085-131. Requirements are, also, outlined for CWM plans and monitoring.

\subsubsection{Estuarine resource replacement (ERR)}

The goal of estuarine resource replacement (ORS 196.830 [formerly Oregon Mitigation Law 541.626]) is to maintain the "functional characteristics and processes of the estuary such as natural biological productivity, habitats, species diversity, unique features and water quality.” The statute also states that the "Director of DSL shall require estuarine resource replacement as a condition for any permit for filling or removal of material from an intertidal or tidal marsh area of an estuary.” The distinction between tidal and intertidal is not clear. As required by the 1979 statute, in 1984 DSL adopted the administrative rules for estuarine mitigation entitled "Estuarine Mitigation: the Oregon Process” (141-085-0240 to 141-085-0262) (Hamilton 1984). The purpose of these rules was to delineate the requirements for compensatory mitigation when material is filled or removed from an intertidal or tidal marsh area of an estuary. In these rules, the definition of mitigation is “...the creation, restoration, or enhancement of an estuarine area to 
maintain the functional characteristics and processes of the estuary, such as its natural biological productivity, habitats and species diversity, unique features and water quality.” As demonstrated by this definition, prior to the adoption of the CWM rules, mitigation for estuaries meant compensatory mitigation, rather than the sequence of avoidance, minimization, and compensation.

\subsubsection{Estuarine boundaries for ERR}

Jurisdictional determinations are crucial for the implementation of the Removal-fill Law and for Estuarine Resource Replacement. However, determining the boundaries of land subject to regulation is no trivial matter. The estuarine mitigation rules define the inland extent of the estuary by the head of tide as indicated by river mile (to the tenth of a mile) and corresponding latitude and longitude. The line of nonaquatic vegetation, if discernible, or highest measured tide (HMT), defines the vertical extent. Estuarine Resource Replacement is required for impacts between highest measured tide and extreme low tide (Smith 1983). The head of tide is defined as the furthest upstream extent of tidal influence. Tidal influence can be in the form of salinity, flow direction, and river stage. Although the head of tide is the Bonneville Dam on the Columbia River, the inland extent of the Estuarine Resource Replacement rules is River Mile 38 at the western edge of Puget Island near Knappa, Oregon. Maps showing the heads of tide were created by DSL from 1979, 1984, and 1988 surveys (depending upon the estuary) and published in 1989 (DSL 1989). The line of nonaquatic vegetation can be identified through wetland delineation, but the highest measured tide elevation proves more difficult to identify. Although state ownership of tidelands extends to mean high water (MHW), an average of all observed high tides, and can generally be determined through field observation, HMT is the highest tide actually observed on a tide staff (Hamilton 1984). This elevation can be extrapolated to a particular location that has been surveyed relative to the same datum. Without a professional survey or documented evidence, however, this elevation may not be observable since it is a onetime event. Therefore, determining the vertical extent of the estuary for Removal-fill jurisdiction and ERR is difficult if there is "no line of nonaquatic vegetation” or no wrack line.

For example, riprap was placed along the Umpqua River near Scottsburg for bank stabilization during the winter of 2006. The homeowner claimed that they were above the HMT and there was no easy way to refute their claim. No estuarine fringe wetlands are present along the banks of this upper part of the estuary, so HMT is used to determine what is jurisdictional. However, the closest available estimated HMT elevation of 10.5 feet (NGVD 1947) is from 
Reedsport, at least 13 river miles downstream from the site. Due to geomorphic changes in the estuary and the attenuation of tidal force when moving upstream, simply extrapolating this HMT elevation would not be accurate, even if DSL has access to detailed topographic surveys. Theoretically, numerous tide gauges could be installed through out each estuary to assist with jurisdictional decisions. However, there are only three active tidal gauges along the entire Oregon Coast (NOAA 2006). Although an extensive network of tidal gauges could generate useful data for DSL and other resource agencies, the installation and operation of such a network would be cost prohibitive for DSL. In the mean time, permit coordinators need to be able to efficiently and make legally defensible jurisdictional calls from field inspections. For this reason, it may be more realistic to use the mean of the higher tide elevation or Mean Higher High Water (MHHW) as the jurisdictional boundary, if no wetlands are present. The difference in HMT versus MHHW ranges between 3 to 5 feet vertically, depending upon the estuary.

\subsubsection{Estuarine habitat relative values system}

In order to abide by the law to replace functions of estuarine habitats, a relative habitat value system was developed. The framework was first developed for the Columbia River Estuary based upon available data sources (Smith 1983) and then adopted for all of Oregon's estuaries with some modification (Hamilton 1984). A diverse group of stakeholders including ecologists, coastal government representatives, environmentalists and industrial representatives assigned relative values to each estuarine habitat class (Quarterman 1985). The relative value for each habitat class was adjusted based upon substrate, salinity and tidal regime (subtidal or intertidal). The habitat classification system incorporated the Oregon Department of Fish and Wildlife estuarine habitat classification system (Bottom et al. 1979), which was modeled after the US Fish and Wildlife Service wetland classification (Cowardin et al. 1979). In order to calculate mitigation credits, a relative value system ranging from the lowest habitat value of 1 to the highest habitat value of 6 was created (Figure 5). This system was based upon perceived estuarine functional characteristics and processes, scarcity, social and aesthetic values, and unique features.

Impacts to estuarine habitats are to be compensated through the restoration, creation, or enhancement of estuarine habitat elsewhere within the estuary. Unlike with CWM, there is no stated preference for "in-kind" mitigation at the class level. The relative value system was actually designed for cross-class trades. Although different terminology was used, an 
environmental preference was implied for the habitats with the higher assigned values such as seagrass and low marsh.

In terms of Cowardin classification, Estuarine is the 'System', Intertidal or Subtidal is the 'Subsystem' and 'Emergent' is the 'Class'. In the CWM rules “in-kind” means same Cowardin and/or HGM class. This preference stated in the CWM rules has influenced the application of ERR, but more at the 'System' level. In other words, impacts to estuarine habitat would not be compensated for with Riverine, Lacustrine, or Palustrine wetlands. However, the reverse has been permitted due to the widespread historical losses of estuarine habitat, depending upon the habitat quality of the non-tidal wetland proposed for impact. This is particularly true if the nontidal wetland was formerly estuarine, but was disconnected from tidal influence by dikes.

Definitions of restoration, creation, and enhancement were included in the ERR rules. "Restoration of an Estuarine Area" means to revitalize or re-establish functional characteristics and processes of the estuary diminished or lost by past alterations, activities, or catastrophic events. A restored area must be a shallow subtidal or an intertidal or tidal marsh area after alteration work is performed, and may not have been a functioning part of the estuarine system when alteration work begins. "Creation of an Estuarine Area" means to convert an upland area into a shallow subtidal or an intertidal or tidal marsh area by land surface alteration. The area to be converted must be an upland area lying above the line of nonaquatic vegetation when alteration work begins. "Enhancement of an Estuarine Area" means a long-term improvement of existing estuarine functional characteristics and processes that is not the result of a creation or restoration action. An example of an enhancement activity may be increasing tidal flushing through a partial dike breach. 


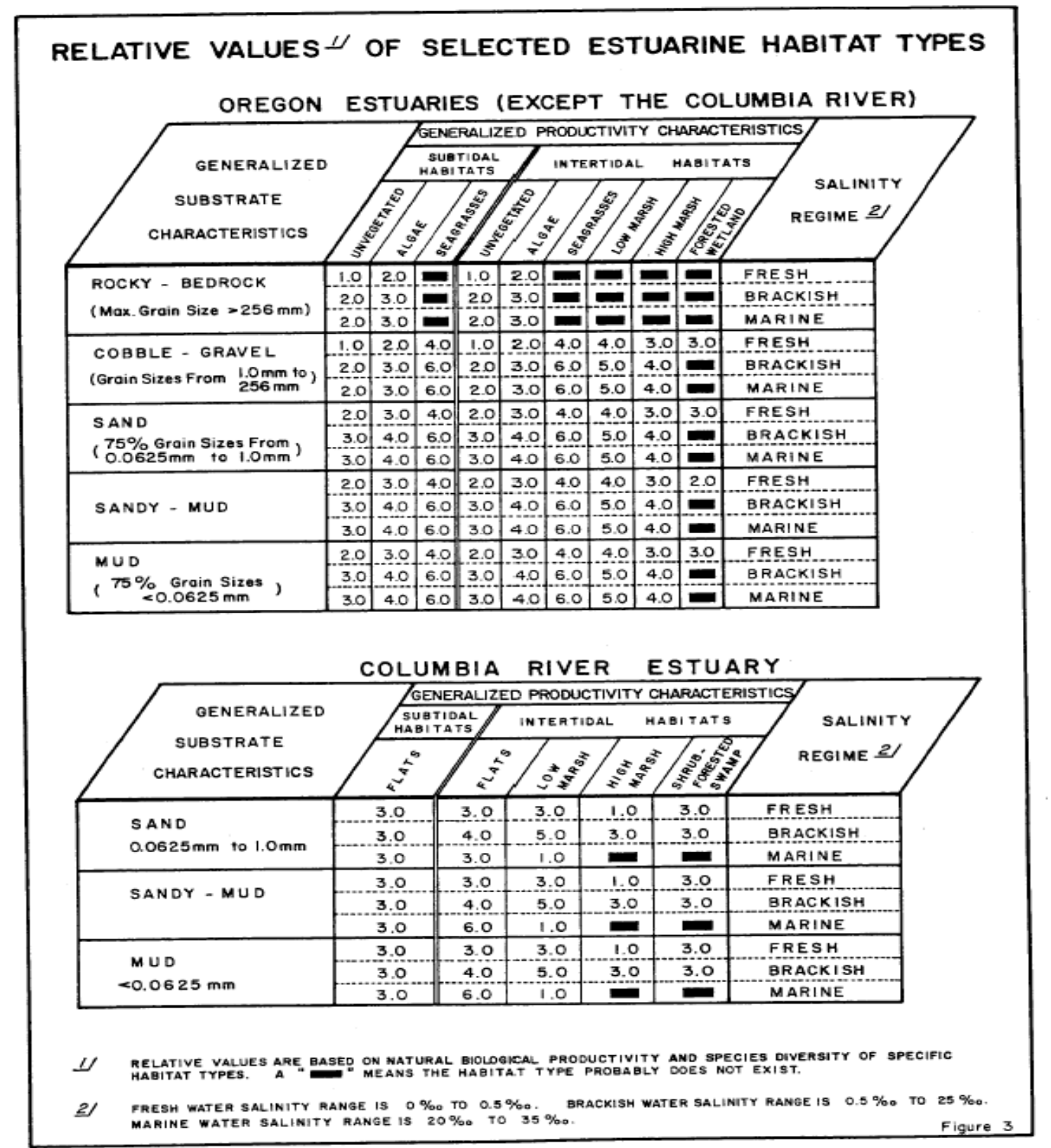

Figure 5: Estuarine Habitat Types and Relative Values (Hamilton 1984). 


\subsubsection{Replacement requirements}

The area required for a mitigation site involving restoration or creation of intertidal or tidal marsh habitats is calculated based upon the equation below, with the stipulation that the area of the mitigation site cannot be smaller than the area of the development (impact) site:

$$
\mathrm{AM}=(\mathrm{RVd} / \mathrm{RVm})(\mathrm{AD})
$$

Where

$$
\begin{aligned}
& \mathrm{AM}=\text { Area of mitigation site } \\
& \mathrm{RVd}=\text { Adjusted relative value of the development site } \\
& \mathrm{RVm}=\text { Adjusted relative value of the mitigation site } \\
& \mathrm{AD} \quad=\text { Area of development site }
\end{aligned}
$$

The adjusted relative value of the development site and of the mitigation site (RVd and RVm) can be determined (Figure 5) based upon the substrate, salinity regime, and habitat type. The depth to which impacts to subtidal habitat are to be mitigated is to extreme low water (Smith 1983), -3 MLLW for most Oregon estuaries (Hamilton 1984). If the mitigation site involves the creation or restoration of shallow subtidal habitats, the area of the mitigation site (AM) is doubled. In CWM, wetland habitat becomes deepwater habitat at two meters. Credits determined for enhancement mitigation are calculated by subtracting the value of the existing habitat, before it is enhanced, from the projected value of the habitat post-enhancement multiplied by the number of acres that will be enhanced.

CWM rules were developed later than ERR but did not integrate the ERR rules. As a result, there are conflicting meanings of restoration. While the ERR rules would consider reconnecting estuarine habitat to the estuary 'restoration', the CWM rules would not consider the project 'restoration', if the site, although disconnected from the estuary, meets wetland criteria. For CWM, dike removal would grant restoration credit (1:1 ratio) under the footprint of the dike, but enhancement credit (3:1) would be granted for the area behind the dike if it is degraded, but currently meets wetland criteria (according to the 1987 USACE manual). ERR rules would provide restoration credit based upon the compensation equation. The ERR mitigation site must be within the same estuary as the impact site.

Mitigation banking is allowed and explained briefly in the ERR rules, although there are currently no estuarine mitigation banks from which to purchase credits. Credits for banks are calculated the same way as for other forms of mitigation (using the relative values table and appropriate equation). A recent amendment to the rules (141-085-0263-3b p.74 March 27, 2006) 
allows the application of alternative methods to calculate banking credits with approval by the DSL Director. As with regular ERR, mitigation bank service areas are defined by the boundaries of the estuary. By rule, a Mitigation Trust Fund could be set up to provide loans at the prime interest rate for approved mitigation banks. Funds would come from gift, bequest, donation, or grant. Loans are to be paid within ten years and are to be paid back in ten annual installments. Deep draft development estuaries (Columbia River, Coos Bay, and Yaquina Bay) were identified as the highest priority areas for loan disbursal, followed by shallow draft estuaries (Nehalem, Tillamook, Siuslaw, Umpqua, Coquille, Rogue, and Chetco). Such a fund has never been set up.

By rule, DSL is required to maintain a record, by estuary, of the size and type of habitat involved in intertidal (for some reason subtidal is not mentioned) Removal-fill sites and mitigation sites. However, due to database changes and file storage policies, there are gaps in the tracking of Removal-fill activity per estuary. In terms of Cowardin class and acreage, intertidal and subtidal estuarine impacts and mitigation are being tracked in the "wetland area impacts” field in the permit database, LAS, with records starting at 2001. Hard copies of active permits issued prior to 2001 are stored onsite in DSL's storage room. Inactive permits are purged after seven years to avoid storage issues. Thus, it is unknown what the total Removalfill activity and compensatory mitigation is on an estuary-wide basis since the rules were adopted in 1984.

Only minor amendments were made to the ERR rules in 2004 when CWM rules were overhauled. One change involved replacing the term 'Estuarine mitigation' with 'Estuarine Resource Replacement'. Cash payment was not an approved mitigation option in the 1984 rules; however, this statement was removed in the updates. This sentence may have been removed to allow for participation in the payment-to-provide program, which is described in detail for CWM (141-085-0156). However, at a policy level but not regulatory level, payment to provide and conservation in lieu are not generally allowed as estuarine mitigation options. Monitoring of sites, previously discretionary, is now required annually for five years (141-085-0151). 


\section{CHAPTER 3}

\section{PERMIT INVENTORY}

\subsection{Introduction and Methodology}

An inventory and evaluation of all available Removal-fill permits requiring estuarine mitigation was undertaken. Permits were identified by searching DSL's LAS database, which dates back to 2001. Prior to this period, WANG was the database that tracked Removal-fill permitted activity. During the WANG to LAS transition, the only field populated from WANG era permits was the authorization number. Consequently, all the remaining specific detailed information about these pre-2001 permits was not captured digitally. The hard copy permit file was retained if the permit was still active and/or was less than seven years old (permits are only legally required to be kept for seven years if no longer active). In order to determine if these WANG-era permits involved estuarine mitigation, the physical file had to be reviewed.

Therefore, permits available for review were either expired permits issued in 1998 or later or active permits.

An October 2005 query was made in the LAS database for all Removal-fill permits that required estuarine mitigation. The search criterion used for this query was Cowardin class beginning with ' $E$ ' for estuarine. This query resulted in 59 records, which included 49 compensatory mitigation records and 10 Wetland Enhancement/Creation General Authorization records. The 10 Wetland Enhancement/Creation General Authorizations were removed from the sample as they are not 'compensatory mitigation' for estuarine impacts making the sample size 49. Eight of the 49 records were compensatory mitigation in Klamath County, located on the east side of the Cascade Mountains. These records were erroneously assigned a Cowardin classification E2EM or estuarine intertidal emergent habitat and consequently removed from the review, resulting in 41 records. However, closer inspection of the query revealed that there were 10 duplicate records, decreasing the number of valid records to 31 . These 31 mitigation projects are associated with 12 Removal-fill permits, but involved distinct estuarine Cowardin wetland types.

Pre-LAS permits that involved estuarine mitigation that were either still active or less than 7 years old were also reviewed. The query, mentioned above, did not capture these older permits because the fields, including Cowardin class, were not populated for these permits. In 
order to determine which of these pre-LAS permits would be appropriate for review, I used the mapping option in LAS to display the shape file of the Oregon Estuaries and the heads of tide points. One mile (one section wide) polygons were drawn around each estuary and, if available, head of tide location (which did not always correspond). The reason one mile buffers were used was because the locations of the mitigation sites were mapped to the centroid of the Public Land Survey section and not an actual location. The ‘display mitigation projects' option was used to display all mitigation sites within the drawn polygon. Due to the coarse mapping accuracy, sites could be overlooked if only those within the estuary were reviewed. The mitigation project numbers and corresponding authorizations were noted for each estuary region, resulting in 85 more permits, not captured by the initial query. Authorization files were located in the DSL file room, however, the majority of files were either not on the shelf (64 permits) or after closer inspection, did not involve estuarine mitigation (17 permits). Based on the permit numbers of the 64 permits not in the file room, it is assumed that these files were thrown out, rather than not signed out, because they are no longer active and older than seven years $(<5,000$-permit numbers are assigned in chronological order-older permits have lower numbers and vice versa). Permit files older than seven years have been purged from the file room. The database manager noted that these purged physical permit files are generally deleted from the database but sometimes this second step is missed. This manual mapping effort resulted in four additional permits resulting in 16 total permits for review. As demonstrated by this experience, DSL's current record keeping system does not allow for easy access to permitted wetland impact and mitigation project data for analysis.

This investigation did not involve an evaluation of the accuracy of the information contained in the permit file. Nor did this investigation attempt to evaluate actual mitigation success or functional replacement, both of which are outside the scope of this study. 


\subsection{Results}

\subsubsection{Development activity}

The 16 Removal-fill permits were associated with a range of development activities (Table 1) resulting in 16.895 acres of permitted non-tidal and estuarine wetland impacts (Table 2). Permits associated with road transportation accounted for the highest percentage (29\%) of permitted activity (Figure 6). However, the largest acreage impact (5.58 ac.) was related to industrial shipping (Figure 7). Road transportation impacted 2.51 acres (Figure 7).

\begin{tabular}{|c|l|}
\hline Permit & \multicolumn{1}{|c|}{ Development Activity } \\
\hline $23373 \mathrm{RF}$ & Aviation \\
\hline $23612 \mathrm{FP}$ & residential development \\
\hline $24813 \mathrm{RF}$ & bridge replacement \\
\hline $25631 \mathrm{RF}$ & boat ramp replacement \\
\hline $26323 \mathrm{RF}$ & industrial barge dock \\
\hline $26467 \mathrm{RF}$ & residential development \\
\hline $26538 \mathrm{RF}$ & road realignment \\
\hline $30205 \mathrm{SP}$ & bank stabilization \\
\hline $30681 \mathrm{FP}$ & dock extension \\
\hline 31597 RF & boat ramp modification \\
\hline 31744 RF & bridge construction \\
\hline $10375 \mathrm{FP}$ & industrial development \\
\hline 04152 FP & bridge project \\
\hline 05936 RF & bridge project \\
\hline $16086 \mathrm{FP}$ & commercial area \& dock replacement \\
\hline 33602 RF & dock bulkhead replacement \\
\hline
\end{tabular}

Table 1: Development Activity associated with Removal-fill Permits in Oregon Estuaries from 1989-2005. 


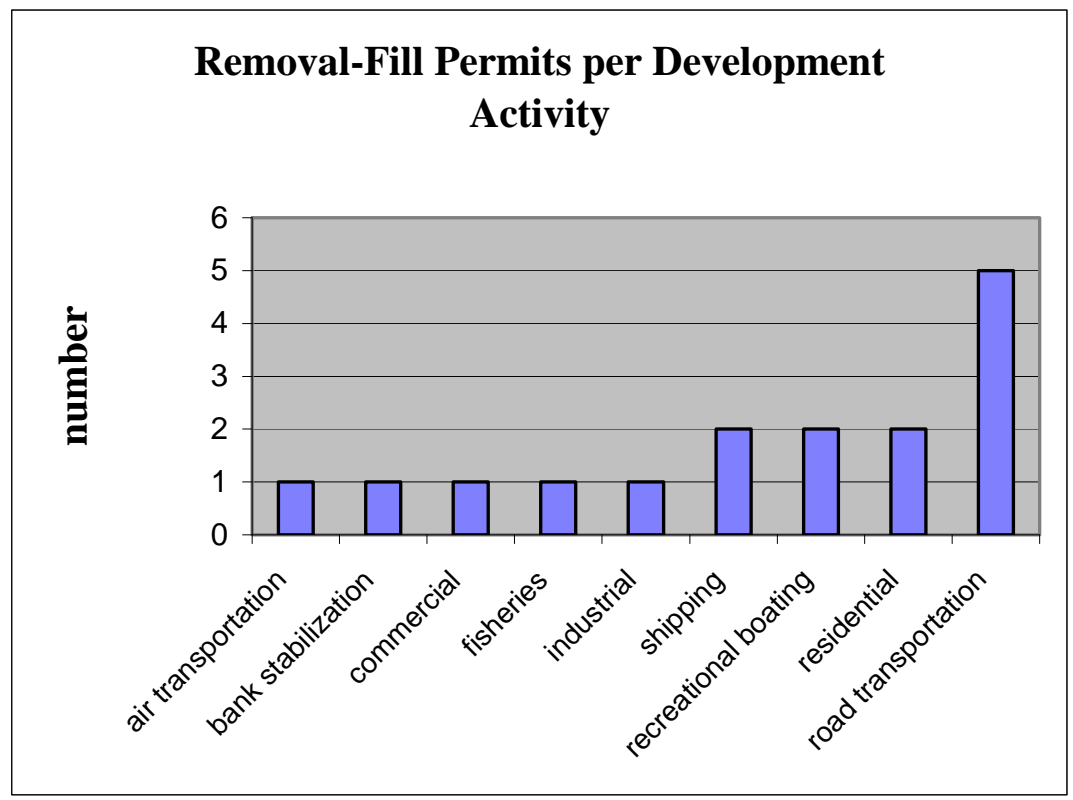

Figure 6: Number of Removal-fill permits per development activity in estuaries from 1989-2005.

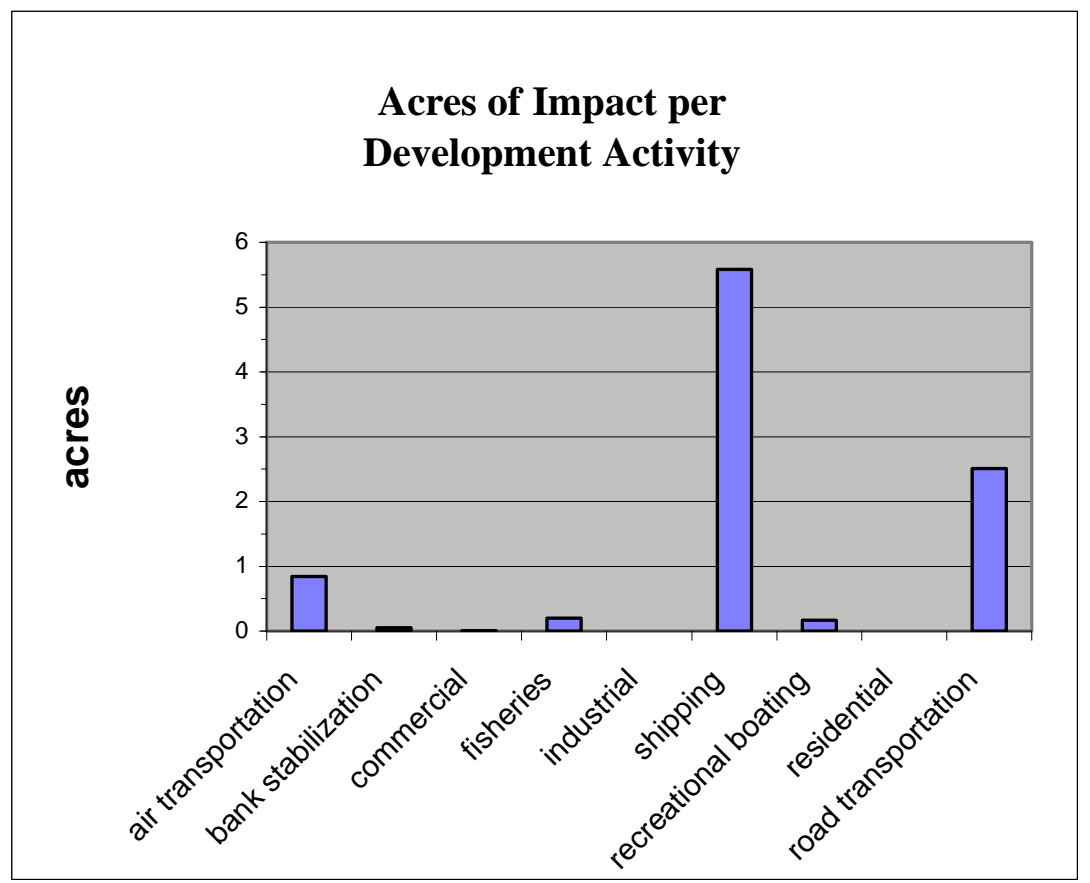

Figure 7: Acres of impact per development activity from 1989-2005.

\subsubsection{Permit description}

A brief description of each permit follows below. Permits with estuarine impacts were compensated by estuarine mitigation are described first, followed by permits with mitigation in which non-tidal impacts were compensated with estuarine habitat. Note that three out of the four non-tidal impacts were formerly estuarine wetlands.

Estuarine wetland impacts compensated with estuarine wetlands: 
1. Permit $\mathbf{0 4 1 5 2} \mathbf{R F}$ was issued in 1989 authorizing 1.8 acres of tidal swamp and 3.1 acres of non-tidal forested and emergent wetland impacts associated with the John Day River (a lower Columbia River tributary) Bridge Project on US route 30 in Clatsop County. Onsite compensation consisted of the restoration and enhancement of 1 acre of non-tidal forested and emergent wetlands. Offsite compensation consisted of creating 2.5 acres of non-tidal forested and emergent wetlands near Youngs Bay and 1.9 acres of intertidal high and low marsh that would drain into Swash Lake at Fort Stevens State Park.

2. Permit $\mathbf{0 5 9 3 6}$ FR was issued in 1991 authorizing a total of 1.4 acres of tidal and non-tidal wetlands impacts associated with a bridge replacement project on the Highway 101 Miami River crossing, a tributary to the Tillamook Estuary in Tillamook County. The 0.7 acres of estuarine channel and intertidal freshwater high marsh were compensated with 1.3 acres of a newly created tidal channel and intertidal emergent marsh adjacent to the impact site.

3. Permit $\mathbf{1 6 0 8 6}$ FP was issued in 1999 authorizing a total of 0.14 acres of estuarine impacts associated with a boardwalk and commercial development project in Florence along the Siuslaw Estuary in Lane County. The 0.14 acres of estuarine intertidal brackish high marsh were proposed to be compensated by restoring 0.22 acres of intertidal brackish high marsh, 1,500 feet upstream from the impact site, through berm removal. However, the project impacts were ultimately compensated by the payment to provide option.

4. Permit $\mathbf{2 3 3 7 3} \mathbf{R F}$ was issued in 2001 authorizing the fill of 2.72 acres of Coos Bay intertidal and subtidal habitat to allow for safety improvements to the North Bend Airport located in Coos County. The impacts were compensated for by restoring tidal influence to 6.87 acres of a diked pasture on Coalbank Slough through dike breaching.

5. Permit $\mathbf{2 4 8 1 3}$ RF was issued in 2002 authorizing the fill of 0.02 acres of estuarine intertidal emergent wetlands for the construction of a bridge over Neawana Creek located in the Necanicum River Estuary in Clatsop County. The impacts were compensated for by enhancing 0.06 acres of (EFR; E2EM) high marsh with woody vegetation.

6. Permit $\mathbf{2 5 6 3 1} \mathbf{R F}$ was issued in 2003 (and reissued in 2004 \& 2005) authorizing 0.06 acres of impact to estuarine intertidal unconsolidated shore for the construction of a port boat ramp in the Rogue River in Curry County. This impact was compensated for by the creation of 0.06 acres of estuarine subtidal $(0.05$ ac.) and intertidal ( 0.01 ac.) unconsolidated shore by an upland excavation. Estuarine rules were used to calculate replacement area.

7. Permit $26323 \mathbf{R F}$ was issued in 2002 authorizing 0.136 acres of impact to estuarine intertidal aquatic bed for a timber dock replacement in Reedsport in the Umpqua River Estuary in Douglas County. This impact was compensated for by the restoration of 0.82 acres of estuarine intertidal emergent habitat by removing fill from a formerly estuarine mud flat on Bolon Island, which is within 1,000 feet of the impact site.

8. Permit $\mathbf{3 0 2 0 5} \mathbf{S P}$ was issued in 2003 and renewed in 2004 authorizing the replacement of a deteriorating bulkhead with riprap for bank stabilization along 0.05 acres of the Nestucca River in Pacific City in Tillamook County. This authorized conversion required 0.05 acres of enhancement mitigation by interspersing willow stakes throughout the (impacted) riprap section of the riverbank.

9. Permit $\mathbf{3 0 6 8 1}$ FP (originally $9772 \mathrm{RF}$ ) was originally issued in 1995, but reissued in 2005, authorizing a dock extension to allow increased cargo capacity in North Bend along Coos Bay in Coos County that would result in the impact of 4.94 acres of intertidal and subtidal wetland habitat. This impact was compensated for with offsite mitigation in Isthmus Slough by dike breaching to reestablish tidal connection to a formerly tidal wetland. 1.4 acres of intertidal wetland habitat under the dike will be restored and 10.2 acres of wetlands will enhanced.

10. Permit $\mathbf{3 1 5 9 7}$ RF was issued in 2004 authorizing the fill of 0.11 acres of estuarine intertidal emergent habitat to upgrade and expand a recreational boat ramp in the lower Columbia River, Clatsop County. This impact was compensated for by enhancing 0.07 acres of estuarine intertidal scrub-shrub habitat by removing invasive Himalayan blackberry (Rubus armeniacus) and planting native willow species (Salix sp.) along the Columbia River bank 300 feet downstream from the impact area between MHHW and HMT.

11. Permit $\mathbf{3 1 7 4 4}$ RF was issued in 2004 authorizing the fill of 0.009 acres of estuarine intertidal emergent habitat for a county bridge replacement in Ferris Creek, a tributary to the lower Columbia River, Clatsop County. This impact was compensated for onsite by enhancing 0.004 acres of estuarine intertidal scrubshrub habitat (as reported by LAS) by moving the bridge abutments out of the intertidal zone. Additionally, the permittee paid \$250 into the Payment to Provide (PTP) program for the remaining 0.005 acres of impact.

12. Permit $\mathbf{3 3 6 0 2}$ RF was issued in 2005 authorizing the fill of 0.202 acres of estuarine intertidal emergent habitat for a bulk head replacement on a port dock on the Columbia River, Clatsop County. This impact was compensated for by enhancing 20 acres of subtidal habitat by replacing a traditional tidegate with a muted tidegate that reintroduced "muted" tidal influence up to a set elevation. 
Non-tidal impacts compensated with estuarine wetlands:

13. Permit 33166 FP (10375 FP WANG) (AU11605-mitigation permit) was issued in 1996 authorizing the development of an industrial park in Toledo in Lincoln County that impacted 0.5 acres of palustrine emergent wetland (formerly estuarine). This freshwater impact was compensated for with the restoration and enhancement of 0.8 acres of freshwater wetland pasture adjacent to Olalla Slough, a tidal arm of the Yaquina River Estuary. The dike will be removed to restore tidal influence to this former tidal wetland creating aquatic bed habitat. Advance mitigation credit was granted to the City of Toledo for an additional 17.31 acres of intertidal emergent/aquatic bed habitat that was restored (dike foot print) and enhanced (wetland behind the dike) as a result of this mitigation project. The advance mitigation acres were not included in Table 2.

14. Permit 23612 FP was first issued in 2002 (and renewed 2003,2004 \& 2005) authorizing 0.838 acres of impact to palustrine emergent wetlands (formerly estuarine) associated with a residential development in Reedsport along Scofield Creek, a tributary to the Umpqua River Estuary in Douglas County. This impact was mitigated with the restoration of 0.838 acres of estuarine intertidal emergent habitat that had been filled on Steamboat Island, which is located in the Umpqua downstream from the impact site.

15. Permit 26467 FP was issued in 2002 authorizing the fill of 0.22 acres of freshwater palustrine scrubshrub/emergent wetlands for a housing development in Gearhart, Clatsop county. This impact was compensated using a combination of out-of-kind and in-kind mitigation. Offsite, 0.33 acres of estuarine intertidal scrub-shrub wetlands from uplands were created. Onsite, 0.02 acres of freshwater palustrine scrub-shrub wetlands were enhanced by managing the invasive grass, Phalarais arundinaceae, through flooding.

16. Permit $\mathbf{2 6 5 3 8}$ RF was issued in 2004 authorizing the fill of 0.65 acres of Palustrine Emergent wetlands (formerly estuarine) for a road alignment project along the Warrenton-Astoria Highway in Clatsop County. This impact was compensated offsite and out-of-kind by restoring 0.65 acres of estuarine intertidal emergent/scrub-shrub wetlands within a larger wetland in Les Shirley Park, Ecola Creek Estuary. Tidal influence was restored by berm removal and historical tidal channel excavation.

\subsubsection{Impacts and mitigation}

Based upon the information provided in the 16 available Removal-fill permits involving estuarine impacts and/or mitigation projects from 1989 to October 2005, a total of 10.787 acres of estuarine habitat were impacted and 45.802 acres of estuarine habitat were restored, enhanced, or created as required for compensatory mitigation (Table 2; Figure 8). Enhancement activities in estuarine habitats accounted for 38.354 acres, about $84 \%$ of the total acres of mitigation projects. However, since enhancement as a form of compensatory mitigation does not result in an increase in estuarine habitat, the enhancement acres were not included in the gain calculation for net change in estuarine habitat. As a result, there was an overall permitted net loss of 3.339 acres of estuarine habitat during this time period. Because six of the 16 permits included nontidal impacts, net changes in those non-tidal habitats were calculated as well. A total of 6.108 acres of non-tidal wetlands were impacted and compensated with a total of 4.420 acres of nontidal wetlands. Four of the 16 permits compensated non-tidal impacts with estuarine mitigation. All of the estuarine impacts with the exception of one subtidal impact were intertidal habitats. E2AB, estuarine intertidal aquatic bed, experienced the greatest net loss at 4.726 acres. The next greatest net loss was -1.8 acres of estuarine intertidal forested wetland. The habitat with the largest net gain was E2EM, estuarine intertidal emergent habitat, with an increase of 2.319 acres. 


\begin{tabular}{|l|c|c|c|c|c|}
\hline $\begin{array}{c}\text { Cowardin } \\
\text { Class }\end{array}$ & Impact & Restoration & Creation & Enhancement & $\begin{array}{c}\text { Net Change } \\
\text { (excluding } \\
\text { enhancement) }\end{array}$ \\
\hline E2AB & 5.076 & 0.350 & & 0.450 & $-\mathbf{4 . 7 2 6}$ \\
\hline E2EM & 2.159 & 4.478 & & 37.770 & $\mathbf{2 . 3 1 9}$ \\
\hline E2EM/SS & & & 2.130 & & $\mathbf{2 . 1 3 0}$ \\
\hline E2FO & 1.800 & & & & $\mathbf{- 1 . 8 0 0}$ \\
\hline E2RS & 0.050 & & & 0.060 & $\mathbf{- 0 . 0 5 0}$ \\
\hline E2SB & 0.600 & & & & $\mathbf{- 0 . 6 0 0}$ \\
\hline E2SS & & 0.100 & 0.330 & 0.074 & $\mathbf{0 . 4 3 0}$ \\
\hline E1UB & 0.140 & & & & $\mathbf{- 0 . 1 4 0}$ \\
\hline E2US & 0.962 & & 0.060 & & $\mathbf{- 0 . 9 0 2}$ \\
\hline PAB & & & 0.600 & & $\mathbf{0 . 6 0 0}$ \\
\hline PEM & 4.588 & 0.900 & 1.400 & & $\mathbf{- 2 . 2 8 8}$ \\
\hline PEM/SS & 0.700 & & & & $\mathbf{- 0 . 7 0 0}$ \\
\hline PFO & 0.500 & & & & $\mathbf{- 0 . 5 0 0}$ \\
\hline PFO/SS & & 0.300 & 0.500 & 0.700 & $\mathbf{0 . 8 0 0}$ \\
\hline PSS & 0.220 & & & 0.020 & $\mathbf{- 0 . 2 2 0}$ \\
\hline R/PSS & 0.100 & & & & $\mathbf{- 0 . 1 0 0}$ \\
\hline Estuarine only & $\mathbf{1 0 . 7 8 7}$ & $\mathbf{4 . 9 2 8}$ & $\mathbf{2 . 5 2 0}$ & $\mathbf{3 8 . 3 5 4}$ & $\mathbf{- 3 . 3 3 9}$ \\
\hline Non-tidal only & $\mathbf{6 . 1 0 8}$ & $\mathbf{1 . 2 0 0}$ & $\mathbf{2 . 5 0 0}$ & $\mathbf{0 . 7 2 0}$ & $\mathbf{- 2 . 4 0 8}$ \\
\hline Total & $\mathbf{1 6 . 8 9 5}$ & $\mathbf{5 . 8 2 8}$ & $\mathbf{1 0 . 0 4 0}$ & $\mathbf{3 9 . 0 7 4}$ & $\mathbf{- 1 . 0 2 7}$ \\
\hline Table $2:$ Perm & & & & & \\
\hline
\end{tabular}

Table 2: Permitted impacts and mitigated acres per Cowardin class for 1989-2005

for permits involving estuarine impacts and/or estuarine mitigation.

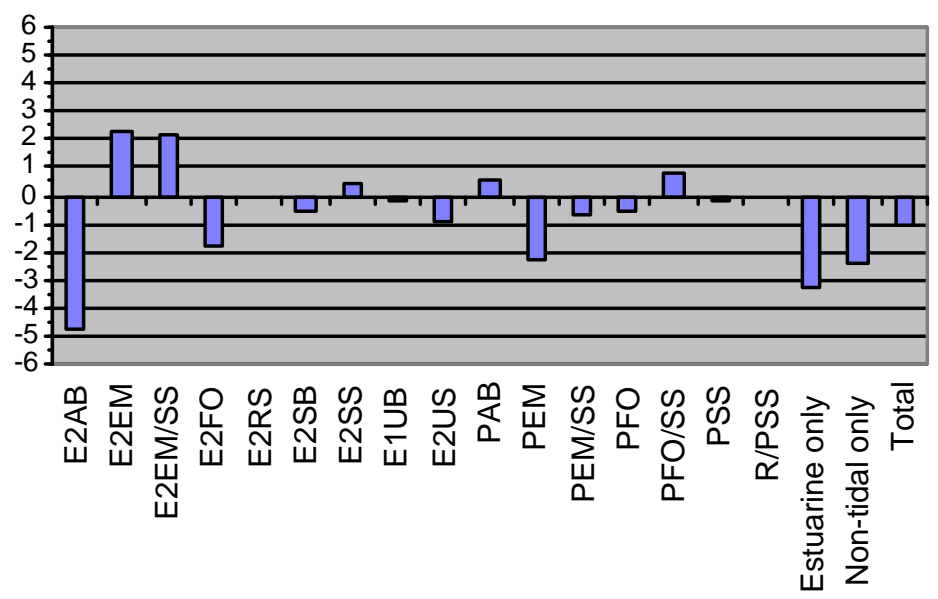

cowardin class

Figure 8: Net change per habitat type 1989-Oct 2005. (E2=estuarine intertidal; E1=estuarine subtidal; $A B=$ aquatic bed; $\mathrm{EM}=$ emergent; $\mathrm{FO}=$ forested; $\mathrm{RS}=$ rocky shore; $\mathrm{SB}=$ stream bed; $\mathrm{SS}=$ scrub-shrub; $\mathrm{UB}=$ unconsolidated bottom; US= unconsolidated sand; $\mathrm{P}=$ Palustrine; $\mathrm{R}=$ riverine)

\subsubsection{Mitigation method}

The method of mitigation (enhancement, restoration, or creation) was determined through the information provided in the permit. For the older permits, mitigation method was determined by the description of the existing habitat and type of mitigation proposed provided by the permittee. For the more recent permits, an accounting sheet filled out by the Removal-fill staff is included in each permit file. This accounting sheet tallies acres of impacted wetland type and acres of mitigation wetland type and acres of mitigation method (restoration, creation, or enhancement). This information was taken at face value and not independently verified to 
determine whether the proposed “restoration” activity was technically “enhancement” as defined by CWM rule. As mentioned in Chapter 1, a habitat that meets wetland criteria prior to mitigation is not restoration, as understood by the Removal-fill definitions (OAR 141-085-0010). However, the definition of "Restoration of an Estuarine Area" means "to revitalize or reestablish functional characteristics and processes of the estuary diminished or lost by past alterations, activities, or catastrophic events.” These definitions are in conflict with one another since restoration of an estuarine area could be considered enhancement under CWM, if the formerly estuarine habitat is no longer a functioning part of the estuary but meets wetland criteria.

Restoration, as reported by the applicant, was the most common method of mitigation used (in five of the 16 permits) and creation was the least common method (used in three permits) (Figure 9). However, enhancement projects involved the greatest number of acres, as shown in Figure 10. Enhancement of estuarine habitat involved about 38 acres, or $84 \%$ of total acres of required compensatory estuarine mitigation.

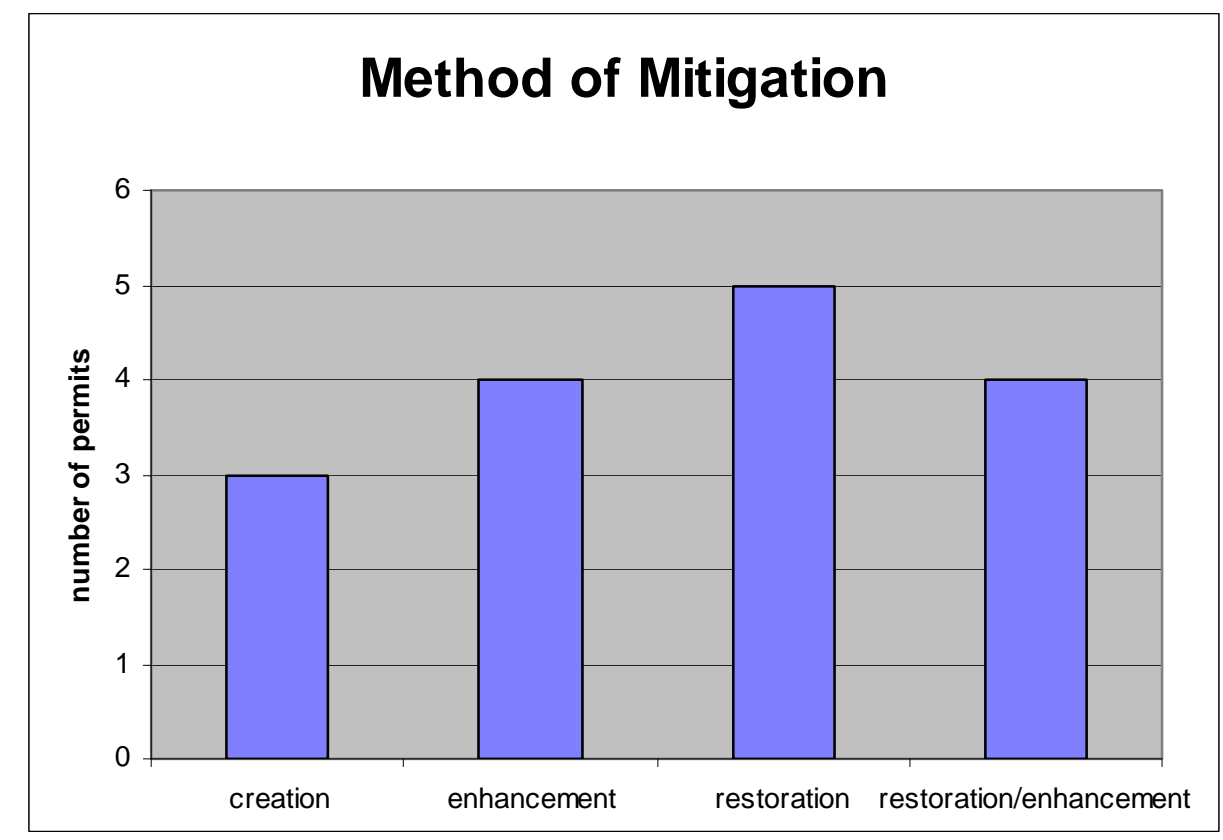

Figure 9: Number of permits per mitigation method, 1989-2005. 


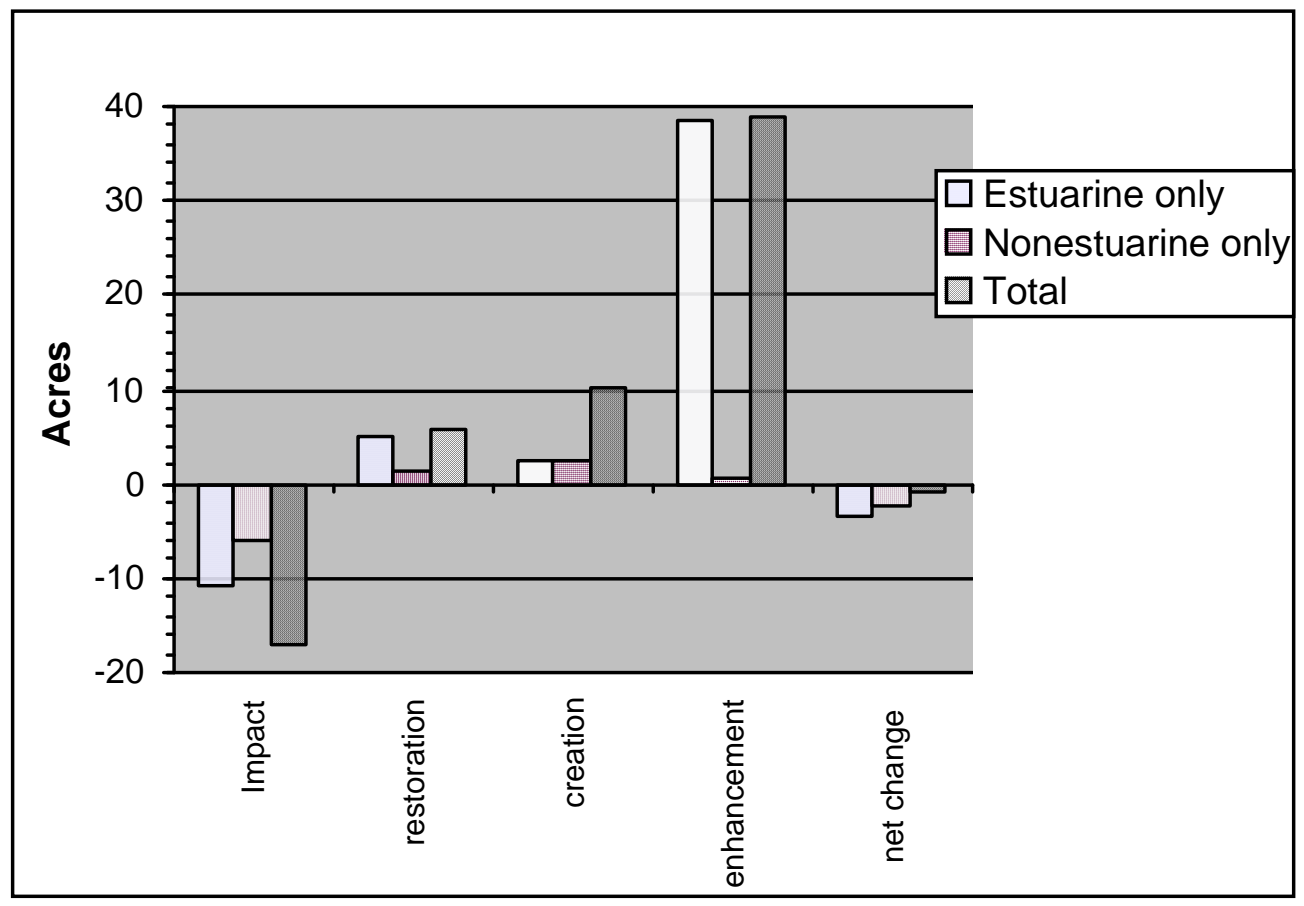

Figure 10: Acres of impact versus mitigation method for permits during 1989-2005.

Net change values do not factor in enhancement acres.

\subsubsection{Impacts per estuary}

Of the 10.787 acres of estuarine impact that occurred, the greatest impacts occurred in the estuaries classified for 'development' in the Estuary Plans. Coos Bay experienced the greatest acres of impact during this time period, followed by the Columbia River (Figure 11). Minor impacts to estuaries classified as ‘conservation’ occurred: in the Necanicum, 0.02 acres of impact were associated with a county bridge project and in the Nestucca, 0.05 acres of impact were associated with a bank stabilization project. 


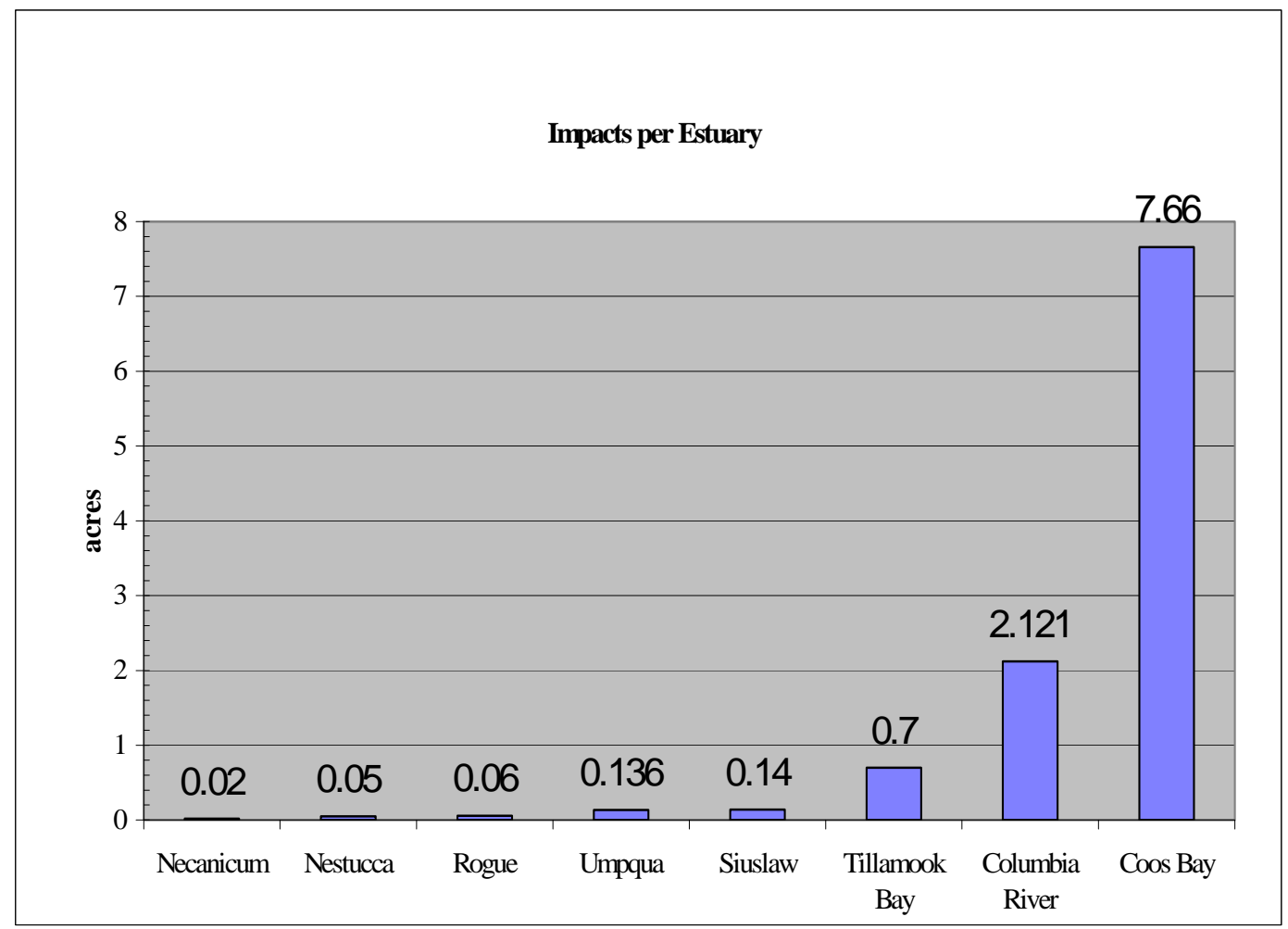

Figure 11: Estuarine Impacts in acreage per estuary during 1989-2005.

Of the 16 permits issued during this time period, only five permits used the estuarine rules to calculate the size of the mitigation project; the other permits used either the CWM ratios or no set ratio. Half of the permits involved on-site compensatory mitigation, the other half involved offsite mitigation. One permit compensated for impacts with a combination of restoration and the Payment to Provide (PTP) program. Due to poor tracking methods for the PTP program, it is unclear what the on-the-ground outcome of these PTP funds was. There were no estuarine mitigation banks available for credit purchase during this time period.

\subsubsection{Compensation ratios}

Ratios of mitigation acres to impact acres were calculated for each permit. Because some permits involved both non-tidal and estuarine impacts, ratios were calculated two different ways: all mitigation acres to all impacted acres and only estuarine impact acres to only estuarine mitigation acres. Ratios ranged from a low of 0.44 to 1 to a high of 99.01 to 1 (Table 3). For all mitigation acres to impact acres, the average ratio is 7.78 to 1 . This average was heavily influenced by the anomalous ratio of 99.01 to 1 . The median ratio of all mitigation acres to all impacted acres is 1.57 to 1 , a more accurate reflection of the ratios actually used. 


\begin{tabular}{|c|c|c|c|c|c|}
\hline $\begin{array}{c}\text { Year } \\
\text { First } \\
\text { Issued }\end{array}$ & $\begin{array}{c}\text { Permit } \\
\text { Number }\end{array}$ & County & $\begin{array}{c}\text { Mitigation } \\
\text { Acres to } \\
\text { Impacted } \\
\text { Acres }\end{array}$ & $\begin{array}{c}\text { Estuarine Mitigation } \\
\text { Acres to Estuarine } \\
\text { Impact Acres }\end{array}$ & Rules Applied \\
\hline 2004 & 31744 RF & Clatsop & 0.44 to 1 & 0.44 to 1 (plus PTP) & None \\
\hline 2004 & 31597 RF & Clatsop & 0.64 to 1 & 0.64 to 1 & None \\
\hline 2005 & 25631 RF & Curry & 1 to 1 & 1 to 1 & ERR \\
\hline 2005 & 23612 FP & Douglas & 1 to 1 & NA & CWM \\
\hline 2004 & 26538 RF & Clatsop & 1 to 1 & NA & CWM \\
\hline 2003 & 30205 SP & Tillamook & 1 to 1 & 1 to 1 & None \\
\hline 1989 & 04152 FP & Clatsop & 1.15 to 1 & 1.18 to 1 & ERR \\
\hline 1999 & 16086 FP & Lane & 1.57 to 1 & 1.57 to 1 & ERR \\
\hline 1991 & 05936 RF & Tillamook & 1.57 to 1 & 2.17 to 1 & None \\
\hline 2003 & 26467 RF & Clatsop & 1.59 to 1 & NA & functional assessment/ \\
\hline 1996 & $10375 F P$ & Lincoln & 1.60 to 1 & NA & CWM \\
\hline 1995 & 30681 FP & Coos & 2.35 to 1 & 2.35 to 1 & CWM \\
\hline 2001 & 23373 RF & Coos & 2.53 to 1 & 2.53 to 1 & CWM \\
\hline 2002 & 24813 RF & Clatsop & 3 to 1 & 3 to 1 & CWM \\
\hline 2002 & 26323 RF & Douglas & 6.03 to 1 & 6.03 to 1 & ERR \\
\hline 2005 & 33602 RF & Clatsop & 99.01 to 1 & 99.01 to 1 & None \\
\hline
\end{tabular}

Table 3: Ratios of mitigation acres to impact acres for permits involving estuarine mitigation during 1989 to 2005.

The areal requirement for compensatory mitigation is based upon the type of mitigation activity (restoration, creation or enhancement) and whether the ERR relative values or the CWM ratios are applied. When impacts to estuaries are permitted, the ERR rules apply. If non-tidal impacts are compensated for with tidal mitigation, CWM ratios are required, per rule. On a procedural note, one permit stated that the guidance from DSL was to use the method that produced the larger mitigation area, although this practice is not documented in the rules or DSL's standard operating procedure document.

For each permit, the method used to determine mitigation acres per impact acres and the resultant ratio in the permit was noted (Table 3). To demonstrate how ERR relative values compared to the CWM ratios, ratios were calculated for the method(s) not used in the permit. Five of the 16 permits in review did not use either method, thus both ERR and CWM values were calculated for comparison. The results of these different methods (Figure 12) illustrate that in two of the three permits that used ERR relative values, the CWM ratios would have required larger mitigation areas. The permitted mitigation ratio for permit 33602 was almost 100 to 1. Also, in all three permits that used CWM ratios for estuarine impacts, the estuarine relative values would have resulted in 50-60\% less mitigation area. In the cases in which no set method was used to calculate mitigation requirements, CWM ratios would have resulted in the same or more acres of mitigation per acre of impact. For ten of the 12 permits (Figure 13), the ERR 
relative values would have required less mitigation acres than the CWM ratios. ERR rules required, on average, $78 \%$ less mitigation area than the CWM ratios.

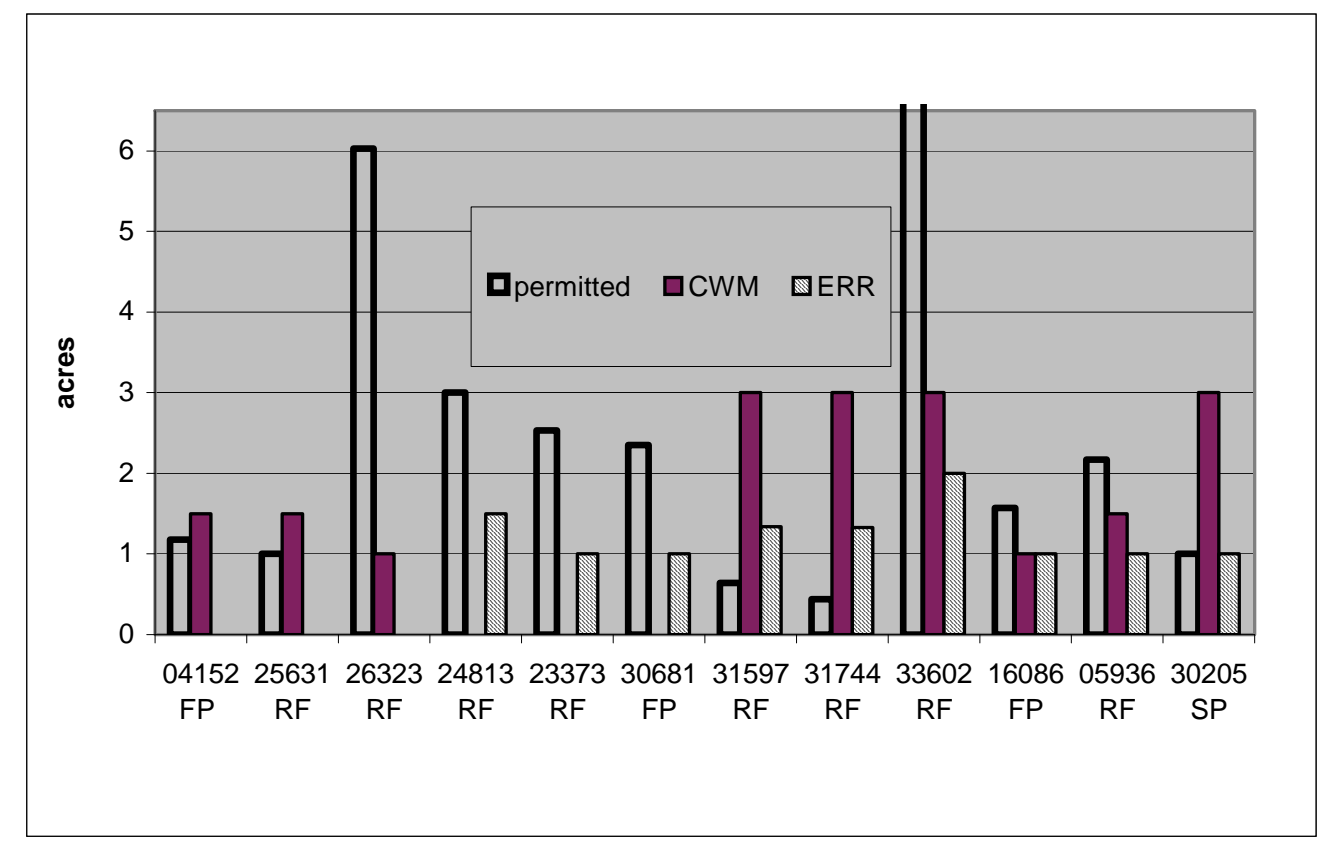

Figure 12: Permitted acres of mitigation per acres of impact compared to hypothetical acres of mitigation if freshwater ratios and/or estuarine relative values used. Permits with out-of-kind mitigation are not included.

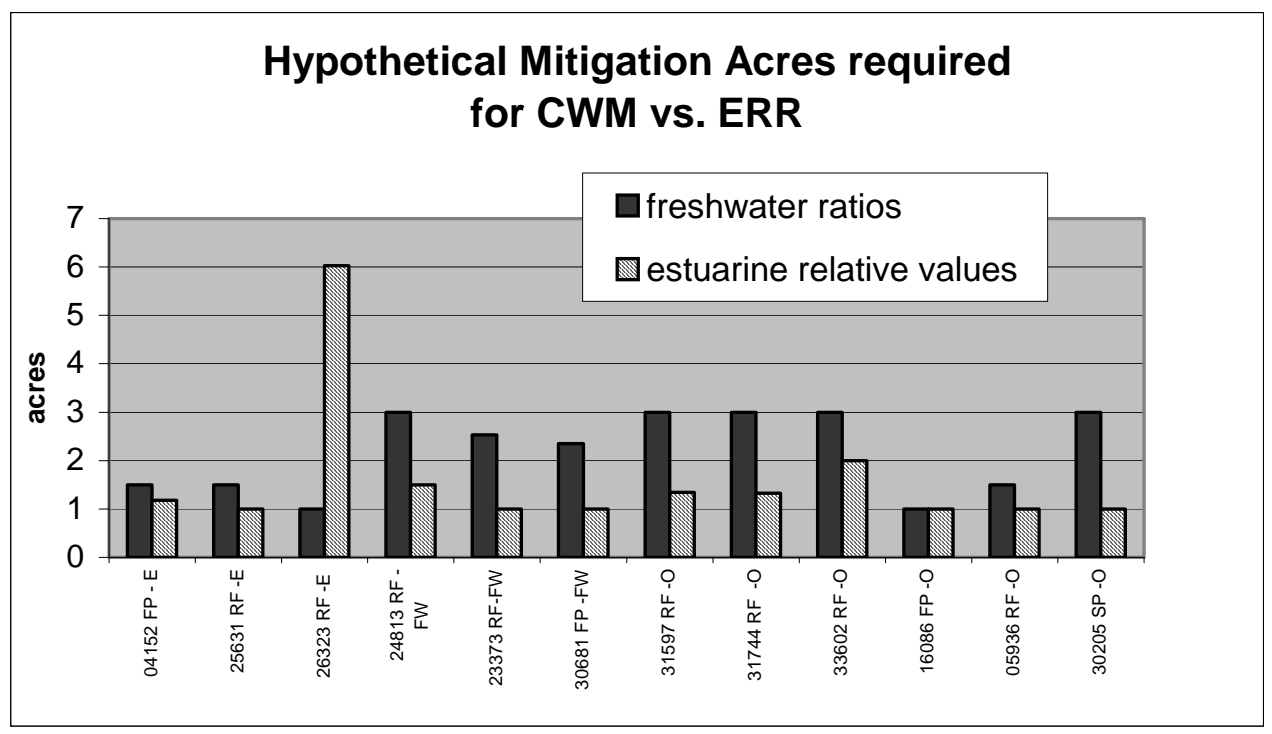

Figure 13: Acres of mitigation per acre of impact for the 12 permits with estuarine impacts. E (estuarine resource replacement), FW (freshwater compensatory wetland mitigation) or O (other method) after the permit number indicates which method was actually used in the permit. 


\subsubsection{Success criteria}

As set out by DSL's CWM rules (not explicitly stated in the ERR rules), mitigation plans are required to have clearly defined goals, objectives, and success criteria. The success criteria used in the Removal-fill program (DSL 2001) for mitigation plans are developed from the following matrix of quantifiable parameters:

-USACE 87 manual wetland criteria;

-soils information (color/depth/texture/organic matter);

-hydroperiod;

-vegetation survival and cover (invasive and native species);

-slope, elevation, and topography; and

-water chemistry.

Based upon a review of the success criteria used in the 16 permits reviewed in the 2005 permit inventory, the success criteria were grouped into 24 different categories (Table 4). Of the 16 permits, 11 were issued after the 2001 creation of the success criteria document. Acreage of the mitigation wetland, while reported elsewhere in the permit, was only included as the success criterion for six of the 16 permits and five of the 11 permits that were issued after 2001. Only three permits used the USACE '87 manual for hydrology and vegetation as success criteria for the wetland, despite the state's adoption of this manual for identifying wetlands. Two of the permits involved unvegetated flat habitats and thus the '87 manual would not be relevant. Vegetation criteria were most commonly used with $63 \%$ or 10 permits (55\% or 6 permits issued post-2001) using at least one type of vegetation criteria. Half of the 16 permits (6 of the 11 permits issued post-2001) used a hydrology-related indicator and 44\% (45\% for post-2001) of the permits specified an elevation for the mitigation wetland. If no tidal restrictions exist, elevation in estuarine systems generally dictates tidal hydroperiods. Therefore, this success criterion combined with hydrology would result in 98\% (100\% for post-2001 permits) of the permits using a hydrology-related success criterion. Slope, another important attribute of estuarine wetlands, was only used as a success criterion in three permits. Soils and water salinity were both used only once as success criteria in separate permits. 


\begin{tabular}{|c|c|c|c|c|}
\hline Success Criteria & $\mathbf{N}$ & $\%$ & \begin{tabular}{|c|}
$\mathrm{N}$ \\
post \\
$2001-$ \\
guidance \\
\end{tabular} & $\%$ \\
\hline Buffer Specifications & 2 & 13 & 2 & 18 \\
\hline buffer area & 1 & 6 & 1 & 9 \\
\hline buffer slope & 1 & 6 & 1 & 9 \\
\hline buffer vegetation & 1 & 6 & 1 & 9 \\
\hline Acreage & 6 & 38 & 5 & 45 \\
\hline creation acreage & 1 & 6 & 1 & 9 \\
\hline restoration acreage & 6 & 38 & 5 & 45 \\
\hline vague-area & 1 & 6 & 0 & 0 \\
\hline Elevation & 7 & 44 & 5 & 45 \\
\hline Wetland slope & 3 & 19 & 2 & 18 \\
\hline Soil & 1 & 6 & 0 & 0 \\
\hline Tidal Channel & 5 & 31 & 2 & 18 \\
\hline tidal channel elevation & 1 & 6 & 1 & 9 \\
\hline tidal channel slope & 1 & 6 & 0 & 0 \\
\hline tidal channel water duration & 1 & 6 & 0 & 0 \\
\hline tidal channel-vague & 1 & 6 & 0 & 0 \\
\hline Vegetation & 10 & 63 & 6 & 55 \\
\hline vegetation cover native & 5 & 31 & 3 & 27 \\
\hline vegetation cover invasive & 9 & 56 & 7 & 64 \\
\hline vegetation diversity & 2 & 13 & 2 & 18 \\
\hline vegetation survival & 5 & 31 & 3 & 27 \\
\hline 87 manual hydrophytic plants & 3 & 19 & 3 & 27 \\
\hline water chemistry & 1 & 6 & 1 & 9 \\
\hline Salinity & 1 & 6 & 1 & 9 \\
\hline hydrology & 8 & 50 & 6 & 55 \\
\hline water depth & 2 & 13 & 2 & 18 \\
\hline water duration & 1 & 6 & 1 & 9 \\
\hline water duration-vague & 2 & 13 & 0 & 0 \\
\hline 87 manual hydrology & 3 & 19 & 3 & 27 \\
\hline
\end{tabular}

Table 4: Summary of success criteria used in estuarine resource replacement associated with Removal-fill permits from 1989-2005 inventory.

Of the 16 permits that required compensatory mitigation, nine have completed the mitigation project and three permits have completed their mitigation project and required monitoring period ('off-hook') (Table 5). Ten of the permits were considered compliant with the permit conditions relative to mitigation, but still in the monitoring phase of the permit conditions. Compliant for the purposes of this project means that the permittee has completed the mitigation project and has adhered to the permit conditions (submitted annual monitoring reports), but is still in the required monitoring phase of the mitigation requirement. One permit was not considered compliant for not doing the mitigation project. This assessment was based upon the information found in the permit file, in the LAS database, and from communication with the permit coordinator. 
For seven permits (44\%), the mitigation status was unknown, mainly due to a change in internal processing of monitoring reports. All monitoring reports used to be processed by one staff member, the mitigation specialist, and recorded in a separate database, rather than LAS. As of February 2005, this duty is no longer the responsibility of the mitigation specialist, but of each permit coordinator. During the transition period, not all monitoring reports were returned to the permit files, nor was the mitigation data entered into LAS. Since the winter of 2005, a new system has been developed to track mitigation monitoring reports in LAS. Monitoring reports received after winter 2005 are numbered and logged into LAS by one staff member and then reviewed by the appropriate permit coordinator. It is the responsibility of the permit coordinator to ensure the mitigation information in LAS is current by indicating the status of the mitigation project, the location of the mitigation project, and the compliance status of the mitigation. However, these fields were not populated for any of the active (11) permits that required monitoring involved in this inventory. If a monitoring report or some indication of the mitigation status could not be found in the permit file or could not be located at the permit coordinator’s desk, the mitigation status was indicated as ‘status unknown’ (Table 5).

\begin{tabular}{|c|c|c|c|c|c|c|}
\hline Permit & $\begin{array}{c}\text { Year } \\
\text { Permit } \\
\text { First } \\
\text { Issued } \\
\end{array}$ & $\begin{array}{c}\text { Year } \\
\text { Mitigation } \\
\text { Project } \\
\text { started } \\
\end{array}$ & $\begin{array}{c}\text { Monitoring } \\
\text { Length }\end{array}$ & Project done? & Compliant? & Off-hook? \\
\hline 4152 & 1989 & 1989 & 3 years & Yes & Yes & Yes \\
\hline 5936 & 1991 & 1991? & 5 years & Yes & Status unknown & Status unknown \\
\hline 16086 & 1999 & & NA & Yes-PTP & Yes & Yes \\
\hline 23373 & 2001 & 2001 & 5 years & Yes & Yes & No \\
\hline 23612 & 2002 & & 5 years & No & Yes & No \\
\hline 24813 & 2002 & 2002 & 4 years & Yes & Status unknown & No \\
\hline 25631 & 2003 & & 5 years & No & Yes & No \\
\hline 26323 & 2002 & 2003 & 5 years & Yes & Status unknown & No \\
\hline 26467 & 2002 & 2002 & 5 years & $\begin{array}{l}\text { Yes-On-site/ } \\
\text { Status } \\
\text { unknown- } \\
\text { offsite }\end{array}$ & Status unknown & No \\
\hline 26538 & 2004 & 2004 & 1 year & Yes & Yes & Status unknown \\
\hline 30205 & 2003 & & 3 years & No & No & No \\
\hline 30681 & 1995 & 2000 & 10 years & Yes & $\begin{array}{c}\text { Yes (vague success } \\
\text { criteria) }\end{array}$ & No \\
\hline 31597 & 2004 & & Not required & No & Status unknown & Status unknown \\
\hline 31744 & 2004 & & Not required & $\begin{array}{l}\text { No-onsite/ } \\
\text { Yes-PTP }\end{array}$ & Yes & No \\
\hline 33166 & 1996 & 2006 & 10 years & No & Yes & No \\
\hline 33602 & 2005 & 2005 & Not required & Yes & Status unknown & Status unknown \\
\hline
\end{tabular}

Table 5: Status of estuarine mitigation projects from 1989-2005. 


\subsection{Summary of Permit Inventory}

Based on the inventory of available permits, only 16 permits have been issued resulting in about 11 acres of estuarine impacts from 1989 to October 2005. For comparison, during 2002 through 2004, 175 acres of wetlands (all types) were impacted associated with 135 permits processed and 584 acres restored, enhanced, or created as required for compensation (DSL 2005). Clearly, Removal-fill activity in Oregon estuaries is a very small part of wetland impacts overall. The largest impacts resulted from transportation and shipping activities. Nine of the 16 permits involved restoration for compensatory mitigation (as defined by the ERR rules), while three involved creation and four involved enhancement. Only four of those nine restoration treatments would be considered 'restoration' for the entire mitigation area as defined by CWM rules (e.g. RF 26323-fill removal, RF 31744-bridge abutment removal, FP 23612-fill removal, RF 26538-fill removal). The other six involved dike or berm removal that allowed tidal inundation to the freshwater wetland behind the dike.

Prior to the CWM rules, restoration credit was given for the footprint of the dike removal and the area behind the dike that would be reconnected to tidal inundation. However, the current practice is to apply the CWM definitions of restoration and enhancement, thus, granting restoration credit (1:1) to the dike footprint and enhancement credit (3:1) to the area behind the dike (if it meets wetland criteria prior to dike breach). Unlike CWM, the ratio of mitigation acres to impact acres varies per habitat type as dictated by the estuarine relative values chart (Figure 5). Theoretically, the ratio can never be less than 1:1 (per rule) or greater than 6:1. For example, if the dike removal restored a high brackish marsh, the relative value would be a 4 . If the impact site was 10 acres of low brackish marsh, the relative value would be 5 , thus the compensation ratio would be 1.25 to 1 . However, if the impact site relative value was equal to or less than the relative value of the mitigation site, the ratio would always be $1: 1$, since the impact can not be larger in area than the mitigation site.

The Cowardin classes most commonly proposed for mitigation are estuarine intertidal emergent habitats, as demonstrated by increases in this habitat type with minor losses in estuarine intertidal aquatic bed habitat. Mitigation efforts resulted in a total net loss of estuarine habitat of about three acres, due to enhancement acres approved for estuarine resource replacement. Cowardin classes created in the three creation projects were intertidal scrub-shrub marsh with subtidal channels, intertidal high emergent marsh with subtidal channels, and 
unvegetated intertidal/subtidal sand flats. Cowardin classes restored were intertidal scrubshrub/emergent high marsh and low marsh. Enhancement activity involved willow stake planting along a riverine section of the estuary, woody planting in a high emergent marsh, invasive species removal and willow planting, and a tide gate replacement to increase tidal flushing in a subtidal channel.

As a result of the agency practice of purging inactive records after seven years, this inventory did not capture all of the permitted impacts. This inventory, also, revealed the difficulty of readily accessing data on wetland impacts and mitigation projects using the current database due to the lack of precision in mapping the impact and mitigation sites. The practice of purging records combined with imprecise mapping tools makes assessing cumulative estuarine impacts, and wetland impacts in general, from Removal-fill permits impossible. Also, functional assessment data and monitoring reports, if available, are buried in permit files, which make it difficult to understand functions being gained and lost per estuary. Overall, replacement ratios required by the ERR rules resulted in less areal compensation than the CWM ratios would require. Success for compensatory mitigation was heavily dependent upon vegetation criteria; in some cases, mitigation success, in terms of compliance, was challenging to assess due to the lack of information. 


\section{CHAPTER 4 \\ ESTUARINE ECOLOGY AND RESTORATION}

\subsection{Introduction}

Estuarine mitigation rules developed to implement the Estuarine Resource Replacement statute were based upon the report Habitat classification and inventory methods for management of Oregon estuaries (Bottom et al. 1979). This resource was a synthesis of the best available science on Oregon's estuaries from the middle twentieth century. While many definitions of estuaries exist, this report adopted Pritchard's (1967) definition of estuaries as "bodies of water semi-enclosed by land and connected with the open ocean within which salt water is usually diluted by fresh water derived from the land." This report developed a classification system of Oregon’s estuarine habitat based upon original fieldwork and available data from the literature. In terms of available data, datasets existed for half of the major estuaries, excluding the Columbia River. Much data was available on climate, hydrology, and water quality with less information known about estuarine sediments in terms of erosion and accretion, particle size, and sediment quality. Among other research topics, available data on the distribution and productivity of flora and fauna per estuary were listed. Some datasets (both complete and incomplete) were available on the distribution of mammals, invertebrates, and fish for each major estuary. Little was known about bird communities and even less data existed on macroalgae, seagrass, and microalgae. Likewise, little was known about zooplankton communities and distribution. In addition to identifying data gaps, the report identified data gaps, methods for filling those gaps, and suggested application of those data. These partial datasets were used to classify estuarine habitats in Oregon.

Based on their perceived ecological characteristics relative to biological productivity, species diversity, and water quality, a stakeholder group assigned relative values to the Bottom et al. (1979) classification for the purpose of developing the ERR rules (Quarterman 1985). The committee rated seagrasses the highest value and unvegetated habitats the lowest (Table 6). This method of rating on a scale of one (lowest) to six (highest) assumed that all habitats of the same class functioned the same without consideration of position in the estuary, relation to adjacent habitat and surrounding land use, or how the habitat fit into the larger estuarine ecosystem. 


\begin{tabular}{|l|c|}
\hline \multicolumn{1}{|c|}{ Habitat } & $\begin{array}{c}\text { Average } \\
\text { Productivity } \\
\text { Value }\end{array}$ \\
\hline unvegetated & 2.38 \\
\hline high marsh & 2.92 \\
\hline forested wetland & 3 \\
\hline algae & 3.38 \\
\hline low marsh & 3.54 \\
\hline flats & 3.7 \\
\hline seagrass & 5.33 \\
\hline
\end{tabular}

Table 6: Average productivity value based upon estuarine mitigation rules (Hamilton 1984).

Over the years, various research and management programs have been established throughout Oregon's estuaries. Through EPA's National Estuary Partnership program, both Tillamook Bay (i.e. Strittholt and Frost 1996; Sullivan et al. 2005; Tillamook Bay National Estuary Project 1999; Charland 1997; Colbert and McManus 2003; Follansbee and Stark 1998; Shreffler and Griffin 2000) and the Columbia River Estuary (i.e. Evans et al. 2006; LCREP 2005; Roegner et al. 2006; have been extensively studied. EPA’s Pacific Coastal Ecology Branch of the Western Ecology Division located in Newport, Oregon has undertaken studies of the estuarine condition, nutrient cycling, and food webs Yaquina Bay (e.g. Kentula and DeWitt 2003; Griffen et al. 2004; DeWitt et al. 2004). Additionally, the EPA Pacific Coastal Ecology Branch has been involved in the five-year EMAP Western Coastal Pilot Project designed to assess the condition of the West Coast's ecosystems (Nehlson et al. 2004). The US Forest Service's work on the Salmon River estuary has focused on tidal marsh restoration over the last 30 years (Morlan 1991)and more recently the response of juvenile salmon to these restoration efforts (Bottom et al. 2005; Gray et al. 2002). Through the National Estuarine Research Reserve program, an extensive profile of the ecology of the South Slough Estuary, a branch of Coos Bay has been published documenting the ecology of the South Slough and results of tidal restoration efforts (Rumrill 2006).

In an effort to paint a broad picture of the current understanding, this section will provide a brief overview of estuarine ecology and restoration with a Pacific Northwest focus. An inventory of estuarine habitat will be provided, followed by a review of estuarine primary productivity. The status of nekton in Oregon's estuaries will be briefly summarized. Invasive species threats will be outlined followed by a description of water quality in Oregon's coastal watersheds. A more detailed review of selected intertidal subhabitats including mudflats, tidal marshes, and seagrasses will be provided. Human caused estuarine wetland impacts will be 
summarized followed by a review of restoration efforts to reverse the trends. The status of restoration ecology with an identification of failures and successes and recommended performance standards to assess restoration efforts will conclude this chapter.

\subsection{Estuarine Habitat Inventory}

The Oregon Estuary Plan book (OEP) (Cortright et al. 1987) has maps of the intertidal and subtidal habitats for each of Oregon 17 major estuaries from the mouth to the head of tide based on the Bottom et al. (1979) classification. As summarized by Good (1999), Table 7 shows the distribution of estuarine habitat type and area of contributing watershed. About half of Oregon's estuarine area is subtidal. While tidal flats makeup almost 28\% of Oregon's total estuarine habitat, macroalgal/eelgrass beds account for about 7\% of the total area and tidal marshes (salt, fresh, \& forested) total about $15 \%$ of estuarine habitat. Habitat ratios and distribution vary based on physical differences per estuary. For instance, the Columbia River Estuary has no eelgrass/algal beds, but accounts for a majority of the tidal forested/scrub-shrub habitat in Oregon.

\begin{tabular}{|c|c|c|c|c|c|c|c|c|}
\hline Estuary & $\begin{array}{c}\text { Salt } \\
\text { marsh }\end{array}$ & $\begin{array}{c}\text { fresh } \\
\text { marsh }\end{array}$ & $\begin{array}{c}\text { forested/ } \\
\text { scrub- } \\
\text { shrub }\end{array}$ & $\begin{array}{c}\text { tidal } \\
\text { flats }\end{array}$ & $\begin{array}{c}\text { Eelgrass/ } \\
\text { algae }\end{array}$ & $\begin{array}{c}\text { Subtidal } \\
\text { area (ac.) }\end{array}$ & $\begin{array}{c}\text { Watershed } \\
\text { Estuary (ac.) }\end{array}$ & area (sq.mi.) \\
\hline Columbia & 1488 & 5728 & 4290 & 21391 & 0 & 47914 & 80811 & 259000 \\
\hline Necanicum & 94 & 35 & 3 & 136 & 4 & 179 & 451 & 87 \\
\hline Nehalem & 509 & 3 & 12 & 581 & 652 & 992 & 2749 & 855 \\
\hline Tillamook & 881 & 0 & 3 & 4226 & 2024 & 2082 & 9216 & 540 \\
\hline Netarts & 228 & 0 & 0 & 1224 & 957 & 334 & 2743 & 14 \\
\hline Sand Lake & 462 & 0 & 0 & 255 & 66 & 114 & 897 & 17 \\
\hline Nestucca & 205 & 0 & 0 & 430 & 242 & 299 & 1176 & 322 \\
\hline Salmon & 238 & 0 & 0 & 28 & 76 & 96 & 438 & 75 \\
\hline Siletz & 274 & 0 & 0 & 425 & 461 & 301 & 1461 & 373 \\
\hline Depoe Bay & & & & & & & 25 & 15 \\
\hline Yaquina & 619 & 2 & 0 & 807 & 968 & 1953 & 4349 & 253 \\
\hline Alsea & 460 & 0 & 0 & 764 & 564 & 728 & 2516 & 474 \\
\hline Siuslaw & 746 & 0 & 0 & 541 & 338 & 1435 & 3060 & 773 \\
\hline Umpqua & 1054 & 52 & 95 & 1196 & 399 & 3748 & 6544 & 4560 \\
\hline Coos Bay & 1699 & 28 & 0 & 4240 & 2256 & 5125 & 13348 & 605 \\
\hline Coquille & 276 & 0 & 0 & 228 & 103 & 475 & 1082 & 1058 \\
\hline Sixes & & & & & & & 330 & 129 \\
\hline Elk & & & & & & & 290 & 94 \\
\hline Rogue & 39 & 5 & 0 & 201 & 77 & 558 & 880 & 5100 \\
\hline Pistol & & & & & & & 230 & 106 \\
\hline Chetco & 0 & 4 & 0 & 9 & 103 & 55 & 171 & 359 \\
\hline Winchuck & & & & & & & 130 & 70 \\
\hline Total & 9272 & 5857 & 4403 & 36682 & 9290 & 66863 & 132897 & 274874 \\
\hline \% Total & $\mathbf{7}$ & $\mathbf{4 . 5}$ & $\mathbf{3 . 3}$ & $\mathbf{2 7 . 8}$ & $\mathbf{7 . 1}$ & $\mathbf{5 0 . 3}$ & $\mathbf{1 0 0}$ & \\
\hline
\end{tabular}

Table 7: Acres of habitat type per estuary (Good 1999). 
The OEP was based upon aerial photography flown in the 1970s but little is known about the resolution, what the tide cycle was at the time of the photos, or the accuracy of the data. Current conditions may not be reflected in the OEP due to human or natural changes to estuarine habitat since publication. Furthermore, access to better mapping technologies such as better resolution, remote sensing, and improved processing techniques are additional reasons to reinventory Oregon's estuaries. Nevertheless, the OEP is a useful coast wide resource because of its standardized format and its availability as Geographic Information Systems (GIS) layers on the Oregon Coastal Atlas website (Oregon Coastal Atlas 2006).

\subsection{Primary Productivity}

Primary productivity in Oregon's estuaries is contributed by phytoplankton (mostly diatoms), eelgrass meadows, macrophytes in marsh systems, macroalgae, and tideflats. Table 8 shows net primary production estimates for Oregon's estuaries (Emmet et al. 2000). While a number of studies have estimated primary productivity for tidal marshes, less is known about other habitat types, especially planktonic primary productivity. Primary productivity in most small west coast estuaries was found to be nitrogen limited (Nelson et al. 2005).

\begin{tabular}{|c|c|c|c|c|c|c|}
\hline Estuary & $\begin{array}{c}\text { Annual } \\
\text { planktonic } \\
\text { pp. }\end{array}$ & $\begin{array}{c}\text { Aerial } \\
\text { Annual Tidal } \\
\text { Marsh npp. }\end{array}$ & $\begin{array}{c}\text { Aerial } \\
\text { Annual } \\
\text { Eelgrass } \\
\text { npp. }\end{array}$ & $\begin{array}{c}\text { Annual } \\
\text { seaweed } \\
\text { npp. }\end{array}$ & $\begin{array}{c}\text { Annual } \\
\text { Tideflat } \\
\text { npp. }\end{array}$ & Reference \\
\hline Columbia & & $432-1,501$ & & & 38-97 (gpp) & $\begin{array}{l}\text { Macdonald } \\
\text { 1984; } \\
\text { McIntire \& } \\
\text { Amspoker } \\
1984\end{array}$ \\
\hline Nehalem & & $35-702$ & & & & Eilers 1975 \\
\hline Netarts Bay & & & $400-737$ & 1,120 & 12 & $\begin{array}{l}\text { McIntire et al. } \\
\text { 1983; Kentula } \\
\text { \& McIntire } \\
1986\end{array}$ \\
\hline Siletz River & & $480-800$ & & & & $\begin{array}{l}\text { Gallagher \& } \\
\text { Kibby } 1981\end{array}$ \\
\hline $\begin{array}{l}\text { Yaquina } \\
\text { Bay }\end{array}$ & & & & & 3 & $\begin{array}{l}\text { McIntire et al. } \\
1983\end{array}$ \\
\hline Coos Bay & & $123-480$ & & & & $\begin{array}{l}\text { Taylor \& } \\
\text { Frenkel 1979; } \\
\text { Hoffnagle } \\
1980\end{array}$ \\
\hline $\begin{array}{l}\text { Oregon } \\
\text { Estuaries }\end{array}$ & & $180-740$ & & & & $\begin{array}{l}\text { Kibby et al. } \\
1980\end{array}$ \\
\hline
\end{tabular}

Table 8: Net primary production estimates (gC/m2-yr) per habitat type in Oregon’s estuaries (Emmett et al. 2000). 
West coast estuaries have extensive areas of mud flats due to high sedimentation rates and tidal fluctuations (Emmett et al. 2000). Although tidal flats can contribute a high proportion of organic carbon, few studies have measured their primary productivity. A Puget Sound study showed tidal flat annual net primary productivity to be $1,286 \mathrm{gC} / \mathrm{m}^{2}-\mathrm{y}$. A Columbia River Estuary study (McIntire \& Amspoker 1984) estimated benthic gross primary productivity (excluding macrophytes) for the estuary's intertidal region to be 2.175 x $10^{6} \mathrm{~kg}$ carbon per year. However, due to the size of the Columbia River's drainage basin $(647,497 \mathrm{sq} . \mathrm{km})$, this is a small fraction of the allochthonous riverine inputs of organic carbon into the estuary. Average water column concentrations of chlorophyll a for west coast estuaries were found to be less than $8 \mathrm{ug} / \mathrm{L}$ (Nelson et al. 2005).

\subsection{Pacific Northwest Estuarine Fisheries}

Although Pacific Northwest estuaries are relatively intact (Emmett et al. 2002), the native oyster population was decimated by the late 1800's and salmon populations have been on the decline since the early 1900's (Nelson et al. 2005). Estuarine condition has been linked to salmon survival, especially for subyearling Chinook salmon (Mangusson \& Hilborn 2003). Salmonid species rely upon estuaries for temporary habitat for feeding, resting, and acclimating to different salinity regimes, particularly during their juvenile stage. Different salmonid species (coho, Chinook, chum, steelhead and cutthroat trout) depend upon these diverse habitats for varying lengths of time at different times in their life cycles. For example, Oncorhynchus kisutch juveniles (Coho) spend only a few days in the estuary on their way to the ocean sometime between March through July; while Oncorhynchus tshawytscha (spring Chinook) spend days to months in the estuary during the same time period (IMST 2002).

The concepts of landscape ecology are being applied to the recovery efforts for salmon by recognizing the need to maintain and restore a heterogeneous, mosaic of habitats both in river channels and in estuaries (IMST 2002). Tidal channels, marshes, eelgrass beds (Thom et al. 2003), and tidal creeks provide refuge from predators and feeding habitat, while brackish waters are used as places to acclimate prior to entering saline marine waters (Miller \& Simenstad 1997). Coho use estuarine wetlands for over wintering habitats, but spend less time in estuarine habitats than Chinook. Juvenile salmon generally feed on benthic detritivores such as copepods and crangonid shrimp that are found on surface sediments in shallow mudflats, marshes, and sloughs (Thom 1987). 
Other Pacific Northwest research has focused on English sole and Dungeness crab use of estuaries (Gunderson et al. 1990; Armstrong et al. 2003; Holsman et al. 2003). Based upon extensive trawl surveys (1983-1987) in Grays Harbor and Willapa Bay, Washington, both species were found to spawn offshore, but enter estuaries as juveniles to take advantage of warmer water temperature and greater food supplies. Also, English sole may migrate into estuaries due to decreased competition for food sources from butter sole (Isopsetta isolepis), but probably not for predator avoidance since predation rates were found to be greater in estuaries than in coastal waters. While English sole spend their first year in the estuary and then migrate back to the ocean, Dungeness crab do not migrate into the estuary until after their first year in the ocean, where they stay for about a year before returning to the ocean. Emigration from the estuary appears to be related to size.

While Gunderson et al. (1990) documented that juvenile English sole and Dungeness crab in fact use the estuary for its warmer water and increased food supply, they did not attempt to document any patterns of habitat use within the estuary. Rooper et al. (2003) attempted to determine this for juvenile English sole use of four Pacific Northwest estuaries. Trawl surveys from 1998-2000 and 1983-1988 were analyzed. Based on fish densities, juvenile English sole were found to prefer lower side channel habitat to lower main channel and upper estuary habitat, which are shallower and adjacent to intertidal flats, to the lower main channel or the upper estuary. Based on seasonal density data, the authors concluded that estuaries may have a carrying capacity for large juvenile English sole.

\subsection{Invasive Species}

Invasive species have become a concern in Oregon's estuaries. The nonnative cord grass, Spartina alterniflora, has invaded Willapa Bay, Washington, quite dramatically (Simenstad \& Thom 1995) and is predicted to invade a majority of Oregon’s estuaries (Daehler \& Strong 1996). Spartina patens has been detected on Cox Island in the Siuslaw River Estuary in Oregon. Over 100 nonnative species have invaded Oregon's estuaries (Carlton et al. 2003) including the European green crab Carcinus maenas and the purple varnish clam Nuttallia obscurata. Established in the Columbia River in the 1980's, Pseudodiaptomus inopinus, the invasive Asian copepod, was also found in Coos Bay, Umpqua River, Yaquina River, and Tillamook Bay during a 1992 study and tends to be found in warmer, slow moving rivers with long salinity intrusion zones (Cordell \& Morrison 1996). This species was also found in the 
Siuslaw and Coquille in a 1996 sampling (Bollens et al. 2002). The potential ecological and economic impacts of these invasions are not fully understood. Vectors for invasions include ballast water transport, aquaculture practices, and recreational boating (Bollens et al. 2002).

\subsection{Water Quality}

Studies have established water quality baseline data for Oregon's estuaries (Nelson et al. 2005; Mrazik 2004). While overall water quality is good, some water quality concerns have been identified in Oregon's coastal watersheds. Water quality issues vary by watershed and estuarine system. Estuarine wetlands play an important role in the biogeochemistry of estuaries. No studies to date in Oregon have looked specifically at the influence of estuarine wetlands on estuarine water quality. As land use patterns change along the coast, threats to Oregon's water quality may change (Good 2000).

A study that assessed a number of environmental indicators of small West coast estuaries revealed overall good water quality (Nelson et al. 2005). Most of the small estuaries had adequate dissolved oxygen concentrations, low pesticide and toxic metal contamination, and had a range of acidic to alkaline pHs. Of all small West coast estuaries, Oregon's estuaries had the lowest levels of mercury and arsenic, but had the highest copper concentrations in estuarine fish tissue.

Estuaries are very productive ecosystems due to the combination of riverine and marine allochthonous and autochthonous inputs. Marine and riverine inputs change seasonally, resulting in dynamic and complex nutrient cycling. One study examining the nutrient cycle in Tillamook Bay revealed that nutrient cycling is controlled by a combination of freshwater riverine inputs, biological nutrient uptake, and seasonal coastal upwelling (Colbert \& McManus 2003). While rivers supply the Bay with the inorganic nutrients of silica and nitrogen year round, phosphorous enters the Bay from riverine inputs in the winter, but from coastal upwelling during the other seasons. Excessive nutrient inputs into estuaries can lead to eutrophication. However, based on the Tillamook Bay study (Colbert \& McManus 2003), the authors conclude that human-induced eutrophication is unlikely in Tillamook Bay's current conditions due to high flushing rates in the winter when watershed-derived phosphorus concentrations are the highest. Also, phosphorus tends to be the limiting nutrient in this system, preventing phytoplankton blooms year round. However, watershed-derived nutrient inputs may be causing eutrophication problems in Yaquina 
Bay as seen by macroalgal blooms (Kentula \& DeWitt 2003). The potential for eutrophication in Oregon's estuaries varies for each estuary and is the combination of human and natural factors.

Other water quality issues have been documented in Oregon's coastal watersheds and estuaries. Many of Oregon's coastal watersheds do not meet water quality standards for salmon habitat due to elevated stream temperatures and sediment-covered spawning beds and for the shellfish harvesting due to high fecal bacteria concentrations (DEQ 2004; DEQ 2006; Sullivan et al. 2005). The source of these water quality problems originate from a variety of land use practices in the watershed that include forestry, agriculture, and residential development.

Estuarine wetlands, similar to other wetlands, have the capacity to function as sinks, sources, or transformers of particulate and dissolved nutrients depending upon site specific and landscape factors (Mitsch \& Gosselink 2003). For example, a Chesapeake Bay study (Correll et al. 1992) analyzed nutrient flux in the landscape. Sampling in the upper part of the estuary demonstrated the influence of high marsh, low marsh, and shallow subtidal mudflats on nutrient transport and transformation. Each habitat was found to import particulate matter and export dissolved nutrients. The high marsh released more particulate organic carbon, more dissolved organic N, and less dissolved phosphate than the low marsh. While the low marsh imported more particulate matter than the high marsh, subtidal mudflats trap even more particulate matter than marshes and export dissolved phosphate into the water column. The mudflat was also able to trap nearly all of the nitrate from the watershed and some from the Bay and is considered to play a significant role in retaining sediment in the upper part of the Rhode River estuary. A Tanzania study (Gereta et al. 2004) revealed the buffering influence of fringing salt marshes on water quality indicated by dissolved oxygen concentrations in the Seronera River.

An input-output budget was developed for a salt marsh along the southern Atlantic coast (Dame et al. 2000). The low salt marsh imported significant amounts of particulate and dissolved materials including inorganic suspended sediments, particulate organic carbon, nitrate and nitrite, particulate phosphorous, soluble reactive phosphorous, and chlorophyll, but exported only dissolved organic nitrogen and ammonium. Nitrogen and phosphorus were recycled within the marsh. Particulate matter was removed by sedimentation and by marsh mussels. Dissolved nutrients were removed by epiphytes, benthic microalgae, and sediments within the marsh.

No studies have analyzed the role of estuarine wetlands on the water quality of Oregon's estuaries. However, as coastal economies change from natural resource-based to retiree and tourist-based, increased residential development may increase water quality threats to estuaries (Huppert et al. 2003). The State of the Environment Report (Good 2000) identifies water quality 
degradation as a major threat to Oregon's estuaries, particularly to eelgrass meadows, due to increased nonpoint source pollution and increased freshwater withdrawals to accommodate development associated with tourism and retiree destinations.

\subsection{Estuarine Subhabitat Functions and Values}

Estuarine wetland habitats provide numerous functions that are valued by society (Table 9). Values attributed to these various functions include support of invertebrate and vertebrate fisheries, birds and other wildlife, erosion control, recreational value, protection of biodiversity, and improved water quality. Wetland function varies per wetland type but also by location and condition. For example, while Short et al. (2000) identified 'wave and current dampening' as a function of salt marshes on the east coast, this function was not identified as a major function of Oregon's tidal marshes (Adamus 2005). Also, there is variation in interpretation of what constitutes a function versus a value and the terms are often used interchangeably. While Short et al. (2000) identified 'support of fisheries and wildlife' as a value, Adamus (2005) identified maintenance of these as a function. The tidal marsh functions (Adamus 2005) were identified in relation to the development of a rapid tidal wetland HGM functional assessment method, which will be discussed in more detail in the next chapter. Rapid functional assessments have not been developed for mudflat or eelgrass habitats in Oregon's estuaries. These three habitats will be described briefly below. 


\begin{tabular}{|c|c|c|}
\hline Function & Short et al. (2000) & Adamus (2005) \\
\hline \multicolumn{3}{|l|}{ Eelgrass } \\
\hline canopy structure & $\mathbf{X}$ & \\
\hline epibenthic and benthic production & $\mathbf{X}$ & \\
\hline epiphyte and epifaunal substratum & $\mathbf{X}$ & \\
\hline nutrient and containment filtration & $\mathbf{X}$ & \\
\hline nutrient regeneration/recycling & $\mathbf{X}$ & \\
\hline organic matter accumulation & $\mathbf{X}$ & \\
\hline organic production and export & $\mathbf{X}$ & \\
\hline oxygen production & $\mathbf{X}$ & \\
\hline primary production & $\mathbf{X}$ & \\
\hline Sediment filtration and trapping & $\mathbf{X}$ & \\
\hline seed production/vegetative expansion & $\mathbf{X}$ & \\
\hline self sustaining ecosystem & $\mathbf{x}$ & \\
\hline wave and current energy dampening & $\mathbf{x}$ & \\
\hline \multicolumn{3}{|l|}{ Salt marsh } \\
\hline canopy structure & $\mathbf{X}$ & \\
\hline maintain natural botanical conditions & & $\mathbf{X}$ \\
\hline epibenthic and benthic production & $\mathbf{x}$ & \\
\hline $\begin{array}{l}\text { export aboveground plant \& animal } \\
\text { production }\end{array}$ & & $\mathbf{X}$ \\
\hline $\begin{array}{l}\text { maintain element cycling rates and } \\
\text { pollutant processing; stabilize sediment }\end{array}$ & & $\mathbf{X}$ \\
\hline nutrient and containment filtration & $\mathbf{X}$ & \\
\hline nutrient regeneration/recycling & $\mathbf{X}$ & \\
\hline organic export & $\mathbf{X}$ & \\
\hline organic matter accumulation & $\mathbf{X}$ & \\
\hline primary production & $\mathbf{X}$ & \\
\hline produce aboveground organic matter & & $\mathbf{x}$ \\
\hline sediment filtration and trapping & $\mathbf{X}$ & \\
\hline seed production/vegetative expansion & $\mathbf{X}$ & \\
\hline self sustaining ecosystem & $\mathbf{X}$ & \\
\hline wave and current energy dampening & $\mathbf{X}$ & \\
\hline maintain habitat for anadromous fish & & $\mathbf{X}$ \\
\hline maintain habitat for ducks and geese & & $\mathbf{x}$ \\
\hline maintain habitat for native invertebrates & & $\mathbf{X}$ \\
\hline $\begin{array}{l}\text { maintain habitat for native landbirds, small } \\
\text { mammals, \& their predators }\end{array}$ & & $\mathbf{X}$ \\
\hline $\begin{array}{l}\text { maintain habitat for nekton-feeding } \\
\text { wildlife }\end{array}$ & & $\mathbf{x}$ \\
\hline $\begin{array}{l}\text { maintain habitat for other visiting and } \\
\text { resident fish }\end{array}$ & & $\mathbf{x}$ \\
\hline maintain habitat for shorebirds & & $\mathbf{X}$ \\
\hline maintain habitat for visiting marine fish & & $\mathbf{x}$ \\
\hline \multicolumn{3}{|l|}{ Mudflat } \\
\hline epibenthic and benthic production & $\mathbf{X}$ & \\
\hline nutrient regeneration/recycling & $\mathbf{X}$ & \\
\hline primary production via benthic algae & $\mathbf{X}$ & \\
\hline sediment filtration and trapping & $\mathbf{X}$ & \\
\hline
\end{tabular}

Table 9: Ecological functions identified for selected estuarine subhabitats (Short et al. 2000; Adamus 2005). 


\subsubsection{Unvegetated flats}

Mudflats exist in areas sheltered from wave action (Little 2000). Unlike on sandy beaches, mudflats exist where wave action is low but tidal currents are high. Coarser sediments are found in tidal channels that dissect finer sediment mudflats. Muddy sediments provide habitat for a diversity of organisms living on the surface and within the sediments. Some surface microorganisms (epipelon) include diatoms, cyanobacteria, and flagellates; animals living on the surface (epifauna) include crabs and snails; and animals living in the sediment (infauna) include bivalves, mollusks, crustaceans, and polychaete worms. Mudflats, like other estuarine habitats, are dynamic and change over time. Depending upon sediment erosional and depositional patterns driven by water movement, unvegetated mudflats support eelgrass meadows in shallow subtidal systems and salt marshes at higher elevations. Mudflat elevation relative to the tides dictates what vegetation will be supported, if any at all.

Mudflat habitats constitute over a quarter of estuarine habitat in Oregon (Cortright et al. 1987). Research about Oregon's estuarine mudflats has focused on oyster and clam aquaculture (e.g., Nordstrom et al. 2004) and the ecology of mud and ghost shrimp (e.g., Horning et al. 1989). At least one Pacific Northwest study attempts to assess the environmental impact of aquaculture on benthic invertebrates of mudflats in Willapa Bay (Simenstad \& Fresh 1995). Burrowing shrimp are widely distributed and abundant throughout tidal flats of Pacific estuaries and have been found to play an important role in nutrient cycling in estuaries. For example, based upon a study of mudflats in the Yaquina and Salmon estuaries, mudflats dominated by Thalassinid burrowing shrimp (Neotrypaea californiensis and Upogebia pugettensis) contribute a significant portion of summer-time dissolved inorganic nitrogen to the water column, second to the ocean's contribution (DeWitt et al. 2004). Burrowing shrimp, U. pugettensis, plays a significant role in phytoplankton filtration in coordination with the bivalve Cryptomya californica combined with gravitational particle settling, as demonstrated by a study of the Yaquina estuary (Griffen et al. 2004). This study also concluded that $U$. pugettensis may compete for phytoplankton with the commercially-cultivated Pacific oyster, Crassostrea gigas. MacIntyre et al. (1996) reviewed the literature to shed some light on the "secret garden" of "unvegetated' sediments like mud and sand flats. While only one study originated from an Oregon estuary, this publication reveals how microalgae growing on the sediment surface may be contributing a significant portion of estuarine gross primary productivity. 


\subsubsection{Tidal marshes}

Current understanding of tidal marsh ecology is summarized in Weinstein \& Kreeger's “Concepts and Controversies in Tidal Marsh Ecology” (2000). This text largely focuses on the Gulf and Atlantic Coasts, which have much larger expanses of tidal marshes than the Pacific Coast. In this text, research related to the Pacific Northwest is relative to the role of tidal marsh ecosystems in supporting fish, specifically declining salmonid populations (Simenstad et al. 2000). Briefly, this article describes how the marsh and its associated tidal channels support juvenile salmon by providing foraging opportunities, protection from predators, and resting areas. Traditionally, tidal marshes have been considered the vegetated part of the tidal flat; however, from an ecosystem perspective, tidal salt marshes are now thought to include mudflats and tidal channels as well as adjacent tidal brackish and freshwater wetlands (Wolanski et al. 2004).

In exploring the role of tidal marshes in nekton production, Kneib (2000) recommends defining the marsh "ecoscape” to include not only the intertidal vegetated surfaces at the land/water margin but also shallow ponded areas on the marsh surface and intertidal channels that allow nekton to access the marsh. As subtidal channels are not intertidal and do not support plant assemblages, they are not technically part of the marsh ecoscape, but many researchers (e.g., Deegen et al. 2000; Weinstein et al. 2005) stress the importance of subtidal creeks. Subtidal channels maintain connection with the estuary during low tide and should be viewed as corridors between elements (habitats) within the estuarine ecoscape. In fact, nekton do not directly use the vegetated intertidal habitats but benefit from their production through the trophic relay (Kneib 1997). Due to the export of dissolved nutrients or particulate matter from marshes into open water, tidal marshes provide trophic support to nekton. The few resident nekton in tidal marshes may transfer energy to the estuary through excretement or through predator prey interactions. Based upon current understandings, food webs are more complex than once thought and detrital outwelling tends to only happen during storm events. Rather than detrital outwelling into the ocean, tidal marsh 'outwelling' occurs predominately in the form of nekton (Childers et al. 2000).

The role of tidal marshes in trapping sediment and nutrient cycling was also explored. Sediment trapping rates were observed on a restored tidal marsh in the Salmon River estuary, Oregon (Frenkel \& Morlan 1991). From 1978 to1988, the marsh surface was found to be 3 to 7 centimeters higher in elevation due to a combination of sediment accretion and soil swelling. 
Along the Atlantic, Teal and Howes (2000) concluded that salt marshes trap phosphorus, reduce ammonia in surface waters, and detain and retain nitrate in discharging groundwater. Salt marshes function within the context of the landscape by exporting organic nutrients to the ocean and intercepting land-derived inorganic nutrients (Valiela et al. 2000). The function of filtering land-derived nutrients has significant implications for impacts to other estuarine habitat and to the ecosystem as a whole. For instance, in a Waquoit Bay study (Massachusetts), while phytoplankton and macroalgae biomass increased with increased land derived nitrogen loads, seagrass biomass decreased.

Despite knowledge gaps that exist in understanding the mechanisms underlying tidal marsh ecology, these habitats provide many functions valued by society including support of declining salmonids, maintaining estuarine water quality, and supporting complex food webs. As a result of their importance to primary and secondary production combined with their significant losses, these habitats should be prioritized for restoration in the Pacific Northwest.

\subsubsection{Eelgrass beds}

As one of the most productive ecosystems in the world (Duarte 2002), eelgrass is quick growing (Kentula \& McIntire 1986) with high below ground biomass and provides habitat for numerous plants and animals including black brant geese, macroalgal (Kentula \& DeWitt 2003) and invertebrate epiphytes, clams, and Pacific herring (Penttila 2001). Eelgrass beds provide refuge from predators for Dungeness crab and harpacticoid copedpods, an important juvenile salmon prey resource, are found in abundance in eelgrass meadows, an important juvenile salmon prey resource (Thom 1987). Also, eelgrass beds can alter currents and trap organic matter (Fonseca et al. 1998). Studies have shown a positive correlation between salinity and light availability to Zostera marina abundance (Duarte 2002; Kentula \& DeWitt 2003; Thom et al. 2003). In at least the Tillamook Bay, marine sediment deposition appears to be a significant controlling factor of eelgrass shoot density and distribution (Shreffler \& Griffith 2000). Biomass tends to be higher with prolonged tidal inundation (Kentula \& McIntire 1986). Likewise, desiccation from aerial exposure, rather than temperature or irradiance, was the limiting factor for growth of $Z$. marina in the upper intertidal zone of the Yaquina Bay (Boese et al. 2005). Due to high below ground biomass, low decomposition rates, and low direct herbivory, seagrasses are responsible for $15 \%$ of carbon storage in the ocean (Duarte 2002). About 24\% of eelgrass net production is exported from the beds (Duarte 2002), providing a significant contribution to the estuarine and marine detrital food chain (Kentula \& McIntire 1986). 
Oregon's estuaries support two species of eelgrass, Zostera marina (native) and Zostera japonica (introduced). Z. marina is generally found -6.6 m to $1.8 \mathrm{~m}$ MLLW, while Z. japonica occurs between 1-2.4 MLLW (Weinmann et al. 1984). The percent of coverage of submerged aquatic vegetation (both seagrasses and macroalgae) only constitute $7.1 \%$ of all 132,897 acres of estuarine habitat in Oregon, on average, ranging from 0 acres in the Columbia River Estuary to $17 \%$ (2,256 acres) of Coos Bay. Although given the highest relative value rating in the ERR rules, little was known regarding the seasonal coverage, productivity, biomass, and associated animal species of Oregon's seagrass beds, in particular Z. japonica (known as Z. nana then). A small body of literature on Oregon's eelgrass beds exists. Some eelgrass research has been undertaken on those estuaries with the largest percentages of eelgrass beds, namely Coos Bay, Yaquina Bay, Tillamook Bay, and Netarts Bay. This research has mostly focused on the human and natural influences on the distribution (Cortright et al. 1987), abundance, and primary productivity of eelgrass (Thom et al. 2003; Kentula \& McIntire 1986; Kentula \& DeWitt 2003), with one study estimating the natural and human influence on habitat change (Borde et al. 2003). Technological advances have been made to more accurately map eelgrass beds (Strittholt \& Frost 1996), however, due to the dynamic nature of these habitats, multiple surveys are necessary to accurately depict eelgrass distribution and abundance (Fonseca et al. 1998).

Duarte (2002) provides a global perspective on the future of seagrass meadows. Due to the high light requirements of eelgrass species, water quality problems such as increased turbidity and eutrophication of coastal waters has negatively impacted eelgrass beds worldwide (Fonseca et al. 1998). Only a couple of studies have looked at the impact of water quality on eelgrass beds in Oregon. A Yaquina Bay study looked at potential impacts of eutrophication on macroalgal growth outshading eelgrass beds (Kentula \& DeWitt 2003) and a Tillamook Bay study (Shreffler \& Griffin 2000) found that light availability was adequate for supporting healthy eelgrass communities. Water quality standards were developed for eelgrass beds in the Chesapeake that may be appropriate for other temperate estuaries such as those found in Oregon (Table 10) (Fonseca et al. 1998). Most west coast estuaries (Nelson et al. 2005) have total suspended solids concentrations less than $19.1 \mathrm{mg} / \mathrm{L}$ and chlorophyll a concentrations less than $7.9 \mathrm{ug} / \mathrm{L}$. 


\begin{tabular}{|l|l|l|l|l|l|}
\hline $\begin{array}{l}\text { Salinity regime } \\
\text { (ppt) }\end{array}$ & $\begin{array}{l}\text { Light attenuation } \\
\text { coefficient }(\mathrm{Kd} / \mathrm{m})\end{array}$ & $\begin{array}{l}\text { Total Suspended } \\
\text { Solids } \\
(\mathrm{mg} / \mathrm{L})\end{array}$ & $\begin{array}{l}\text { Chlorophyll a } \\
(\mathrm{ug} / \mathrm{L})\end{array}$ & $\begin{array}{l}\text { Dissolved } \\
\text { Inorganic } \\
\text { Nitrogen (uM) }\end{array}$ & $\begin{array}{l}\text { Dissolved } \\
\text { Inorganic } \\
\text { Phosphorus (uM) }\end{array}$ \\
\hline $0-0.05$ & 2.0 & 15 & 15 & & 0.67 \\
\hline $0.5-5$ & 15 & 15 & & 0.67 \\
\hline $5-18$ & 2.0 & 15 & 15 & 10 & 0.33 \\
\hline$>18$ & 1.5 & 15 & 10 & 0.67 \\
\hline
\end{tabular}

Table 10: Submersed aquatic vegetation habitat requirements developed for Chesapeake Bay (Fonseca et al. 1998).

In addition to reduced water clarity and macroalgal blooms from watershed inputs, other potential threats to eelgrass beds exist from shell fishing (Thom et al. 2003; Shreffler \& Griffin 2000), channel dredging, dock and bridge shading, scarring from boat propellers, and ship wakes (Fonseca et al. 1998; Thom et al. 2003). Efforts to maintain water clarity in estuaries by reconnecting tidal marshes to their estuaries will improve overall estuarine water quality (Mitsch \& Wang 2000; Wolanski et al. 2004) and consequently protect eelgrass meadows.

\subsection{New Tidal Datum}

Based upon 1976 NOAA tidal data from benchmarks along the Oregon Coast, tidal elevations for MLLW, MLW, MHW and MHHW were adopted in the ERR rules in OAR (14185-266). Also, the elevation of MLLW was reported relative to National Geodetic Vertical Datum (NGVD) 1947 (and in some cases 1929). Highest water is also provided for various benchmarks along the coast with the qualification that this value is estimated and does not include the effects of storm surge, but may be used to estimate the location of highest measured tide. Since the adoption of the tidal elevations (OAR 141-85-266), a more accurate national geodetic datum (NAVD 1988) and an updated tidal epoch, National Tidal Datum Epoch (NTDE), which reflects changes in local mean sea level along the coast based upon 1983 to 2001 tidal data, have been established. The tidal elevations in the rules and all new epoch tidal information is shown in Table 11 (NOAA 2006). 
The new epoch values do not vary significantly from the old epoch. Most differences were less than 0.5 feet with the greatest difference of -1.89 ' extreme low tide for Drift Creek - Alsea Bay. However, it is recommended that DSL adopt the most updated and accurate tidal elevations. Not all stations in the 1984 rules met the standards of the new epoch and thus were not updated.

\subsection{Estuary and Estuarine Wetland Changes}

Although Pacific Northwest estuaries, relative to other estuaries in the United States, have experienced the least degradation (Emmett et al. 2000), anthropogenic impacts have occurred. Impacts started with the onset of European-American settlers converting higher elevation estuarine land to agriculture in the mid 1850s through diking, draining, and channelizing tidal channels (Good 2000). As communities grew, ports began to develop along the larger estuaries resulting in channel dredging, jetty construction, and intertidal filling for docks and other shipping infrastructure. Impacts to estuaries came to a near halt during the 1970's due to the development of protective federal and state policies and regulations. A few studies have estimated changes to Oregon's estuaries during this time period and have focused on estuarine fringe habitat (i.e., tidal swamps, high marsh, and low marsh). In general, a quarter of total estuarine habitat has been lost of which virtually all of this was tidal wetland (Good 2000). Losses of area vary by estuary, ranging from the greatest loss of $81 \%$ in the Coquille estuary to only $1 \%$ loss in Sand Lake estuary (Table 12). These losses were mainly due to diking, draining, and filling associated with agriculture and, later for port-related development. Tidal wetland loss was greatest in the Coquille (-94\%), Nestucca (-91\%), Tillamook (79\%), and Yaquina (-71\%). 


\begin{tabular}{|c|c|c|c|c|c|c|c|}
\hline \multirow[t]{2}{*}{ Estuary } & \multicolumn{2}{|c|}{$\begin{array}{c}\text { Actual } \\
1970 \text { Area (acres) }\end{array}$} & \multirow{2}{*}{$\begin{array}{l}\text { Diked or } \\
\text { Filled } \\
\text { Tidal } \\
\text { Wetland }\end{array}$} & \multicolumn{2}{|c|}{$\begin{array}{c}\text { Estimated } \\
1870 \text { Area (acres) }\end{array}$} & \multicolumn{2}{|c|}{$\begin{array}{c}\text { Percent Change } \\
(1870-1970)\end{array}$} \\
\hline & $\begin{array}{c}\text { Tidal } \\
\text { Wetland }\end{array}$ & $\begin{array}{c}\text { Total } \\
\text { Estuary }\end{array}$ & & $\begin{array}{c}\text { Tidal } \\
\text { Wetland }\end{array}$ & $\begin{array}{c}\text { Total } \\
\text { Estuary }\end{array}$ & $\begin{array}{c}\text { Tidal } \\
\text { Wetland }\end{array}$ & $\begin{array}{c}\text { Total } \\
\text { Estuary }\end{array}$ \\
\hline Columbia & 16,150 & 119,220 & 30,050 & 46,200 & 149,270 & $-65 \%$ & $-20 \%$ \\
\hline Necanicum & 132 & 451 & 15 & 147 & 466 & $-10 \%$ & $-3 \%$ \\
\hline Nehalem & 524 & 2,749 & 1,571 & 2,095 & 4,320 & $-75 \%$ & $-36 \%$ \\
\hline Tillamook & 884 & 9,216 & 3,274 & 4,158 & 12,490 & $-79 \%$ & $-26 \%$ \\
\hline Netarts & 228 & 2,743 & 16 & 244 & 2,759 & $-7 \%$ & $-1 \%$ \\
\hline Sand Lake & 462 & 897 & 9 & 471 & 906 & $-2 \%$ & $-1 \%$ \\
\hline Nestucca & 205 & 1,176 & 2,160 & 2,365 & 3,336 & $-91 \%$ & $-65 \%$ \\
\hline Salmon & 238 & 438 & 313 & 551 & 751 & $-57 \%$ & $-42 \%$ \\
\hline Siletz & 274 & 1,461 & 401 & 675 & 1,862 & $-59 \%$ & $-22 \%$ \\
\hline Yaquina & 621 & 4,349 & 1,493 & 2,114 & 5,842 & $-71 \%$ & $-26 \%$ \\
\hline Alsea & 460 & 2,516 & 665 & 1,125 & 3,181 & $-59 \%$ & $-21 \%$ \\
\hline Siuslaw & 746 & 3,060 & 1,256 & 2,002 & 4,316 & $-63 \%$ & $-29 \%$ \\
\hline Umpqua & 1,201 & 6,544 & 1,218 & 2,419 & 7,762 & $-50 \%$ & $-16 \%$ \\
\hline Coos Bay & 1,727 & 13,348 & 3,360 & 5,087 & 16,708 & $-66 \%$ & $-20 \%$ \\
\hline Coquille & 276 & 1,082 & 4,600 & 4,876 & 5,682 & $-94 \%$ & $-81 \%$ \\
\hline Rogue & 44 & 880 & 30 & 74 & 910 & $-41 \%$ & $-3 \%$ \\
\hline Chetco & 4 & 171 & 5 & 9 & 176 & $-56 \%$ & $-3 \%$ \\
\hline TOTAL & 24,176 & 0,301 & 50,436 & 74,612 & 220,737 & $-68 \%$ & $-24 \%$ \\
\hline
\end{tabular}

Table 12: Changes in estuarine wetlands from 1870 to 1970 (Good 2000).

Thomas (1983) reports that 24\% of estuarine habitat in the Columbia River was impacted between 1870 and 1970 . Of that 24\% loss, there was a $77 \%$ loss of tidal swamps and $43 \%$ loss of tidal marshes. While open water decreased by $16 \%$ in the Columbia River, flats and shallows increased by $10 \%$ over this same time period.

Sherwood et al. (1990) report a 15\% decrease in tidal prism and a net sediment accumulation of 68,000,000 $\mathrm{m}^{3}$ in the Columbia River Estuary during from 1867 to 1958 due mainly to channel dredging for navigation. Since the late 1800 s, a $60 \%$ reduction of Columbia River sediment output to the ocean has been estimated due to climate change, water withdrawals, flow regulation, and dredging (Jay \& Naik 2002). Due to estuarine wetland habitat losses, estimates of primary productivity losses include $82 \%$ reduction from emergent plants, and 15\% reduction from benthic macroalgae (Sherwood et al. 
1990). Concurrent with reduced autochthonous (estuarine) production, inputs of riverine detritus from freshwater phytoplankton have increased, resulting in a food web shift. Simenstad and Burke (in progress) have developed a new classification for the lower Columbia River estuary that will provide new estimates for historical wetland habitat losses by hydrogeomorphic river reach. Preliminary results show losses that are greater than Thomas' (1983) estimates.

Changes to Coos Bay estuarine habitat were estimated by Borde et al. (2003). While $16.2 \%$ of total estuarine area was lost from 1863 to $1995,28.2 \%$ of tidal wetlands, 26.2\% eelgrass habitat, and 18.5\% tidal flat were lost during this time period (Table 13). These losses were mainly due to filling and armoring of the channel for navigation and port development purposes.

\begin{tabular}{|l|c|c|c|c|}
\hline Habitat (ha) & $\mathbf{1 8 6 3}$ & $\mathbf{1 9 1 6}$ & $\mathbf{1 9 9 5}$ & \multicolumn{1}{c|}{$\begin{array}{c}\mathbf{1 8 6 3} \text { to } \\
\mathbf{1 9 9 5} \\
\text { change }\end{array}$} \\
\hline $\begin{array}{l}\text { Below extreme } \\
\text { low water }\end{array}$ & 1325 & 1444 & 1282 & -3.24 \\
\hline $\begin{array}{l}\text { Potential } \\
\text { eelgrass habitat }\end{array}$ & 684 & 452 & 505 & -26.2 \\
\hline Tidal Flat & 1939 & 2071 & 1580 & -18.5 \\
\hline Tidal Wetland & 476 & 470 & 342 & -28.2 \\
\hline Total & 4424 & 4436 & 3709 & -16.2 \\
\hline
\end{tabular}

Table 13: Wetlands and tidal elevation surface area for Coos Bay (source: Borde et al. 2003).

\subsection{Status of the Science of Tidal Wetland Restoration}

\subsubsection{Introduction}

The Coastal Management Program has actively managed and protected Oregon's estuaries since the 1970s and, due to comprehensive estuary plans, $98 \%$ of the remaining tidal wetlands are protected from future physical alteration (Good et al. 1999). Between 1971-1987, 704 acres were impacted by removal/fill permits (Good 1996; Fishman 1987). As illustrated by the fall 2005 permit inventory, since 1989, 11 acres of predominantly intertidal habitat were permitted for impacts and due to the estuarine resource replacement rules, there was a net loss of only 3 acres. However, a significant portion of tidal wetlands was altered prior to protection (Table 12). 
Through regulatory and nonregulatory programs, efforts are being made to reverse the trend. Scranton's study (2004) continues the estuarine habitat change estimates where the State of the Environment Report (Good 2000) stopped, but does not estimate wetland changes in the Columbia River estuary (Table 14). From 1970 to 2002, it is estimated that estuarine wetlands along Oregon's Coast have increased in area by more than 3,300 acres due to active restoration efforts or to passive dike failure. Those estuaries that experienced the most significant increases in tidal wetland area from 1970 to 2002 were the Siuslaw, the Salmon River, Siletz Bay, Yaquina Bay, Alsea Bay, and the Umpqua River (Table 14). Restoration (in the general sense) efforts in the Columbia River estuary as reported by the Lower Columbia River Estuary Partnership have resulted in the restoration of over 3,000 acres of restored wetland and riparian habitat in that system (LCREP 2005).

Despite the gain of wetland acres during the last 30 years, Scranton (2004) reports that less than $20 \%$ of Oregon's historical tidal wetlands remain. Discrepancies exist between these two datasets in terms of losses. Scranton estimates 59\% more altered wetlands (49,960.75 acres) than Good's estimate of 20,386 acres of diked and filled lands since 1870's. Scranton attributes differences in the area of altered wetlands due to access to higher resolution datasets and improved technologies (i.e., GIS software, Geodatabase feature allowing for more accurate representation of boundary habitat), and different interpretations of estuarine edge. Scranton (2004) wove together a number of primary and secondary datasets to develop the Oregon coastal tidal wetlands geodatabase. These datasets included historical (1939/1941) and contemporary (2001/2002/1986) aerial photography, National Ocean Service's Coast Surveys, a 1957 reconstruction of Tillamook Bay, NWI datasets of 1979 and 2004, LWIs, NRCS hydric soils datasets, the 1972 Division of State Lands Filled Lands Inventory, and the Oregon Estuary Plan Book. Good (2000) relied mostly upon secondary datasets including the 1972 Division of State Lands Filled Lands Inventory. Regardless of the data source, there has been a substantial amount of tidal marsh loss in Oregon, particularly intertidal forested/scrub shrub and higher elevation, intertidal emergent wetlands.

\begin{tabular}{|c|c|}
\hline Estuary & Difference \\
& 2002 \& 1970 \\
& Existing \\
& wetlands \\
\hline
\end{tabular}




\begin{tabular}{|l|c|}
\hline & (acres) \\
\hline Necanicum & 38.37 \\
\hline Nehalem Bay & 183.48 \\
\hline Tillamook Bay & 281.54 \\
\hline Netarts Bay & 159.04 \\
\hline Sand Lake & 40.84 \\
\hline Nestucca Bay & 16.02 \\
\hline Salmon River & 356.66 \\
\hline Siletz Bay & 353.47 \\
\hline Yaquina Bay & 322.02 \\
\hline Alsea Bay & 236.18 \\
\hline Siuslaw River & 621.04 \\
\hline Umpqua River & 344.73 \\
\hline Coos Bay & 231.82 \\
\hline Coquille River & 148.4 \\
\hline Rogue River & -1.42 \\
\hline Chetco River & 2.34 \\
\hline Table 14: Changes
\end{tabular}

Table 14: Changes in acres of existing tidal wetlands in Oregon's estuaries between 1970 \& 2002 (Scranton 2004).

Tidal wetland restoration, as with restoration ecology in general, is an emerging scientific disclipine (NRC 1992). While some successes have been documented, areas for improvement still exist (RAE-ERF 1999; Thayer \& Kentula 2005). "Restore America’s Estuaries” and the Estuarine Research Federation (RAE-ERF 1999) summarize the state of estuarine restoration by reporting that researchers have learned to effectively restore vegetation and flow patterns at small intensively managed restoration sites over the last thirty years. The highest level of restoration success has been with estuarine marshes, although few restoration sites were being monitored (Kusler \& Kentula 1990). Relatively high rates of success, compared to other wetland types, are a result of predictability of hydrology and more available monitoring data documenting their success. Bogs, fens, and forested wetlands are seldom replaced due to difficulty and/or length of time required for maturity.

Overall, the need for basic scientific research to better understand ecological functions of wetland habitats still exists, but some progress has been made on developing predictive models to aid in restoration designs. Selection of restoration and reference sites and understanding tidal flow dynamics for individual projects could benefit from improved models (RAE-ERF 1999). Advances have been made in project planning, articulating goals more clearly and in monitoring; however, there is still room to allow adaptive management into restoration monitoring (Callaway 2005). Thom et al. (2005) recommend admitting uncertainty in projected outcomes of mitigation plans and 
overcompensating due to these uncertainties. Incorporating landscape ecology principles into restoration design is necessary to achieve success (Weinstein et al. 2005). Identifying ways to measure if a restoration site is on the desired trajectory is still considered a challenge (Thayer \& Kentula 2005).

\subsubsection{Successes}

Some specific restoration successes have been documented for estuarine habitats. Short et al. (2000) document successes for salt marsh, eelgrass, and mudflat habitat at a mitigation site in a New Hampshire estuary. A created and natural oligohaline marsh/creek system in North Carolina showed similar species composition, total fauna density, and species richness after three years (West et al. 2000). Fonseca et al. (1998) provide specific guidance on how to successfully compensate impacts to eelgrass beds through transplantation. Because of their role in supporting juvenile salmonids and significant historical loss of tidal marsh habitat, tidal marsh restoration has occurred in a number of estuaries in the Pacific Northwest with promising functional and structural responses including reestablishment of tidal marsh plant communities and tidal channels (Frenkel \& Morlan 1991; Cornu \& Sadro 2002; Thom et al. 2002). Research has demonstrated salmonid use of restored marshes (Miller \& Sadro 2003; Bottom et al. 2005; Gray et al. 2002; Milller \& Simenstad 1997). For example, juvenile salmon (chum and fall Chinook) were found to temporarily reside (1-43 days) in a restored brackish tidal marsh with both subtidal and intertidal channels and on vegetated and unvegetated flats in the Puyallup River Estuary, Washington during spring seaward migration (Shreffler et al. 1992). A study assessing fish usage of five restored salt marshes in Texas (Rozas et al. 2005) demonstrated high populations of nekton species compared to pre-restored conditions, although less nekton diversity was observed compared to a reference marsh system. Bottom et al. (2005) conclude that access to restored tidal wetlands in the Salmon River Estuary, Oregon, has increased opportunities for rearing, as well as increased the diversity of life-history patterns of juvenile Chinook salmon. Borde et al. (2004) provide a national review of innovative and successful coastal habitat restoration. Projects include the restoration of salt marshes, seagrass, kelp beds, mangrove forests, coral reefs, and oyster reefs. 


\subsubsection{Defining success}

Whether restoration has been successful really depends upon the context in which the question is asked. At least two different types of success can be measured: regulatory success (compliance), and ecological success (functional equivalency) (Hackey 2000). Another type of success relates to 'public' success, in which the local community becomes involved in implementing and managing the restoration (i.e., pulling invasive species, planting native plants) and in valuing the ecological, recreational, and aesthetic value of the restored ecosystem. For example, as demonstrated by the Duwamish estuary in the Seattle area, some success is being made in highly urbanized ecosystems, especially if restoration goals incorporate societal values (i.e., reduction of human health risks, provision of recreational opportunities), as well as biological goals (Simenstad et al. 2005).

Three common measures for assessing regulatory success of mitigation wetlands are: does the site meet wetland criteria, is it the required size, and does it replace lost functions? Regulatory success in terms of permit compliance has not been achieved based upon the recent General Accounting Office (2005) evaluation of the Clean Water Act Section 404 wetlands regulatory program. The goal of this evaluation was to assess to what extent the USACE oversees compensatory mitigation. Based upon a review of USACE mitigation guidance and 249 permits requiring compensatory mitigation from seven geographicallyrepresentative USACE districts, the report concluded that regulatory guidance was vague and inconsistent with regard to monitoring expectations, the recourse the district should take when reports were not submitted, and how much time should be allocated for compliance inspections. For those permits requiring monitoring reports (89), only 24\% indicated that a monitoring report had been received and only $15 \%$ of the permits had received compliance inspections. The report concluded that due to the lack of oversight found on the permits reviewed, the USACE is unable to assess whether compensatory mitigation has been performed, if the mitigation program is effective, and whether this program is contributing to the national goal of no net loss of wetlands.

Ambrose (2000) assesses the success of mitigation policy in the US in general and 
concludes that the rate of wetland loss has been reduced but 'no net loss' has not been achieved. DSL’s Annual Report on Agency Performance Measures (DSL 2004) states that restoration and creation projects for CWM for impacts achieve or exceed no net loss in terms of acreage, but it is unclear what functions are being gained from these mitigation projects and if the gains offset functions lost at the mitigation sites. The few available qualitative assessments examining the functional replacement of mitigation wetlands reveal that most projects result in moderate to low quality wetlands.

Monitoring periods for regulatory mitigation projects are generally three to five years, while nonregulatory (voluntary) projects may or may not be monitored due to funding constraints. The difficulty of assessing functional equivalency of mitigation wetlands within short time periods can be demonstrated by looking at 16 different attributes of function over a seven-year time frame (Simenstad \& Thom 1996). Attributes of topography, sediments, vegetation, water chemistry, water temperature, plant growth, survival \& distribution, benthic/planktonic invertebrates, and fish \& bird occurrence and density were monitored in a created estuarine wetland in the Puget Sound area. Of these attributes, epibenthic taxa richness, fish richness/density, and bird usage indicated functional trajectories after three to five years. Functional trajectories are performance curves extrapolated from short-term datasets (usually three to five years) used to assess whether a long-term ecological function will be replaced at a mitigation site. However, all the other attributes indicated that the wetland was either still in the early stages of development or diverging relative to reference brackish wetlands. Achievement of mitigation goals after the typical three to five year monitoring period is largely dependent upon which parameters are being measured and how specific and achievable the goals are. Instead of the three to five years required in most regulatory wetlands programs, a 10-year (Frenkel \& Morlan 1991), a 15-year (Mitsch \& Wilson 1996) or 20-year (NRC 2001) monitoring time frame has been recommended. This is deemed not feasible for regulatory projects.

\subsubsection{Causes of Restoration Failure}

Restoration failure can be attributed to a number of factors including lack of scientific understanding of local ecosystem processes, improper construction or implementation, insufficient monitoring time, and lack of remediation efforts during the 
monitoring period (West et al. 2000). Lewis (2000) argues that failure has less to do with lack of science and more to do with the communication and implementation of the science into the regulatory setting due to inadequate training of regulatory staff in the state-of-the-art restoration methods. In Oregon, consultants design restoration projects that are then approved by regulatory staff. Furthermore, Lewis (2000) thinks that a successful program should not stop at the development of policy and a permitting program, but focus on training and retraining of staff, program monitoring, compliance monitoring, enforcement, and adaptive management.

Most restoration studies document changes in vegetation, such as species diversity, to measure success and largely ignore ecosystem processes such as primary productivity and nutrient accumulation (Zedler \& Callaway 1999). Low plant diversity does not necessarily indicate inferior hydrogeological and geochemical functions and vice versa (NRC 2001). For example, after ten years, due to poor nutrient accumulation in the soil, a constructed marsh in California has not met the goal of providing habitat for the endangered light-footed clapper rail. Long-term (40 years) extrapolations predict the marsh's soil will not be equivalent to a natural wetland and thus will not produce canopy requirements for nesting rails, the goal of the mitigation plan (Zedler \& Callaway 1999).

Reference wetlands should be used in restoration plans to provide a standard to work towards (Brinson \& Rheinhardt 1996). However, using reference wetlands requires long term monitoring to understand how much natural variability should be expected and how reference wetlands change over time (Simenstad \& Thom 1996). Long-term ecological research sites are needed to conduct manipulative experiments on wetlands to better predict endpoints of estuarine wetland development. Reference data are available for 120 tidal wetlands along the Oregon Coast (Adamus 2005), which can be used to provide baseline information for future studies.

Extrapolating site-specific success to restoring larger scale ecosystems areas remains a challenge for estuarine restoration scientists and practitioners (RAE-ERF 1999). Better models at the ecosystem level are needed to shed some light on species life cycles and habitat links. Simenstad and Cordell (2000) recommend developing assessment criteria and metrics based upon a habitat's capacity, function, and realized function to enhance juvenile salmon survival rates due to the transitory nature of salmon. 
Also, Simenstad et al. (2000) recommend incorporating different temporal and spatial scales within the estuary and watershed into salmon recovery efforts relative to tidal marsh restoration. Appropriate siting of restoration projects is crucial to supporting ecosystem functions. Zedler (1996b) offers the following advice for identifying restoration choices using a landscape paradigm: larger systems support biodiversity, wetlands need to be connected to adjacent ecosystems to support biodiversity, restoration sites should be located nearby existing ecosystems to support dispersal and recruitment, small habitat remnants have less resilience so build on existing wetland systems rather than create new small habitat, and use creation as a last resort.

GIS have enhanced the ability to apply landscape ecology principles to wetland mitigation due to the ability to handle large datasets for identifying potential restoration sites that meet regulatory requirements for functional replacement (Roise et al. 2004) and for ensuring wetland types are appropriate for the geomorphic and hydrologic setting (Spivey \& Ainslie 2004). Appropriate landscape placement will avoid the need for overly engineered restoration plans and result in wetland sustainability (NRC 2001).

\subsubsection{Regulatory Compliance}

In a frank critique of compensatory mitigation, Race and Fonseca (1996) recommend refocusing on enforcing permit conditions as a strategy for improving regulatory restoration. Despite numerous reports revealing poor results and net losses, and extensive scientific and policy recommendations for improvement, compensatory mitigation has failed to maintain a base of wetland habitat for permitted impacts. Rather than focus on scientific fixes based upon better understanding of landscape and restoration ecology and improved understanding of assessing and replacing wetland function, they suggest focusing simply on permit compliance and particularly on ensuring wetland acreage is replaced. In the face of budget constraints, Race and Fonseca (1996) recommend random permit auditing to demonstrate the threat of an audit. Furthermore, Cairns (2000) stresses the importance of involving the public to improve the success of restoration endeavors. Educating the public about what ecological services are provided by wetlands will help to garner support for their restoration, but also for wetland conservation. 


\subsubsection{Need to Incorporate Adaptive Management}

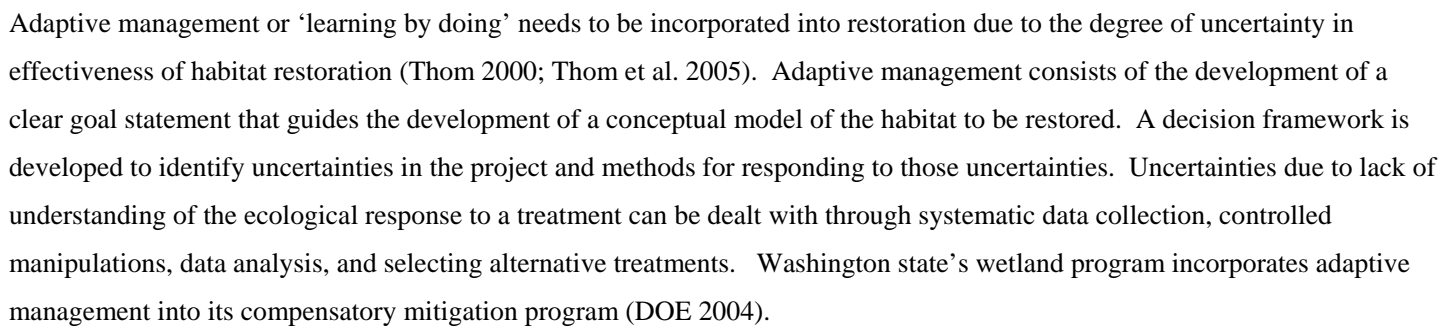

Thom et al. (2005) demonstrate the implementation of an adaptive management program for an eelgrass mitigation project at a ferry terminal. The goal of the project was no net loss of eelgrass due to terminal reconstruction. The performance criterion was: after five years, eelgrass density (number of shoots per $\mathrm{m}^{2}$ ) in the restored plots must be at least $85 \%$ of the reference plots. A secondary goal was to assess new concepts in ameliorating shading effects, but no specific performance criterion was set except to see how well eelgrass would grow under glass bricks (that would reduce $60 \%$ photosynthetically active radiation that would be incorporated into the dock walkway and to better understand the effect of propeller wash and drifting woody debris on eelgrass growth. To incorporate uncertainty into the mitigation plan, the size of the planting area was overcompensated by a 9:1 replacement ratio. Compensation was done 18 months in advance of impact to reduce temporal loss. Paired reference and restoration sites would be monitored for 10 years to document maturation of the eelgrass meadows and also allow for the assessment of El Nino on growth.

The adaptive management framework included predictions of success probabilities, a monitoring program to assess progress towards the goals, an agreement to adjust goals based upon monitoring results, scheduled annual meetings to review data, and dissemination of results through meetings, reports, and peer-reviewed publications. The last component of the framework was considered particularly important for improving future eelgrass mitigation projects.

The results of this study called for adaptation of the management plan. After four years, eelgrass density in both the deep and shallow water plots had stabilized. The density of the plots in the shallow water was correlated to the density after the first year. Based upon this experiment, five year monitoring periods may be adequate for achieving stability for this habitat type. The predictive relationship between the first year and the 
fourth year can help inform management decisions early on, such as choosing to eliminate plots that showed poor survival after the first year. Reference sites with water depths similar to the transplant site, rather than proximity, were found to be better reference sites. Total abundance was a better indicator of success than mean shoot density. Natural climate variations such as El Nino and La Nina that may be affecting natural growth rates should be factored into performance by concurrently monitoring reference sites.

\subsubsection{Performance Criteria}

Although adaptive management should allow for changes in mitigation goals or objectives, ambiguous goals, objectives, and success criteria have been cited as a major reason for the inability to fully evaluate mitigation projects for compliance and functional equivalency (NRC 2001; ELI 2004; West et al. 2000; Kusler \& Kentula 1990; Race \& Fonseca 1996; Hackney 1998; Short et al. 2000). The recommendation is to develop clear goals that can be measured using quantifiable success or performance criteria. Performance criteria need to be relevant to the stated goal of the mitigation project. The importance of distinguishing among goals, objectives, and success criteria has been emphasized in order to enforce compliance (e.g., NRC 2001). Goals are broad statements of the project purpose; objectives outline the steps to achieve the goals; and success criteria are measurable attributes that assess if the objective has been met (California Coastal Commission 1995). As outlined by the Washington program, goals should identify the proposed wetland area, hydroperiod, and Cowardin class/HGM subclass (DOE 2004). The objective of the mitigation plan should describe the proposed wetland type and expected function(s) and the specific treatments that will result in the proposed wetland size, hydroperiod, and plant community types. Performance standards should outline measurable indicators for these wetland parameters, such as wetland delineation of a specific acreage, inundation of a specific depth for a specific duration, percent areal cover of target vegetation community, level of diversity within the targeted community type, and maximum allowable percent areal coverage of invasive vegetation species.

In a USACE permit review study of San Francisco District permits from 1988 to 1995, 72\% of the 110 wetland mitigation projects (Breaux \& Serefiddin 1999) measured vegetation as the success criterion and only $22 \%$ of the permits included used hydrologic 
features. Wildlife was assessed qualitatively as evidence of use. Monitoring periods were typically five years. Despite the critique of relying upon vegetation performance criteria, Breaux and Serefiddin (1999) deemed using the predominance of 70-90\% percent vegetation cover criterion for tidal wetland permits scientifically sound due to the rapid growth of vegetation, ease of restoring these habitat types with proper grading and elevation, and assumption that marsh fauna will quickly follow plant colonization. This study recommended using a combination of vegetation and wildlife use success criteria to understand functional gains and losses based upon a size-dependent tiered system. For impacts between two to five acres, vegetation criteria, water quality or soil, water budget, and wildlife inventories (one parameter at a high intensity, two parameters of medium intensity, and three parameters at low intensities (zooplankton, benthic invertebrates, fish, etc.) for up to five years was recommended. Impacts greater than five acres or those projects using dredged material or creation should monitor the same parameters, with one wildlife inventory and the addition of a special functional study (hydrologic, nutrients, sedimentation, vegetation dynamics, etc.) with monitoring periods five to 20 years.

In the DSL permit review summarized in the previous chapter, success criteria were sometimes vaguely written and sounded more like goals than success criteria. For instance, the only success criteria used for a recent mitigation project (33602 RF) involving a tidegate replacement was "the new tide gate will enhance tidal exchange between the slough and Bay, and will re-connect over two miles of intertidal, estuarine habitat”. As written, there is no way to measure whether the success criteria have been met or not. It is unclear what the target function is for enhancement. If the objective is to reduce water temperature for anadromous fish because the water behind the tide gate is much warmer than the water in front of the tidegate, then water temperature would be the parameter to measure for a success criteria. More appropriate success criteria would be to report the minimum and maximum tidal elevation that the new tide gate will allow relative to the marsh elevation compared with the old tide gate. If the tidegate replacement is going to affect intertidal habitat, then the current and target Cowardin class should be noted and vegetation monitoring before and after the project should be done to determine if the plant community responds. Total acreage of enhanced habitat should also be reported, rather than two miles of intertidal estuarine habitat. 
Another recent estuarine resource replacement plan associated with a Removalfill permit (35391-RF) demonstrates the need to clearly define goals and objectives in order to identify appropriate success criteria. An impact of 0.11 acres of intertidal unconsolidated shore mudflat and subtidal river bottom was mitigated with an offsite culvert enlargement project with the intent of allowing increased tidal flushing to a 0.337 acre high marsh and 0.478 acre mud flat system that had been separated from the estuary by a road. A 15” culvert would be doubled to increase tidal flushing. No success criteria were included in the authorization. The only follow up required was to provide photo documentation that the culvert had been replaced. Therefore, compliance success will be achieved if the culvert is enlarged.

\footnotetext{
However, the functional result of the mitigation will not be assessed and thus will not be used to determine if the 0.11 acre impact was indeed "compensated" or to inform future enhancement projects. The mitigation plan generally described the site and vaguely described the problem and anticipated results but did not spell out goals, objectives, or success criteria. The stated purpose in the mitigation plan was to restore tidal hydrology that would increase the amount of brackish water entering the marsh and consequently change the plant community to be more typical of a high salt marsh. Additionally, water quality was expected to improve, organic input increase, and the distribution and abundance of macro-invertebrates and fish increase. Flow velocity would be reduced by the larger culvert and consequently improve fish passage. Maximum flow estimates were provided for the current and future culvert, as well as current tide ebbing rates and elevations for the marsh side and bay side of the culvert. No data were provided on water quality, organic content of soil, or invertebrate or fish use.
}

Three plant species occurring at the upland/wetland transition (Juncus effusus, Rubus laciniatus, and Carex obnupta) were mentioned, but were said to be characteristic of the degraded marsh. Vegetation species found on the uplands were named. However, no wetland delineation was done, nor transect data of vegetation found throughout the marsh provided. The plan mentioned that estuarine wetland plants were lacking at the site; however, in visiting the site (pers. observation 02/14/06), there was no obvious difference between the vegetation on the tidally-restricted side of the culvert versus the unrestricted side. No functional assessment was done at the impact site or at the mitigation site to understand what functions were being lost and what functions were being gained. Mudflat functions include epibenthic and benthic production, primary production, nutrient regeneration and recycling, and sediment filtration and trapping (Short et al. 2000) and mudflats provide feeding opportunities for numerous invertebrates, birds, fishes, and mammals (Simenstad et al. 1991). Twelve similar tidal marsh functions were identified in Oregon's tidal HGM rapid assessment methodology (Adamus 2005). The pre-treatment mitigation site constitutes more mudflat area than high marsh area. Objectives and success criteria could be created for each of the subunits. NOAA's recommended success criteria for coastal restoration projects could be used to develop success criteria (Table 15).

The goals of the mitigation project will influence which success criteria are appropriate. For instance, if the goal of the project is to improve salmonid habitat of the marsh, then one objective could be to improve water quality for salmon on the restricted side of the culvert and the success criteria could be to measure appropriate water quality parameters such as temperature and dissolved oxygen. In order to determine if the water quality is in fact degraded, these parameters should be measured before treatment and then target temperature levels and dissolved oxygen concentrations should be set. 
Another objective could be to improve foraging opportunities for salmonids. The success criteria could be to sample density/diversity of infauna, macrofauna. Likewise, another objective could be to restore high marsh plant communities. The success criteria would then focus on desirable vegetation species presence/absence, composition or percent cover. Another possible goal could be to improve access to salmonid habitat. One objective for improving salmonid habitat is to improve fish passage through culvert replacement. This objective could be quantified by measuring flow and velocity through the culvert and monitoring fish presence before and after the treatment. The results of monitoring could serve to inform future culvert enlargement projects. If ecological benefits are observed due to the treatment, there is at some data that supports the rationale to continue to offer mitigation credit for culvert enlargement. If no changes are observed before and after treatment, then other strategies for improving tidal flushing under roadways should be explored.

Another concern with success criteria is that they should attempt to measure function or at least use the appropriate structure (physical and biological features) as a functional surrogate within appropriate time frames. Short et al. (2000) demonstrate a method for developing success criteria for restored eelgrass beds, salt marsh, and mudflat habitats based upon a literature review, field observations, and statistical analysis. Assuming structural elements were indicative of function, structural indicators were developed for chosen habitat functions based upon literature review. These indicators were then ranked in terms of relative importance for each function. The most important indicators were then monitored at reference sites. Mean, coefficient of variance, and standard deviation were computed for the data collected for each indicator. The highest ranking indicators were also assessed for cost to find the most cost-effective parameters. Appropriate time frames were then calculated for monitoring the most cost effective, high ranking parameters based upon reference data. The results showed that in New Hampshire, after three years, eelgrass plants had become established after three years, salt marsh plant communities had become established after four to six years, and mudflats were developing after six to nine months. This study demonstrates the ability to develop cost-effective success criteria that can be measured to gain insight on functional gains of mitigation projects. 
Oregon's program could benefit from developing defensible success criteria through the methodology utilized by Short et al. (2000). Basing compensatory wetland mitigation success solely upon vegetation criteria has been criticized widely (e.g. NRC 2001; ELI 2004; Weinstein et al. 2005 “...gone forever will be success criteria like 85\% survival of planted vegetation after three years.”). Vegetation success criteria are used because they are relatively easy and cheap to carry out; however, they may not be adequate indicators of ecosystem function and thus will not provide a complete picture on the achievement of functional replacement as required in statute or no net loss of function (ELI 2004; West et al. 2000). Based upon the DSL permit inventory completed for this project, vegetation characteristics were predominantly used for success criteria.

While developing success criteria as described by Short et al. (2002) may be a long-term goal for mitigation projects, a short-term goal could be to monitor additional variables, beyond vegetation, that may be more appropriate for assessing function. Success criteria could be based upon NOAA's guidance manual for setting success criteria in coastal restoration projects (Table 15, Pinitt et al. 1998). NOAA recommends structural and functional characteristics per estuarine habitat type that should be monitored at the minimum for restoration projects and should be used to develop success criteria. This document also provides contact information for scientists with particular coastal expertise and reference publications.

Specific protocols for assessing success criteria during the monitoring phase of mitigation projects could be adapted from the monitoring protocols put forth by a draft report developed for the Lower Columbia River Estuary (Roegner et al. 2006). This document offers a set of monitoring protocols that sufficiently assess ecological change from restoration efforts, yet are financially feasible to undertake. The metrics include water surface elevation, water quality (temperature, salinity, dissolved oxygen), landscape features, vegetation (composition, cover, and survival rates), and fish (presence, size/age structure, and species). This report will be available through the Pacific Northwest National Laboratory in Richland, Washington.

Incorporating recommendations for improving compensatory mitigation will require an increase in commitment from the DSL Removal-fill Program. This commitment will involve requiring applicants to clearly articulate mitigation goals and 
objectives and to choose success criteria that are measurable, relate to the goal, and attempt to assess function. Success criteria beyond vegetation will require an increased financial commitment from the permit holder, but the alternative is the status quo of low quality sites or unclear ecological success, which some would argue is not worth the effort and does not fulfill legal requirements. In order to incorporate adaptive management, there must be a willingness by permittees to openly admit failure that must be met without retribution from the Removal-fill Program.

\begin{tabular}{|l|}
\hline RIPARIAN HABITATS \\
\hline Structural Characteristics \\
\hline Buffer zone \\
\hline Hydrogeomorphic degree of sinuosity and stream order \\
\hline Instream large woody debris (LWD) per unit stream length, positioning of instream LWD \\
\hline Presence of boulders/rocks/cobbles/sand \\
\hline Water temperature \\
\hline Functional Characteristics \\
\hline Benthic invertebrate and finfish utilization \\
\hline Biomass production \\
\hline Identification of biological community structure \\
\hline SALT MARSH HABITATS \\
\hline Structural Characteristics \\
\hline Desirable vegetation species presence/absence, composition, percent cover \\
\hline Fish and shellfish (in creeks and on marsh surface) density/diversity \\
\hline Flooding regime \\
\hline Marsh surface elevation/slope \\
\hline Organic matter content \\
\hline Salinity \\
\hline Sediment grain size \\
\hline Functional Characteristics \\
\hline Benthic invertebrate, finfish, and bird utilization \\
\hline Biomass production \\
\hline Identification of biological community structure \\
\hline ROCKY SHORELINES \\
\hline Structural Characteristics \\
\hline Hydrogeomorphic characteristics as a result of energy dynamics \\
\hline Plant/animal zonation patterns \\
\hline Functional Characteristics \\
\hline Benthic invertebrate and finfish utilization \\
\hline Identification of biological community structure \\
\hline MUD FLATS \\
\hline Structural Characteristics \\
\hline Density/diversity of infauna, macrofauna \\
\hline Development of creek/stream dendrisity \\
\hline Flooding regime \\
\hline
\end{tabular}


Salinity

Sediment grain size

Slope and elevation/relief

Functional Characteristics

Benthic invertebrate and finfish utilization

Identification of biological community structure

Sediment stability

Bird foraging

\section{HARD BOTTOM}

Structural Characteristics

Salinity

Topographic complexity

Functional Characteristics

Benthic invertebrate and finfish utilization

Biomass production

Flora and fauna production rates

Source of attachment for sessile organisms

SOFT BOTTOM

Structural Characteristics

Density/diversity of infauna

Organic matter content

Salinity

Sediment grain size

Functional Characteristics

Benthic invertebrate and finfish utilization

Biomass production

Identification of biological community structure

SEAGRASS

Structural Characteristics

Bottom coverage

Salinity

Functional Characteristics

Benthic invertebrate and finfish utilization

Biomass production

Habitat stabilization and persistence

Identification of biological community structure

WATER COLUMN

Structural Characteristics

Dissolved oxygen concentration/percent saturation

Light penetration (Secchi disk visibility)

Salinity

Temperature

Turbidity

Functional Characteristics

Biomass production

Table 15: Recommended structural and functional attributes for monitoring restoration projects (Pinnitt et al. 1998). 


\subsubsection{Tidal Marsh Restoration Techniques}

Restoration of tidal influence to previously diked or cut-off tidal marshes has been done through regulatory and nonregulatory restoration efforts throughout the United States since the early 1970s. However, few studies have actually monitored the effects of restoring tidal influence (Philip Williams et al. 2004). Those that have been monitored have generally shown positive ecological results, although more long-term datasets of biological monitoring is necessary. The Handbook for Tidal Marsh Restoration (Zedler 2001) provides a comprehensive science-based resource, mostly derived from experience in Southern California, for designing, implementing, and monitoring tidal marsh restoration.

Tidal restoration projects have been undertaken in the Pacific Northwest for a number of purposes, including to provide rearing habitat for juvenile salmon. For instance, in 1978 in the Salmon River Estuary, nonregulatory restoration to historical conditions efforts began with breaching of a dike along a salt marsh to reintroduce tidal influence. Two additional dike breaching projects followed in 1987 and 1996 (Bottom et al. 2005). According to Good (2000), 300 acres of salt marsh have been restored from these dike breaching efforts in the Salmon River estuary. Through the various dike breaching activities over the past twenty years, monitoring of ecological recovery has shown increased peak standing biomass, reestablishment of salt marsh plant communities (Morlan 1991;Frenkel \& Morlan 1991) and increased juvenile Chinook salmon use (Cornwell et al. 2001; Gray et al. 2002; Bottom et al. 2005). Similarly, about 200 acres of salt marsh have been restored in the South Slough of Coos Bay through dike breaching and surface elevation manipulation and the ecological response is being monitored (Cornu \& Sadro 2002).

Although estuarine marsh restoration has been shown to produce relatively high success rates partially due to predictable hydrology and organisms adapted to daily desiccation and inundation (Kusler \& Kentula 1990; West et al. 2000), restoration plans need to consider grade and elevation (Cornu \& Sadro 2002) and subsided marsh surfaces (Morlan 1991). Elevation of the marsh surface will dictate the degree and frequency of tidal inundation and thus dictate the formation of subtidal and intertidal channels, the type of plant community that will colonize the restored marsh, and the type of nekton that will 
utilize the marsh. Subsidence occurs because diked marshes are cut off from sediment deposition from tides and rivers, soil becomes compacted, and organic material is oxidized due to drainage (Cornu \& Sadro 2002). In addition to marsh elevation subsidence, soil and water quality concerns ensue from oxidation. When estuarine soils behind dikes oxidize, sulfides bound to iron are released from the soil as sulfates and sulfuric acid, making the soil highly acidic which then causes heavy metals to be released into the water column, having deleterious impacts on marsh plant communities (Portnoy \& Giblin 1997; Anisfeld \& Benoit 1997). According to Frenkel \& Morlan (1991), restoration of prediked elevations may take 50 years based upon current accretion rates at the Salmon River Estuary. Similarly, Thom et al. (2002) estimate full restoration of marsh elevation to take 75-150 years in Grays Harbor, WA. Sediments may become highly alkaline after breaching due to changes in reduction-oxidation potential in marsh sediments that mobilize phosphate, ammonium, and reduced iron, affecting water quality (Portnoy 1999; Portnoy \& Giblin 1997; Anisfeld \& Benoit 1997). Tidal forces can also cause extensive sedimentary erosion while vegetation is becoming established (Simenstad \& Thom 1996). In addition to site considerations, habitat linkages and landscape considerations are integral to achieving ecological restoration (Simenstad et al. 2000; Weinstein et al. 2005). Estuary-wide ecological benefits result from marsh restoration due to the marsh's role in supporting primary and secondary production through exchange of materials and organisms with the estuary.

Results of the South Slough NERR tidal marsh restoration project in Oregon (Cornu \& Sadro 2002) reveal the ability to jumpstart the response of restoration through marsh surface elevation manipulation. Marsh surface elevations were manipulated with breached dike material relative to tidal elevations creating a low, mid, and high marsh. Tidal channel morphology, vegetation, and fish characteristics were monitored for three years. Marsh surface gradient, in addition to elevation, was found to influence tidal channel development. Higher densities and species richness of fish were found on the lower marsh surface elevations. Plant diversity increased with marsh elevation.

Design parameters to facilitate tidal exchange and allow nekton access to the marsh from adjacent open waters were provided by Weinstein et al. (2005), based on experience from east coast United States restoration projects. Restoration designs 
should maximize edge by creating high drainage density and sinuosity. Marsh plain elevations should be slightly below mean high tide so that the marsh surface is inundated every tidal cycle, with areas above mean tide flooded half of the time. Siting restoration project close to intact marshes that can supply plant propagules will allow for rapid recolonization without planting. Intertidal marsh to subtidal water ratio should be 4:1 with $2-4 \%$ of the marsh surface inundated with shallow pools. Tidal elevation, surface elevation, and tidal channels are the most important design considerations to facilitate nutrient and nekton exchange between marshes and the estuary. Additional design guidance for salt marsh restoration can be extracted from a Sonoma Baylands project (Marcus 2000). The size of the breach should be large enough to accommodate the entire tidal prism, to not restrict tidal exchange. In order for tidal channels to develop, marsh surfaces should not be greater than 2' feet NGVD.

\subsubsection{Seagrass Restoration Techniques}

Fonseca et al. (1998) provide a thorough science-based resource for conserving and restoring seagrass. Seagrass transplantation has moved beyond an experimental technique and has been proven to be an effective mitigation technique. However, this report cautions that transplantation should be seen as a last practicable alternative. Preservation is still considered the most cost-effective technique because once habitat is lost, turbidity from unstable sediments may make restoration impossible. Ratios for seagrass transplantation are recommended to be at least 1.5 to 1 , if not more, and sites should be monitored for at least 10 years.

Two of the most important parameters that few researchers quantitatively measured were bioturbation and light regime. Apparently, seagrasses are especially vulnerable to bioturbation prior to becoming established post-transplantation. Waterfowl such as black brant can heavily graze on seagrass, as do sand dollars and burrowing shrimp. As a result, Fonseca et al. (1998) describe caging techniques to prevent new transplant destruction. As mentioned previously, if high light requirements are not met, seagrass mortality will occur. Light requirements are even greater for transplanted seagrasses than for already established seagrass meadows. 
Thom (1990) assesses the success of transplanting projects in the Pacific Northwest. Although results relative to success were variable, the conditions that produced better results were:

-low turbidity sites;

-sites with medium-grained sand with moderate organic material substrate;

-sites with low wave action and little sediment movement;

-flat sites;

-shallow subtidal sites;

-sites that were planted with larger area than target to incorporate plant mortality;

-submerged transplant conditions and planted within 24 hours;

-transplant sites with similar light, temperature and wave action as donor site;

-sites that were tested with experimental transplants; and

-sites that were monitored quarterly for shoot number and area for at least 2 years.

Thom's (1990) conclusions from assessing transplanting projects include that transplanting seagrasses to another site usually results in a net loss of seagrass habitat and that onsite mitigation is preferred. Also, because most seagrass mitigation projects fail to replace habitat losses at a 1 to 1 ratio, Fonseca et al. (1998) recommend a 2.5:1

replacement ratio. Also, if seagrasses are transplanted to a site that historically did not support seagrass, this may not be an appropriate site to colonize seagrass.

Whether these projects have achieved functional equivalency remains to be seen. Fonseca et al. (1998) considered transplanting a success if the acreage is planted, persists, and, ultimately, replaces the same resource functions of the damaged seagrass beds. Impact sites need to be assessed for function and, due to the temporal/spatial variability, assessed more than once. Although different methods were described to assess function, indicators mostly focused on faunal use, and one type of functional assessment was not recommended.

Currently in Oregon, there is at least one mitigation project involving the transplantation of eelgrass beds from an Oregon Department of Transportation (ODOT ) bridge replacement project over the North Fork of the Siuslaw River, just east of Florence. This project was largely designed based upon the recommendations described by Fonseca et al. (1998). Zostera marina, Zostera japonica, and macroalgal species, Ulva spp. and Enteromorpha spp. will be impacted. Steve Rumrill, research coordinator at SSNERR, developed the mitigation and monitoring plan. During peak biomass in summer 2005, field surveys were done to characterize the impact site. The spatial extent, 
location, plant density, percent cover, species composition, and blade length and width of the eelgrass bed as well as physical characteristics such as temperature and ambient light conditions will be noted at the impact site. Transplanting is scheduled to occur in summer of 2006. The transplant site will be located on the southwest side of the bridge. The bare root/staple method described by Fonseca et al. (1998) will be the method utilized to transplant. The replacement ratio will be 1.5:1 (transplant bed size to impact bed size) and the site will be monitored for ten years. While efforts should be made to avoid and minimize impacts, this may be impossible, as with the bridge replacement projects.

\subsection{Summary}

Significant advances have been made in understanding estuarine ecology over the past quarter of a century, but knowledge gaps still exist. Estuarine research in Oregon has been focused on the role of tidal marshes in supporting salmon populations, as well as expanding our general understanding of estuarine ecology. Some work has been done to inventory and assess eelgrass meadows in Oregon's estuaries. Research focused on understanding the role of estuarine tidal marshes and mudflats in nutrient cycling in Oregon's estuaries may assist in responding to current and future water quality threats to eelgrass habitats and estuaries in general. More work is needed to better understand the role of mudflats in primary productivity. Also, research looking at the influence of watershed-scale processes on estuarine health throughout Oregon is recommended for improved ecosystem management, as the Tillamook Bay and Lower Columbia River Estuary Partnerships have undertaken. Clearly, Oregon's estuaries have lost a significant percentage of their tidal marshes, no doubt contributing to declining salmon runs. Though not quantified, we presume that degree of loss contributes to the loss of other organisms. The framework of landscape ecology viewed through both resident and migrating fauna life histories has shed light on the importance of considering not only the 'relative value' of a specific estuarine wetland as laid out in the estuarine mitigation rules but how that particular habitat fits into the larger estuarine landscape. 
Finally, Restore America’s Estuaries’ fundamental principles provide an adequate summary of recommendations for improving restoration success (RAE-ERF 1999).

These include:

- Preservation of existing habitat is considered crucial to the success of estuarine restoration.

- Long-term stewardship and protection is necessary for estuarine restoration to be achieved.

- There needs to be an increase in restoration activity and the size of restoration efforts.

- Restoration plans need to be developed at the estuary-wide and watershed levels.

- The public should be aware of, be involved in and have access to restoration sites in order for them to be successful.

- A stakeholder process is recommended when developing restoration plans.

- Project goals should be clearly stated and monitored for more than five years.

- Success criteria should consider both functional and structural elements and should be linked to reference habitats.

- Restoration site plans should consider offsite impacts such as potential flooding of nearby property.

- Engineering designs should incorporate ecological processes.

- Adaptive management should be incorporated into restoration activities. 


\section{CHAPTER 5}

\section{WETLAND ASSESSMENT TOOLS AND COMPENSATION METHODS}

\subsection{Introduction}

While the ERR rules predated functional assessments, stipulations addressed the concept of functions by requiring mitigation to maintain unique features, habitats and species diversity, and water quality. Unique features are defined as 'physical, biological, chemical, and esthetic characteristics, and attributes...that are uncommon, extraordinary, rare, threatened, or endangered'. Unique features are to be replaced by in-kind mitigation, while habitats and species diversity are to be maintained by in-kind or likekind (not defined) and water quality is to be maintained by enhancement activities. Charged with achieving 'no net loss of area and function' and with improved understanding of the functions, values, and services provided by wetlands, federal and state wetland regulatory programs, including DSL's Removal-fill Program, have been developing and incorporating rapid functional assessment tools, such as the hydrogeomorphic functional assessment method (HGM) into compensatory mitigation requirements.

DSL’s compensatory wetland mitigation rules state a preference for onsite mitigation projects that replace the Cowardin class, HGM subclass, and functions of the impacted wetland (if impact is 0.2 acres or more). If onsite mitigation is not practicable or if offsite is environmentally preferable, several offsite options are available. These include physical in-kind mitigation, purchasing credits from an approved mitigation bank, paying in to the payment to provide (PTP) program allowing for third party mitigation, or, in rare cases, preserving high quality wetlands at-risk for threat through the conservation in lieu option. In DSL's ERR rules, preference is given to in-kind or "likekind” mitigation and is to occur within the same estuary as the impact site. Mitigation banking was an option for ERR, if available, but PTP and conservation in lieu were not yet recognized as compensatory mitigation options. 
One rapid assessment tool specifically developed for Oregon’s estuarine wetlands is the tidal HGM. This section begins with an introduction of the Hydrogeomorphic functional assessment approach, followed by a description of the tidal HGM, a comparison to the ERR relative values system, and a discussion of the potential application of this tool in compensatory mitigation, including examples from the mitigation literature and agency programs. The appropriateness of alternative mitigation options for estuarine impacts such as offsite, out-of-kind, banking, payment to provide, and conservation in lieu will also be discussed.

\subsection{HGM Functional Assessment}

Numerous functional assessment tools have been developed to rapidly assess wetland functions for regulatory purposes (Bartoldus 1999). The HGM functional assessment method is, currently, the preferred methodology for the national 404 program (Federal Register 1997) and for Oregon’s Removal-fill Program. Ainslie (1994) first introduced the concept of applying an HGM-based functional assessment method into the 404 wetlands regulatory program. The Corps of Engineers took the lead in developing HGM and provides National guidance on how to develop regional guidebooks. Several states, including Oregon, have taken the lead in developing HGM classification and guidebooks. HGM requires the development of regional assessment methods per HGM subclass based upon a thorough literature review and field measurements from numerous reference sites that represent the full range of conditions. This development phase identifies a list of wetland functions performed by the HGM subclass and generates a number of environmental indicators that can be used in the field to assess the functional capacity of a wetland. Based upon scores for each field indicator, a Functional Capacity Index (FCI) score is calculated for each function based upon a scale of 0 , lowest, to 1 , highest functioning. The FCI can be multiplied by the size of the wetland assessment area to get Functional Capacity Units (FCUs). Wetland assessment areas can be subdivided into partial wetland assessment areas if different conditions exist on the site that will significantly affect the FCI or if different impacts (fill one area and dredge 
another) are proposed for each partial wetland area (Smith et al. 1995). It is not recommended to rely solely on the FCI without consideration of area. Area needs to be explicitly incorporated into the functional score by multiplying the FCI by the wetland assessment area to get FCU of the Wetland Assessment Area. FCUs are to be determined at the impact site before impact with a post-impact prediction assessment. The same assessment procedure is to be done at the mitigation site to assess current conditions and predict functional lift from proposed treatment.

Scores can be compared only from wetlands of the same HGM subclass, as each assessment model was calibrated using reference wetlands specific to that subclass. Wetlands from different regional wetland subclasses should only be compared using direct quantitative measurement data, an endeavor generally not feasible in the regulatory context (Smith et al. 1995). This limitation-the inability to compare wetlands of different subclasses-can be problematic for use in regulatory programs. However, Brinson and Rheinhardt (1996) suggest that if a different subclass is offered as mitigation, HGM assessment results from the different subclasses could used to understand the functional tradeoffs. However, allowing mitigation that replaces a function (i.e., wintering and migrating waterbird support), but not the lost HGM subclass (i.e., riverine compensated with slope/flat) is considered an inappropriate use of a reference-based functional approach. The HGM procedure also was not intended to assign monetary value to the wetland functions (Smith et al. 1995).

\subsection{Oregon’s HGM Functional Assessments}

HGM regional functional assessment guidebooks have been developed for Oregon's tidal wetlands (Adamus 2005) and the Willamette Valley ecoregion (Adamus \& Field 2001). Both of these assessment tools have been developed from extensive literature reviews and field measurements from numerous reference sites. HGM tools attempt to make a clear distinction between wetland functions and values, and attempt to assess only functions. While function is what a site does, a value is the socio-economic significance that is placed on that function. The Oregon HGM Guidebooks, however, do include a separate section for assessing wetland values. Observable field indicators are 
assessed and incorporated into mathematical models to generate function capacity scores per individual function on a scale of 0 to 1 . Because each regional HGM Guidebook is based upon reference sites specific to the region and subclass(es), scores from different subclasses and or from different regions with similar functions should not be compared. Also, individual function capacity scores are to be treated individually and not summed into a single score.

\subsubsection{ERR compared to HGM functional assessment}

DSL’s CWM rules require functional assessments for both impacted and mitigation sites and HGM assessment is the preferred method, when available. While DSL's program tracks HGM class in the database, DSL is not formally tracking functions lost and gained per permit, although this information can be found in the hard copy of the permit file. Often, however, function loss and replacement is based only on Best Professional Judgment and is not quantified. In contrast, the ERR rules do not require HGM functional assessments since they predate the concept and the ratios incorporate relative values, a simplified and more subjective version of a 'functional assessment'.

\footnotetext{
In the ERR relative values table, tidal marshes were divided into high marsh, low marsh, fresh tidal marsh, and shrub marsh and were distinguished from one another based mostly on tidal elevation, but also sediment type and salinity regime, as a surrogate for landscape position. These habitats were rated based on "natural biological productivity and species diversity" (Hamilton 1984). The Oregon tidal HGM (Adamus 2005) defines three subclasses of Estuarine Fringe wetlands based upon position in the landscape and primary source of hydrology (riverine vs. marine). In terms of relating the ERR classification (Bottom et al. 1979) to the tidal HGM classification, High Marsh would translate to Marine-sourced High (MSH) and Low Marsh to Marinesourced Low (MSL), and fresh water high marsh and forested/shrub marsh would be lumped into the River-sourced (RS) subclass. The tidal HGM, as suggested in the name, emphasizes the significance of the abiotic control of tides on this class of wetlands, rather than the traditional emphasis on salinity regimes in estuarine habitat. As salinity concentration is temporally and spatially dynamic, tidal influence is considered a more reliable measure for determining whether the wetland falls into the Estuarine Fringe HGM class, especially near the head of tide. RS Estuarine Fringe wetlands, either emergent or forested vegetation, occur at the upper end of the estuary in which river flow is the predominant source of hydrology; however, water level fluctuates due to tidal influence on river stage at least once during every annual growing season. Estuarine Fringe wetlands that are MSH are inundated by the tides rarely, but at least annually during spring tides, and MSL are inundated at least once daily.
}

Compared to the relative value system that only considered the functions of productivity and species diversity of tidal marsh habitat, the tidal HGM framework identified 12 functions from the scientific literature (Table 16). These 12 functions are more specific than the relative values table. 'Productivity' from the relative value system was further delineated in the tidal HGM system into 'produce above ground organic matter' and 'export aboveground plant \& animal production' and 'species 
diversity' from the relative value system was fleshed out to eight different functions in the tidal HGM, recognizing the fundamentally different fauna supported by tidal marshes and their distinct habitat requirements. In addition to identifying more specific functions relative to species diversity, water quality was described in more detail in the tidal HGM as the 'maintenance of element cycling rates, pollutant processing; stabilize sediment'.

\begin{tabular}{|l|l|}
\hline \multicolumn{2}{|c|}{ Functions of Estuarine Fringe Wetlands } \\
\hline Relative Values & Tidal HGM \\
\hline Productivity & Produce Aboveground Organic Matter \\
\hline & Export Aboveground Plant \& Animal Production \\
\hline Species Diversity & Maintain Habitat for Native Invertebrates \\
\hline & Maintain Habitat for Anadromous Fish \\
\hline & Maintain Habitat for Visiting Marine Fish \\
\hline & Maintain Habitat for Other Visiting and Resident Fish \\
\hline & Maintain Habitat for Nekton-feeding Wildlife \\
\hline & Maintain Habitat for Ducks and Geese \\
\hline & Maintain Habitat for Shorebirds \\
\hline Unique Features & Maintain Habitat for Native Landbirds, Small Mammals, \& Their Predators \\
\hline Water Quality & Maintain Element Cycling Rates and Pollutant Processing; Stabilize Sediment \\
\hline
\end{tabular}

(Adamus 2005).

The relative values table was generated from the expert opinions of "trained scientists and natural resource managers" (Hamilton 1984) combined with a diverse group of stakeholders including ecologists, coastal government representatives, environmentalists, and industrial representatives (Quarterman 1985). In contrast, the tidal HGM Guidebook was developed and calibrated for each function based upon a set of environmental indicators extracted from the literature and from field observations at 120 reference sites (41 MSH, 47 MSL \& 31 RS). However, regional coastal wetland experts did help develop the function scoring models. Additionally, this method considers human threats to the habitat based on current land use.

On average, the relative values table rated Low Marsh habitat higher than High Marsh for 'natural biological productivity and species diversity' (Table 17). However, the average of all functional capacity scores for the MSH and MSL reference wetlands were not that different from one another and individual function scores ranged in value 
depending upon a number of environmental indicators. The point being, depending upon specific indicators per wetland assessment area, functional capacity scores will vary, unlike the relative values score, which assigns one score per substrate, salinity regime, and habitat. Although the tidal HGM scores are "all relative and have no absolute meaning with regard to function capacity” (Adamus 2005), these scores were rated based on indicators extracted from the best available science about tidal marshes and actual field surveys.

\begin{tabular}{|c|c|c|c|c|c|c|}
\hline \multicolumn{6}{|l}{$\begin{array}{l}\text { Estuarine Resource Replacement } \\
\text { Rules }\end{array}$} & \multicolumn{2}{l|}{ Tidal HGM } \\
\hline & High Marsh & Low Marsh & $\begin{array}{c}\text { Freshwater } \\
\text { Tidal }\end{array}$ & MSH (42) & MSL (47) & RS (31) \\
\hline Min & 3 & 4 & 1 & 0.00 & 0.00 & 0.00 \\
\hline Max & 4 & 5 & 3 & 1.00 & 1.00 & 1.00 \\
\hline Average & 3.67 & 4.33 & 2.5 & 0.49 & 0.47 & 0.44 \\
\hline Median & 3.5 & 4.5 & 3 & 0.49 & 0.47 & 0.43 \\
\hline
\end{tabular}

Table 17: Summary statistics of the estuarine resource replacement rules 'natural biological productivity and species diversity' of habitat types (Hamilton 1984) and function capacity scores for the 120 wetlands surveyed for tidal HGM method (Adamus 2005).

The tidal HGM method provides a more objective, systematic, and explicit way of evaluating habitat functions for specific wetland sites than the overly generalized and somewhat arbitrary relative values table developed for the estuarine mitigation rules. Due to improved methodologies for assessing wetland functions such as the tidal HGM, it is recommended that the relative values table be abandoned, the CWM rules be adopted for estuarine wetlands, and the tidal HGM for impact and mitigation sites be required to assess functions.

\subsubsection{HGM potential application}

The tidal HGM tool provides the opportunity to assess each tidal wetland using a systematic and objective methodology for assessing function, which can inform what functions are being lost and gained within the realm of wetlands regulation. The tidal HGM assessment tool was designed to quantify function(s) that will be lost at an impact site in order to compensate for lost functions at a proposed mitigation site. Also, this tool can be used to design and predict estuarine wetland functions in CWM plans. Because 
the tool was developed based upon reference wetlands that were at least partially tidally influenced, running the method on former tidal wetlands that receive no tidal influence may not produce meaningful results. For enhancement mitigation, the HGM can be run before the mitigation treatment to quantify the pre-mitigation level of functioning and to track functional improvements throughout the monitoring period of the project once the mitigation project is completed. Also, if a different HGM subclass, within Estuarine fringe class, is offered as mitigation than what was impacted, HGM scores can quantify the functional trade-off.

\subsubsection{Estimating Ecological lift}

Potential ecological lift at a mitigation site based on hypothetical scenarios can be quantified using the HGM assessment. For example, if five pieces of large woody debris (LWD) were added to a marsh surface that had less than one piece, the model could quantify potential functional increase. This could be an iterative process using different scenarios to estimate ecological lift such as the addition of 10 LWD pieces, entire dike breaching versus a partial breach, remeandering tidal channels, or tide gate replacement. Due to the novelty of an HGM tool for estuarine fringe wetlands, its utility or sensitivity is yet to be realized.

Within the assessment, two indicators address changes to wetland hydroperiod: 'Dike Dry' and 'Dike Wet'. The 'Dike Dry' questions address to what degree has the area that is still wetland become drier as a result of installation of dikes, ditches, tidegates, culverts and other artificial constrictions. The 'Dike Wet' questions address alterations that have resulted in longer hydroperiods. The 'Dike Dry' response options are: no hydrological constrictions exist, the site still floods daily, some areas no longer flood daily, or the site no longer floods daily. (To accurately assess the full range of the tidal regime, the assessment would need to be run during a spring tide (strong) which occurs on the full or new moon and then again on the neap tide (weak) which occurs on the first and last quarter.)

The tool is sensitive enough to detect drastic hydrologic modifications, but not small-scale enhancement activities. For example, it would quantify ecological lift from a tidegate removal, but not necessarily a tidegate upgrade that would allow monthly flooding. All other things being equal, the tide gate removal would reintroduce daily 
flooding, resulting in a higher functional score, as opposed to the lower score for monthly inundation.

Likewise, if the enhancement activity involved a culvert enlargement, the assessment method would not be sensitive enough to detect it. For example, there is a current enhancement mitigation project of a tidal marsh along Yaquina Bay. The tidal marsh is currently separated from the estuary by a county road with one culvert in the road allowing for tidal exchange. The enhancement treatment is to enlarge the culvert from 15 ” to 30 " diameter. The current culvert allows daily but restricted tidal flushing, a mid-range score. The new culvert is predicted to allow better tidal flushing, yet still restricted, thus the score will remain the same, resulting in no detected 'ecological lift' by the method. A partial dike breach versus an entire dike breach would also go undetected.

The mitigation plan for the culvert enlargement predicts a change in plant community from a more freshwater system to more salt tolerant species due to an increase in water salinity concentrations. The assessment method can be used to track functional changes with respect to plant community and salinity regime over time. While some permittees have the budget to hire a tidal hydrologist to do hydrological modeling to better predict the ecological benefit of increasing a culvert to a certain size, most permittees, such as the county transportation department in this case, do not have the funding to pay for such analyses and must rely upon rapid assessment tools such as the HGM assessment method. Although, as illustrated above, the tool is not sensitive enough to detect most minor hydrologic enhancement activities.

\subsubsection{Calculating enhancement credit}

Enhancement credit calculation in the current ERR rules is based upon the concept that one habitat is inherently more valuable than another and changing one habitat to another more valuable habitat type is considered ecologically beneficial. For instance, all brackish regimes were rated higher than freshwater (except in the Columbia River estuary). Within the ERR framework, the relative value of a salinity regime remains static regardless of a site's individual capacity to perform specific functions and may not reflect current societal values. For example, if the wetland habitat was a freshwater Sitka Spruce wetland that was high functioning for wildlife habitat that had been diked for over 150 years, the relative value chart would assign the wetland a 3 in its 
current state and would grant enhancement credit if tidal inundation was reintroduced to form a high brackish marsh with a value of 4. Using an HGM framework, this same wetland would be assessed for numerous different functions and depending upon the results of an assessment would not likely be appropriate for an enhancement activity. Furthermore, the CWM rules dissuade against this type of mitigation since enhancement credit is not given for a Cowardin class or HGM class change, unless it is environmentally preferable. Due to the documented rarity of Sitka spruce wetlands, the 'enhancement' benefit of such an action is dubious.

Few datasets document the hydrologic and ecological response from culvert enlargement. One Connecticut study (Boumans et al. 2002) used field data to calibrate a simulation model that could be used to predict hydrologic response to hypothetical scenarios including culvert enlargement, tidegate removal, and partial dike breaching. This model has the capacity to run simulations on various culvert designs and partial breaches and predict what type of marsh habitat will result based upon elevation changes. The Marsh Response to Hydrologic Manipulation Model has not been applied to tidal restoration projects in Oregon.

As tidegates fail, many are being replaced with so-called 'fish friendly' designs and in some cases (i.e., RF 33602) applicants are receiving enhancement credit for this effort. A recent study (Giannico \& Souder 2005) looked at the operation, types, and environmental effects of tidegates in the Pacific Northwest on fish. According to this document, no tidegate is completely fish friendly, but some are "friendlier" than others. Friendlier tidegates open wider, for longer periods of time, create less water velocity and turbulence, and allow for a gradual salinity change. The environmental effects of tidegates are extensive and impact biological, chemical, and hydrological cycles.

Little research has been done on the ecological improvement from tidegate replacement activity or on the impact of tidegates on juvenile salmon populations, in general. The Tillamook Estuary Partnership (Charland 1998) provides some useful tidegate and culvert information for projects aimed at improved water quality and fish passage. The culvert must be large enough, installed low enough relative to low water levels, and those with "pet door” designs should remain at least 50\% filled even at the lowest water levels. While inventories and prioritizations for road culvert replacement on 
state and county-owned roads relative to fish passage issues in Oregon have been completed (Mirati 1999), no comprehensive survey of tidegates in all of Oregon's estuaries exists. One survey was undertaken of tidegates in Tillamook Bay (Charland 1997) that identified the location, condition, and potential habitat value above the 49 tidegates assessed. Recommendations were made for potential modification of each tidegate.

The actual 'enhancement' benefit of tidegate replacement to wetlands is unknown. While some tidegates improve tidal flushing in subtidal channels, most tidegates restrict sheet flow over marsh surfaces. As noted by Giannico and Souder (2005), more research is needed to understand the improved ecological function of fishfriendly tide gates, which will inform whether enhancement credit for this activity is warranted.

\subsubsection{Additional enhancement ideas}

Due to the extensive literature review and field surveys involved in developing the tidal HGM manual, the science behind the tool generates enhancement ideas. ERR defines enhancement vaguely and attributes any 'long-term improvement of existing functional characteristics' that is not considered restoration or creation to be 'enhancement'. DSL's CWM rules define enhancement as increasing the function of an existing wetland that is degraded by hydrologic manipulation, such as ditching. Enhancement credit is not given solely for tree planting and invasive species removal, nor for establishing a wetland buffer despite the potential ecological benefits. The limitation on the activities that are granted enhancement credit is to help ensure that an actual functional lift results, especially when an HGM functional assessment is not used.

Ecologically-based enhancement activities for estuarine habitat are not explicitly outlined in the rules or standard operating procedures. For example, enhancement credit is not formally given for adding large woody debris (LWD) to the marsh surface and to tidal channels and for restoring natural channel networks. Gonor et al. (1988) document the importance of LWD in estuaries as invertebrate and bird habitat and document the significant decrease of available wood sources in estuaries due to forestry and navigational practices. Adamus (2005) recognizes the importance of LWD on marsh surfaces and in tidal channels and uses it as a functional indicator. 
Research summarized by Adamus (2005) demonstrates the importance of tidal channels to tidal marsh ecology. Greater channel length per draining marsh area results in increased tidal circulation. Additionally, tidal channels provide corridors for fish and other nekton to access the marsh, as well as export detritus into the estuary. Tidal channels create ecotones in the marsh with rapid changes in abiotic characteristics that support a diversity of organisms including invertebrates and fish. Marshes with complex channel networks are able to process particulate and dissolved nutrients more efficiently, making nutrients more readily available for plant uptake. Tidal channels are thought to provide predator refuge as well as areas for marine salinity acclimation for anadromous fish. Marsh tidal channels that are straightened are less supportive of fish production than those that meander (Weinstein et al. 2005). Waterfowl are also dependent upon channels and open water areas.

Williams et al. (2002) provide some guidance on appropriate tidal channel morphology in San Francisco Bay. Hydraulic geometry can help to size tidal channel excavations in restored marshes, forecast channel sedimentation or erosion responses to changes in tidal prism, and predict minimum tidal prism. For a given tidal prism, crosssection morphology can be predicted. Based on tidal channel morphometry of a New Jersey salt marsh, Zeff (2002) reports that tidal drainage patterns follow Horton's Law of Stream Numbers and Law of Stream Lengths can be used to design tidal channels at mitigation sites. However, channel morphology varies considerably across the marsh landscape and among natural marshes due to marsh age and soil type (Zedler 2001; Adamus 2005) making it difficult to develop one model that could be applied for all tidal marshes and data are lacking regionally. Historical aerial photos will sometimes reveal larger tidal channels, but usually smaller channels are obscured. Hydrologic modeling is recommended for designing any complex tidal channel morphology.

In conclusion, naturally meandering subtidal and intertidal channels and the presence of LWD on the marsh surface and in tidal channels are both important features of functioning marshes. Enhancement credit should be granted if tidal channel restoration and the addition of LWD to the marsh surface and to tidal channels are components of a mitigation project.

\subsubsection{HGM shortcomings}


Although the HGM functional assessment provides a more objective, systematic, and referenced-based tool, there are still some details that need to be worked out for regulatory application. In relation to its application in estuarine habitats along the Oregon coast, it is only applicable for specific estuarine habitat: high marsh, low marsh and forested habitat, but not unvegetated, algal, or seagrass beds. Although developed for the Puget Sound to assess fish and wildlife function, the Estuarine Habitat Assessment Protocol (Simenstad et al. 1991) may be the most appropriate tool to assess those habitats not covered by the tidal HGM. However, this tool does not assess all functions performed by these habitat types. Nevertheless, it does provide a standard and objective method to be used to assess functional replacement of mitigation sites relative to development sites.

The tidal HGM method is not applicable across HGM class (i.e. Riverine for Estuarine Fringe), subclass (MSH to MSL), or even formerly Estuarine Fringe wetlands, since it was developed in relation to subclass-specific reference sites. Furthermore, HGM assessments intentionally ignore the social significance and services provided by the wetland functions and thus do not consider public interest needs (Kusler 2003).

There are, as yet, no HGM regional assessment methods available for Oregon's non-tidal coastal wetlands. The only other regional HGM method currently available is the Willamette Valley HGM, which was based on reference sites from that ecoregion. This limitation poses a problem for regulatory application because dike breaching is sometimes proposed as compensatory mitigation for permitted coastal non-tidal wetland impacts, especially if formerly estuarine. Based on the rarity of permitted estuarine impacts, the inability to apply this functional assessment across HGM class, its insensitivity to some enhancement techniques, and its inapplicability to formerly estuarine wetlands (likely candidates for restoration), use of the tidal HGM application in the Removal-fill Program will be limited, unless these constraints are reduced.

\subsubsection{Oregon Rapid Wetland Assessment Program}

HGM assessment methods are based upon the best available science and data collected from numerous reference sites. Consequently, these assessments are resource- 
intensive to develop. In place of an HGM method for every ecoregion of the state, DSL has developed a concept paper for the Oregon Rapid Wetland Assessment Method (ORWAP) and hopes to have a developed tool by 2008 (Morlan pers. comm. 2/6/06). The intent of the ORWAP is to assess wetland functions based a more limited suite of functions, than those incorporated into the HGM Guidebooks and to include separate rating scores for wetland condition and wetland values. ORWAP will be based on literature and professional judgment of regional experts, but will not be based on reference site data. This tool will be designed for determining what functions are being lost at the impact site and what potential functions will be replaced by the mitigation site. The intent is for ORWAP to be applicable across wetland types, unlike the HGM.

\subsection{Compensation}

\subsubsection{Incorporation of functional assessments into ratios}

Both section 404 of the CWA and the Removal-fill Law require replacement of lost functions as well as no net loss goals. Because functional assessment science is still relatively new, ratios are typically used to ensure 'no net loss' and also as a surrogate for replacing functions. Oregon's wetland regulatory program, as in other states with a regulatory program, requires straightforward and predictable compensation ratios. However, research has shown that typical ratios and typical CWM requirements are not achieving 'no net loss' in area and probably not function (Ambrose 2000; NRC 2001; Castelle et al. 1992). In fact, compensatory mitigation projects may be resulting in wetland types not found naturally in the landscape and that function very differently than the impacted wetlands (Gwin et al. 1999). As described in Chapter 2, Oregon’s CWM program requires compensation ratios at one acre restored for one acre impacted (1:1), 1.5:1 for creation and 3:1 for enhancement activities. The stated purpose of these ratios is to maintain the state's wetland resource, offset temporal loss of functions, replace wetland functions, and compensate for likelihood of success. Requiring a higher ratio for creation than restoration assumes a greater risk for creation success and requiring the greatest ratios for enhancement attempts to minimize the areal loss associated with 
enhancing function. However, mitigation method (restoration, creation, enhancement) does not explicitly account for temporal loss, for likelihood of success per habitat type, or for lost functions. Because bogs, fens, and vernal pools are considered rare or difficult to replace, conservation in lieu is allowed for compensating impacts, although replacement ratios are determined on a case by case basis. Also, any Oregon Natural Heritage imperiled (S1 designation) or threatened (S2 designation) wetland plant community that supports a rare plant or animal population is also acceptable for conservation in lieu. The ERR also uses ratios but attempts to incorporate functional value into the ratio with the relative values table and maintenance of the state's wetland resource, but does not consider likelihood of success or temporal loss.

Most state wetland programs use compensatory mitigation ratios ranging from less than 1:1 to greater than 5:1 depending upon mitigation method and/or wetland type (Lupi et al. 2002; Adamus 2004). For instance, in Michigan, common type wetlands require a 1.5:1 ratio, while impacts to rare wetland types require 5:1 (Lupi et al. 2002). The USACE focuses on functional replacement rather than ratios in implementing the Clean Water Act's 404 program, although compensation ratios are to be at least 1:1. However, USACE provides little guidance on how to determine how much area is required to replace wetland functions. DSL has not developed a standard procedure for incorporating functional assessments into the compensation ratios, but is interested in exploring methods to systematically and better incorporate functional assessment results into CWM requirements. Options for CWM replacement requirements include maintaining the current system, replace areal ratios with functions, or integrate functions into areal replacements.

Brinson and Rheinhardt (1996) describe how to use reference-based functional assessments (HGM) in calculating mitigation ratios per function and provide guidance on how to determine overall compensation ratios. For example, if the function "Recycles Nutrients and Other Elements” for a wet pine flat scores 0.51 before impact and 0.00 after impact, a mitigation site of the same size will have to perform the same function at the same level after treatment. In this case the ratio will be 1:1. However, if the mitigation site functions at 0.75 prior to treatment and is expected to be fully functioning after treatment with a 1.0 score, than the replacement ratio for that function will have to 
be 2 units replaced per 1 unit loss. Since all wetlands will perform multiple functions, it will be necessary to determine how to incorporate all of these functions into a mitigation site. This study concluded with three recommendations for doing this: give priority to hydrologic variables because they are crucial to overall wetland function; base ratios on priority functions established per region; or use the function with the highest score at the impact site to determine overall replacement acreages.

Findlay et al. (2002) developed a reference-based functional assessment using three HGM subclasses in New York and recommended its utility in understanding the functional capacity of a particular wetland to inform management decisions (conservation, restoration, or allowable impact). However, they noted subjectivity in choosing reference sites due to logistical and financial constraints. Additionally, they reported both size independent and area weighted functional scores, but were not able to resolve the question of "is twice the area and half the function equal to half the area with twice the function"? While flood storage capability is proportional to wetland area, other function-area relationships are likely not linear.

Despite HGM's reference-based approach to assessing wetland function, it was not designed to answer questions about how to compensate impacts with 'out-of-kind' mitigation. Using the function with the highest score may be the best approach (Brinson \& Rheinhardt 1996; Adamus \& Field 2001). Using Brinson and Rheinhardt’s (1996) recommendation to prioritize regionally important functions, "Maintain Habitat for Anadromous Fish” could be considered an more important function relative to the 11 other functions due to the region's struggle with restoring declining salmon populations. The FCI for this function could be multiplied by the area of the impact site to determine the number of FCU needed at the mitigation site to determine the compensation ratio. Similarly, for those watersheds such as the Coquille which have identified water quality problems "Maintain Element Cycling Rates and Pollutant Processing; Stabilize Sediment" may be considered the most important function and consequently used to determine compensation ratios. Although not the original intent, the tidal HGM method could be used in conjunction with a non-tidal coastal wetland HGM method, if one existed, to guide ‘similar function’ but ‘out of HGM class’ decisions. 
Breaux and Serefiddin (1999) recommend incorporating function into areal ratios on a case-by-case basis since our knowledge of functions 'remains rough and uncertain'. A minimum threshold of 1:1 would maintain no net loss (if actually constructed to required size and successful), but they recommended higher gain to loss ratios for certain conditions: high quality wetland losses, wetland compensation occurring out of the watershed, projects having high risk of failure, high temporal losses for late-to-mature habitats, subdividing large sites, or impact projects that interrupt corridors. One possible rationale for the disincentive for out-of-watershed wetland mitigation is the direct (or indirect via groundwater) hydrological connection between wetlands and waterways. If wetland functions related to water quality, water storage/delay, and maintenance of fish habitat are exported to another watershed, problems such as flooding, water quality and reduced habitat for fish populations may result. However, similar negative results could be observed by allowing offsite mitigation that transports wetland functions from upper reaches of the watershed to lower reaches and vice-versa.

Washington's wetland program represents a good example of how to incorporate functions and values into areal requirements (Hruby 2004). This program has developed a wetland rating system based on their sensitivity to disturbance, their significance, their rarity, the ability to replace them, and the functions they provide. Functions are assessed using the Washington State Wetland Functional Assessment Methods, an HGM-based approach, developed on a regional basis for different classes. Improving water quality, hydrologic functions, and wildlife habitat functions are assessed and given approximately equal weight on a 100-point scale (Hruby 1999, 2000). The rating system consists of four categories in which wetlands falling into Category I are most sensitive to disturbance, are significant, are rare, are difficult to replace, or provide many functions well. Category I wetlands found along Washington's coast include undisturbed estuarine wetlands (> 1 acre), mature and old-growth forested wetlands, natural heritage wetlands (e.g., supporting rare plants or Threatened and Endangered species), coastal lagoon wetlands, bogs, and those wetlands that are high functioning (scoring greater than $70 \%$ in all functions).

Among other wetland types, estuarine wetlands that are disturbed and less than one acre in size and interdunal wetlands greater than one acre are considered Category II. 
Interdunal wetlands, although not covered by the HGM functional assessment, were rated based upon the significant wildlife habitat they provide in dunal ecosystems. Also, wetlands that perform al functions well (51\% to 69\%) are considered Category II. Category III wetlands score within 30-50\% and are more disturbed and isolated than Category II. Category IV wetlands score less than 30 percentile and are also considered easier to replace and enhance. Greater mitigation ratios are required for higher category wetlands, providing a disincentive for impacting them (Table 18). For example, Category IV wetlands require 1.5:1 for creation, 3:1 for rehabilitation, 1:1 for restoration, and 6:1 for enhancement, while Category I wetland mitigation ratios require 4:1, 8:1, 1:1, and 16:1, respectively. Alkali, bog, and coastal lagoon wetlands are considered impossible to replace and are avoided. Rehabilitation refers to mitigation that restores environmental processes at both the site and landscape scales, the original HGM class or Subclass. In contrast, enhancement focuses on structural improvements for only a few functions at the site level and generally involves gains in only one or a few functions.

\begin{tabular}{|c|c|c|c|c|c|}
\hline $\begin{array}{l}\text { Category and } \\
\text { Type of } \\
\text { Wetland } \\
\text { Impacts }\end{array}$ & $\begin{array}{l}\text { Re-establishment } \\
\text { or Creation }\end{array}$ & \begin{tabular}{|l} 
Rehabilitation \\
Only ${ }^{21}$
\end{tabular} & $\begin{array}{l}\text { Re-establishment or } \\
\text { Creation (R/C) and } \\
\text { Rehabilitation (RH) }\end{array}$ & $\begin{array}{l}\text { Re-establishment or } \\
\text { Creation }(\mathrm{R} / \mathrm{C}) \text { and } \\
\text { Enhancement }(\mathrm{E})^{21}\end{array}$ & $\begin{array}{l}\text { Enhancemen } \\
\text { t Only'z1 }\end{array}$ \\
\hline $\begin{array}{l}\text { All Category } \\
\text { IV }\end{array}$ & $1.5: 1$ & $3: 1$ & $1: 1 \mathrm{R} / \mathrm{C}$ and $1: 1 \mathrm{RH}$ & 1:1 R/C and $2: 1 \mathrm{E}$ & $6: 1$ \\
\hline $\begin{array}{l}\text { All Cate gory } \\
\text { III }\end{array}$ & $2: 1$ & $4: 1$ & $1: 1 \mathrm{R} / \mathrm{C}$ and $2: 1 \mathrm{RH}$ & $1: 1 \mathrm{R} / \mathrm{C}$ and $4: 1 \mathrm{E}$ & $8: 1$ \\
\hline $\begin{array}{l}\text { Category II } \\
\text { Estuarine }\end{array}$ & Case-by-case & $\begin{array}{l}\text { 4:1 Rehabilitation of } \\
\text { an estuarine } \\
\text { wetland }\end{array}$ & Case-by-case & Case-by-case & Case-by-case \\
\hline $\begin{array}{l}\text { Category II } \\
\text { Interdunal }\end{array}$ & $\begin{array}{l}2: 1 \\
\text { Compensation must } \\
\text { be interdunal } \\
\text { wetland }\end{array}$ & $\begin{array}{l}4: 1 \\
\text { Compensation must } \\
\text { be interdunal } \\
\text { wetland }\end{array}$ & $\begin{array}{l}1: 1 \mathrm{R} / \mathrm{C} \text { and } 2: 1 \mathrm{RH} \\
\text { Compensation must } \\
\text { be interdunal wetland }\end{array}$ & $\begin{array}{l}\text { Not considered an } \\
\text { option }{ }^{22}\end{array}$ & $\begin{array}{l}\text { Not } \\
\text { considered } \\
\text { an option }\end{array}$ \\
\hline $\begin{array}{l}\text { All other } \\
\text { Category II } \\
\end{array}$ & $3: 1$ & $6: 1$ & $1: 1 \mathrm{R} / \mathrm{C}$ and $4: 1 \mathrm{RH}$ & $1: 1 \mathrm{R} / \mathrm{C}$ and $8: 1 \mathrm{E}$ & $12: 1$ \\
\hline $\begin{array}{l}\text { Category I } \\
\text { Forested } \\
\end{array}$ & $6: 1$ & $12: 1$ & $1: 1 \mathrm{R} / \mathrm{C}$ and $10: 1 \mathrm{RH}$ & $1: 1 \mathrm{R} / \mathrm{C}$ and $20: 1 \mathrm{E}$ & $24: 1$ \\
\hline $\begin{array}{l}\text { Category 1- } \\
\text { based on } \\
\text { score for } \\
\text { functions } \\
\end{array}$ & $4: 1$ & $8: 1$ & $1: 1 \mathrm{R} / \mathrm{C}$ and $6: 1 \mathrm{RH}$ & $1: 1 \mathrm{R} / \mathrm{C}$ and $12: 1 \mathrm{E}$ & $16: 1$ \\
\hline $\begin{array}{l}\text { Category I } \\
\text { Natural } \\
\text { Heritage site }\end{array}$ & $\begin{array}{l}\text { Not considered } \\
\text { possible }{ }^{23}\end{array}$ & $\begin{array}{l}\text { 6:1 Rehabilitation of } \\
\text { a Natural Heritage } \\
\text { site }\end{array}$ & $\begin{array}{l}\text { R/C Not considered } \\
\text { possible } e^{33}\end{array}$ & $\begin{array}{l}\text { R/C Not considered } \\
\text { possible }\end{array}$ & Case-by-case \\
\hline $\begin{array}{l}\text { Category I } \\
\text { Coastal } \\
\text { Lagoon }\end{array}$ & $\begin{array}{l}\text { Not considered } \\
\text { possible } \text { s }^{3}\end{array}$ & $\begin{array}{l}\text { 6:1 Rehabilitation of } \\
\text { a coastal lagoon }\end{array}$ & $\begin{array}{l}\text { R/C not considered } \\
\text { possible ex }\end{array}$ & $\begin{array}{l}\text { R/C not considered } \\
\text { possible }\end{array}$ & Case-by-case \\
\hline $\begin{array}{l}\text { Category I } \\
\text { Bog }\end{array}$ & $\begin{array}{l}\text { Not considered } \\
\text { possible }\end{array}$ & $\begin{array}{l}\text { 6:1 Rehabilitation of } \\
\text { a bog }\end{array}$ & $\begin{array}{l}\text { R/C Not considered } \\
\text { possible } e^{23}\end{array}$ & $\begin{array}{l}\text { R/C Not considered } \\
\text { possible }\end{array}$ & Case-by-case \\
\hline $\begin{array}{l}\text { Category I } \\
\text { Estuarine }\end{array}$ & Case-by-case & $\begin{array}{l}\text { 6:1 Rehabilitation of } \\
\text { an estuarine } \\
\text { wetland }\end{array}$ & Case-by-case & Case-by-case & Case-by-case \\
\hline
\end{tabular}


Table 18: Washington’s wetland compensatory mitigation ratios (DOE et al. 2006).

\subsubsection{Temporal loss and habitat maturation}

King \& Price (2004) propose a method to develop defensible wetland mitigation ratios that considers quality and quantity of replacement wetland in relation to the impacted wetland. They recommend considering five elements in a mitigation ratio to account for different ecosystem services provided by the impacted and replacement wetland. These include:

1. existing level of function pre treatment

2. expected level of function post treatment

3. length of time before mitigation site is fully functioning

4. risk of failure,

5. and differences in landscape position of the impacted versus the mitigation wetland.

The authors critique the adequacy of 1:1 ratios by describing an unlikely scenario. A 1:1 compensation would be acceptable: if the mitigation site does not provide any wetland services prior to treatment, if each mitigation acre fully replaces wetland services associated with each acre of impacted wetland, and the mitigation site is immediately fully functioning. In place of 1:1 ratios, they propose a replacement ratio formula that is based upon the economic principle of a "net present value" formula often used for assessing traditional investments. The equation provides an incentive for undertaking mitigation pre-impact, which is reflected in the lower ratios required for advance mitigation compared to those mitigation projects undertaken concurrently or after development. An excel spreadsheet is provided with this model to automate calculations.

Ratio =

$$
\sum_{\mathrm{t}=0}^{\mathrm{T}}{ }_{\text {max }}(1+\mathrm{r})^{-1}
$$$$
(B(1-E)(1+L)-A)\left[\sum_{t=-D}^{C} \frac{(t+D)}{C(1+r)^{1}}+\sum_{C-D+1}^{T}(1+r)^{-1}\right]
$$

where:

$\mathrm{A}=\quad$ wetland function provided per acre of mitigation site pre treatment, expressed as a percentage of the per acre value of the original wetland.

$\mathrm{B}=\quad$ maximum level of wetland function per acre of mitigation site, expressed as a percentage of the per acre value of the original wetland. 


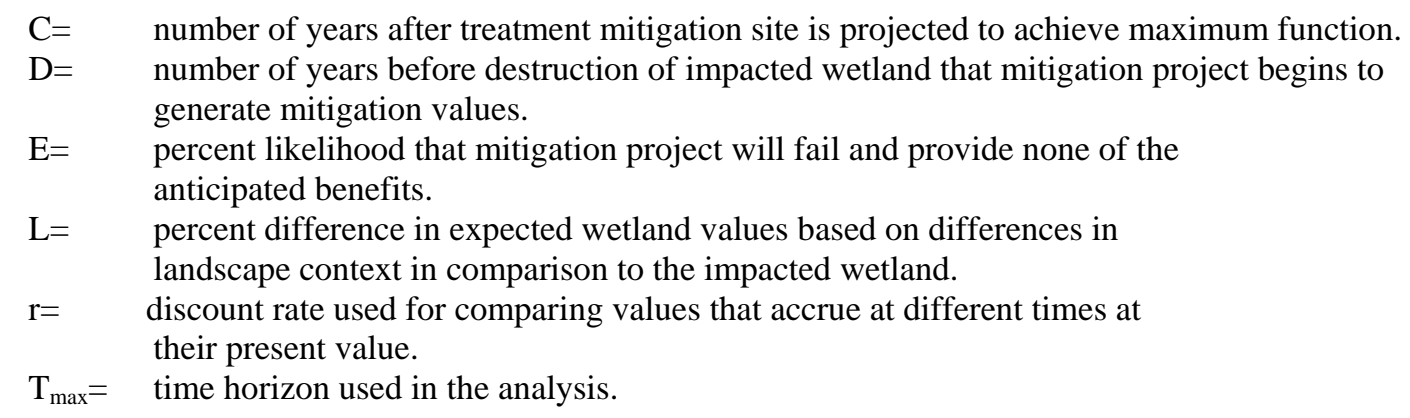

This model allows more flexibility in the determination of compensation ratios than DSLs CWM ratios. It factors in the ecological temporal loss associated with mitigation projects, a factor currently ignored by DSL's rules, and the level of function of both the impacted and mitigation wetland. The level of function is to be expressed as a percentage relative to the impacted wetland. While DSL requires functional assessments, the results are not integrated into compensation ratios.

Although King and Price’s model would incorporate function and area into a compensation ratio, the user would have to decide how to represent numerous functional scores by one variable. The HGM functional assessment, the DSL preferred method, considers about a dozen functions relative to water quality, water storage, and habitat provision for different fauna. Brinson and Rheinhardt (1996) suggest allowing a regional established priority to dictate which of the numerous functional scores to use, applying the highest functioning score, or focusing on the hydrologic functional score. This equation also requires the applicant and regulatory agency to apply his/her best professional judgment when considering risk of failure and the length of time for project to become fully functional.

Habitat Equivalency Analysis (HEA) (Dunford et al. 2003) is used to estimate appropriate amounts of compensation for losses resulting from environmental damage from oil or hazardous material spills. Although used for compensating accidents, this framework may be useful in offsetting permitted estuarine habitat impacts not addressed in the tidal HGM such as impacts to mudflats, eelgrass beds, and algal beds. This method factors in the temporal loss during project maturation and quantifies services lost with services replaced in dollars. This method values services performed on site and off site of the compensation habitat, but also quantifies the value of the site prior to mitigation treatment. 
Despite the lack of peer-reviewed literature, this method has been widely applied. In terms of wetlands application, HEA has been used to determine compensation for eelgrass impacts and marsh impacts. Similar to King and Price's model (2004), HEA uses a single measure of ecological services, an over simplification of habitats that perform numerous functions. In some cases, in-kind compensation is not possible, such as with impacts to subtidal sediments. Having a broad understanding of ecosystem needs allows such out-of-kind compensation decisions to be made. As with functional assessments, HEA stresses having an understanding of baseline conditions pre impact and recognizes that this is a static value due to daily, seasonal, and annual changes that occur naturally. As compensatory ecosystem services are offset further and further away from the impact site, it is assumed that values will change. Conversion factors are used when compensatory mitigation provides different kinds of services than the damaged site (outof-kind). Two different options are described in the HEA: same habitat type but with different level of function or quality or different habitat type and not of comparable quality. For the same habitat type with different level of function, a functional assessment could account for this by offsetting acreage with function and vice versa. For instance, if a poorly functioning 2-acre tidal wetland has high (0.8 on a scale of $0-1)$ score for providing shorebird habitat and the replacement 2 acre wetland has potential low (0.4) capacity for shorebird habitat, then maybe 4 acres of wetland should be required for replacement. Again, there is no evidence that double the amount of lower-scoring habitat replaces the functions of the higher-scoring habitat.

\subsubsection{Offsite compensation}

Traditionally, there has been a preference for onsite and in-kind mitigation in the realm of wetlands mitigation (EPA \& USACE 2/6/1990 memorandum) due to the assumption that lost functions are more likely to be replaced closest to the impact by a similar wetland type (Race and Fonseca 1996). However, this preference has resulted in the creation and enhancement of atypical, poor quality wetlands in locations where they do not receive appropriate hydrology and are often not sustainable (NRC 2001). Mitsch and Wilson (1996) report success problems with onsite mitigation due to proximity to human altered landscapes and frequent disturbance regimes such as high levels of storm water inputs, susceptibility to invasive species, and excess bacteria from pet waste (DOE 
2004). Offsite options are becoming more acceptable and sometimes encouraged if a watershed assessment has prioritized a particular function or the on-site option has a high risk of failure due to proximity to disturbance (NRC 2001). However, the implications of full-scale adoption of offsite options should be well-understood. For example, mitigation banking has recently been criticized for transfer wetland functions from urban to rural areas (Ruhl \& Salzman 2006).

In Washington (DOE 2004), onsite mitigation is preferred if the impacted function is particularly site-dependent such as water quality and quantity functions. Onsite mitigation is also required if the impact area connects to other habitats and open spaces and if the onsite location has a buffer and a high probability of success. If onsite mitigation is not sustainable, Washington's program recommends mitigation within the same portion of the drainage basin (upper, middle or lower) to maintain hydrologic function. Nearby drainage basins with similar geology may be appropriate; if there are no adequate locations within the same portion of the drainage basin. The preference is to locate the site as close to the impact site as possible. Offsite compensation would also be acceptable if the onsite impacts are to low quality or the offsite option is a bank or inlieu- fee program. These decisions are made on a case-by-case basis.

The USACE provides guidance on onsite versus offsite mitigation (NWMAP 2004a). Onsite mitigation is preferred unless the impact is small and then mitigation banking or in-lieu-fee arrangements are made. Preference can also be given to offsite if it is considered "environmentally preferable" compared to onsite options. Offsite mitigation is to occur as close to the impact site as possible and not in a different watershed due to the dependence of functions and values such as flood storage, nutrient detention, sediment filtering, and critical species habitat on location. Compensatory mitigation options should incorporate likelihood of success, ecological sustainability, practicability of monitoring and maintenance, proximity to impacts, and economic cost of onsite versus offsite. Race and Fonseca (1996) recommend against onsite mitigation in highly urbanized systems, however Ruhl and Salzman (2006) critique the transfer of wetland functions from urban area to rural areas. Watershed approaches, as described in the next chapter, are being recommended (MAP 2002; NRC 2001) for siting and prioritizing mitigation. 


\subsubsection{In-kind vs. out-of-kind compensation}

The concept of in-kind versus out-of-kind mitigation is an issue that needs to be addressed relative to estuarine compensatory mitigation. In-kind mitigation refers to the replacement of the same lost Cowardin class, HGM subclass, and/or functions performed by a permitted wetland impact. ORS 196.825(5) states that "compensatory wetland mitigation shall be limited to replacement of the functional attributes of the lost wetland", which seems to limit CWM to in-kind. However, DSL's CWM rules allow for out-ofkind mitigation if the project is considered environmentally preferable; replaces wetland functions that address problems that are identified in a watershed management plan or water quality management plan approved by a watershed council or public agency; replaces wetland types (Cowardin/HGM) and functions historically lost in the region; or replaces rare or uncommon plant communities appropriate to the region. Because almost all of the remaining estuarine habitat is protected under Goal 16 Estuary Plans, very few impacts are permitted through DSL's Removal-fill program; thus, permitted impacts to estuarine habitat will be infrequent, making in-kind mitigation infrequent, as well. The statue may need to be modified to read that CWM shall replace of functional attribute of lost wetland or functions historically lost in the region.

The breakdown of available estuarine acres zoned for development within the development estuaries (Cortright et al. 1987) is illustrated in Table 19. Deep draft development estuaries have the largest amount of acres designated for development; however only 113.2 development acres are tidal marshes. Within these development estuaries there may be a market for "in-kind" mitigation at the Cowardin System "Estuarine" level. Due to their extensive loss, the rationale could be made to mitigate any estuarine impact (e.g., impacts to mudflats), except eelgrass beds, with tidal marsh restoration. Also, to restore the historical extent of tidal wetlands within an estuary, the case could be made to compensate impacts to formerly tidal wetlands (i.e., diked) with tidal wetland mitigation. This practice could be one strategy for DSL to directly work toward Oregon's benchmark of restoring 250 acres of estuarine wetland per year.

\begin{tabular}{|c|c|c|c|}
\hline Estuary & $\begin{array}{c}\text { Zoned for } \\
\text { Dev't (ac.) }\end{array}$ & $\begin{array}{c}\text { Tidal Marsh Zoned } \\
\text { for Dev't (ac.) }\end{array}$ & $\begin{array}{c}\text { Zoned } \\
\text { Mitigation (ac.) }\end{array}$ \\
\hline Columbia River & 2970.3 & 16.6 & 244 \\
\hline Yaquina Bay & 1011.2 & 3.4 & 625.5 \\
\hline
\end{tabular}




\begin{tabular}{|c|c|c|c|} 
Coos Bay & 2556.4 & 38.5 & 206.4 \\
\hline Nehalem & 186.7 & 26.1 & 88.3 \\
\hline Tillamook & 132.9 & 0 & 42 \\
\hline Siuslaw & 108.9 & 5.4 & 58 \\
\hline Umpqua & 1146 & 22.6 & 93.1 \\
\hline Coquille & 115.8 & 0.6 & 55.2 \\
\hline Rogue & 121.6 & 0 & $?$ \\
\hline Chetco & 55.6 & 0 & 0 \\
\hline
\end{tabular}

Table 19: Estuarine habit and tidal marsh habitat zoned for development and acres zoned for mitigation in Oregon's estuaries (Cortright et al. 1987).

As a standard practice at DSL, permitted estuarine impacts are generally not compensated with non-tidal habitat due to their historical loss and highly valued functions, including importance to juvenile salmon. Similarly, federal guidance under section 404 recommends not compensating tidal wetland impacts with non-tidal wetlands, but recommends against the reverse as well (NWMAP 2004a). But then, as a general statement, the USACE guidance and DSL's CWM rules allow out-of-kind when it provides more watershed benefits than in-kind.

Washington's wetland mitigation program prefers in-kind compensation when it will provide the greatest ecological benefits for the landscape (DOE 2004). In-kind compensation is required if the affected wetlands and functions are high quality; limited or rare within a watershed; the affected functions are integral to the maintenance of environmental processes: or the wetland type supports sensitive or listed species. Because estuarine wetlands provide important habitat for threatened and endangered species and have experienced extensive losses, Washington accepts the restoration of estuarine wetlands as compensation for freshwater wetland losses. Out-of-kind mitigation is also accepted if the impact wetland is dominated by Phalaris arundinaceae or other invasive species. Additionally, out-of-kind type is acceptable if the impacted wetland type and function is found in abundance in the landscape or the proposed out-ofkind is limited in the landscape. Finally, out-of-kind mitigation is accepted when the impacted wetland is impossible to replace. A handful of questions are provided to help guide the appropriateness of out-of-kind decisions:

-What functions, habitat types, or species are being affected and are they vital to the watershed?

-What are the priority species, habitat types, or functions important to restore the watershed?

-How will the proposed compensatory mitigation maintain, protect, or 
enhance impaired functions of a watershed?

-Will the proposed compensatory mitigation have a high likelihood of

success and be sustainable given anticipated future land uses?

\subsubsection{Out-of-kind as applied to Oregon's estuarine wetlands}

Due to significant historical losses and the provision of rearing habitat for dwindling salmon populations by estuarine wetlands, DSL's CWM rules already provide the legal authority to allow the compensation of non-tidal habitat with estuarine tidal wetlands. Every coastal watershed with the exception of the Necanicum, Netarts, and Sand Lake has lost over $41 \%$ of its estuarine wetlands and in the case of the Coquille, Nestucca, Tillamook, and the Yaquina, over 70\% has been lost (Good 2000). These significant historical estuarine wetland losses could make the case for out-of-kind mitigation for every coastal permit with non-tidal impacts.

However, mitigation, unlike voluntary restoration, involves tradeoffs, which requires a full understanding of what is being lost and what is being gained. What the rules do not explicitly address are what functions, habitat types, or species are being affected at the impact site and how would the losses affect these functions and values on a watershed level? To address this concern, parameters could be set by rule to limit outof-kind mitigation. If the impact site does not provide a regionally important function, is poorly functioning as demonstrated with a functional assessment, does not represent a rare habitat, does not support threatened and endangered species, is not a bog, fen, vernal pool, forested wetland, or other Special Area of Concern as designated by ORNHIC, then out-of-kind mitigation could be acceptable.

If the in-kind option has the potential to result in an undesirable aquatic habitat that is dominated by non-native invasive species, out-of-kind is preferred (USACE guidance 2004). For example, Phalaris arundinaceae is a nuisance weed that is ubiquitous in many disturbed wetlands in Oregon. If the in-kind site option is bordered by or down stream from this invasive, the likelihood is high that the mitigation site will also become invaded. This weed is very adaptable and able to withstand varying hydroperiods, however, it is not a halophyte and does not persist in brackish or saline conditions. Based on this reasoning, the argument could be made for tidal marsh 
restoration as CWM for impacts to a palustrine emergent wetland type that is both common on the landscape and highly disturbed.

Another factor to consider is the level of difficulty to replace the impacted habitat. Studies have shown relatively good success with restoration of tidal habitat such at tidal marshes and seagrasses, largely due to the predictability of hydrology (Kusler and Kentula 1990; Fonseca et al.1998; Frenkel \& Morlan 1991) and therefore such tidal marsh restoration could be considered environmentally preferable. However, some habitats are difficult to replace, such as bogs, fens, and forested swamps, and under current CWM rules conservation in lieu is recommended. However, if these wetlands are rare, then no impact should be permitted in the first place.

Replacement of scarce functions relative to common functions is another criterion for an out-of-kind preference. Tiner (2005) describes a methodology developed by the USFWS for enhancing NWI data to understand what functions have been significantly lost from the landscape. The goal was to produce a pre-settlement and a contemporary map showing the distribution of wetlands, produce a functional assessment for each time period, and compare the changes in wetland extent and functions for the Nanticoke Watershed, a tributary of the Chesapeake Bay. Pre-settlement wetlands were identified using soil survey data and USGS orthophotomaps $(1: 24,000)$ and then classified into Cowardin class. The contemporary dataset used was the 1998 NWI. Descriptors for landscape position, landform, water flow path, and water body type were added to the pre-settlement and contemporary NWI digital database to create enhanced NWI classifications. The descriptors were correlated to wetland functions using a landscapelevel wetland assessment approach known as the "Watershed-based preliminary assessment of wetland functions” or W-PAWF. W-PAWF was based upon scientific literature on wetland ecology and the expert opinion of wetland biologists. A watershed profile was produced that highlights wetlands of potential significance for 10 functions including surface-water detention, stream flow maintenance, nutrient transformation, sediment/particle retention, coastal storm-surge detention, shoreline stabilization, provision of fish and wildlife habitat, provision of other wildlife habitat, and conservation of biodiversity. GIS-based maps depicting the area of functionally significant wetlands for the two time periods were generated. The cumulative loss of wetlands for specific 
functions was determined by the change in area. Wetlands were weighted depending upon a high or moderate level of function for each function. The functional assessment for each time period revealed a $50 \%$ area loss of wetlands important for sediment retention, $23 \%$ loss of wetlands stabilizing shorelines, and $87 \%$ loss of stream flow maintenance. Change in functional capacity was also calculated; revealing a 50 to $77 \%$ loss of original capacity with only $36 \%$ of original capacity for stream flow maintenance. Although this analysis provides a gross estimate of pre-settlement wetland extent and function, the results of Tiner's (2005) analysis can provide a preliminary understanding of what functions are "scarce" throughout the landscape, inform restoration priorities, and guide out-of-kind mitigation decisions.

Currently, a different HGM subclass is considered out-of-kind for CWM. The rationale for preferring in-kind mitigation is to maintain overall wetland functions within some unit of landscape, usually a watershed. However, assuming that wetland functions can be replaced through CWM, a preference for in-kind mitigation will not result in holistic ecological restoration if a certain wetland type was disproportionately lost prewetlands regulations. As illustrated previously, tidal marshes are an example of wetland types and functions that have been disproportionately altered. However, without status and trends studies, it is difficult to know if other coastal wetland types and functions have been disproportionately lost. Therefore, adopting an out-of-kind compensation policy in which nonestuarine wetland impacts are mitigated with estuarine wetlands should be implemented with caution and in conjunction with inventories and other statewide priorities. The Oregon coastal wetland status and trends study scheduled for release in fall 2006 may shed some light on the out-of-kind policy question.

The argument could be made that compensating non-tidal impacts with estuarine habitat goes against the 'no-net-loss of wetlands' policy if the mitigation site is former estuarine habitat that already meets wetland criteria, albeit degraded. Giving mitigation credit for restoring tidal influence would result in a permitted overall loss of wetland acres. Conversely, important estuarine function could be gained from this mitigation site. The 'tradeoff' may be more justified if the impact site was poorly functioning and/or common in the landscape. 


\subsubsection{Mitigation banking}

Interest in mitigation banking has grown rapidly over the past decade with $30 \%$ of compensatory mitigation activity now involving mitigation banking, nationally (Morlan, pers. comm. 03/20/06). Banks provide an offsite alternative for small impacts that may be difficult to mitigate at the development site and, due to the small size and location, may not be ecologically beneficial. Landscape ecology's theory of island biogeography supports that there is a direct relationship between patch size and species richness (Turner et al. 2001). Since they consolidate mitigation for several small wetland losses and provide mitigation prior to the permitted impact minimizing temporal losses, some would argue that banks are ecologically superior and others would argue that they remove important wetland functions from urban areas to rural areas (Ruhl \& Salzman 2006). More time and data is needed to accurately assess the merits of banking versus other forms of compensatory mitigation. In the interim, proposals for mitigation banks are carefully reviewed for their ecological feasibility by an interagency committee, the Mitigation Bank Review Team (MBRT) and, if approved, credits are not released until specific ecological performance criteria are met.

Banks are only approved in regions that demonstrate a need as indicated by Removal-fill permit activity. Generally, service areas for banks are based upon watershed or other ecologically significant boundaries. According to DSL's Wetland Mitigation Banking guidebook for Oregon (2000), Removal-fill permitting activity needs to be occurring within 10 to 15 miles of the bank site in order to be considered a need. Furthermore, as with onsite mitigation, the bank must provide wetland types and functions similar to those anticipated to be lost due to permitted filling. Therefore, bank proposals not only need to demonstrate that Removal-fill activity is happening nearby but wetland functions that are being impacted can be replaced by the bank.

Although there are some advantages to banks, some ecological limitations of banks exist. For one, certain wetland functions are very site-specific, such as nutrient removal, and the opportunity for the wetland to perform that function is dependent upon landscape position and adjacent land uses (Crooks \& Ledoux 1999). The ability of a wetland to buffer against floodwaters is also dependent upon watershed location. Also, 
without a regional restoration strategy for mitigation, banking may result in loss of wetland diversity (Bedford 1996).

Banking in Oregon

Oregon's first mitigation bank was established in 1987 by the Port of Astoria in Young's Bay near the Astoria Airport (Jackson 1991). The goal of the bank was to restore 33.8 acres of pasture to tidal marsh and swamp habitat. A total of 89.9 mitigation credits were granted for 11 acres of brackish marsh, 16.3 acres of brackish swamp, and 2 acres of estuarine channel that could be used in exchange for estuarine impacts in the Columbia River Estuary. Credits were calculated using the relative habitat values provided in the ERR rules. All of these credits have since been sold and it is unknown what the net functional tradeoffs are as a result of this bank. However, a fifth year monitoring report by Jackson (1989) states that "The creation of a tidal marsh is not indicated by the observations of the survey”, but “ ...a freshwater wetland with very little tidal influence is developing at the Astoria Mitigation Bank.”

Although the first mitigation bank was on the north coast, most banking activity is occurring in the Willamette Valley where the majority of urban and suburban development and thus Removal-fill permitting is occurring. However, as Oregon's coastal economy moves away from natural resource extraction to recreation, tourism, and retirement industries, land use needs may change as well (Huppert et al. 2003). Tidal marshes diked and converted for agricultural purposes may no longer be an economically viable land use. With the average price of credit sales at $\$ 50,000$ per acre, landowners may consider mitigation banking as an alternative income-generating source. Also, in light of Oregon’s Measure 37 passed in 2005, the property compensation measure, landowners may be interested in applying for a land use exemption to develop agriculturally-zoned lands for residential or commercial purposes. The potential impact of this measure on Removal-fill activity in estuaries is yet to be determined.

As described previously, the Oregon Estuary Plan Book (Cortright et al. 1987) illustrates estuary management plans per estuary. Only $6.4 \%$ or $8,405.4$ acres of Oregon's estuaries are within development management units. There are 2,970.3 acres of estuarine habitat designated for development in the Columbia River, of which only 16.6 acres are tidal marsh. The other two deep draft development estuaries, Coos Bay (38.5 
acres of tidal marsh) and Yaquina (3.4 acres of tidal marsh), have 2,556.4 acres and 1011.2 acres zoned for development, respectively. Assuming there is an economic demand for developing these areas zoned for development, mitigation banks may be appropriate for these estuaries. Currently, a handful of Liquified Natural Gas plants are being proposed along the Columbia River Estuary. Two sites are being proposed for Warrenton, another on the Columbia at Bradwood, Knappa, and one near Clatskanie. However, the Bradwood plant is furthest along in its application to the Federal Energy Regulatory Commission, but it is too early to tell how many estuarine and non-tidal wetland impacts will be associated with the terminals and pipeline development for the plant.

Both Astoria's and Newport's airports are experiencing growth with the addition of Cape Air Airlines and possibly Big Sky airlines (The Daily Astorian 2/15/06). The Port of Astoria has received Federal Aviation Administration funds to add additional hangars at the airport. Furthermore, Astoria’s economy is changing from a resource extraction-based to more of a tourist-based economy. These development trends that may impact estuarine and formerly estuarine habitat may suggest the need for a mitigation bank in deep development estuaries, assuming impacts will be to estuarine habitat. The need for banks may not exist for shallow draft estuaries and, certainly, not for conservation or natural estuaries. Shallow draft estuary channels are dredged to a depth of 22 feet or less, while deep draft estuaries are dredged to a depth of greater than 22 feet.

Due to strong protections, the demand for estuarine replacement habitat is low, unless out-of-kind mitigation is permitted. The same conditions for determining the appropriateness of individual permits opting for out-of-kind mitigation should apply for mitigation banks that will sell a majority of out-of-kind credits. Since banks will account for numerous to hundreds of acres of future impacts, the ecological benefit for offering out-of-kind credits should be deliberated with even more caution.

The Siuslaw estuary provides a good case example. The MBRT is considering a mitigation bank proposal for an approximate 200-acre marsh in the Siuslaw River Estuary, seven river miles upstream from the Pacific Ocean in Cushman, Oregon. According to Good (2000), the Siuslaw Estuary has lost 63\% of its tidal wetlands and 
$29 \%$ of the entire estuary. Brophy (2005a) estimates a $67 \%$ loss of estuarine wetlands of which a quarter are actively being restored. Scranton (2004) delineated remaining tidal wetlands into tidal HGM subclasses with 22.67\% Marine Source Low, 6.39\% Marine Source High, and 4.62\% River Source. Over 23\% of the estuary was mapped as Restoration Consideration Area (RCA) including a 63-acre portion of the proposed mitigation bank (Scranton 2004). The RCAs for the bank proposal are the yellow areas pictured in Figure 14. Restoration Consideration Areas are areas that are diked or partially filled for agriculture or commercial purposes that are potential candidates for restoration of tidal circulation based review of geotechnical digital data only (no on-site feasibility was undertaken). Based upon Scranton (2004), less than one-third of the total proposed bank area is considered a RCA. 

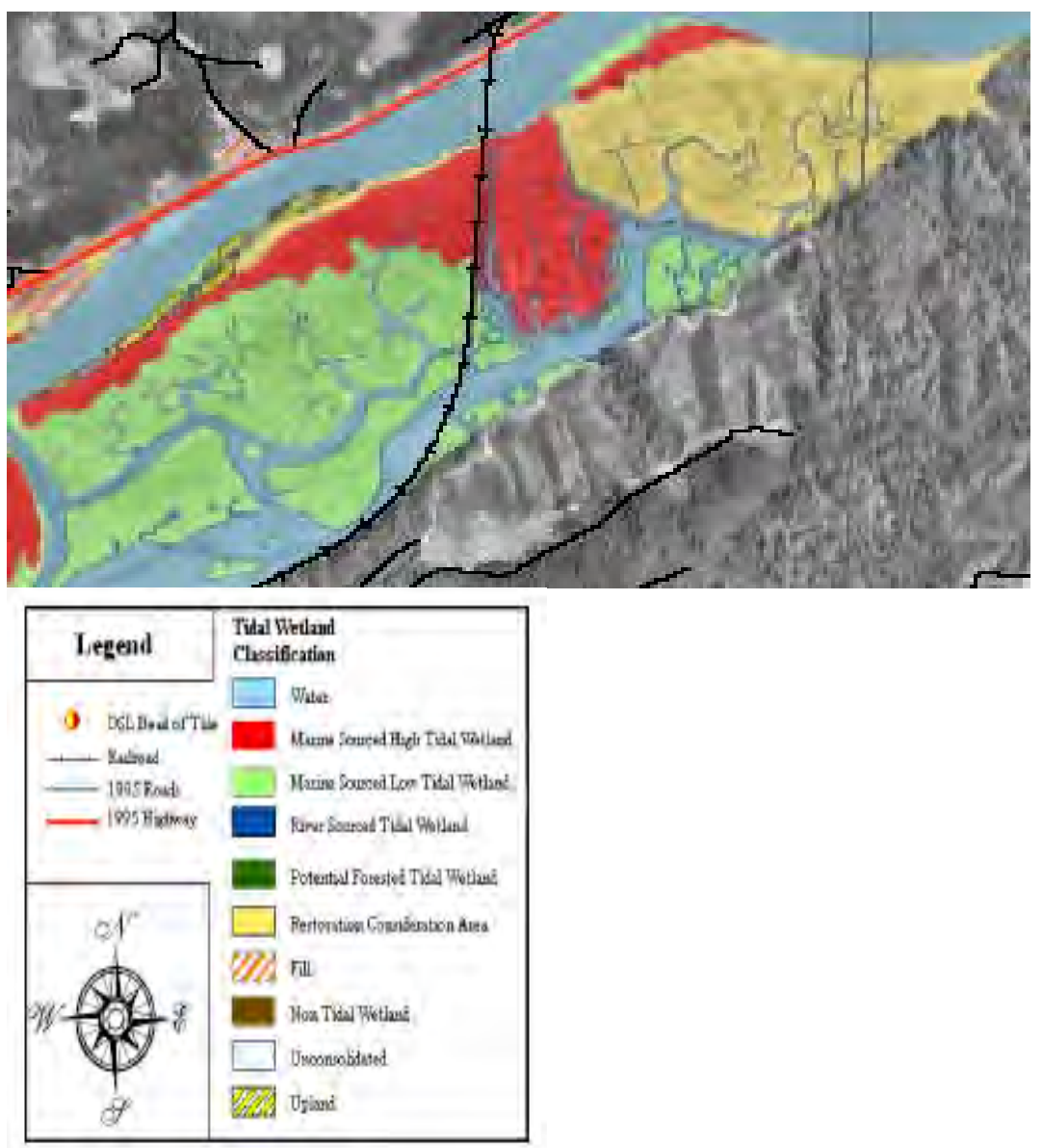

Figure 14: Restoration Consideration Areas (RCA) in yellow within proposed Siuslaw Bank (Scranton 2004).

Estuarine restoration priorities were established in the Siuslaw Basin (Brophy 2005a). Tidal shrub and forested wetlands were considered high priorities due to significant (97\%) historical losses. The Siuslaw once supported the fourth largest aerial extent of tidal spruce swamp along Oregon's coast. Protection of remaining estuarine wetland sites was mentioned as the top priority, which makes a case for conservation in lieu for tidal spruce swamps. Certainly within the estuary, tidal wetlands and their associated goods and services have been lost from the estuarine landscape.

The portion of the proposed mitigation bank east of the railroad tracks (Figure xx) was prioritized for 'conservation' (Brophy 2005), since it is the second largest undisturbed tidal marsh in the Siuslaw. The diked-portion on the east side of the railroad was identified as a medium-high restoration site (ranked $20^{\text {th }}$ out of 70,1 being the highest priority) based upon a combination of factors including size, tidal channel condition, connection to adjacent wetlands, current vegetation diversity, and potential to support salmonid diversity. The restorative activity would be dike breaching and potentially remeandering the straightened tidal channels. Based upon both Scranton (2004) and Brophy (2005), the eastern portion of the proposed mitigation bank is a medium-high priority for restoration, while the western portion is a good candidate for conservation. Based upon ecological priorities within the estuary, a mitigation bank may be appropriate only for the eastern portion of the proposed bank and a narrow strip along the northwest part of the proposed bank.

Incidentally, a portion of another site that was zoned for mitigation, since it was a former dredged material disposal site, in the Siuslaw estuary plan is currently a functioning tidal marsh and would not be a suitable mitigation site, but many other sites were 
identified and prioritized for restoration that would make more appropriate candidates for mitigation. Based upon Brophy's prioritization, sites zoned for mitigation in the estuary plans may need to be reassessed to reflect current conditions and to incorporate up-to-date restoration priorities.

Beyond the estuary, priorities need to be established at a larger landscape scale to understand the needs of the entire ecosystem and to guide out-of-kind decisions. Watershed priorities (Ecotrust 2002) were established for the Siuslaw river and estuary by the Siuslaw

Watershed Council. Due to the Siuslaw watershed's low water storage ability, valley bottom forested wetlands historically provided important flood storage during the winter and augmented summer base flows. Digital NWI maps were only available for the estuary-part of the watershed council's assessment (Ecotrust 2002), so current wetland distribution and historical losses in the upper part of the watershed were estimated to be significant, comparable to the Willamette Valley wetland losses, which were estimated to be $57 \%$ of historical wetland distribution (Morlan 2000). Within 200' on either side of the river, the riparian zone was estimated to be only 36\% forested and the extent of riverine wetland loss is unknown, but estimated to be significant in agricultural areas. While lower valley, low gradient aquatic habitat has experienced the greatest impacts, the mid to upper regions are more intact. The strategies recommended for restoring the Siuslaw Watershed were to first acquire secure and protect the best habitat through acquisition and then focus on restoring (in the general sense) the more degraded habitat (Ecotrust 2002). Compensatory mitigation through PTP funds or banks could help to finance the restoration needs of the more heavily degraded lowland wetlands. In terms of coho restoration, this inventory argues that the best present habitat lies in the somewhat confined low to moderate gradient stream areas since the lower valleys have significant challenges to habitat restoration such as high water temperatures and high flows.

Based upon the Ecotrust watershed assessment, priorities were primarily for land acquisition for mid- to upper-gradient habitats and secondarily for restoration of lower valley wetland habitat for flood storage. The tidal HGM does not identify flood storage as one of the primary functions of Oregon's tidal wetlands. The proposed mitigation bank near Cushman would restore the HGM subclass, Marine Sourced Low and High Marsh, which would provide little, if any, flood storage. 
Also, a large portion of this proposed bank site is in relatively good ecological shape (Brophy 2005), but would not meet federal requirements for conservation in lieu mitigation since it is not at risk for development. The site is too wet to farm, does not support much woody vegetation so would not support timber production, and would require extensive levee construction and maintenance to support any residential or commercial development. Due to extensive logging and drift removal in the Siuslaw, placement of LWD was identified as a possible restoration measure (Brophy 2005). Enhancement through spruce plantings and addition of LWD to the marsh surface and tidal channels is proposed for this portion of the site. Functional lift would mostly occur for fish and piscivorous birds, but little to no improvements would be made for other functions. With increased development and increased impervious surface within Florence and Dunes City, water quality and water storage are at least two functions that will become increasingly important. Allowing impacts to wetlands that may perform these functions that would not be replaced by an upstream estuarine mitigation bank may be shortsighted. Since the watershed council did not identify specific wetland habitats that were identified to provide flood storage, it is unclear which sites they are targeting.

Economic trends must also be considered when approving a mitigation bank. The market for the bank will come primarily from development-related impacts in Dunes City and Florence, located near the mouth of the Siuslaw. Florence experienced a $40.4 \%$ population growth from 1990 to 2000 census (Cai 2005). The Siuslaw is designated as a shallow development estuary, allowing for a range of uses.

Based upon current population trends, there may be economic demand for a mitigation bank, but for different HGM/Cowardin classes. The LWIs for both Dunes City and Florence reveal common wetland types of palustrine forested (PFO), palustrine scrub shrub (PSS) and/or palustrine emergent (PEM). Therefore, a majority of the potential permitted wetland impacts will be to nonestuarine wetlands and thus, in order to replace lost function, compensatory mitigation projects will involve these wetland types.

Little research has focused on the current and historical distribution and ecological significance of Oregon's coastal non-tidal wetland habitat types and, consequently, they have little protection, outside the Removal-fill Program, the Clean Water Act (Larsen 2005), and the Goal 5 and 17 significant wetland status. In terms of 
the ecological significance of the freshwater wetland types common to the Florence and Dunes City region, the Washington Department of Ecology (Hruby 2004) reports that isolated wetlands provide the same range of functions as non-isolated wetlands and provide water quantity, water quality and habitat functions. Small wetlands are considered important to reducing the distance between wetlands and making species dispersal more successful. Furthermore, small wetlands provide habitat for some species including amphibians that are not found in larger wetlands. A mitigation bank that contains these HGM/Cowardin classes would probably be more appropriate than a mitigation bank of estuarine intertidal emergent habitats to respond to future impacts.

In summary, from an ecological perspective a portion of the proposed bank has been identified as a medium-high priority restoration site, but about half of the bank is relatively unaltered. Additionally, a majority of the bank already meets wetland criteria, so approval of this bank would result in a net loss of wetland acreage. Without a wetland change study for the entire watershed and a complete understanding of non-tidal wetland function within this basin that would be sacrificed as a result of this bank, this out-of-kind mitigation decision does not seem prudent. Even with a better understanding of the freshwater wetlands that would be implicated by the proposed bank, only impacts to low functioning wetlands should be eligible for purchasing credits from a hypothetical estuarine mitigation bank credits. If information on the freshwater wetlands were available and a bank was approved, bank credits should only be available for the 63-acre, diked-portion of the proposed bank and not the relatively unaltered western portion.

Voluntary land acquisition and restoration efforts by groups such as Oregon Habitat Joint Venture may be a more appropriate strategy for gaining back disproportionately lost tidal wetland habitat. Joint Venture (1994) has identified freshwater and tidal wetland needs for Lane County, which include specific land acquisition and restoration needs relative to bird habitat.

If a watershed approach identified tidal wetlands as priorities for a particular watershed and an estuarine mitigation bank was approved, the next challenge is to determine how to credit and debit credits from the bank. Credits are determined per bank. Generally, credits are calculated based upon the CWM ratios; however, functional assessments can be used to determine credits by quantifying 'ecological lift' in function 
due to mitigation treatment. The preferred functional assessment is the HGM, but there is currently no easy way to translate between HGM classes. Furthermore, there are only two HGM assessment methods in Oregon. Other functional assessments could be used. However, the need still exists to translate those functional assessments into a common currency that can relate credits at the bank to debits at the impact site. The same assessment system would need to be used for the credits as well as the debits. A rating system, similar to Washington's, could be developed in which the impact site's functional characteristics would dictate the ratio requirements.

\subsubsection{Conservation in lieu}

Federal guidance on preservation as compensatory mitigation under section 404 of the Clean Water Act (NWMAP 2004b) offers guidance on when it's the sole compensation method and when it's a component of the mitigation plan. In the first scenario, wetland habitats that are under a demonstrable threat and perform regionally important physical, chemical, and biological functions can utilize the conservation in lieu option. As described previously, estuarine habitat is well-protected under the Oregon Coastal Management Program and mostly state-owned below mean high tide. High marsh and tidal spruce wetlands are generally found above mean high tide and, thus, are generally in private ownership, but still subject to the Removal-fill law. While most high marsh has been converted to agricultural purposes and has potential restoration needs if used for compensatory mitigation, any remaining intact tidal spruce swamp that is not already protected by current zoning should be eligible for conservation-in- lieu due to its rarity. Unless current land use laws are radically altered by Measure 37 and by the recommendations of the Governor's land use task force, the Big Look, a demonstrable direct threat does not exist for other estuarine habitat, as required by the federal framework for this mitigation option. Conservation in lieu as a component of a mitigation plan may be justified for estuarine habitat. For example, upland habitat adjacent to a proposed estuarine marsh restoration site could be offered as conservation in lieu, especially if areas around the proposed marsh have experienced an increase in development and associated impervious surface that may pose stormwater runoff issues to the marsh. 
DSL allows conservation in-lieu for difficult to replace wetlands such as bogs, fens, and vernal pools, but does not require a demonstrable threat to exist. As an aside, if DSL wants to assume the entire 404 program from the EPA, the conservation in lieu program may need to be expanded to include habitats experiencing a demonstrable threat. Based upon documented national and regional success with restoring estuarine marsh, eelgrass, and mudflat habitat, the only habitat that would be considered difficult to replace would be forested estuarine wetland such as tidal spruce. Due to its significant loss and length of time required to achieve fully functioning tidal spruce habitat, this habitat should be eligible for conservation in lieu depending upon the characteristics of the impact site and if the site is not currently protected by another mechanism. Even though conservation in lieu represents a net loss of wetland habitat, the benefit of conservation in lieu is that there is no temporal loss as the site matures and no risk of failure (Chapman \& Julius 2005).

\subsubsection{Payment to provide}

Under DSL's CWM rules, Payment to Provide (PTP) funds are automatically accepted for minor impacts to wetlands (less than 0.2 acres) if no mitigation bank exists in the area. By law, cost is based upon the average cost of mitigation bank credits, currently $\$ 60,000 /$ acre. The standard operating procedure is to not allow PTP funds to offset estuarine impacts, although this was allowed for two of the permits reviewed in this inventory (31744 RF and 16086 FP). The rules do not prevent PTP for estuarine impacts, although the current thinking is not to allow it. PTP funds are made available for to nonprofit groups and agency to perform wetland restoration. The motivation for voluntary restoration is different than the motivation behind compensatory mitigation. While voluntary restoration efforts are undertaken to achieve a net gain in wetlands habitat for ecological purposes, compensatory mitigation is undertaken as a permit condition for impacting a wetland. It is easy to assume that with voluntary, there is a greater commitment to the success of the project and it is more effective ecologically. If this were the case, all compensatory mitigation could be in the form of PTP and then used to restore the aquatic system functional needs of the landscape. However, voluntary restoration programs also have constraints on siting projects (i.e., willing landowners) 
and also struggle to secure funds for project monitoring. OWEB recently developed an effectiveness monitoring program for watershed councils’ restoration projects. There is no specified time period for monitoring voluntary restoration sites, while with compensatory mitigation, monitoring is required by rule for 5 years. Five years is usually not long enough to achieve ecological success, but this may be more monitoring than voluntary restoration projects are able to do, as restoration grants generally do not cover monitoring costs.

As with many PTP programs, DSL's has not adequately tracked how funds have been used to replace wetland losses. DSL is in the process of improving the program in terms of tracking the funds and matching impacts to projects to help guide how the funds are used; the application process for receiving PTP funds for restoration/enhancement projects; and the level of monitoring and reporting that should be required after the money is awarded. The PTP option should be available for estuarine impacts, as it is for non-tidal impacts. PTP has good potential to help with the net gain of the estuarine wetland goal, if the program can be used for out-of-kind CWM for non-tidal impacts. Groups applying for these funds should be held to the same standards as for CWM projects in which the ecological rationale for the restoration decision is provided within the context of a landscape-based plan, a functional assessment is provided before and after the restorative treatment, and specific and appropriate goals, objectives, and success criteria are developed. As with all mitigation sites, monitoring and long-term protection for the site should also be provided. However, at the time of this writing, the USACOE/EPA are developing a mitigation rule that may greatly restrict PTP due to accountability and other concerns.

Summary Recommendations

In summary, the ERR regulations should be replaced with the more sophisticated CWM rules. The relative values table would be replaced with the tidal HGM functional assessment method. All impacts to formerly estuarine wetlands should be compensated with estuarine habitat. The application of the tidal HGM will be limited in its use for restoration projects but can help design CWM plans and track ecological lift at mitigation sites. If a component of a restoration project, enhancement credit should be given for the addition of LWD to marsh surface and tidal channels and re-establishment of historical tidal channels. More research is needed to understand the ecological lift of culvert enlargement, partial dike breaches, and tidegate replacement. The South Slough National Estuarine Research Reserve should address some of these research needs.

All estuarine impacts should be compensated with estuarine fringe wetland due to historical loss. Out-of-kind mitigation (i.e., Estuarine fringe for Palustrine) should be allowed if the impact site is a low functioning wetland. CWM program needs to develop a methodology for incorporating function more predictably and systematically into the current ratios. One option for doing this is to develop a rating system similar to Washington's and higher quality wetland sites would require higher ratios, which would result in a disincentive for impacting these wetlands. Temporal loss should also be incorporated into mitigation ratios. Short of an HGM method for each ecoregion, the ORWAP method (under development) would allow for a standard statewide method for assessing wetlands that could be used to rate wetland types and also help guide compensatory mitigation decisions. Mitigation banking for estuarine habitat does not seem appropriate in estuaries that are not experiencing estuarine impacts, particularly in the absence of an overall ecosystem restoration strategy, which would identify the functional needs of the estuary as well as the watershed. If an ecosystem restoration strategy is available, an estuarine bank may be warranted assuming the bank site is in need of restoration. Deep draft development estuaries may be appropriate locations for estuarine mitigation banks. Conservation in lieu should be allowed for tidal spruce wetlands and other rare types per ONHP that do not already have 
protective status. Payment to provide should be allowed for small impacts to estuarine habitat when this program has developed more rigorous requirements akin to the CWM program. 


\section{CHAPTER 6}

TAKING A WATERSHED APPROACH TO ESTUARINE MITIGATION

\subsection{Introduction}

In response to the growing concern about the effectiveness of wetland compensatory mitigation as required under Section 404 of the Clean Water Act (NRC 2001), an interagency group of federal agencies, including USACE, EPA, NOAA, USFWS and NRCS, released the National Wetlands Mitigation Action Plan (MAP) on December 26, 2002 (NWMAP 2002). The MAP “encourages the placement of mitigation where it would have the greatest benefit and probability for long-term sustainability” (ELI 2004). One of the 17 tasks outlined by the MAP was integration of mitigation into a watershed context. This recommendation could inform DSL's Estuarine Resource Replacement program, as well as benefit the entire Removal-fill Program, especially since a long-term goal is to assume the authority of implementing the federal 404 program from EPA. In January 2006, under a State Programmatic General Permit from the USACE, DSL was granted partial Section 404 permitting authority. The scientific rationale for a watershed approach is summarized below. Examples of how other states have incorporated mitigation into a watershed approach are provided, followed by the identification of Oregon's resources that are currently available and those needing to be developed to achieve such an approach.

\subsection{Call for a Watershed Approach}

Compensatory mitigation has reduced the diversity of wetland types across the landscape. Naturally occurring wetland types are extremely diverse, yet compensatory wetland mitigation projects tend to involve few wetland types (Bedford 1996), usually palustrine emergent types resulting in the "ring around the pond" design described by Kentula et al. (1992). Because wetland occurrence is largely dictated by hydrologic source, flow direction, and landscape position (Brinson 1993), the practice of restoring or 
creating wetlands at a particular site needs to consider such factors. Also, cumulative effects of wetland impacts and corresponding mitigation must be understood at the landscape level (Tanner 1990). Bedford (1996) suggests considering mitigation decisions within watershed, ecoregion, and political boundary contexts by setting mitigation goals within landscape boundaries. In addition to different spatial scales, temporal scales need to be considered, such as historical wetland distribution and future development plans (ELI 2004). Foote-Smith (1996) recognizes that appropriate landscape units vary per wetland function. While the "function-shed" of mammals and birds will be beyond watershed boundaries, water quality and flood storage "functionsheds" operate within watershed units. The "function-sheds" of salmonids can be quite large, involving all types of aquatic habitat such wetlands, lakes, rivers, estuaries, and marine habitat. Individual mitigation decisions should then be made within appropriate landscape units consistent with established goals. These goals should at the very least require that mitigation wetlands be appropriately placed hydrogeologically so that they are self-maintained and support or re-establish wetland diversity within a landscape setting.

Bedford (1996) recommends the creation of wetland landscape profiles using the HGM classification system with some regional refinements. Wetland landscape goals and profiles can be used as the basis for determining "hydrologic equivalence” into compensatory wetland mitigation. Approval of a permit to impact a wetland would only be possible if a hydrologically equivalent mitigation site was available.

Landscape ecology theory supports the idea that landscape form landscape dictates how the system functions (Turner et al. 2001). Elements on the landscape interact with one another. The matrix is the dominant element of a landscape, while patches are elements connected by corridors that are found throughout the matrix. In light of advances in landscape ecology, consideration of the wetland to be restored within the landscape context is recommended (Wolanski et al. 2004; Weinstein et al. 2005). A landscape context is important to wetland functions and values such as flood storage, flood conveyance, fisheries, waterfowl, song bird habitat, mammal habitat, reptile and amphibian habitat, recreational uses, and pollution prevention and control (Kusler 2003). 
Using concepts of landscape ecology, Tanner (1990) introduced an estuarine-wide mitigation plan as an alternative to the permit-by-permit consideration for the Duwamish Estuary in the Puget Sound. Mitigation sites were chosen based not only on the degraded state of the wetland unit, but how these wetland patches were connected to one another through corridors, as well as how those wetlands were connected to upland habitat. Riparian buffers were considered particularly important for minimizing the affects of human land use on the restored wetland.

Zedler (1996) recognized the need to adopt a regional restoration strategy in southern California, where only $15 \%$ of historical coastal intertidal wetlands remain and few mitigation options are available due to intense development. While coastal development along Oregon's coast is much less intense than southern California, Oregon has an opportunity to learn from their experience and implement proactive approaches. A regional restoration plan would include a characterization of the existing resource base, identification of unique characteristics, establishment of regional biodiversity goals, identification of appropriate restoration and enhancement sites and procedures, identification of proposed mitigation needs, match mitigation needs with restoration opportunities in-kind first and out-of-kind second based upon regional priorities, and monitor mitigation and apply adaptive management.

A watershed approach looking at riverine and estuarine wetland restoration opportunities makes sense for salmon restoration. Salmonids need a mosaic of habitats throughout their life-stages in headwater streams, lowland rivers, and estuaries (IMST 2005). Unconstrained lowland habitat have the greatest abundance of salmon due to the presence of habitat diversity such as side channels, lakes, backwaters, sloughs and beaver ponds (IMST 2005 cites Benda et al. 2002, Reeves et al. 1998, Burnett 2001, Sharma \& Hilborn 2001). These habitats are used for rearing and migration. Research has shown that healthy smolt production (ultimately population recovery) is dependent upon adequate rearing habitat in lower elevation streams, valleys and estuaries (Bradford et al. 2000). Also, historically, juvenile coho depended upon slow water habitat during the winter along the coast range (Lichatowich 1989). Additionally, a study by Pess et al. (2001) documented low-gradient stream channels adjacent to wetlands as the most productive coho spawning habitats. Wintering habitat availability has been thought to 
limit coho, steelhead, and cutthroat trout abundance in two coastal Oregon streams (Solazzi et al. 2000). After Chum spawn in Oregon's lowland rivers and streams, they migrate to the estuary (Salo 1991). Fall Chinook spawn in lower reaches of rivers or tributaries and coho spawn in either lower or upper stream reaches (Groot and Margolis 1991).

Additional landscape considerations should be taken into account. For instance, how will the project address regional biodiversity management goals and also how will predicted future land use affect the site's integrity. In an estuarine environment, the tidal prism will increase as intertidal habitat is restored (Crooks \& Ledoux 1999). Generally speaking, reduced tidal prisms from diking and draining of intertidal habitat has altered the shape, tidal dynamics, and sedimentation of estuaries. Increased tidal prism in the inner estuary from dike removal will result in the widening of the estuary mouth causing the erosion of lower estuarine intertidal habitat. Also, heterogeneous landscape structure (Turner et al. 2001) influences the way in which organisms interact with the environment. Siting mitigation next to natural marshes can support faunal and floral recruitment (Moy \& Leven 1991). Adjacent sand dune complexes were found to influence a salt marsh's water retention (Broome et al. 1988). Salt marsh function has been found to be linked to eelgrass meadows in relation to some nekton (Irlandi \& Crawford 1997). Biodiversity in estuarine habitat is also linked to adjacent upland ecosystems. Ecosystem restoration, of which mitigation is a part, requires the restoration of habitat and functions that are scarce within the landscape and connectivity amongst restored and existing habitat (Crooks \& Ledoux 1999).

Geographic Information Systems (GIS) are being widely used to incorporate landscape ecology into wetlands regulation. One application is to assess the suitability of a proposed mitigation site. For example, Van Lonkhuyzen et al. (2004) describe a method for assessing the suitability of mitigation sites using GIS. Using hydrology, soils, historical condition, vegetation cover, adjacent vegetation, and land use data, variables were weighted on a scale of 1 to 3 based upon perceived relative importance and suitability scores ( 0 to 1 scale) were developed for different attributes per variable. Locations with scores of 0.6 or higher were identified for as potential wetland mitigation sites. This model was applied to a mitigation site in Illinois, which was considered 
suitable for mitigation with a 0.77 suitability score. Wildlife habitat and supporting species diversity were the main functional objectives considered.

\subsubsection{Mitigation action plan}

As per recommendations from Bedford, Brinson, and others from the scientific community (NRC 2001), efforts have been made to incorporate a landscape perspective into wetland mitigation. In most cases, the watershed has been the unit of choice for working towards landscape-based decision making. The EPA defines a watershedapproach as "a coordinating framework for environmental management that focuses on public and private sector efforts to address highest priority problems within hydrologically-defined geographic areas, taking into consideration both ground and surface water flow.” The MAP federal guidance on off-site and out-of-kind mitigation (NWMAP 2004a) recommends using a 'holistic watershed plan', which is as plan that has been reviewed by federal and state agencies, considers multiple stakeholders, addresses issues of habitat, water quality, water quantity, competing uses, cumulative impacts, and restoration priorities. Without a 'holistic watershed plan' to guide off-site and out-of-kind, the federal guidance is to consider site conditions, sensitive species needs, problems such as flooding and poor water quality, current trends in habitat loss or conversion, development trends, and the long-term benefits of available options. A watershed plan also provides a framework and tracking up for understanding and tracking

cumulative impacts. A watershed approach will stretch current thinking of compensatory mitigation since it will allow more flexibility than the in-kind, onsite approach and may even include upland restoration.

The "National Symposium on Compensatory Mitigation and the Watershed Approach” (ELI 2004) provided MAP with direction and input about how to incorporate watershed-based planning tools and resources into compensatory mitigation. A watershed-based approach should include four elements:

-a landscape assessment based upon the ecoregion or HGM setting -an assessment of lost and remaining aquatic resources -an analysis of priorities and restoration options based upon aquatic resource functional needs, and -determine where, when, and how much aquatic resources need to be restored.

\subsubsection{North Carolina's watershed approach}


Some states have worked towards adopting watershed approaches to their regulatory wetlands program. North Carolina has developed some innovative programs and tools that are considered watershed approaches. North Carolina's Ecosystem Enhancement Program (NCEEP) has received national attention for its innovation in meeting the mitigation needs of the state's transportation department through a 2003 memorandum of agreement between the Department of Environmental Quality and the USACE (ELI 2005). NCEEP replaced North Carolina's Wetlands Restoration Program, a nonregulatory restoration program developed in part to improve the ecological effectiveness of mitigation through watershed planning and to act as an in-lieu-fee provider. The goal of NCEEP is to provide quality mitigation in advance of impacts and to incorporate compensatory mitigation into comprehensive watershed restoration plans. Mitigation projects are to provide the greatest ecological benefits, be the most cost effective, and meet watershed goals. Watershed goals are based upon Watershed Restoration Plans completed in 1998 for 17 major river basins in the state. Watershed Restoration Plans identify restoration goals, identify priority subbasins with water quality information, watershed boundaries, land cover data, and wetland impact information. The MBRT only allows mitigation banks in targeted subbasins or if they meet the goals of the watershed restoration plan.

NCEEP manages the in-lieu-fee program by consolidating CWM payments for the department of transportation's impacts and for other permittees to undertake largescale mitigation projects that are focused on improving water quality. While the North Carolina Department of Environmental Quality is responsible for processing regulatory permits, the NCEEP provides high quality mitigation options that incorporate both regulatory and nonregulatory restoration goals into its strategy. Current fees are $\$ 13,123$ per acre of non-riparian wetland; \$26,246 per acre of riparian wetland; \$131,230 per acre of salt marsh; and $\$ 0.96$ per square foot of riparian buffer. Permittees are encouraged to mitigate through NCEEP first, but are also given the option to undertake onsite physical mitigation. NCEEP also collaborates with the MBRT. NCEEP is working towards the goal of carrying out $90 \%$ of the state's compensatory mitigation and by 2014 intends to have restoration mitigation projects at least 7 years old before they are eligible to be used as compensatory mitigation. 
Mitigation is to occur within the same river basin and physiographic province as the impact and within the same water supply watershed. In-kind mitigation is preferred unless out-of-kind is considered environmentally preferable. Replacement ratios vary depending upon the mitigation method and the proximity to waters of the state. For restoration of wetlands within 150 feet of the mean high water or ordinary high water level of a perennial or intermittent waterway, a 4:1 ratio is required. If the wetland is greater than 150 feet from a water body, a 2:1 ratio is required for restoration. Linear projects require a 2:1 ratio for impacts less than three acres and a 1:1 ratio is required for all other wetland restoration projects. If the mitigation involves creating wetlands, the restoration ratio is to be multiplied by 1.5; for enhancement, the restoration ratio is multiplied by 2; and for preservation, the restoration ratio is multiplied by 5 .

Along the coast, North Carolina developed the watershed-based wetland evaluation program called the Coastal Region Evaluation of Wetland Significance or NCCREWS (NC-CREWS 1997). This evaluation involved assessing the ecological significance of coastal wetlands in 20 coastal counties to help guide decisions in permitting wetland impacts. This method has since been applied in 17 more counties in North Carolina’s Inner Coastal Plain (NC-CREWS 1999). Due to the large geographic area of the evaluation, a Geographic Information Systems (GIS)-approach was needed rather than a site-specific functional assessment approach. The watershed-based procedure incorporated principles of wetlands and landscape ecology. Relatively small hydrologic watershed units were used, but units of any size would be appropriate. GIS layers were already available and were used to assess the functions and values of wetlands per watershed using ESRI's ARC/INFO software:

-National Wetlands Inventory data with both HGM \& Cowardin class -NRCS soils data -Landsat TM 1992 land use/land cover -USGS DLG 1:24,000 scale hydrography -Strahler stream order (derived from USGS DLG) -14 digit Hydrologic Unit Codes (HUCs) (5,000-50,000 acres)

-Natural Heritage Program endangered species occurrence -State Division of Water Quality 1:100,000 scale water quality classification data -Natural Heritage Program statewide priority protection areas and 
-Natural Heritage Program anadromous fish spawning areas.

While the method stated some flexibility in the required layers that could be used for the analysis, the layers in bold font were considered essential for meaningful results. Both HGM and Cowardin classes were used in the evaluation. While HGM class captures the abiotic features (hydrologic source/flow direction/position in the landscape) of the wetland, the Cowardin class provides dominant vegetation type. HGM wetland class (riverine, depressional, or headwater) was used to determine what functional characteristics would be assessed and then ratings, in some cases, were made based upon Cowardin classes. Indicators of functional characteristics per wetland class were based upon field data from 400 reference sites along North Carolina's southeastern coastal plain. If reference data are not available, best professional judgment could be used to correlate wetland type to wetland function, although less accurate. Landscape characteristics were considered more important than the wetland characteristics in assessing functional significance. In total, 39 parameters were assessed, of which 21 were landscape features and 18 were wetland features.

Scores for each of these parameters are aggregated into a composite score for: water quality function, hydrologic function, habitat function, and risk factor. The water quality functions assessed were attributes relative to nonpoint source pollution and floodwater filtration. Nonpoint sources were rated based upon percent of watershed developed and used for agriculture, proximity to waterbody, watershed position, wetland type and soil type. Headwater wetlands were assumed to be most effective at removing nonpoint source pollutants. Soils series were classified into high, medium and low classes based upon flooding frequency, clay content, and organic content. Mean annual exports of nitrogen and phosphorus were assumed for different land uses based upon scientific findings. All depressional wetlands were ranked low for floodwater cleansing function. The hydrology function was assessed based upon surface runoff storage, floodwater storage, and shoreline stabilization. All depressional wetlands were ranked low for shoreline stabilization function. Habitat functions were evaluated based upon the occurrence of threatened and endangered species, terrestrial habitat characteristics, and 
landscape features such as adjacency to other wetlands, nature of surrounding habitat, and degree of isolation.

Parameters considered for the risk factor evaluated the wetland's significance in relation to land use. Wetlands in watersheds with high percentages of wetland area were given low ratings, while the reverse received high ratings. Rarity of the wetland type was also considered. If the wetland coverage was low and the wetland type was rare, than the wetland was given a high rating. The watershed's water quality characteristics, the degree of difficulty in replacing the wetland functions, and the 'enhancement potential' of the site were also considered to incorporate the potential risk of wetland loss. The rationale for assessing 'enhancement potential' was to understand the lost opportunity for restoring/enhancing the site, if the potential existed to enhance or restore the site to a higher level of function. For this risk consideration, wetlands that had been at least partially drained with natural vegetation intact were rated 'high'; wetlands that were drained or partially drained and converted to an intensively managed forest system (e.g., pine plantation) were rated 'medium'; and wetlands that were intact but of low functional significance were rated 'low'.

Wetland types were assessed in terms of the replacement difficulty in terms of the availability of in-kind compensation sites within the watershed. Williams (2002) describes the GIS-based methodology used to identify potential wetland restoration and enhancement sites per watershed in North Carolina. The datasets used to identify potential restoration sites included soil maps, land use, DCM wetland type, and hydrography. Sites were classified by current and historical plant community type and placed into nine different disturbance classes based upon disturbance types (drained/cleared, ditched/cleared, drained, ditched, impounded, excavated/filled) and conditions, which were then placed into six restoration or enhancement types. This dataset was designed for both regulatory and nonregulatory mitigation/restoration efforts. Based upon an earlier iteration of Williams' (2002) wetland restoration database, wetland sites were evaluated on the availability of suitable mitigation sites within the same watershed. A 'high' rating was given if no replacement sites were identified in the watershed; a 'medium' rating for a non-wetland site within the watershed; and a 'low' rating if the degraded wetland site of the same type was identified within the watershed. 
Wetlands were also assessed in terms of the practicality of restoring a given wetland type. In North Carolina, estuarine forested wetlands, pocosins, and maritime dunal/swale wetlands are considered difficult to replace and therefore are assigned a 'high' rating. Bottomland hardwood, swamp forest, and headwater swamps were given a 'medium' rating in terms of replacement difficulty. If the wetland's function(s) could be relatively easily replaced (e.g., freshwater marsh, estuarine scrub-shrub), a 'low' rating was assigned.

An overall wetlands ecological significance numerical score is calculated from the four function/risk scores. To avoid exaggerating the scientific validity of the quantitative scores, they were assigned high, medium, and low designations. These scores are intended to be used as starting points for guiding permit decisions and are not intended to substitute for site-based functional assessments. A high score indicates the wetland is ecologically significant and should not be sacrificed for removal/fill activities, medium wetlands need a case-by-case evaluation, and low wetlands are considered suitable for impacts. Although all wetlands are lumped into three broad categories, qualitative scores can be traced back to individual function scores, if watershed goals have already been set, such as for water quality.

This approach, as with the HGM approach, separates the opportunity to perform a function from the capacity of the wetland to be able to perform that function. The opportunity is dictated by land uses that are external to the wetland and capacity is dictated by the wetland characteristics and landscape position. Land use changes within the watershed will change a wetlands opportunity to perform a function and therefore this database will need to be updated as land use changes occur. Due to previous ecologically significant designations, high ratings were automatically assigned to any salt/brackish marshes, any wetland within 300 feet from a designated Primary Nursery Area for larval finfish and crustaceans, wetlands known to support threatened or endangered species, or a wetland with a critical natural area designation from the Natural Heritage Program.

North Carolina's Division of Coastal Management (DCM) has developed other GIS-based tools and datasets to aid in the location and assessment of wetlands and wetland restoration with the overall goal of developing a Wetland Conservation Plan. 
The Wetland Type Mapping data set identifies the location, type, and extent of wetlands in the coastal plain using NWI data (1981/82), soil survey data, and Land Use/Land Cover data (1994) (DCM 1999). The layer produced a more recent dataset, which incorporates soils, HGM, and Cowardin class to map a DCM specific wetland classification system that was field verified.

\subsubsection{San Francisco Bay}

Goals and objectives were developed by state, local, and federal partners to identify restoration sites in San Francisco Bay (ELI 2004). First, quantitative regional goals were set to determine how much of what kinds of habitats are needed where and why. Policies and programs were then adjusted to achieve the desired distribution of habitat types. Adaptive management was used to reassess goals as necessary. Mitigation projects were linked to impact sites and net habitat changes were tracked within a watershed and regional context. One of the results of this effort was a webbased tool called the Bay Area Wetland Tracker that shows the location, size, sponsors, habitats, contact persons, and status of planned and existing wetland restoration, mitigation, creation, and enhancement projects in the San Francisco Bay Area.

\subsubsection{Alabama}

A wetland conservation plan was developed for a rapidly developing county in Alabama, in which one-third of the area is wetland. Although county's tourism and fishing industries rely upon revenue generated from wetlands, no statewide wetland regulations exist. An HGM wetland profile per watershed was developed from NWI data and combined with ditch distribution, water regime, land use data, road data, threatened and endangered species, wellhead protection areas, flood zones, and soils data to build the Remote Wetland Functional Assessment Model. Based upon landscape and wetland characteristics, each wetland was assessed for level of function with respect to wildlife habitat, water quality improvement, groundwater recharge, and flood control. Based upon functional threshold scores, each wetland was classified for management purposes as conservation, enhancement, or restoration (ELI 2004). While 88\% of the county's wetlands were found to be suitable for conservation, $10 \%$ were considered appropriate 
for enhancement, and only 1\% was found to be suitable for restoration. A field verification of the model revealed accuracy to be $85.6 \%$. This map was designed for planning purposes.

\subsection{Oregon's Resources for Implementing a Watershed Approach}

Oregon is on the right trajectory for adopting a watershed approach into the Removal-fill program. With the passage of the state Wetlands Conservation Act in 1989, cities are granted the legal authority to develop Wetlands Conservation Plans to balance wetlands protection with development. The report "Recommendations for a Nonregulatory Wetland Restoration Program” (Good \& Sawyer 1998) recognized the need to incorporate both voluntary and regulatory (CWM) wetland restoration prioritizations into landscape contexts and to develop HGM functional assessments for Oregon. While Oregon has made some strides towards this approach, some obstacles still exist to achieving a landscape approach. One of the Removal-fill Program's biggest shortcomings is not having a GIS-based permit database.

Inventories of remaining estuarine wetland habitat are available in Oregon Estuary Plan Book (Cortright et al. 1987), the State of the Environment Report on Oregon's Estuaries (Good 2000), and the GIS Tidal Wetland Assessment (Scranton 2004). DSL's wetlands program has approved local wetland inventories for tidal and nontidal wetland habitat for many coastal communities. Also a wetland change detection study from 1982 to 2001 aerial photography is nearly complete for coastal wetland habitat below 100' in elevation. Coarse landscape assessments based upon the HGM setting per ecoregion have been developed for the state of Oregon (Adamus 2001) and HGM functional assessment tools have been developed for Oregon’s tidal wetlands (Adamus 2005).

Watershed councils have developed watershed assessments and restoration priorities for most coastal rivers. While these have focused mostly on stream and riparian habitat needs, some inventories have considered wetlands. Additionally, estuarine wetland prioritizations have been done for a number of estuaries including the Lower Columbia River Estuary (Evans et al. 2006), Nehalem (Brophy \& So 2005a), Yaquina and Alsea (Brophy 1999), Siuslaw (Brophy 2005a), Umpqua (and Smith River) (Brophy 
\& So 2005ab) and Lower Elk/Sixes Rivers (Brophy 2003), and Tillamook Basin (TBNEP 1999). These priorities can be used to guide both regulatory and nonregulatory restoration in coastal watersheds.

Other state agencies and nonprofit agencies have also developed ecological priorities, which could inform mitigation decisions using a landscape approach. Regulatory restoration can be carried out through the normal compensatory method or through the PTP program or mitigation banking program. A watershed approach will allow compensatory mitigation to move beyond the concept of in-kind vs. out-of-kind mitigation to an approach that considers the functional needs of the ecosystem. These concepts will be discussed in more detail below.

\subsubsection{Wetlands Conservation Plan}

Eugene is the only city in Oregon that has an approved Wetlands Conservation Plan, which was adopted in 1992. During plan development, Eugene mapped historical and current wetlands within an 8,000-acre area where a majority of wetlands were thought to occur. The wetlands were assessed for functions and values including support of rare plants and animals and connectivity to other habitat and then prioritized. Within the Wetland Conservation area, 19\% of the land was wetlands. Based upon the results of the wetland assessment, $79 \%$ of the wetlands were designated for protection/restoration and the remaining $21 \%$ for development.

Although based upon a land use planning boundary, rather than watershed boundaries, Eugene's successful Wetland Conservation Plan (ELI 2004) demonstrates that the regulatory tools already exist for municipalities to develop regional plans for wetland management, including siting of mitigation projects. In rule, estuarine management plans may be recognized by the state as Wetland Conservation Plans, although none to date have applied for this designation. However, estuary plans may need to be updated to reflect current wetland conditions. For example according to the tidal wetland restoration prioritization for the Siuslaw (Brophy 2005), a portion of an area zoned for mitigation is a functioning tidal marsh and not a good candidate site for compensatory mitigation.

\subsubsection{GIS Permit Database}


Geographic Information System (GIS) is a computer system designed the for management, analysis, and display of geographic knowledge (ESRI 2006). This tool has revolutionized the ability of natural resource managers to efficiently analyze many, large datasets with a spatial component at mutiple scales. However, DSL has not fully taken advantage of this tool in the Removal-fill Program. An integral piece of the Removal-fill Program is the LAS database, which stores permitted Removal-fill activity in wetlands and waterways at the tax lot level. Information stored includes data on authorizations for impacts, wetland determination/delineation activity, and compensatory wetland mitigation information per tax lot. To report on the state's no net loss goal, wetland impacts and mitigation are tracked in tabular form. For the impact site, the size (in acres) of each type of HGM subclass and Cowardin class impact is tracked in LAS. Likewise, the size of each type of HGM subclass and Cowardin class restored, created, or enhanced is, also, tracked. Not designed as a geodatabase but a database for processing permits, LAS has a very basic mapping component which uses USGS topographic maps at a 1:100,000 scale which displays the location of the impact site and mitigation site as points in the centroid of the Township Range Section.

Therefore, the mapping capabilities of the LAS database does not allow permit coordinators to effectively implement the program, nor adopt a watershed approach to making permit decisions. For example, most mitigation sites are to be protected in perpetuity. Due to its coarse scale and poor accuracy, LAS' mapping program does not allow staff to efficiently respond to questions about whether a particular tax lot has a mitigation site on it or if a proposed CWM site is mitigation for an earlier permitted impact. Impact and mitigation sites would need to be represented by polygons at the same scale as tax lot data to better understand the footprint of the development activity. While developing a Wetlands Conservation Plan, a city or county identifies wetlands for development, conservation, and mitigation/restoration beyond the tax lot level to at least within their political boundaries. Therefore, compensatory mitigation planning has been considered at a broader level. However, as mentioned previously, Eugene is the only city that has an approved Plan. The ERR rules require DSL to map impacts and mitigation per estuary. Estuary plans dictate management units per estuary but due to human and natural changes, they may not reflect reality and the zoned mitigation sites may not be 
appropriate within the context of ecosystem restoration. Developing a geodatabase of Removal-fill impacts and compensatory mitigation with mapped polygons would allow permitters to understand how permitted and proposed Removal-fill activity at the tax lot level fit within the estuary, watershed, and ecoregion and would allow for a more meaningful understanding of 'no net loss' of wetland function within an ecologically meaningful scale (i.e., estuary or watershed versus political boundary).

With the relevant datasets (layers), permit processors could easily determine what aquatic resources exist in a particular watershed or ecoregion, what aquatic resources have been historically lost, what impacts have already been permitted adjacent to the permit at hand to start to understand cumulative aquatic impacts, and the restoration priorities for a given estuary, watershed, or ecoregion.

This database should also be integrated with the land management program, which is responsible for leases and easements in state owned waterways to better understand potential impacts of state-owned water uses such as docks and boat ramps. Ideally, all state (and federal) natural resource agencies as well as nonprofit groups involved in wetland, riparian, and upland restoration should tie into the same GIS database to adopt an ecosystem approach to restoration. However, development of a DSL geodatabase is a recommended starting place. A GIS database could be developed by a contractor with advice from a team of DSL staff including the in-house GIS person, technology manager, the wetlands program manager, a Removal-fill permit manager, and a permit coordinator. Upon development, the database should maintained by a DSL GIS staff person.

\subsubsection{Data}

\section{Local wetland inventories}

Local wetland inventories (LWIs) have been created for 18 of the 42 coastal towns and cites that show the location of all tidal and non-tidal wetlands at the tax lot scale (Table 20) (DSL 2006). However, there are still urban coastal communities that do not have LWIs such as Brookings, Coos Bay, North Bend, Newport, Pacific City, and Manzanita. Some, but not all, of these inventories are available as GIS layers. Making 
LWIs readily accessible in GIS form for applicants and permit staff can improve permit and mitigation decisions. These LWIs are developed according to standards in rule by DSL and are approved by DSL before they can be adopted by local governments and before they become part of the State Wetlands Inventory (SWI). DSL, as the lead state agency for wetlands and the agency responsible for the SWI, is responsible for making LWIs more available and useful to the public and staff.

\begin{tabular}{|l|l|}
\hline \multicolumn{2}{|l|}{$\begin{array}{l}\text { Approved \& Pending Coastal } \\
\text { Local Wetlands Inventories }\end{array}$} \\
\hline Astoria & Lincoln City \\
\hline Bandon & Port Orford \\
\hline Bay City & Reedsport \\
\hline Cannon Beach & Rockaway Beach \\
\hline Depoe Bay & Seaside \\
\hline Gearhart & Tillamook \\
\hline Dunes City & Toledo \\
\hline Florence & Waldport \\
\hline Gold Beach & Warrenton \\
\hline
\end{tabular}

Table 20: Coastal communities with approved or pending Local Wetland Inventories (DSL 2006).

NC-CREWS' method, including the scientific basis and the assumptions made to efficiently rate wetlands within a watershed boundary, are described in detail in report form (Sutter et al. 1999). Therefore, this model with minor modifications would be relatively easy to implement in Oregon, assuming financial resources were available to do the analysis. Currently, GIS layers are available for most of the required layers either from the Oregon Geospatial Enterprise Office (GEO 2006) or are already part of DSL's GIS data collection. USGS Digital Line Graph 1:24,000 scale hydrography are available from Oregon Geospatial Enterprise Office, as are Level IV ecoregions. Watershed delineations for $4^{\text {th }}, 5^{\text {th }}$, and $6^{\text {th }}$ Hydrologic Unit Codes are already part of DSL's GIS data, as are soils data, essential salmon habitat, and water quality limited rivers and lakes. Land Use/Land Cover is available for free from USGS seamless data website and is also already on the Oregon Coastal Atlas webpage. Digital NWI data at 1:24,000 scale are still being processed for the coast. The north and south coast are currently available. The Oregon Natural Heritage Program has GIS data of rare and endangered species and 
historical vegetation maps derived from the 1850s General Land Office Survey

(ORNHIC 2006). A tidal-wetland geodatabase (Scranton 2004) is available for the entire coast excluding the Columbia River estuary. Reference site data are available for 120 tidal wetlands associated with development of the tidal HGM (Adamus 2005); however, no consistent datasets exist for all non-tidal wetlands for each coastal watershed.

Although many of the GIS data sets are available to rate wetlands as High, Medium, and Low similar to the North Carolina program, the resolution of the datasets is fairly coarse and consequently, not all wetlands will be captured. DSL needs to make decisions at the tax lot scale. Land use data resolution is $30 \mathrm{~m}$ and NWI maps are available at the 1:24,000 scale. When available and georeferenced, LWI maps should be used in place of NWIs. Despite the issues of scale, developing this type of resource could be very beneficial for DSL's Removal-fill Program.

While Goal 5 and 17 identify priority wetlands within local communities and watershed inventories and assessments identify priority acquisition and restoration sites, there is not one consistent, watershed-based evaluation of all of Oregon's coastal or statewide wetlands. Permit decisions need to be made within timelines set by law, thus those processing permits do not have time to undertake thorough research of the proposed wetland impact at hand. While functional assessments are already required as part of a wetland fill permit application, an improved GIS has the capacity to provide a landscape context for making CWM decisions with regard to type and location.

Wetland Profiles for Coastal Watersheds

An HGM classification for the state of Oregon has been developed, which profiles Oregon's wetlands by HGM class per ecoregion (Adamus 2001). From an HGM-based assessment, Oregon's wetlands were divided into 14 subclasses that potentially perform 11 major functions. The occurrence and importance of each class/subclass was identified per ecoregion. Potential functions for each subclass were also on a scale from 0 (minimal/absent) to 3 (more important function). Within the coast and coast range, riverine and estuarine fringe classes and subclasses were identified as both common and important for this region. Depressional bogs were considered uncommon and important. All other subclasses of depressional, slope, flats, and lacustrine fringe wetlands were considered uncommon except, outflow and valley but there potential functions were not 
deemed 'more important'. NWI maps can be enhanced with HGM classifications to create "wetland profiles" for various regions as described by Bedford (1996). From such landscape profiles, one can obtain a crude picture of wetland functions and changes for a region over a period of time. The coastal wetland change study (in progress) will include HGM classification.

\section{Estuarine Habitat Inventory}

Albeit dated, the Oregon Estuary Plan Book (Cortright et al. 1987) provides GIS and hard copy maps of intertidal habitat for each estuary, which fulfills the "assessment of remaining aquatic resources” requirement for approaching compensatory mitigation from a watershed concept (see section 6.2.1 Mitigation Action Plan). Many sources (Good 2000; Scranton 2004; Brophy 1999, 2003,2005b; Brophy \& So 2005a,2005b,2005c) provide estimates of tidal marsh losses relative to historical coverage per Oregon estuary since European-American settlement. Estimated losses of other estuarine habitat (eelgrass habitat and tidalflats) are available for Coos Bay (Borde et al. 2003) and the Columbia River Estuary (Thomas 1983), but not for other estuaries. Scranton's inventory is a geodatabase, while Goods is not. Scranton's estimates do not include Oregon's largest estuary, the Columbia River, but Good’s (2000) do based upon Thomas (1983). Neither Good (2000) nor Scranton (2004) estimate losses by subclass (high marsh, low marsh, etc.). Brophy and So (2005a) estimate that tidal swamp (forested/scrub-shrub) habitats have suffered the greatest losses (90-95\%) relative to tidal marshes. Most of the direct anthropogenic impacts have occurred in the higher elevations of the estuary where the land was relatively drier.

Simenstad and Burke (in progress) are developing a Lower Columbia River estuary GIS-based nested hierarchical classification scheme and inventory that provides six classification levels from coarser to finer spatial resolution: ecosystem province, ecoregion, hydrogeomorphic reach, ecosystem complex, catena, and primary cover class. When completed, this new resource will provide an understanding of the contemporary and historical distribution of wetland classes in the lower Columbia river estuary. Scranton's dataset uses the HGM classification, while Good uses general habitat type based on Oregon's Estuary Plan Book. Scranton created a detailed GIS-based dataset (available at Oregon’s Coastal Atlas - http://www.coastalatlas.net/) of the areal extent of 
the HGM tidal subclasses for each Oregon estuary, except the Columbia River Estuary. This dataset was based upon a number of data sources including aerial photography, the NWI, and the Oregon Estuary Plan Book. According to Scranton (2004), total estuarine area is around 120,000 acres of which 50,000 acres is open water and almost 12,000 acres is tidal wetlands (Figure 15). Marine-sourced low tidal wetlands (MSL) make up the greatest area of tidal wetlands at about 5,700 acres and marine-sourced high tidal wetlands (MSH) consist of about 4,700 acres. Only about 1,400 acres of river-sourced tidal wetlands (RS) exist along the coast. Forested tidal wetland (PF) covers about 4,100 acres.

While fill covers about 7,400 acres of formerly estuarine habitat, Scranton identified over 44,500 acres of habitat with the potential for restoration (RCA). RCA's are generally former tidelands that were diked, ditched, and/or partially filled for agriculture or commercial purposes. The type of marsh lost was not reported due to the difficulty in determining this. These sites were identified using remotely sensed data, which have not been ground truthed. Socio-political factors, such as land ownership and willingness for property owner to undertake restoration, were also not considered.

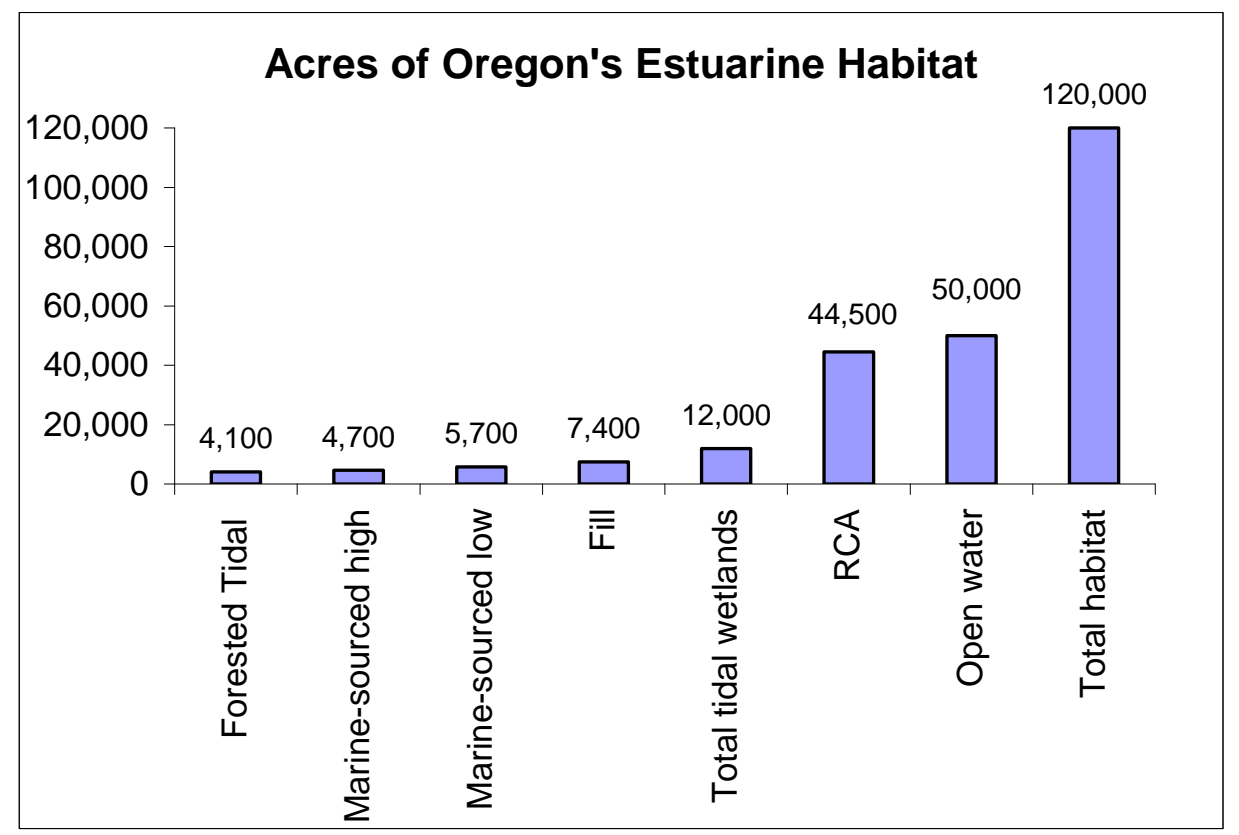

Figure 15: Distribution of estuarine habitat in Oregon (Scranton 2004). 
In terms of restoration consideration areas (RCA) as a percentage of area per estuary, the Coquille has the greatest potential area, followed by Winchuck Estuary, and the Chetco has the fewest RCAs (Figure 16).

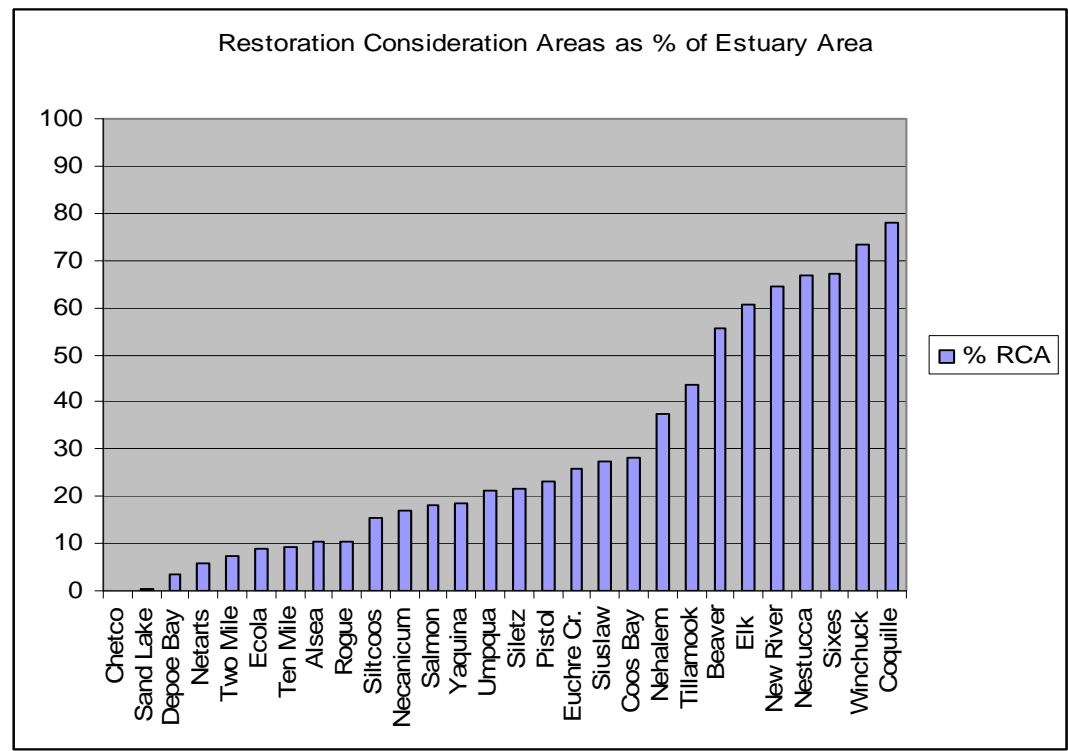

Figure 16: Restoration Consideration Area's as a percent of Estuary Area (source:

Scranton 2004)

A breakdown of percent habitat type per estuary provides a quick indication of what the mosaic of tidal marsh habitat is in relation to open water. Maps were generated to understand the distribution of tidal marsh habitat along the estuarine gradient (Figure
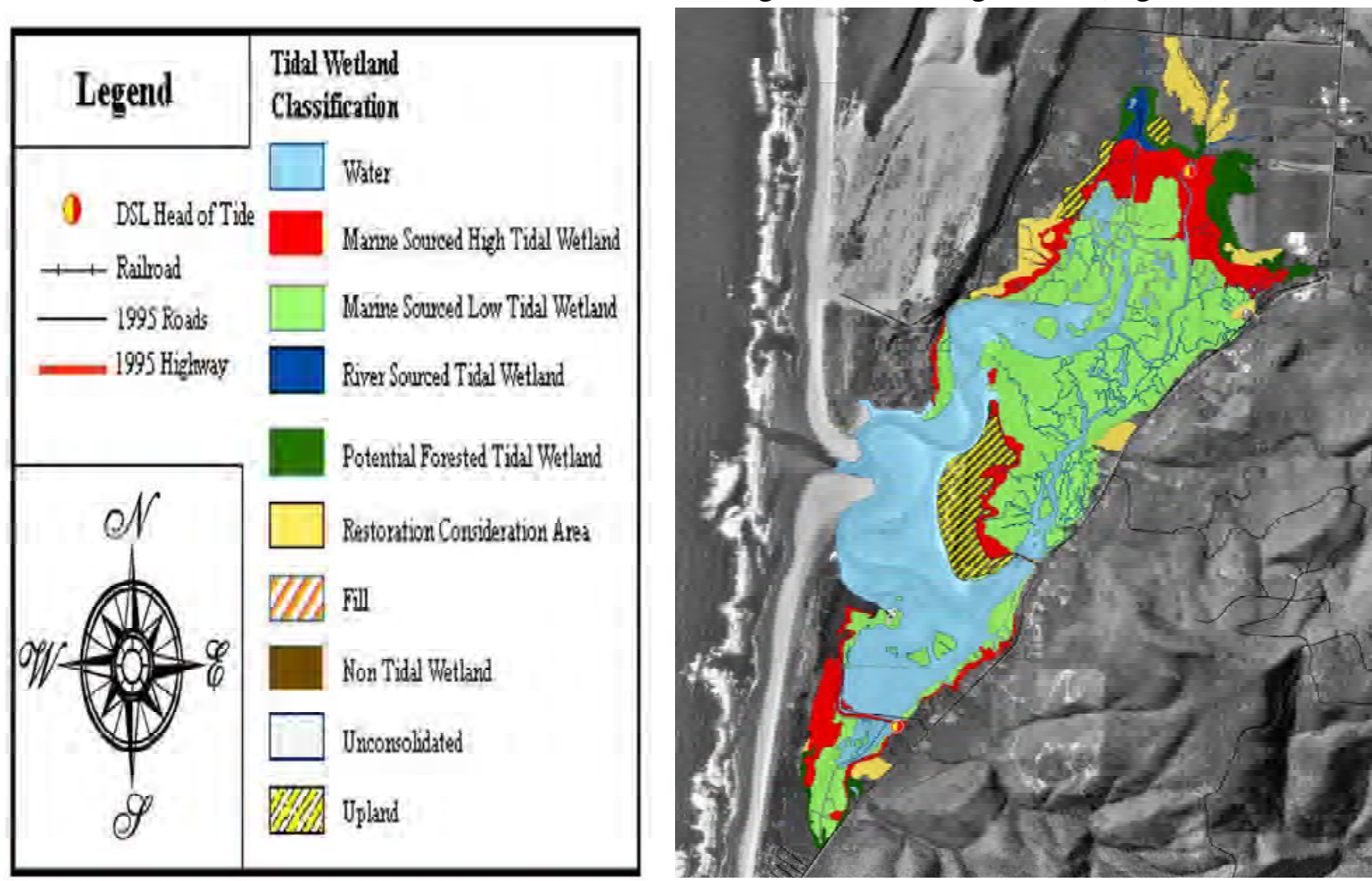
Figure 17: Oregon Coastal Tidal HGM classification (source: Scranton 2004).

Knowledge of cumulative impacts in terms of wetland habitat loss combined with an understanding of the deleterious effect of those wetland losses can help to inform compensatory mitigation decisions (Johnson 2005). For example, the Coquille has only $12 \%$ of the estuary in open water with $78 \%$ of the estuary categorized as RCA (Figure 18). Currently, tidal marshes only make up about $2 \%$ of the estuary. The Coquille estuary is water quality limited for anadromous fish, recreational, and shell fishery uses due to the following parameters: dissolved oxygen, chlorophyll a, temperature, and fecal coliform (DEQ 2002). Tidal marshes function in trapping sediment and mediating biogeochemistry processes that can improve water quality (Adamus 2005). While the needs of the entire watershed should be considered, restoration priorities for this estuary may be tidal channels and tidal marshes that have the potential to score high in the ‘maintain element cycling rates, pollutant processing, and stabilize sediment” function (Adamus 2005). Adequate GIS tools-available to applicants and permit staff-allow this data sources to be readily used for these types of decisions. 


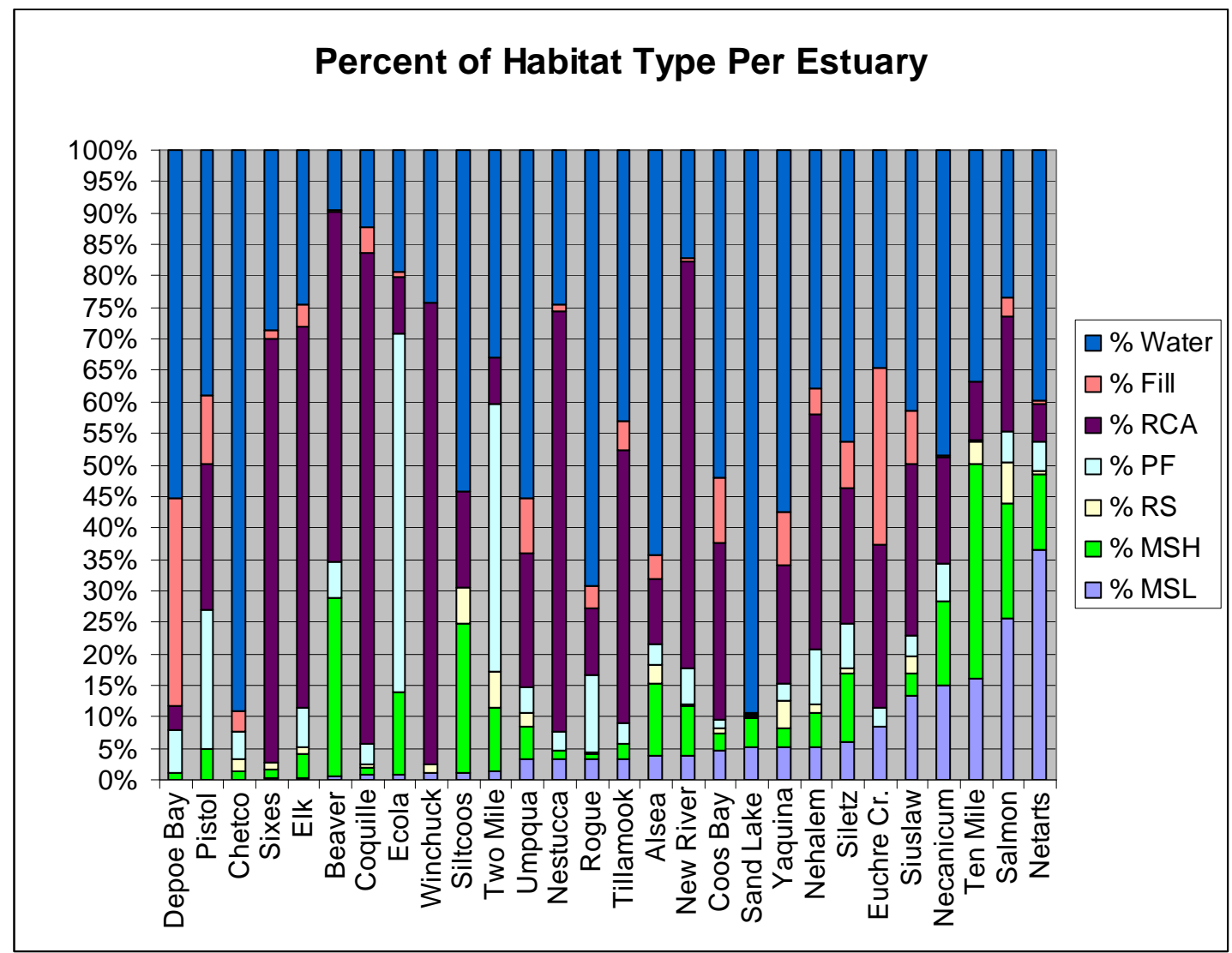

Figure 18: Breakdown of estuary tidal HGM class per estuary (source: Scranton 2004).

\subsubsection{Estuarine and watershed-based restoration priorities}

Tidal wetland (intertidal emergent and forested wetlands) restoration and preservation priorities were developed for a handful of estuaries based upon a number of factors (Table 21). Most of these priorities were developed for watershed councils with the exception of the Tillamook Bay (Tillamook Bay National Estuarine Project) and the Nehalem and Umpqua (USFWS Oregon Coastal program) Prioritizations. The Lower Columbia River Estuary Partnership has identified restoration priorities for the Columbia River estuary (Evans et al. 2006). An estuarine and freshwater wetlands site prioritization was also done for the Elk and Sixes River Basins on the Oregon South Coast for Oregon Trout (Brophy 2003). 
Brophy's (and Brophy and So) restoration and preservation sites were prioritized based upon size, salmonid usage, support of unique plant communities, landownership, and level of restoration complexity. Due to the significant losses of tidal swamp (forested or scrub-shrub) wetland (90-95\% compared to tidal marshes $70 \%$ ) combined with their unique support of salmonid habitat functions, former tidal swamp habitat was given higher priority than other former tidal wetland types. Sites were assessed based upon aerial photography and offsite work with no landowner contact. Actions recommended ranged from protection, tidegate modification or removal, culvert replacement, dike breaching/dike removal, tidal channel restoration, fill removal, and establishment of buffers. Brophy's assessments are in separate .pdf files per estuary, but were created using a GIS and with some preprocessing could easily be incorporated into a DSL GIS.

Due to the development of the Oregon Plan for Salmon and Watersheds and its implementation through voluntary watershed councils made up of diverse stakeholders, most watershed councils have developed watershed assessments identifying restoration priorities in relation to salmonids (Table 21). Because estuaries provide important functions in relation to different salmon species at different times in their life cycles, coastal watershed councils have started to recognize the need to identify potential estuarine restoration sites. Additionally, salmon, as anadromous species, also need freshwater habitat and marine habitat.

\begin{tabular}{|l|l|l|l|l|}
\hline Inventory/Assessment Title & Author & $\begin{array}{l}\text { Tidal } \\
\text { Wetlands? }\end{array}$ & $\begin{array}{l}\text { Nontidal } \\
\text { Wetlands? }\end{array}$ & $\begin{array}{l}\text { Restoration } \\
\text { priorities? }\end{array}$ \\
\hline WATERSHED & & & & \\
\hline Coos Bay Lowland Assessment \& Restoration Plan & Coos Watershed Association 2005 & partially & Yes & Yes \\
\hline Ecola Creek Watershed Assessment & Parker 2001 & Yes & Yes & \\
\hline Kilchis Watershed Analysis & Follansbee \& Stark 1998 & Yes & Yes & riparian only \\
\hline Lower Alsea Watershed Analysis & BLM \& USFS 1999 & Yes & Yes & Yes \\
\hline Miami River Watershed Assessment & Snyder et al. 1999 & No & Yes & \\
\hline MidCoast 6th Field Watershed Assessment & Garono \& Brophy 2001 & Yes & Yes & Yes \\
\hline Necanicum Watershed Assessment & Snyder et al. 2002 & Yes & Yes & \\
\hline Nehalem Watershed Assessment & Johnson 1999 & No & No & \\
\hline
\end{tabular}




\begin{tabular}{|l|l|l|l|l|} 
Nestucca/Neskowin Watershed Assessment & Barczak 1998 & Yes & Yes & Yes \\
\hline Netarts Watershed Assessment & Follensbee \& Mondragon 1999 & Yes & Yes & Yes \\
\hline Rock Creek Watershed Assessment & Garono \& Brophy 1999 & Yes & Yes & Yes \\
\hline Siuslaw Watershed Assessment & Ecotrust 2002 & Yes & Yes & \\
\hline $\begin{array}{l}\text { Tillamook Bay Comprehensive \& Conservation } \\
\text { Management Plan }\end{array}$ & $\begin{array}{l}\text { Tillamook Bay National Estuary } \\
\text { Program 1999 }\end{array}$ & Yes & Yes & Yes \\
\hline Trask River Watershed Assessment & Follansbee 1998 & Yes & Yes & Yes \\
\hline $\begin{array}{l}\text { Wetland Site Prioritization: Lower Elk and Sixes } \\
\text { River, Curry County, Oregon }\end{array}$ & Brophy 2003 (for Oregon Trout) & Yes & Yes & Yes \\
\hline Wilson River Watershed Assessment & Snyder et al. 2001 & Yes & Yes & Yes \\
\hline ESTUARY-ONLY & Author & Tidal & Nontidal \\
\hline $\begin{array}{l}\text { Lower Columbia River Restoration Prioritization } \\
\text { Framework }\end{array}$ & Evans et al. 2006 & Wetlands? & priorities? \\
\hline Nehalem Tidal Wetlands Prioritization & Brophy \& So a2005 & Yes & No & Yes \\
\hline $\begin{array}{l}\text { Oregon Coastal Watershed GIS Tidal Wetland } \\
\text { Assessment }\end{array}$ & Scranton 2004 & Yes & No & Yes \\
\hline $\begin{array}{l}\text { Oregon estuarine conservation \& restoration priority } \\
\text { evaluation: Opportunities for salmonid and wetland } \\
\text { functions enhancement in Oregon's estuaries. }\end{array}$ & Lebovitz 1992 (for Oregon Trout) & Yes & No & No \\
\hline Siuslaw River Estuary & Brophy 2005b & Yes & No & Yes \\
\hline Tidal Wetlands Prioritization for the Smith River & Brophy \& So 2005b & Yes & No & Yes \\
\hline Tidal Wetlands Prioritization for the Umpqua & Brophy \& So 2005c & Yes & No & Yes \\
\hline Yaquina \& Alsea Estuarine Wetland Prioritization & Brophy 1999 & Yes & No & Yes \\
\hline
\end{tabular}

Table 21: List of Watershed-based assessments and restoration priorities for Oregon's Coastal Watersheds and Estuaries.

These watershed assessments summarize the ecological needs of the watershed and usually have identified priority sites for restoration, which can help to guide mitigation decisions from a landscape perspective. If onsite mitigation is not practicable and/or out-of-kind mitigation is appropriate because the impact wetland is poorly functioning, a watershed assessments can help guide what types of aquatic habitats are priorities for restoration, where the restoration needs are the greatest, and, thus, what the best ecological compensation for the impact should be for all offsite mitigation options: in-kind, out-of-kind, offsite, payment to provide, conservation in lieu, and banking. Most importantly, these watershed council based-priorities have been developed at the local level with stakeholder input. Socioeconomic considerations are just as important if not more so than ecological considerations for setting restoration priorities because without landowner and community support, restoration will not happen. However, as mentioned previously, "in-kind” mitigation will be rare since estuarine impacts are fairly rare.

Out-of-kind, PTP, and mitigation banking choices can be made based upon watershed assessments in two ways. One is when considering actual sites and the other is for determining if the proposed mitigation site fits into the needs of the watershed. For 
instance, if water quality has been identified as the highest priority, then mitigation sites located in the landscape that have the opportunity and capacity to perform this function well could be considered acceptable for 'out-of-kind' mitigation. Or if a particular site has been targeted as a high priority restoration site in a watershed assessment and the land owner is willing to sell the site for restoration, then 'out-of-kind' mitigation could be preferable, assuming the impact site is low functioning. The Removal-fill law limits CWM to replacing lost functions at the impact site, but, as spelled out in rule, allows for exceptions when the out-of-kind HGM subclass/Cowardin class: is deemed environmentally preferable, performs priority functions addressed in a watershed management plan, has experienced significant historical losses, and/or supports rare plant communities.

In order for these inventories to be useful they need to be readily accessible to both the applicant and permit processor. Currently, these reports are located on various watershed councils websites, with restoration priorities buried in reports. Sponsored by OSU digital library, the North Coast Explorer (http://northcoastexplorer.info/index.aspx) is a clearinghouse for natural resource, mostly salmon related, publications for the North Coast. All available watershed council inventories and assessments are available on this website for North Coast basins. An expansion of this resource to Oregon's southern border would provide efficient access to watershed assessments for the entire Oregon coast. Additionally, GIS maps per coastal drainage that identify stream and wetland habitat priorities for restoration could also inform permittees and permiters in impact and mitigation decisions. For example, habitats identified in the assessments as rare or perform priority functions would require a more rigorous avoidance alternatives analysis. If a habitat could not be avoided but was fairly common in the watershed and was not considered a high priority, then perhaps a less rigorous alternatives analysis could be required and compensatory mitigation would be appropriate. If the plant community was common and an HGM functional assessment of the non-tidal wetland revealed low scores for all functions and a priority for that watershed is rearing habitat for salmon, then 'outof-kind' restoration of a tidal marsh that would provide rearing habitat could be considered environmentally preferable. This out-of-kind mitigation could be done by the 
permittee or, if available, credits could be purchased from a bank, or PTP funds could be targeted to a nonprofit or other agency doing this type of restoration.

\section{Watershed limitations}

Watershed inventories and assessments in their current state are not a panacea, however. One reason is that they are salmon centric and only consider floodplain or riverine wetlands. Because watershed councils were created in response to declining salmonid populations, the inventories are largely focused on stream and riparian restoration and in some cases ignore wetlands altogether, especially if they are isolated from the stream network. In addition to ignoring nontidal wetlands, most inventories of coastal watersheds stop at the limits of the estuary. Some inventories have been done just for the estuaries and have not been integrated into the watershed inventory. Also, these watershed assessments ignore groundwater. Generally, these watershed assessments do not apply the HGM functional assessment, if they do assess wetlands. Finally, these inventories will become dated and will need to be updated as habitats become restored and/or priorities change. Therefore, DSL permit staff could use watershed assessments as tools to better understand the ecological priorities of the watershed, but would need to apply their own analysis/decision criteria as to whether a proposed compensatory mitigation plan is consistent with state law.

\subsubsection{Oregon Coast Level IV Ecoregions}

A landscape framework that may be more appropriate for fauna that are not solely dependent upon aquatic habitat, such as birds and mammals, may be ecoregions. The state of Oregon has been divided into ecoregions that are based characteristic patterns of climate, geology, topography, and natural vegetation that shape and form the function of the watersheds (Omernik \& Gallant 1986). Ecoregions are identified at several "levels" from most to least differentiated. At ecoregion Level 3, the Oregon Coast falls into one ecoregion, the Coast Range Ecoregion, which extends from the crest of the coast range west to the ocean. At level 4, the Coast Range Ecoregion is further subdivided into 7 regions (Figure 19). 


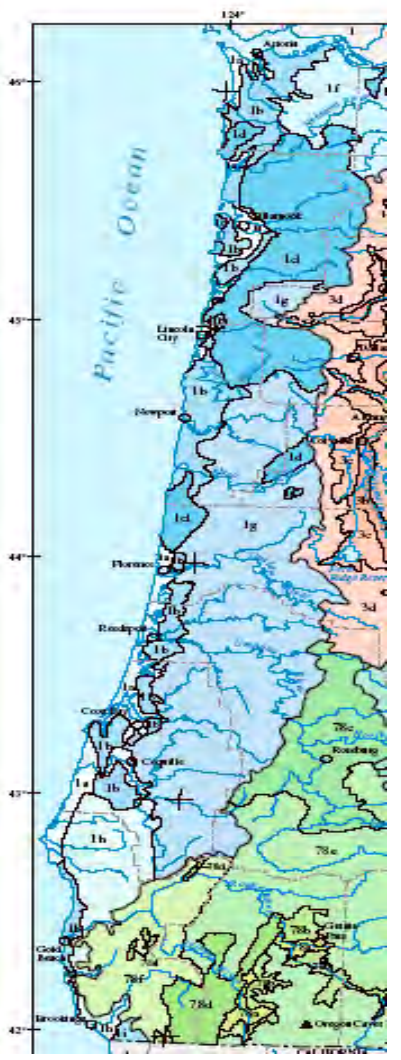

Figure 19: Oregon Coast Level IV Ecoregions (Thorson et al. 2003).

These divisions are Coastal Lowlands, Coastal Uplands, Volcanics, Willapa Hills, Midcoast Sedimentary, Southern Oregon Coastal Mountains, and Redwood Zone. The Coastal Lowlands ecoregion (1a-1i) contains beaches, dunes, and marine terraces below 400 feet elevation. Wet forests, lakes, estuarine marshes, and tannic streams are characteristic features of the landscape.

Although Section 404 of the Clean Water Act requires consideration of cumulative impacts and not just direct impacts at the project scale, effective tools for cumulative impact assessment are not readily available to permit processors. Though the Removal-fill law does not specifically address assessing cumulative impacts, it does require evaluating 'reasonably expected and adverse impacts”, both direct and indirect. While an individual wetland impact may have little effect on ecosystem health, the cumulative sum of wetland impacts may result in comprised ecological functions at the landscape level such as loss of flood attenuation, degraded water quality, and loss of wildlife habitat (Johnson 2005). Because different types of wetlands perform different 
functions depending upon hydrogeomorphic setting in the landscape, landscapes with similar physical characteristics support similar types of wetlands (Bedford 1996). By splitting wetlands into specific functional classes (HGM class), a hydrogeomorphic wetland profile (HGM WP) of the abundance and diversity of wetlands within ecoregions can be developed. By developing and comparing HGM WPs for a reference (largely undeveloped) subwatershed and a highly developed subwatershed within the same ecoregion in Colorado, Johnson (2005) estimated cumulative impacts of wetland losses within the highly developed watershed. For this study, wetland polygons identified from aerial photography by the US Forest Service and others were placed into HGM classes. Land use/land cover data was classified into two management units: altered and natural. Knowing the ratio of HGM class wetlands within the reference and developed subwatershed from the same ecoregion, an understanding of wetland-related cumulative effects can be estimated. For example, if the proportion of depressional and lacustrine fringe wetlands increased at the expense of riverine wetlands, the inference can be made that the landscape is less able to perform riverine wetland functions such as sediment export or provide refugia for salmonids. Furthermore, surface water storage is increased with an increase in depressional and lacustrine fringe wetlands. Results from this study verified the hypothesis that ecoregions of the same class support similar wetland types and, conversely, that different ecoregions support different wetland types. This method requires an intact watershed and an impacted watershed within the same ecoregion. Knowing what wetland functions have been lost from a particular ecoregion can help to understand landscape restoration needs and inform out-of-kind compensatory mitigation decisions at the ecoregion scale.

\subsubsection{Other Coastal Priorities}

In addition to restoration priorities generated by watershed councils and academic sources, state agencies and nonprofit groups have put forth the effort to identify priority habitats for both land acquisition and restoration needs. Conservation in lieu, as a form of compensatory mitigation, (OAR 141-085-0131) is acceptable for rare species and difficult-to-replace wetland habitats with ORNHIC S1 or S2 designations and/or vernal pool, fens, and bogs. There may be rationale to allow this form of compensatory mitigation to be used for wetland habitats that are healthy but in private ownership and 
experiencing conversion threats. Chapman and Julius (2005) argue for the use of land acquisition as compensatory restoration when credible threats exist. The functions of the land to be acquired would need to be assessed to understand what functions are being preserved in relation to what functions are being lost at the impact site. The estuarine wetland restoration prioritizations that have been developed by watershed councils identify habitats that are a priority for acquisition. These prioritizations combined with the habitats identified by other agencies in this next section could be used as rationale to allow for the conservation in lieu method as CWM. Furthermore, increasing coordination among agencies may reduce duplicative efforts and allow ecological goals to be achieved more efficiently.

Oregon Watershed Enhancement Board's priority ecological systems

The Oregon Watershed Enhancement Board (OWEB 2004) established statewide priorities for terrestrial and aquatic land acquisition currently held privately per basin for the purpose of restoration and protection of salmon populations, fish and wildlife habitat, and water quality. Priorities emphasized habitats and species that have experienced significant losses in population or distribution over time, as recognized by the State and Federal Endangered Species Acts, GAP Analysis, Partners in Flight, Oregon Natural Heritage Information Center, and Oregon Department of Fish and Wildlife. The GAP Analysis identifies how well native animal species and habitats are represented in the present-day network of conservation lands. Those species and habitats not sufficiently represented in conservation lands are considered conservation 'gaps' (ORNHIC 2006). Similar to the GAP program but focused on migratory birds across North and South America, Partners In Flight was started in 1990 as a nonprofit dedicated to conserving habitat for birds not adequately covered by existing conservation initiatives (Partners in Flight 2006). A number of resource conservation principles guided OWEB's prioritization process. Those principles relevant to restoration include:

-stabilizing partially degraded yet still functioning ecosystems, -securing habitat in areas experiencing development, -restoring function, -improving connectivity (corridors) between habitats for migration, and -complementing existing conservation networks. 
Due to the focus of this project, only coastal (tidal and non-tidal) wetland priority species identified by OWEB are included and discussed. Estuarine channels were identified as priority habitats due to their productivity and importance to anadromous and resident fish. Acquiring both small and large estuarine channels and lands where they can be restored is considered an OWEB priority.

Ecological priorities were established on a regional watershed (basin) basis (Table 22). The North Coast includes all watersheds and estuaries south of the Columbia River to the Umpqua Basin. The South Coast Basin includes rivers and estuaries draining the Coast Range and Klamath Mountains as far north as Coos Bay and as far south Pistol River, but excluding the Rogue River. The Lower Columbia, Umpqua, and Rogue basins were treated separately.

\begin{tabular}{|c|c|c|}
\hline Basin & Non-tidal Wetland Priorities & Estuarine Habitat Priorities \\
\hline \multirow[t]{4}{*}{ L. Columbia River } & Depressional wetland shrublands & Intertidal freshwater wetland \\
\hline & Freshwater aquatic beds & Intertidal mudflat \\
\hline & Freshwater mudflats & Tidal Salt marsh \\
\hline & Western Oregon wet prairie & \\
\hline \multirow[t]{7}{*}{ North Coast } & Fens & Eelgrass beds \\
\hline & Floodplain/linear wetlands & Intertidal mudflat \\
\hline & Forested wetlands & Intertidal salt marsh \\
\hline & Freshwater marsh/aquatic beds & Intertidal freshwater wetlands \\
\hline & Lowland/montane depressional shrub wetlands & \\
\hline & Mesic herbaceous wetlands & \\
\hline & Wet prairies & \\
\hline \multirow[t]{7}{*}{ Umpqua Basin } & Autumnal freshwater mudflats & \\
\hline & Depressional wetland broadleaf forests & \\
\hline & Coniferous forested wetlands & \\
\hline & Depressional wetland shrublands & \\
\hline & Sphagnum bogs and fens & \\
\hline & Vernal pools & \\
\hline & Western Oregon wet prairie & \\
\hline \multirow[t]{2}{*}{ Rogue Basin } & Deciduous Swamp & Intertidal freshwater wetlands \\
\hline & Subalpine/montane wet meadow & Intertidal mudflat \\
\hline
\end{tabular}




\begin{tabular}{|l|l|l|}
\cline { 2 - 3 } & Western Oregon wet prairie & Tidal Salt marsh \\
\hline South Coast & Deciduous Swamp & Intertidal freshwater wetland \\
\cline { 2 - 3 } & Freshwater Emergent & Intertidal mudflat \\
\cline { 2 - 3 } & Western Oregon wet prairie & Tidal Salt marsh \\
\hline
\end{tabular}

Table 22: Priority habitats established by Oregon Watershed Enhancement Board (OWEB 2004). 


\section{Coastal and estuarine conservation plan}

The Oregon Coastal Management Program identified priority conservation areas in the Coastal and Estuarine Conservation Plan (OCMP 2005) for Oregon's coastal zone as far inland as the $6^{\text {th }}$ order Hydrologic Unit Codes, which included heads of tide.

Although the intent of this plan was to identify priority habitats with significant ecological value for land acquisition, the identified habitats could be used as the ecological rationale for allowing out-of-kind mitigation as well as guide the site selection for such mitigation. Priority habitats are those that:

1. have experienced significant losses,

2. are rare,

3. are experiencing a high level of threat,

4. are vulnerable to disturbance,

5. support biodiversity conservation,

6. provide habitat for declining species, and

7. will produce the greatest long-term benefits to wildlife.

The following list is a synthesis of priority estuarine habitats (in no particular order) that were identified:

1. Sitka Spruce swamps

2. Intertidal salt marshes

3. Intertidal freshwater wetlands

4. Eelgrass beds

5. Intertidal mudflats

6. Sand bars in the estuary

7. Low gradient unconfined channels and floodplains

\section{Oregon Biodiversity Project}

The Oregon Biodiversity Project (1998) identified specific priority areas related to conservation of biodiversity:

1. Cape Blanco region priority habitats including estuaries, core coho, fall Chinook and winter steelhead habitat, and habitat supporting more than 25 atrisk species.

2. Alsea-Siuslaw Area for salmon habitat and aquatic diversity

3. Nestucca River watershed for aquatic diversity related to chum, coho, Spring Chinook, and winter steelhead. 
4. Tillamook Bay delta for migrating waterfowl and shorebirds, and other estuarine-dependent species.

Other than estuarine coastal wetland habitats, the following were also identified as priority habitats:

-floodplain wetlands, -shrub-scrub wetlands of Sutton Lake, Lane County

(habitat for at-risk species Limbella freyi, and

-southern Oregon bogs with at-risk plants species of Lilium occidentale and Darlingtonia californica.

\section{Comprehensive Wildlife Conservation Strategy}

The Oregon Department of Fish and Wildlife drafted Oregon’s Comprehensive Wildlife Conservation Strategy in fall 2005 (ODFW 2005). This strategy provides a comprehensive and long-term framework for conserving Oregon's natural resources through voluntary programs for private landowners. Those species that are in most need of conservation were identified as "strategy species". Key habitats essential to these strategy species were located and assessed. "Strategy habitats” per ecoregion that are necessary to conserve diverse assemblages of the state's fish and wildlife species were identified. Historical losses and current ecological importance of habitat were considered in identifying strategy habitats. Conservation opportunity areas were then mapped based upon these strategy habitats. This process will be repeated every five years to update the status of strategy species, habitat data, and mapping.

In the coast range ecoregion, seven strategy habitats were identified including estuaries, freshwater aquatic habitats, wetlands, and coastal dunes. "Strategy habitats" were chosen for their significant losses since 1850, historical importance to the ecoregion, amount of remaining habitat managed for conservation, and significance to strategy species. Estuaries were identified as critical for salmon, crabs, other shellfish, marine mammals and seabirds. Strategy species dependent upon estuaries are black brant and salt marsh bird's beak (. Additionally, waterfowl use estuaries as winter habitat, migratory shorebirds use estuaries for stopover feeding, and band-tailed pigeons use estuaries for mineral sources. General threats identified for the Coast Range Ecoregion 
were land use changes and invasive species. The five identified stressors to estuaries were:

1. increasing development and land use conversions,

2. alteration of hydrology,

3. degraded water quality,

4. invasive plants and invertebrates,

5. loss of habitat complexity, and

6. poor management coordination.

Suggested solutions to threats relative to DSL jurisdiction and programs include:

1. provide incentives to protect, maintain, restore estuaries;

2. remove dikes to restore tidal marshes;

3. maintain/restore eelgrass beds;

4. consider water quality impacts of development;

5. develop early detection/control programs to control invasive species such as Spartina spp. and green crabs;

6. coordinate conservation priorities among DSL, DLCD and OWRD; and

7. add large woody debris to provide wind protection, shade, and hiding places.

“Local and specialized habitats" that exist at a finer scale than "strategy habitats" and are rare and/or important to strategy species were also identified. Those estuarine habitats that were given this designation were bays, eelgrass beds, intertidal mudflats, and sandspits. Bays provide winter habitat for waterfowl and rearing habitat for juvenile salmon, while eelgrass beds are integral to the aquatic food chain, provide rearing habitat for juvenile fish, and provide forage for black brant. Intertidal mudflats are important to shorebirds especially during migration, provide important habitat for clams and other invertebrates, and provide mineral springs for band-tailed pigeons. Sandspits provide protected roosting and nesting sites for colonial waterbirds such as American white pelican, brown pelicans, gulls, cormorants, and Caspian terns. Wetland specialized habitats were also identified in the coast range ecoregion including bogs, fens, and depressional wetland forests and shrublands.

This plan also proposes the development of a statewide network of conservation banks that may be used for mitigation requirements for the Removal-fill law and State Endangered Species Law. This strategy also calls for a statewide GIS-database that 
tracks all conservation activities and needs, similar to OWEB's voluntary stream and wetlands restoration database but with upland activity as well.

Although this strategy was developed to be strategic about voluntary conservation efforts by private landowners, these priority habitats and species could help to guide decisions about offsite, out-of-kind, and indirect mitigation options (PTP/bank). The strategy emphasizes the need to "be strategic rather than opportunistic" by targeting strategic habitats, species, and conservation opportunity areas, rather than accommodating any interested landowners. Mitigation sites are to be protected in perpetuity; therefore, it becomes crucial that these sites are chosen with the biggest ecological benefit in mind, not only because the site was convenient to the permitee.

\section{Summary of priorities}

Although these priorities were developed for other purposes, they could be useful in establishing priorities for the regulatory restoration program in Oregon's estuaries. State ownership of estuarine lands extends, vertically, to MHHW (unless sold), but estuarine resource replacement requirements extend to the highest measured tide or line of nonaquatic vegetation. Therefore, a majority of higher elevation estuarine habitat is in private ownership. If no longer in agricultural production, these habitats could be acquired and restored by an individual applicant, by a mitigation bank sponsor, or by a watershed council or nonprofit with PTP funds. However, for any of these estuarine habitat types to be considered “environmentally preferable” to justify “out-of-kind” mitigation, the impact site should not be one of these priority freshwater wetlands.

\subsection{Summary}

Watershed assessments have attempted to assess aquatic resources. These should be used to help guide decisions regarding the acceptability of in-kind versus out-of-kind compensatory mitigation. At the impact site, the condition of the wetland and how it functions within the landscape should influence whether out-of-kind mitigation (estuarine) is an ecologically preferable tradeoff. HGM wetland profiles per watershed 
would provide even better guidance on this policy issue since these profiles consider wetland abundance and distribution in relation to function. Remaining estuarine habitat is largely protected, however, coastal populations continue to grow. Development is not only occurring on upland habitat but on non-tidal coastal wetlands. Little protection exists for non-tidal coastal wetlands outside of the state's Removal-fill program (Good \& Swayer 1998). Many of these non-tidal wetlands are isolated palustrine emergent wetlands (Larsen 2005). In an attempt to better understand the ecological function of isolated wetlands nationally, Comer et al. (2005) found that isolated wetlands support high levels of biodiversity including many at-risk plant and animal species based upon information from state natural heritage programs and the Natureserve Central database. According to Comer et al. (2005), of the 614 at-risk plants in Oregon, 21 are supported by isolated wetlands and of the 374 at-risk animals, only one is associated with isolated wetlands. Of the 41 wetland systems found in Oregon, 29\% are isolated including vernal pools, interdunal wetlands, and Willamette Valley wet prairie. Little research has focused on the ecological function of both isolated and hydrologically connected nontidal coastal wetlands in Oregon.

Nevertheless, OWEB's prioritization framework, the Oregon Biodiversity Project, and ODFW's Comprehensive Wildlife Conservation Strategy have identified many coastal non-tidal wetlands habitats as high priority for acquisition and restoration including freshwater emergent wetlands, wet prairie, depressional wetland shrublands, and freshwater aquatic beds. Tidal wetlands have been targeted as priority habitats for restoration largely in response to salmon recovery efforts. While it seems short-sighted to sacrifice all isolated palustrine wetlands on the coast to restore tidal wetlands as compensatory mitigation through regulatory restoration, functional assessments can help to make out-of-kind mitigation decisions on a case-by-case basis. The case could be made to trade the restoration of tidal marsh for a poorly functioning isolated palustrine wetland. As Bedford (1996), recommended wetland diversity should be preserved throughout the landscape. In some areas such as the Portland metropolitan area (Gwin et al. 1999), mitigation has resulted in reducing that diversity. Along Oregon's coast, wetland diversity has been reduced not due to mitigation but to development patterns of coastal communities living and working along estuaries, thus impacting a large 
percentage of tidal wetlands prior to any regulatory protection. The coastal wetlands change study will provide a useful summary of what Cowardin and HGM wetland classes have been lost from the landscape between 1985/86 and 2001. While distribution of HGM subclasses can provide some indication of what functional changes have occurred within the coastal lowlands ecoregion IV and lower portion of coastal watersheds, a site specific functional assessment tool will need to be developed for the non-tidal coastal wetlands. The Level 4 Ecoregion: Coastal Lowlands, which includes all lands less than 400 feet in elevation, could provide the boundaries for 'out-of-kind' mitigation.

As a pre-screen, the statewide HGM classification (Adamus 2001) could be used to understand what wetland functions have been disproportionately lost from the coastal watershed and inform out-of-kind HGM subclass/Cowardin class trades, especially if lost functions were replaced through 'out-of-kind' mitigation. For example, on a scale from 1 (function present in some sites of this subclass and capacity usually less than in several other subclasses) to 3 (one of the more important subclasses for this function), Riverine and Estuarine Fringe subclasses were both considered common and deemed important and were given the same rating for the following functions: biodiversity support (2), waterbird habitat (2-3), and resident and anadromous fish (3). Riverine wetlands, compared to other HGM classes, score a 1-2 in water storage and delay while estuarine fringe provided minimal support. Riverine impounding wetlands were rated as a 2 (function present in many sites of this subclass and capacity usually greater than in several other subclasses) for greater capacity of sediment stabilization while riverine flow through and both estuarine fringe classes were rated 1 (less capacity to serve this function). Actual functional assessments would need to be made to understand the functions being performed at the impact site to identify potential mitigation sites, which could include out-of-kind wetlands pending upon functions.

Available GIS datasets, which provide wetland type (HGM and Cowardin class), current distribution, historical distribution, and potential restoration sites per watershed allow mitigation decisions to be informed by a landscape approach. These datasets combined with socioeconomic data can help to guide 'out-of-kind' mitigation decisions, the siting of mitigation banks, targeting PTP funds, and conservation in lieu mitigation decisions. A DSL GIS-based database needs to be accessible to the permittee and 
consultants, who are preparing applications for permitted impacts and mitigation plans.

A web-based database would best achieve this accessibility. 


\section{CHAPTER 7 \\ RECOMMENDATIONS}

\subsection{Conclusions}

The estuarine resource replacement program appears to be an artifact of an earlier era. More recently-developed functional assessment methods offer an improvement over the relative values habitat table in the estuarine resource replacement (ERR) rules. Functional assessment methods can consider both aquatic site level and landscape level characteristics for evaluating estuarine wetland habitat. As illustrated by the permit inventory, although estuarine habitat is considered ecologically important, the estuarine mitigation rules do not necessarily require larger replacement ratios than would use of the freshwater wetland ratios. Due in large part to the protective measures afforded to estuarine habitat through the state land use program's Goal 16 and 17, few permitted impacts occur. The compensatory freshwater wetland mitigation rules (CWM) are more sophisticated and provide more explicit guidance regarding mitigation to include the sequencing stressed by the federal 404 program, and thus these rules should be adapted to include estuarine wetlands. The following specific changes are recommended to improve Oregon's estuarine mitigation program.

\subsection{Statutory Changes}

\section{Recommendation I: Introduce legislation to rescind ORS 196.830 (1-5) Estuarine Resource Replacement.}

The Estuarine Resource Replacement statute is an unnecessary redundancy in state law. Within the Removal-fill Law (193.800 et seq.), proposed impacts require demonstration of mitigation as a criterion for permit issuance (196.825 (3i) for all wetlands and waterways, including estuarine. As defined by ORS 196.800(10), mitigation means the reduction of adverse effects of a proposed project by considering avoiding the impact, minimizing the impact, rectifying the impact, reducing the impact, or compensating the impact by replacing or providing comparable substitute wetland or 
water resources. Estuarine resource replacement as a condition of fill or removal from an estuary (ORS 196.830(1)) means the creation, restoration, or enhancement of an estuarine area to maintain the functional characteristics and processes of the estuary. Although spelled out more specifically, estuarine resource replacement is in essence the same as the final step of mitigation: compensating for the impact. Therefore, it is redundant to have overlapping regulations.

Ease of Implementation:

The dissolution of ORS 196.830 (1-5) Estuarine Resource Replacement is merely a housekeeping measure. In order to implement this recommendation, a legislative concept with rationales will need to be developed. Stakeholder support from groups such as the Oregon Department of Land Conservation and Development's Oregon Coastal Management Program and Oregon Coastal Zone Management Association will need to be attained. This recommendation requires the development of a legislative concept and approval by the state Land Board and then legislative approval.

\subsection{Rule Changes}

Recommendation 2: Replace Estuarine Resource Replacement (ERR) rules (141-0850240 through 0257) with Compensatory Wetland Mitigation (CWM) and Compensatory Mitigation (CM) rules.

Because the ERR are based upon outdated understandings of estuarine ecology, estuarine wetland function, and mitigation practices, they should be replaced by the CWM rules. More recently-developed functional assessment methods offer an improvement over the relative values habitat table in the estuarine resource replacement (ERR) rules. As illustrated by the permit inventory, although estuarine habitat is considered ecologically important, the estuarine mitigation rules do not necessarily require larger replacement ratios than would use of the freshwater wetland ratios. In place of the ERR rules, compensatory mitigation in estuaries should be covered by the CWM for freshwater marsh, forested swamps, salt marsh, algae beds, and eelgrass beds and CM should cover impacts to unvegetated soft bottom and rocky bottom habitats. While estuarine wetland habitats are boundaries defined by wetland delineations, unvegetated estuarine habitat should be jurisdictional to the highest measured tide, 
determined by nearby benchmark or field indicators such as wrack lines. Along unvegetated boundaries, if there are no nearby benchmarks to extrapolate from, than field observations of ordinary high water should be used to determine jurisdictional boundaries.

The CWM rules provide detailed guidance on mitigation in terms of mitigation sequencing, required replacement ratios, functional assessments (tidal HGM), and requirements of a mitigation and monitoring plan. Based on the documented success, mitigation credit preference should be given for dike breaching. 'Restoration' credit should be given for removing the footprint of the dike, assuming it is upland, and 'enhancement' credit for the area behind the dike, if it currently meets wetland criteria.

The CM rules do not outline explicit compensation ratios or what activities constitute mitigation and thus additional rulemaking would need to be done to address impacts to nonvegetated estuarine habitat. Payment to provide funds should be allowed for minor estuarine impacts as they are currently allowed for minor impacts to other Cowardin/HGM wetland systems. Mitigation banks developed in estuaries should be covered by the freshwater mitigation banking rules.

Ease of Implementation:

Replacing ERR with CWM and CM rules will require going through the rulemaking process, which includes holding a 30 to 90 day public comment period. Rule changes are made fairly frequently at DSL making this recommendation fairly easy to implement.

\section{Recommendation 3: Adopt updated National Tidal Datum Epoch 1983-2001 tidal elevations and subsequent updates for Oregon's estuaries.}

The tidal elevations reported in OAR 141-85-266 are outdated and based upon an outdated land datum. The Department of State Lands should adopt the 1983-2001 National Tidal Datum Epoch for determining tidal elevation. As new epochs are established, DSL should incorporate them into their administrative rules. Ease of implementation:

This recommendation will require a rule change but will be fairly easy to implement. To allow for future updates without rule changes, the rule could say that 
tidal elevations in Oregon's estuaries should be based upon the most recent tidal epoch established by NOAA.

\section{Recommendation 4: Add tidal swamps to rare and difficult to replace habitats for conservation in lieu CWM option under OAR 141-085-0131.}

Due to the significant loss of tidal swamps (90-95\%) in Oregon's estuaries, their unique ecological importance, and the challenge in restoring them due to the time commitment, such as Sitka swamps, remaining tidal swamp habitat should be eligible for the conservation in lieu CWM option. For in-kind CWM, due to the length of time required to reestablish tidal swamps, conservation in lieu is recommended. If an impact wetland does not perform a critical function, then out-of-kind conservation in lieu of tidal swamp habitat should be accepted if the site is not already protected by another conservation mechanism. At least in the Siuslaw river estuary prioritization (Brophy 2005), two sites with tidal swamp habitat were prioritized for conservation since their current zoning was 'resource use' allowing for commercial farming or forest use. Conservation in lieu CWM would protect this rare and difficult to replace habitat from future permitted impacts.

Ease of Implementation:

Rule changes are made fairly frequently at DSL making this recommendation fairly easy to implement.

Recommendation 5: Adopt DSL mitigation success criteria guidance document in rule so permittees know what metrics are required in mitigation plans.

Based upon the inventory of 16 estuarine mitigation plans, only six included wetland size, three included 'meets wetland definition', ten included a vegetation criterion, seven included wetland elevation, and eight included a hydrology-related criterion. Although CWM rules require goals, objectives, and success criteria in mitigation plans, appropriate success criteria are not listed in rule. Including success criteria in rule would help to ensure that appropriate success criteria are included in mitigation plans as well as permit conditions. 
Success criteria for all wetlands should always include that the wetland meets wetland criteria for the specified area per 1987 Corps Manual. Specifically for estuarine wetlands, target surface water elevation and wetland elevation relative to a land datum (NAVD 88) and tidal gauge datum (MLLW) should always be included as success criteria. Specifications about wetland slope should also be included. A vegetation success criterion should also be included that documents changes in species composition and distribution.

Ease of Implementation:

Rule changes are made fairly frequently at DSL making this recommendation fairly easy to implement. 
Standard Operating Procedures

\section{Recommendation 6: Encourage CWM of tidal marshes for former tidal marsh impacts.}

Many estuarine tidal marshes were diked and drained over the past 150 years, mostly for pasture or other agricultural purposes. Any impacts to wetlands that were historically tidally influenced, but are now poorly functioning freshwater wetlands (e.g., diked, tidegated), should be mitigated by restoring, creating, or enhancing tidal wetland habitat. Estuarine inventories and prioritizations (Table 21) can be used to determine if a site was historically tidal.

Ease of Implementation:

This recommendation will be easy to implement, but will require some outreach to applicants.

\section{Recommendation 7: Allow non-tidal impacts to be compensated with estuarine habitat when impact site does not perform a critical function(s).}

A significant amount of estuarine wetlands have been lost from Oregon's estuaries. Due to their documented importance to supporting juvenile salmonids and their importance in maintaining overall ecosystem function, out-of-kind estuarine mitigation should be allowed to compensate for non-tidal impacts if the impact site wetland is poorly functioning and a common wetland type (e.g., wet pasture). Out-of-kind mitigation should not be allowed for impacted wetland types that have been identified as priority restoration and/or acquisition habitats. An ecological rationale should still be required when estuarine mitigation is offered for non-tidal impacts. The explanation should be more specific than 'estuarine wetlands have been historically lost' and 'are important to juvenile salmon'. This rationale could be used anywhere along the coast since a significant amount of estuarine wetlands have been impacted. In order to fully assess if the trade will benefit the ecosystem as a whole, the functions of the proposed impact site need to be understood.

Restoration efforts on coastal wetlands have been narrowly focused on salmon recovery, which has ignored wetland types not associated with the river's floodplain. Isolated wetlands that are not accessible by salmon have not been studied as extensively in Oregon. Their 
ecological importance and distribution is not as well studied. While the public and agencies value salmon, sacrificing all isolated wetland types for estuarine may not be beneficial for overall ecosystem health. Functional information about the proposed wetland to be impacted should be provided as well as functional information about the proposed wetland to be restored. If the impact site scores high for a regionally important function, such as water quality or salmonid habitat, then the mitigation should occur onsite and in-kind. However, if the wetland proposed for impact is poorly functioning and commonly distributed throughout the landscape, then offsite, out-of-kind estuarine wetland mitigation makes sense. References should be made to landscape-based assessments that have considered wetland types, distributions, and functions associated with those lost functions from a historical and current perspective.

Ease of implementation:

This recommendation will require a shift in the current preference for in-kind and onsite compensatory mitigation within DSL and the regulated public.

\section{Recommendation 8: Only allow estuarine mitigation banks in deep draft estuaries where development trends threaten current and former estuarine wetlands that were diked and converted to agricultural uses.}

Although estuarine wetlands have been extensively impacted, permitted impacts are now rare ( 30 acres since 1970). Estuarine mitigation banks may only be feasible in deep draft estuaries where development threats still exist, water-dependent impacts are allowable by estuary plans, and tidal marsh wetlands and former tidal marshes are zoned for development. Estuarine mitigation banks should be strategically sited based upon estuarine wetland restoration priorities (Table 21). Estuarine mitigation banks should only sell out-of-kind mitigation credits for non-tidal wetlands that are not (and do not have the potential)l for providing crucial functions. A non-tidal coastal mitigation bank may be more appropriate where a majority of impacts will be to non-tidal wetland (i.e. Florence). Estuarine mitigation banks do seem appropriate in deep development estuaries such as the Columbia River and Coos Bay, where development may be occurring on former tidal estuarine habitats that are currently zoned for development.

Ease of implementation: 
This recommendation will require the support of the interagency Mitigation Bank Review Team.

Recommendation 9: As a component of dike breaching or fill removal, enhancement credit should be granted for the addition of large woody debris to the marsh surface and tidal channels re-excavation and remeandering of tidal channels.

Due to the reduced supply of and the importance of large woody debris (LWD) to marsh ecosystems, enhancement credit should be given for the inclusion of large woody debris as a component of a restoration mitigation plan. Furthermore, given the importance of tidal channels to marsh ecosystems, enhancement credit should be given for the excavation and remeandering of historical tidal channels, as a component of a restoration mitigation plan. Hydrologic modeling should be used to designing any complex tidal channel morphology without historical aerial photos or appropriate reference sites. Enhancement credit should only be granted for culvert enlargement and tidegate replacement if the proposed treatment actually improves intertidal marsh ecosystem function by allowing sheet flow across the marsh surface. The tidal HGM (Adamus 2005) can be used as a guide for developing and designing mitigation plans relative to the amount of large wood, the tidal channel density and morphology, culvert enlargement, and tidegate replacement.

Ease of Implementation:

Rule changes are made fairly frequently at DSL making this recommendation fairly easy to implement.

Recommendation 10: Incorporate regional ecological priorities into compensatory mitigation.

A long-term goal of the Removal-fill program should be to coordinate more effectively with nonregulatory restoration efforts to work towards ecosystem-based restoration goals. The tidal wetland assessment data developed by Scranton (2004) 
identified "restoration consideration areas" for each estuary. Estuarine wetland prioritizations (Table 21) are available for many estuaries including the Tillamook Bay, Columbia River, Alsea Bay, Yaquina Bay, Umpqua River, and Siuslaw River. Likewise, most coastal watershed councils have developed restoration and land acquisition priorities for their watershed and estuaries, some of which include wetlands (Table 21). These documents, in addition to regional priorities developed by the Oregon Department of Fish and Wildlife and the Oregon Watershed Enhancement Board, can be used to inform mitigation decisions.

Permittees should work with local watershed councils to identify restoration priorities that can be used to inform permit decisions in terms of siting offsite mitigation. Conservation in lieu could be proposed for those habitats that are identified as priorities for acquisition (i.e., tidal swamp). Payment to Provide funds can be directed to projects based on coastal wetland habitat priorities, with DSL review and oversight.

Additionally, these prioritizations can provide ideas for offsite, in-kind mitigation as well as provide rationale for offsite, out-of-kind decisions.

As permit coordinators become familiar with the players and the issues in their respective counties, they should also become aware of what the ecological needs of their counties are from these watershed council publications and other agency documents, and work with applicants to consider these priorities when determining off-site and out-ofkind compensatory mitigation habitat types and site selection.

Ease of implementation:

This recommendation requires commitment from the agency to reach out to other agencies and groups working on ecosystem restoration and for those regional priorities to be easily accessible to permit coordinators. As a first step, mapped restoration inventories and prioritizations can be incorporated into the LAS mapping program for easy access.

Miscellaneous Recommendations

Recommendation 11: Convene a technical advisory committee to determine a method to integrate functional assessments into compensatory mitigation area requirements. 
Functional assessment scores are not incorporated into compensatory wetland mitigation ratios. Therefore, understanding what functions are being lost and gained as a result of Removal-fill activity and associated compensatory mitigation is based solely upon the assumption that Cowardin class or HGM subclass are indicative of function. However, whether the wetland type is performing a particular function depends largely on the condition of the wetland and whether the wetland has the opportunity to perform the function based upon surrounding land use. Therefore, understanding to what degree Oregon is achieving 'no net loss of wetland function' is virtually impossible. The tidal HGM provides a methodology for assessing level of function for 12 functions performed by tidal wetlands in Oregon. A special advisory committee should be convened to develop a methodology for incorporating level of function into compensation ratios. Ease of implementation:

This topic can be broached but will take a large time commitment from DSL staff and a technical advisory committee to develop an ecologically sound and easy to implement policy. This recommendation will also require some financial resources to achieve, which may be available through federal grant programs such as the Environmental Protection Agency’s wetland program grants. Wetland programs in Washington and North Carolina provide good templates to emulate. A rulemaking will also be required to implement this recommended change.

\section{Recommendation 12: Make mitigation compliance a priority.}

Compensatory mitigation projects should be a top priority within the Removal-fill program. Based upon the permit inventory, the mitigation status of $44 \%$ (7) of the permits was unknown. Although the Removal-fill database is set up to track the status of mitigation and receipt of monitoring reports, these fields for the permits reviewed in this report were not populated. Based upon anecdotal information and through personal observation, permit processing tends to monopolize a majority of staff time, leaving little time to enforce permit compliance and assess the ecological results of mitigation projects. Imposition of tighter permit processing timelines and added responsibilities (e.g., Statewide Programmatic General Permit) exacerbate the problem. As identified in the literature, the enforcement of permit compliance tends to be inadequate in regulatory 
programs. Without prioritizing compliance, DSL has no real way of assessing whether the estuarine resource replacement program has "maintained the functional characteristics and processes of the estuary such as natural biological productivity, habitats, species diversity, unique features and water quality” or if the compensatory wetland mitigation program effectively compensates for wetland area and functions lost through permitted impacts alteration.

Ease of implementation: This recommendation will require additional financial resources to assess overall permit compliance and potential reprioritization of staff time. Hiring additional staff to focus on permit compliance will require legislative approval. In the face of state agency budget constraints, this recommendation may be difficult to achieve.

\section{Recommendation 13: Maintain a digital copy of all permit files in order to assess program more effectively.}

Inactive Removal-fill permits older than seven years are purged from DSL's file room due to lack of storage space. This practice of purging permit files combined with a database change prevented at least 64 permits from being available for evaluation. Therefore, this program evaluation does not provide a complete report of estuarine Removal-fill activity from 1987 to 2001 and associated compensatory mitigation. Either more space should be identified for storing paper copies of expired permits older than seven years or a digital copy of all permit file information, including mitigation plans and monitoring reports, should be kept in order to allow for a more complete picture of Removal-fill activity in Oregon's estuaries and other wetland and water resources. Ease of implementation: This recommendation will require a financial investment either for storage space or staff time for data entry.

\section{Recommendation 14: Develop a GIS-based permit database.}

DSL’s Removal-fill program is in need of a Geographic Information System permit database. An improved database should be capable of tracking permits as it does now, but with improved mapping abilities. Currently, impact and mitigation sites are represented as points in the section centroid. Impact and mitigation sites should be represented by polygons on fine resolution aerial photographs. DSL currently has access 
to 2005 fine-resolution aerial photos ( $1 \times 1 \mathrm{~m}$ pixel size) that could be used in the database. Also, georeferenced tax lot maps, USGS 7.5 minute topographic maps, the State Wetlands Inventory, and the tidal HGM layer (Scranton 2004) should also be incorporated into the database. Development of a GIS-based database will not only enable program enforcement, but will also allow for consideration of permitted cumulative impacts to aquatic resources.

Ease of Implementation:

Achieving this recommendation will be more difficult, as it requires developing a database, dedicating staff time to maintain the database, and training staff to use it. Development of the database could be contracted out to a consulting firm, but an inhouse DSL committee would be needed to develop the conceptual plan. This recommendation will require a prioritization of current staff time or legislative approval to fund a new position.

\section{Recommendation 15: Provide staff with adequate tools for determining jurisdictional extent of the estuary.}

The Removal-fill Law in estuaries is applicable to the elevation of highest measured tide (HMT) or to the wetland/upland boundary if vegetation is present. When impacts are permitted, compensatory mitigation is required from extreme low tide to highest measured tide or wetland/upland boundary. Due to the degree of difficulty in determining the location of HMT without a nearby tidal gauge or benchmark, jurisdictional determinations by permit coordinators, in practice, are currently based upon field indicators such as vegetation breaks or terraces, which may not reflect HMT.

For Removal-fill permits, detailed contour maps indicating tidal elevations including HMT should be submitted with applications in order for permit coordinators to understand the potential impacts of the project to jurisdictional waters. For potential violations of the Removal-fill Law (i.e., riprap placed below HMT without a permit), DSL permit coordinators need to determine the elevation of HMT at a particular tax lot. Whether the burden of proof lies with the potential violator or with DSL is unclear. If the burden of proof is the responsibility of DSL, then the agency will need to be able to pay for professional survey work to determine where the fill is in relation to the state's 
jurisdiction. If unable to incur the cost of a professional survey, then the Removal-fill program staff, in practice, will continue to use ordinary high water for jurisdictional determinations.

Ease of implementation:

A professional survey and mapping effort will most likely be cost-prohibitive under the current budget constraints faced by DSL, unless the Oregon Coastal Management Program deems this important and can secure federal funds to pay for this endeavor.

Recommendation 16: Increase collaboration between Coastal Managers (e.g., Removal-fill permit coordinators) and South Slough National Estuarine Research Reserve.

Although the Removal-fill program and the South Slough National Estuarine Research Reserve are part of the Department of State Lands, interaction between these two programs is limited. Strengthening the interaction and collaboration between DSL's Removal-fill Program and the South Slough National Estuarine Research Reserve has the potential to improve the ecological effectiveness of compensatory mitigation. Similar to the Reserve's dike breaching research (Cornu \& Sadro 2002), additional research is needed to understand the ecological affects of culvert enlargement, tidegate replacement, bank stabilization techniques, and partial dike breaching. Additionally, through South Slough's Coastal Training Program, technical workshops could be offered at low cost to coastal managers such as the Removal-fill staff to enhance their technical expertise with assessing the viability of mitigation plans, developing monitoring plans, identifying appropriate success criteria, and incorporating adaptive management into monitoring plans.

Ease of implementation: This recommendation will take effort by management and time commitment to expose each program to one another's work and to better understand better each other's mission and needs. A first step toward improved collaboration could be for the Removal-fill staff to tour the Research Reserve and for the Reserve's Coastal Training Program staff to survey the technical needs of the Removal-fill staff. 


\section{REFERENCES}

Adamus, P.R. and D. Field. 2001. Guidebook for Hydrogeomorphic (HGM)-based Assessment of Oregon Wetland and Riparian Sites. I. Willamette Valley Ecoregion, Riverine Impounding and Slope/Flat Subclasses. Volume IA: Assessment Methods. Oregon Department of State Lands, Salem, OR.

Adamus, P.R. 2001. Guidebook for Hydrogeomorphic (HGM)-based Assessment of Oregon Wetland and Riparian Sites. Statewide Classification and Profiles. Oregon Department of State Lands, Salem, OR.

Adamus, P.R. 2004. Background information on compensation ratios. Adamus Consulting: Corvallis, OR. Accessed at www.oregonstate.edu/ adamusp. 02/01/06.

Adamus, P.R. 2005. Rapid Assessment Method for Tidal Wetlands of the Oregon Coast: Volume 1 of a Hydrogeomorphic (HGM) Guidebook. Operational Draft. Coos Watershed Association, US Environmental Protection Agency, and Oregon Department of State Lands, Salem.

Ainslie, W.B. 1994. Rapid Wetland Functional Assessment: Its Role and Utility in the Regulatory Arena. Water, Air, and Soil Pollution. 77: 433-444.

Ambrose, R.F. 2000. Wetland mitigation in the United States: assessing the success of mitigation policies. Wetlands (Australia) 19: 1-27.

Anisfeld, S.C. and G. Benoit. 1997. Impacts of flow restrictions on salt marshes: an instance of acidification. Environmental Science and Technology. 31: 1650-1657.

Armstrong, D.A., Rooper, C., and D.Gunderson. 2003. Estuarine production of juvenile Dungeness crab (Cancer magister) and contribution to the Oregon-Washington coastal fishery. Estuaries. 26(4B): 1174-1188.

Bartoldus, Candy C. 1999. A Comprehensive Review of Wetland Assessment Procedures: A Guide for Wetland Practioners. Environmental Concern, Inc. 196 Pp.

Barczak, M.1998. Watershed assessment. Nestucca/Neskowin Watershed Council. Resource Assistance for Rural Environments. University of Oregon. Eugene, OR. 116 Pp.

Bedford, B.L.1996. The need to define hydrologic equivalence at the landscape scale for freshwater wetland mitigation. Ecological Applications. 6(1): 57-68. 
Boese, B. L., B. D. Robbins, and G. Thursby. 2005. Desiccation is a limiting factor for eelgrass (Zoestera marina L.) distribution in the intertidal zone of a northeastern Pacific (USA) estuary. Botanica Marina. Walter de Gruyter. 48:27483.

Blomberg, G.1987. Development and mitigation in the Pacific Northwest. Northwest Environmental Journal. 3(1): 64-91.

Bollens, S.M., Cordell, J.R., Avent, S., and R.Hooff. 2002. Zooplankton invasions: a brief review, plus two case studies from the northeast Pacific Ocean. Hydrobiologia. 480: 87-110.

Borde, A.B., Thom, R.M., Rumrill, S., and L. M. Miller. 2003. Geospatial habitat change analysis in Pacific Northwest coastal estuaries. Estuaries. 26(4B): 1104-1116.

Borde, A.B., O’Rourke, L.K., Thom, R.M., Williams, G.W., and H.L. Diefenderfer. 2004. National review of innovative and successful coastal habitat restoration. Prepared for National Oceanic and Atmospheric Administration. Battelle Marine Sciences Laboratory: Sequim, W.A. 57 Pp.

Bottom, D.B., Kreag, F., Ratti, C., and R. Starr.1979. Habitat Classification and Inventory Methods for the Management of Oregon Estuaries. Report prepared for Oregon Land Conservation and Development Commission. Salem, OR. 109 Pp.

Bottom, D. L., Jones, K.K., Cornwell, T.J., Gray, A., and C.A. Simenstad. 2005. Patterns of Chinook salmon migration and residency in the Salmon River estuary (Oregon). Estuarine Coastal and Shelf Science. 64: 79-93.

Bradford, M.J., Myers, R.A., and J.R. Irvine. 2000. Reference points for coho salmon (Oncorhynchus kisutch) harvest rates and escapement goals based on freshwater production. Canadian Journal of Fisheries and Aquatic Sciences 57(4): 677-686.

Breaux, A. and F. Serefiddin.1999. Validity of performance criteria and a tentative model for regulatory use in compensatory wetland mitigation permitting. Environmental Management. 24(3): 327-336.

Brinson, M.M. 1993. A Hydrogeomorphic Classification for Wetlands. U.S. Army Corps of Engineers, Waterways Experiment Station, Technical Report WRP-DE-4. Vicksburg, MS.

Brinson, M.M. and R. Rheinhardt. 1996. The role of reference wetlands in functional assessment and mitigation. Ecological Applications. 6(1): 69-76.

Broome, S.W., Seneca, E.D., and W.W. Woodhouse. 1988. Tidal marsh restoration. 
Aquatic Botany. 32: 1-22.

Brophy, L.S. 1999. Yaquina and Alsea Estuarine Wetland Prioritization. Prepared for MidCoast Watershed Council. Green Point Consulting: Corvallis, OR. Accessed online at at http://www.GreenPointConsulting.com/reports.html. 04/05/2006.

Brophy, L.S. 2003. Wetland Site Prioritization: Lower Elk and Sixes River, Curry County, Oregon. Prepared for Oregon Trout. Accessed online at http://www.ortrout.org/images/8success/Cape\%20Blanco\%20Assessment.pdf 04/05/2006.

Brophy, L. 2005a. Estuary Assessment Chapter DRAFT. In OWEB Watershed Assessment Manual, Chapter 3. Oregon Watershed Enhancement Board. Salem, OR. 78 Pp.

Brophy, L.S. 2005b. Tidal wetland prioritization for the Siuslaw Estuary. Prepared for the Siuslaw Watershed Council. Green Point Consulting: Corvallis, OR. Accessed online at http://www.GreenPointConsulting.com/reports.html. 04/05/2006.

Brophy, L.S. (Green Point Consulting) and K. So. 2005a. Tidal wetland prioritization for the Nehalem River Estuary. Prepared for the U.S. Fish and Wildlife Service, Oregon Coastal Program, Newport Field Office. Accessed online http://www.GreenPointConsulting.com/reports.html. 04/05/2006.

Brophy, L.S. (Green Point Consulting) and K. So. 2005b. Tidal wetland prioritization for the Smith River Watershed, Umpqua Estuary of OR. Prepared for the U.S. Fish and Wildlife Service, Oregon Coastal Program, Newport Field Office. Green Point Consulting: Corvallis, OR. Accessed online at http://www.GreenPointConsulting.com/reports.html. 04/05/2006.

Brophy, L.S. (Green Point Consulting) and K. So. 2005cTidal wetland prioritization for the Umpqua Estuary. Prepared for the U.S. Fish and Wildlife Service, Oregon Coastal Program, Newport Field Office. Green Point Consulting: Corvallis, OR. Accessed online at http://www.GreenPointConsulting.com/reports.html. 04/05/2006.

Bureau of Land Management. 1999. Lower Alsea Watershed Analysis. Bureau of Land Management, Salem District, Marys Peak Resource Area. Salem, OR.

Cai, Q. 2005. 2004 Oregon Population Report. Population Research Center. College of Urban and Public Affairs. Portland State University, Portland, OR. 25 Pp. Accessed www.pdx.edu/prc. 04/21/06.

Cairns, J. 2000. Setting ecological restoration goals for technical feasibility and scientific validity. Ecological Engineering. 15: 171-180. 
California Coastal Commission. 1995. Procedural guidance for evaluating wetland mitigation projects in California's coastal zone. California Coastal Commission. Accessed 11/3/2005 at http://www.coastal.ca.gov/pubs.html.

Callaway, J.C. 2005. The challenge of restoring functioning salt marsh ecosystems. Journal of Coastal Research. SI(40): 24-36.

Carlton, J., Chapman, J., Yamada, S., Rumrill, S., Burke, J., Fleck, B., Howard, C., Hunt, C., and K. Palacios. 2003. Introduced Species in Oregon Estuaries. Accessed at http://web.science.oregonstate.edu/ yamadas/. 04/21/06.

Castelle, A.J., Conolly, C., Emers, M., Metz, E.D., Meyer, S., Witter, M., Mauermann, S., Bentley, M., Sheldon, D., and D. Dole. 1992. Wetland mitigation replacement ratios: defining equivalency. Shorelands and Coastal Zone Management Program. Washington State Department of Ecology. Olympia, WA. 118 Pp.

Chapman, D.J. and B.E. Julius. 2005. The use of preventative projects as compensatory restoration. Journal of Coastal Research. SI(40): 120-131.

Charland, J. 1997. Reconnaissance Survey of Tide Gates in Tillamook Bay Vicinity Tillamook Bay National Estuary Project. Garibaldi, OR. 21 Pp.

Charland, J. 1998. Tide Gate Modifications for Fish Passage and Water Quality Enhancement. Tillamook Bay National Estuary Project. Garibaldi, OR. 15 Pp.

Childers, D.L., Day Jr., J.W., and H.N. McKellar, Jr. 2000. Twenty more years of marsh and estuarine flux studies: revisiting Nixon (1980). Pp. 391-424.

In Weinstein, M.P. and D.A. Kreeger. Concepts and controversies in tidal marsh ecology. Kluwer Academic Publishers: Dordrecht, The Netherlands. 875 Pp.

Christy, J.A., Alverson, E., Dougherty, M., Kolar, S., Ashkenas, L., and P. Minear. 1998. Presettlement vegetation for the Willamette Valley, Oregon. Compiled from records of the general Land Office Surveyors (c. 1850). Oregon Natural Heritage Program. Portland, OR.

Colbert, D. and J. McManus. 2003. Nutrient biogeochemistry in an upwelling-influenced estuary of the Pacific northwest (Tillamook Bay, Oregon, USA). Estuaries. 26(5): 1205-1219.

Comer, P., K. Goodin, G. Hammerson, S. Menard, M. Pyne, M. Reid, M. Robles, M. Russo, L. Sneddon, K. Snow, A. Tomaino, and M. Tuffy. 2005. Biodiversity values of geographically isolated wetlands: An analysis of 20 U.S. states. NatureServe, Arlington. 
Coos Watershed Association, 2006, Coos Bay Lowland Assessment and Restoration Plan, March, 2006, Charleston, OR: Coos Watershed Association. Accessed at www.cooswatershed.org. 03/01/06.

Cordell, J.R. and S.M. Morrison. 1996. The invasive Asian copepod Pseudodiaptomus inopinus in Oregon, Washington, and British Columbia estuaries. Estuaries. 19(3): 629-638.

Cornu, C.E. and S. Sadro. 2002. Physical and functional responses to experimental marsh surface elevation manipulation in Coos Bay’s South Slough. Restoration Ecology. 10: 474-486.

Cornwell, T. J., Bottom, D. L., and K. K. Jones. 2001. Rearing of juvenile salmon in recovering wetlands of the Salmon River estuary. Oregon Department of Fish and Wildlife. Information Reports 2001-05, Portland, OR.

Correll, D.L., Jordan, T.E., and D. E. Weller.1992. Nutrient flux in a landscape: effects of coastal land use and terrestrial community mosaic on nutrient transport to coastal waters. Estuaries. 15(4): 431-442.

Cortright, R. , Weber, J., and R. Bailey. 1987. The Oregon estuary plan book. Oregon Department of Land Conservation and Development. Salem, OR.

Cowardin, L.M., V. Carter, F. Golet, and E. LaRoe. 1979. Classification of Wetlands and Deepwater Habitats of the United States. FWS/OBS-79/31. U.S. Department of the Interior, Fish and Wildlife Service, Office of Biological Services, Washington, D.C.

Crooks, S. and L. Ledoux. 1999. Mitigation banking as a tool for strategic coastal zone management: a UK perspective. CSERGE Working paper GEC 99-02. Accessed at www.vea.ac.uk/env/cserge/pub/wp/gec/gec_1999_02.pdf. 12/14/05.

Daehler, C.C. and D.R. Strong. 1996. Status, prediction, and prevention of introduced cordgrass Spartina spp. invasions in Pacific estuaries, USA. Biological Conservation. 78: 51-58.

Dahl, T.E.1990. Wetland losses in the United States, 1780's to 1980's. U.S. Fish and Wildlife Service Report to Congress: Washington, D.C.

Dame, R.F., Gregory, L. and E. Koepflier. 2000. Benthic-pelagic coupling in marshestuarine ecosystems. Pp. 369-390. In Concepts and controversies in tidal marsh ecology. Edited by M.P. Weinstein and D.A. Kreeger. Kluver Academic Publishers, Dordrecht. Pp. 597-630. 
Deegen, L.A., Hughes, J.E., and R.A. Rountree. 2000. Salt marsh system ecosystem support of marine transient species. Pp. 333-368. In Weinstein, M.P. and D.A. Kreeger. (eds.) Concepts and controversies in tidal marsh ecology. Kluwer Academic Publishers: Dordrecht, The Netherlands. 875 Pp.

DeLuca, W.V., C.E. Studds, L.L. Rockwood, and P.P. Marra. 2004. Influence of land use on the integrity of marsh bird communities of Chesapeake Bay, USA.

Wetlands 24: 837-847.

DeWitt, T.W., A.F. D’Andrea, C.A. Brown, B.D. Griffen, and P.M. Eldridge. 2004. Impact of burrowing shrimp populations on nitrogen cycling and water quality in western North American temperature estuaries. Pp. 107-115 In Akio Tamaki, editor. Proceedings of the Symposium on Ecology of Large Bioturbators in Tidal Flats and Shallow Sublittoral Sediments - from Individual Behavior to their Role as Ecosystem Engineers, November 2003. Nagasaki University, Nagasaki, Japan.

Duarte, C.M. 2002. The future of seagrass meadows. Environmental Conservation. 29(2): 192-206.

Dunford, R.W., Ginn, T.C., and W.H. Desvousges. 2003. The use of habitat equivalency analysis in natural resource damage assessments. Triangle Economic Research Technical Working Paper No. T-0303. Triangle Economic Research: Durham, NC. 46 Pp.

Ecotrust. 2002. A Watershed Assessment for the Siuslaw Basin. Prepared for the Siuslaw Watershed Council. Prepared by Ecotrust. Portland, OR. Accessed at http://www.siuslaw.org/index.htm. 02/12/06.

Emmett, R., Llanso, R., Newton, J., Thom, R., Hornberger, M., Morgan, C., Levings, C., Copping, A. and P. Fishman. 2000. Geographic signatures of North American west coast estuaries. Estuaries. 23(6): 765-792.

Environmental Law Institute (ELI). 2004. National symposium on compensatory mitigation and the watershed approach symposium report. May 19-21, 2004. Conservation Resources Center. Washington, D.C.

Environmental Law Institute (ELI). 2005. State wetland program evaluation. Phase 1. Environmental Law Institute. Washington, D.C. Accessed at http://www.elistore.org/reports_list.asp?topic=Wetlands. 01/05/06.

ESRI. 2006. Definition of GIS. ESRI webpage. Redlands, CA. Accessed at http://www.esri.com/getting_started/index.html. 06/02/06. 
Evans, N.R., Thom, R.M., Williams, G.D., Vavrinec, J., Sobocinski, K.L., Miller, L.M., Borde, A.B., Cullinan, V.I., Ward, J.A., May, C.W., and C. Allen. 2006. Lower Columbia River Restoration Prioritization Framework. Prepared for the Lower Columbia River Estuary Partnership. Battelle Memorial Institute, Pacific Northwest Division. Richland, WA. 39 Pp.

Federal Register. 1997. The National Action Plan to Implement the Hydrogeomorphic Approach to Assessing wetland Fucntions. June 20, 1997.62 (119): 33607-3360. Accessed at www.usace.army.mil./inet/functions/cw/cecwo/reg/hydrogeo.htm. 04.22.06

Findlay, S.E.G., Kiviat, E., Nieder, W.C. and E.A. Blair. 2002. Functional assessment of a reference wetland set as a tool for science, management, and restoration. Aquatic Science. 64: 107-117.

Fishman, P.A., N.S. Geiger, L. Sharp, J.W. Buell, and L. Wilson. 1987. Estuarine Mitigation Evaluation Project--Mitigation Site Evaluation Notebook. Submitted to the Department of Land Conservation and Development and The Division of StateLands. Fishman Environmental Services, Portland, Oregon.

Follansbee, B. and A. Stark. 1998. Tillamook Bay National Estuary Project. 30 pp. Accessed at http://gisweb.co.tillamook.or.us/library/reports/. 03/01/06.

Follensbe. B. and J. Mondragon 1999. Netarts watershed assessment. Tillamook Coastal Watershed Resource Center. Bay City, OR.

Fonseca, M.S., Kenworthy, W.J.,and G.W.Thayer. 1998. Guidelines for the conservation and restoration of seagrasses in the United States and adjacent waters. NOAA Coastal Ocean Program, Decision Analysis Series No. 12. 222 Pp.

Foote-Smith,C. 1996. Restoration in a watershed context. National Wetlands Newsletter. March-April: 10-13.

Frenkel, R.E. and J.C. Morlan. 1991. Can we restore our salt marshes? Northwest Environmental Journal. 7(1): 119-135.

Fuss, J.D. 1999. Identifying potential wetland restoration sites for estuary-wide restoration planning in Oregon:a pilot project in the Coos Estuary. Marine Resource Management Graduate Program Thesis Project. College of Oceanic and Atmospheric Sciences. Oregon State University. Corvallis, OR. Accessed at http://www.lcd.state.or.us/coast/demis/docs/d_fuss.pdf. 01/05/06.

Garono, R. and L. Brophy. 1999. Rock Creek (Siletz) Watershed Assessment. Prepared 
for the MidCoast Watersheds Council. Siletz Watershed Group. Accessed at http://www.earthdesign.com/rockcreek/DRAFT.PDF. 04/07/06.

Garono, R. and L. Brophy.2001. Midcoast $6^{\text {th }}$ field watershed assessment: Alsea, Ocean Tributaries, Salmon, Siletz, Yachats, Yaquina. Prepared for the MidCoast Watersheds Council. Accessed at http://www.earthdesign.com/midcoast/mcwc6th/MCWC_Assessment.pdf 04/07/06.

General Accounting Office (GAO). 2005. Wetlands protection Corps of Engineers Does Not Have an Effective Oversight Approach to Ensure That Compensatory Mitigation Is Occurring. GAO-05-898. United States Government Accountability Office. Washington, D.C. 42 Pp. Accessed at http://www.epa.gov/owow/wetlands/pdf/GAO05898.pdf. 12/15/05.

Gereta, E., Mwangomo, E., and E. Wolanski. 2004. The influence of wetlands in regulating water quality in the Seronera River, Serengeti National Park, Tanzania. Wetlands Ecology and Management. 12: 301-307.

Giannico, G. and J.A. Souder. 2005. Tide gates in the Pacific Northwest: operation, types and environmental effects. Oregon Sea Grant ORESU-T-05-001: Corvallis, OR. 28 Pp.

Gonor, J.J., Sedell, J.R., and P.A. Benner. 1988. What we know about large trees in estuaries, in the sea, and on coastal beaches. Chapter 4. In From the Forest to the Sea: A Story of Fallen Trees. Ed. By Maser, C., Tarrant, R. Trappe, and J. Franklin. Gen.Tech.Ref. PNW-GTR-229. 153 Pp. Accessed at www.fs.fed.us/pnw/pubs/229intro.pdf. 12/30/05.

Good, J.W. 1987. Mitigating estuarine development impacts in the Pacific Northwest: from concept to practice. Northwest Environmental Journal. 3(1): 93-110.

Good, J.W. 1996. Oregon CZM Profile: Protection of Estuaries and Coastal Wetlands. Unpublished report prepared as part of the National Coastal Zone Effectiveness Study. Oregon Sea Grant and Marine Resource Management Program, College of Oceanic and Atmospheric Sciences, Oregon State University: Corvallis, Or.

Good, J.W. 1999. Estuarine science, management, and restoration. In Watershed Stewardship: A learning guide, Chp. 10. Oregon State University Extension. Corvallis, OR.

Good, J.W. 2000. Summary and current status of Oregon's estuarine systems. In Oregon State of the Environment Report 2000, Statewide Summary. SOER Science Panel. Salem, OR. Section 3.3. Pp. 33-44. 
Good, J.W. and C.B. Sawyer.1998. Recommendations for a nonregulatory wetland restoration program for Oregon. Prepared for the Oregon Division of State Lands and the U.S. Environmental Protection Agency, Region X. Oregon Sea Grant. Corvallis, OR.

Good, J.W., Weber, J.W., and J.W. Charland.1999. Protecting estuaries and coastal wetlands through state coastal zone management programs. Coastal Management. 27: 139-186.

Gray, A., Simenstad, C.A., Bottom, D.L., and T.J. Cornwell. 2002. Contrasting functional performance of juvenile salmon habitat in recovering wetlands of the Salmon River estuary, Oregon, USA. Restoration Ecology. 10(3): 514-526.

Griffen, B.D., T.H. DeWitt, and C. Langdon. 2004. Particle removal rates by the mud shrimp Upogebia pugettensis, its burrow, and a commensal clam: effects on estuarine phytoplankton abundance. Marine Ecology Progress Series 269:223-236.

Groot, C. and L. Margolis. 1991. Pacific salmon life histories. UBC Press, Vancouver, British Columbia, Canada. 564 Pp.

Gunderson, D.R., Armstrong, D.A., Shi, Y., and R.A. McConnaughey.1990. Patterns of estuarine use by juvenile English sole (Parophrys vetulus) and Dungeness Crab (Cancer magister). Estuaries. 13(1): 59-71.

Gwin, S.E., Kentula, M.E., and P.W. Shaffer. 1999. Evaluating the effects of wetland regulation through Hydrogeomorphic classification and landscape profiles. Wetlands. 19(3): 477-489.

Hackney, C.T. 2000. Restoration of coastal habitats: expectation and realty. Ecological Engineering. 15: 165-170.

Hamilton, S.F. 1984. Estuarine mitigation: the Oregon process. Oregon Department of State Lands. Salem, OR.

Holsman, K.K. 2003. The necessity for intertidal foraging by estuarine populations of subadult Dungeness crab, Cancer magister: evidence from a bioenergetics model. Estuaries. 26(4B): 1155-1173.

Horning, S., Sterling, A., and S.D. Smith. 1989. Species profiles: life histories and environmental requirements of coastal fishes and invertebrates (Pacific Northwest) ghost shrimp and blue mud shrimp. Biological Report. US Fish and Wildlife Service. 82, 11, 93. 14 Pp. 
Hruby, T. 2004. Washington State Wetlands Rating System for Western WashingtonRevised. Ecology Publication 04-06-025. Washington State Department of Ecology. Olympia, WA.

Hruby, T., T. Granger, K. Brunner, S. Cooke, K. Dublonica, R. Gersib, T. Granger, L. Reinelt, K. Richter, D. Sheldon, E. Teachout, A. Wald, and F. Weinmann. 1999. Methods for Assessing Wetland Functions. Volume 1: Riverine and Depressional Wetlands in the Lowlands of Western Washington. Part 1: Assessment Methods. WA State Department of Ecology Publication \#99-115.

Huppert, D.D., Johnson, R.L., Leahy, J. and K. Bell. 2003. Interactions between human communities and estuaries in the Pacific Northwest: trends and implications for management. Estuaries. 26(4B): 994-1009.

Independent Multidisciplinary Science Team (IMST). 2002. Recovery of wild salmonids in Western Oregon lowlands. Technical report 2002-1 to the Oregon Plan for Salmon and Watersheds, Governor's Natural Resource Office, Salem, Oregon. Irlandi \& Crawford 1997

Jackson, P.L.1989. Field analysis of estuarine restoration at the Astoria mitigation bank. Geosciences Department. Oregon State University: Corvallis, OR. 12 pp.

Jackson, P.L.1991. Managing Oregon’s estuarine resource lands. Journal of Soil and Water Conservation. January-February: 23-26.

Jay, D. A., and P. Naik. 2002. Separating human and climate impacts on Columbia River hydrology and sediment transport. In G. Gelfenbaum and G. Kaminsky (Eds.), Southwest Washington coastal erosion workshop report 2000, p. 38-48. U.S. Geological Survey Open File Report, 02-229.

Johnson, J. 1999. Nehalem River watershed assessment. Prepared by Environmental Science and Resources Program, Portland State University. For the Upper and Lower Nehalem River Watershed Councils. Portland, OR.

Johnson, J.B. 2005. Hydrogeomorphic wetland profiling: an approach to landscape and cumulative impacts analysis. US Environmental Protection Agency. EPA/620/R05/001. Research Triangle Park, NC. 33 Pp.

Kentula, M.E. and T.H. DeWitt. 2003. Abundance of seagrass (Zostera marina L.) and macroalgae in relation to the salinity-temperature gradient in Yaquina Bay, Oregon, USA. Estuaries. 26(4B): 1130-1141.

Kentula, M.E. and McIntire, C.D.1986. The autoecology and production dynamics of eelgrass (Zostera marina L.) in Netarts Bay, Oregon. Estuaries. 9(3): 188-199.

Kentula, M.E., Sifneos, J.C., Good, J.W., Rylko, M., and K. Kunz. 1992. Trends and 
patterns in section 404 permitting requiring compensatory mitigation in Oregon and Washington, USA. Environmental Management. 16(1): 109-119.

King, D.M. and E.W. Price. 2004. Developing defensible wetland mitigation ratios: a companion to "the five-step wetland mitigation ratio calculator. Prepared by University of Maryland Center for Environmental Science. Prepared for National Oceanic and Atmospheric Administration. Office of Habitat Conservation. Silver Spring, Maryland. 43 Pp.

Kneib, R.T. 2000. Salt marsh ecoscapes and production transfers by estuarine nekton in the southeastern United States. In Weinstein, M.P. and D.A. Kreeger., eds., Concepts and controversies in tidal marsh ecology. Kluwer Academic Publishers: Dordrecht, The Netherlands. p. 267-292.

Kusler, J.A., and M.E. Kentula.1990. Executive summary. In, Kusler, J.A., and Kentula, M.E., eds., Wetland creation and restoration-The status of the science: Washington, D.C., Island Press. p. Xvii-xxv.

Kusler, J. 2003. Final report 1: wetland assessment for regulatory purposes: assessing wetlands functions and values. Association of State Wetland Managers. Berne, NY. Accessed at http://www.aswm.org/propub/functionsvalues.pdf. 10/15/05.

Lower Columbia River Estuary Partnership (LCREP). 2005. Assessing trends in the lower Columbia River. LCREP. Portland, OR.

Lewis, R.R. 2000. Ecologically based goal setting in mangrove forest and tidal marsh restoration. Ecological Engineering. 15: 191-198.

Lichatowich, J.A. 1999. Salmon Without Rivers: A History of the Pacific Salmon Crisis. Island Press. Washington, D.C. 317 Pp.

Little, C. 2000. The biology of soft shores and estuaries. Oxford: Oxford University Press. 252 Pp.

Long, E. R. 2000. Degraded sediment quality in U.S. estuaries: a review of magnitude and ecological implications. Ecological Applications. 10(2): 338-349.

Lupi, F., Kaplowitz, M.D., and J.P. Hoehn. 2002. The economic equivalency of drained and restored wetlands in Michigan. American Journal of Agricultural Economics. 84(5): 1355-1361.

MacIntyre, H.L., Geider, R.J., and D.C. Miller. 1996. Microphytobenthos: the ecological role of the "Secret Garden" of unvegetated, shallow-water marine habitats. 1. Distribution, abundance and primary production. Estuaries. 19(2A): 186-201.

Magnusson, A. and R. Hilborn. 2003. Estuarine influence on survival rates of coho 
(Oncorhynchus kisutch) and Chinook salmon (Oncorhynchus tshawytscha) released from hatcheries on the U.S. Pacific Coast. Estuaries. 26(4B): 1094-1103.

Marcus, L. 2000. Restoring tidal wetlands at Sonoma Baylands, San Francisco Bay, California. Ecological Engineering 15:373-383.

McIntire, D.D. and M.C.Amspoker. 1984. Benthic primary production in the Columbia River Estuary. Department of Botany and Plant Pathology. Corvallis, OR: Oregon State University.

Miller, B.A. and S. Sadro. 2003. Residence time and seasonal movements of juvenile coho salmon in the ecotone and lower estuary of Winchester Creek, South Slough, Oregon. Transactions of the American Fisheries Society. 132: 546-559.

Miller, J.A. and C.A. Simenstad.1997. A comparative assessment of a natural and created estuarine slough as rearing habitat for juvenile Chinook and coho salmon. Estuaries. 20(4): 792-806.

Mirati Jr., A.H. 1999. Assessment of road culverts for fish passage problems on stateand county-owned roads. Statewide Summary Report. Oregon Department of Fish and Wildlife. Salem, OR.

Mitsch, W.J. and J.G. Gosselink. 2003. Wetlands. Third Edition. John Wiley \& Sons, Inc. New York, NY. 919 Pp.

Mitsch , W.J. and N.Wang. 2000. Large-scale coastal wetland restoration on the Laurentian Great Lakes: determining the potential for water quality improvement. Ecololgical Engineering. 15: 267-282.

Mitsch, W.J. and R.F. Wilson. 1996. Improving the success of wetland creation and restoration with know-how, time, and self-design. Ecological Applications. 6(1): 77-83.

Morlan, J.C.1991. Ecological status and dynamics of a salt marsh restoration in the Salmon River Estuary, Oregon. M.S. Thesis. Corvallis, OR: Oregon State University. 126 pp.

Morlan, J.C. 2000. Summary of current status and health of Oregon's freshwater wetlands. In Oregon State of the Environment Report 2000, Statewide Summary. SOER Science Panel. Salem, OR. Section 3.4. Pp. 45-52.

Morlan, J.C. 2006. Personal communication, Janet Morlan, Wetlands Program Manager. Oregon Department of State Lands. Salem, OR.

Moy, L.D. and L.A. Leven. 1991. Are Spartina marshes a replaceable resource? A functional approach to evaluation of marsh creation effort. Estuaries, 14: 1-16. 
Mrazik, S. 2004. Water quality report: ambient monitoring stations in the Oregon coast coho evolutionarily significant unit. Oregon Department of Environmental Quality. Laboratory Division. Portland, OR. 24 Pp.

National Oceanic and Atmospheric Administration (NOAA). 2006. National Tidal Datum Epoch 1983-2001 for Oregon stations. Accessed at http://www.tidesandcurrents.noaa.gov/station_retrieve.shtml?type=Tide+Data. 04/11/06.

National Wetlands Mitigation Action Plan (NWMAP). 2002. National Wetlands Mitigation Action Plan. December 24, 2002. Accessed at http://www.mitigationactionplan.gov/maphtml.html. 11/01/05.

National Wetlands Mitigation Action Plan (NWMAP). 2004a. Federal guidance on the use of off-site and out-of-kind compensatory mitigation under section 404 of the Clean Water Act. April 7, 2004 DRAFT. 9 Pp. Accessed at http://www.mitigationactionplan.gov/040407SiteKindGuidance.html. 12/01/05.

National Wetlands Mitigation Action Plan (NWMAP). 2004b. Federal guidance on the use of preservation as compensatory mitigation under section 404 of the Clean Water Act. August 27, 2004 DRAFT. Accessed at www. mitigationactionplan.gov/Preservation_8-27-04.htm. 03/02/06.

Nelson, W.G., Lee II, H., Lamberson, J.O., Engle, V., Harwell, L., and L.M. Smith. 2004. Condition of estuaries of western United States for 1999: a statistical summary. Office of Research and Development, National Health and Environmental Effects Research Laboratory, EPA/620/R-04/200

Nordstrom, J.L., Kaysner, C.A., Blackstone, G.M., Vickery, M.C.L., Bowers, J.C. and A. Depaola. 2004. Effect of Intertidal Exposure on Vibrio parahaemolyticus Levels in Pacific Northwest Oysters. Journal of Food Protection. 67(10): 2178-2182.

North Coast Explorer. 2006. OSU Natural Resource Digital Library. Accessed at http://northcoastexplorer.info/index.aspx. 04/12/06.

National Research Council (NRC). 1992. Restoration of Aquatic Ecosystems: Science, Technology and Public Policy. National Academy Press, Washington, D.C.

National Research Council (NRC). 2001. Compensating for Wetland Losses Under the Clean Water Act. National Academy Press, Washington, D.C., pp. 82.

Omernik, J.M. and A.L. Gallant. 1986. Ecoregions of the Pacific Northwest. EPA/600/386/033. US EPA, Environmental Research Laboratory, Corvallis, OR. 39 Pp. 
Oregon Biodiversity Project. 1998. Oregon’s Living Landscape: Strategies and opportunities to conserve biodiversity. Defenders of Wildlife. 218 Pp.

Oregon Coastal Atlas. 2006. Oregon Coastal Atlas Website. Accessed at http://www.coastalatlas.net/. 01/06/06.

Oregon Coastal Management Program (OCMP). 2005. Coastal and estuarine land conservation plan DRAFT for Public Review. October 2005. Oregon Coastal Management Program, Oregon Department of Land Conservation and Development. Salem, OR.

Oregon Department of Environmental Quality (DEQ). 2004. Oregon's 2004 Water Quality Assessment. Section 305(b) Report. Oregon Department of Environmental Quality. Water Quality Division. July 2004. 55 Pp.

Oregon Department of Environmental Quality (DEQ). 2006. 303d list 2002 Department of Environmental Quality (DEQ). Accessed at http://www.deq.state.or.us/wq/WQLData/View303dList02.asp. 02/04/06.

Oregon Department of Land Conservation and Development (DLCD). 2001. A citizen's guide to the Oregon Coastal Management Program. Oregon Department of Land Conservation and Development. Salem, OR.

Oregon Department of Land Conservation and Development (DLCD). 2006a. Oregon Statewide Planning Goals \& Guidelines GOAL 16: ESTUARINE RESOURCES OAR 660-015-0010(1). Accessed at http://www.oregon.gov/LCD/docs/goals/goal16.pdf. 03/17/05.

Oregon Department of Land Conservation and Development (DLCD). 2006b. Oregon Statewide Planning Goals \& Guidelines GOAL 17: COASTAL SHORELANDS OAR 660-015-0010(2). Accessed at http://www.oregon.gov/LCD/docs/goals/goal17.pdf. 03/17/05.

Oregon Department of State Lands (DSL). 1989. Heads of Tides for Coastal Streams in Oregon. Engineering Section, Division of State Lands. Salem, OR.

Oregon Department of State Lands (DSL). 2001. February 3, 2001 Success criteria document. Salem, OR.

Oregon Department of State Lands (DSL). 2005. Summary of Activities for Oregon's Removal-Fill Program for Waters of the State 2002-2004. Oregon Department of State Lands. Salem, OR.

Oregon Department of State Lands (DSL). 2006. Administrative Rules 141-085. Salem, 
OR. Accessed at http://www.oregon.gov/DSL/PERMITS/docs/rf_rules_revision_03-06_141085.pdf. 04/16/06.

Oregon Department of State Lands (DSL). 2006. Removal Fill Program. Salem, OR. Accessed at http://www.oregon.gov/DSL/PERMITS/r-fintro.shtml. 04/16/06.

Oregon Department of State Lands (DSL). 2006. Wetlands Program. Local Wetland Inventories. Salem, OR. Accessed at http://www.oregon.gov/DSL/WETLAND/lwi.shtml. 04/16/06.

Oregon Department of Fish and Wildlife (ODFW). 2005. Oregon's Comprehensive Wildlife Conservation Strategy. Oregon Department of Fish and Wildlife, Salem, Oregon. Accessed at http://www.dfw.state.or.us/conservationstrategy/. 12/01/05.

Oregon Geospatial Enterprise Office (GEO). 2006. Oregon Geospatial Data Clearinghouse. Salem, OR. Accessed at //www.gis.state.or.us/data/. 01/06/06/

Oregon Habitat Joint Venture (OHJV). 2006. Oregon’s wetlands: Coast Range. Accessed at http://www.ohjv.org/oregons_wetlands/coastrange.html. 02/05/06. 02/01/06.

Oregon Natural Heritage Information Center (ORNHIC). 2006. Oregon GAP Analysis. Accessed at http://oregonstate.edu/ornhic/or-gap.html. 04/18/06.

Oregon Watershed Enhancement Board (OWEB). 2004. OWEB Prioritization Framework DRAFT. Salem, OR. Accessed at http://www.oregon.gov/OWEB/GRANTS/docs/grants_restoration_prioritization_f rmwork.pdf. 12/10/05.

Oregon Wetlands Joint Venture (OWJV). 1994. Joint Venture Implementation Plans. Northern Oregon Coast. Prepared for: Pacific Coast Joint Venture. Oregon Wetlands Joint Venture. West Linn, OR. Accessed at http://www.ohjv.org/pdfs/northern_oregon_coast.pdf. 03/05.06.

Parker, S. 2001. Ecola Creek Watershed Assessment: A Living Document. Cannon Beach, OR. Accessed at http://www.clatsopwatersheds.org/ecola/ecolaassessment.pdf. 02/10/06.

Partners in Flight. 2006. Partners in Flight website. Accessed http://www.partnersinflight.org/. 04/19/06.

Penttila, D.E. 2001. Intertidal spawning ecology of three species of marine forage fishes in Washington State. Journal of Shellfish Research. 20(3): 1198.

Pess, G.R., Montgomery, D.R., Bilby, R.E., Steel, E.A., Feist, B.E., and H.M. Greenberg. 
2001. Influence of landscape characteristics and land use on coho salmon (Oncorhynchus kisutch) abundance, Snohomish River,Washington. National Marine Fisheries Service, Seattle, WA.

Philip Williams and Associates and P.M. Faber. 2004. Design guidelines for tidal wetland restoration in San Francisco Bay. The Bay Institute and California State Coastal Conservancy, Oakland, C.A. 83 pp.

Pinit, P.T., Bellmer, R.J. and G.W. Thayer. 1998. NOAA Fisheries Technical Guidance Manual for Success Criteria in Restoration Projects DRAFT. NOAA Restoration Center Office of Habitat Conservation NOAA Fisheries. Silver Spring, MD.

Portnoy, J. W. and A.E. Giblin.1997. Effects of historic tidal restrictions on salt marsh sediment chemistry. Biogeochemistry. 36: 275-303.

Portnoy, J.W. 1999. Salt marsh diking and restoration: biogeochemical implications of altered wetland hydrology. Environmental Management. 24(1): 111-120.

Pritchard, D. W. 1967. What is an estuary: physical viewpoint. p. 3-5 in: G. H. Lauf (ed.) Estuaries, A.A.A.S. Publ. No. 83, Washington, D.C.

Quarterman, P.J.1985. Estuarine mitigation policy in Oregon: a history. Unpublished paper. Salem, OR. 20 pp.

Race, M.S. and M.S. Fonseca. 1996. Fixing compensatory mitigation: what will it take? Ecological Applications. 6(1): 94-101.

Roegner, C., Diefenderfer, H., Whiting, A., Borde, A., Thom, R., and E. Dawley. 2006. Monitoring protocols for salmon habitat restoration projects in the lower Columbia river and estuary. DRAFT. Prepared for the US Army Corps of Engineers, Portland District. Pacific Northwest National Laboratory. Richland, WA.

Restore America's Estuaries (RAE). 1999. Principles of estuarine habitat restoration. Report on the Restore America's Estuaries and Estuarine Research Federation Partnership. Year One. RAE-ERF: Arlington, Va.

Roise, J.P., Gainey, K.W., and T.H. Shear. 2004. An approach to optimal wetland mitigation using mathematical programming and geographic information system based wetland function estimation. Wetlands Ecology and Management. 12: 321331.

Rooper, C.N., Gunderson, D.R., and D.A. Armstrong.2003. Patterns in use of estuarine habitat by juvenile English sole (Pleuronectes vetulus) in four eastern north pacific estuaries. Estuaries. 26(4B): 1142-1154. 
Rozas, L.P., Caldwell, P., and T.J. Minello. 2005. The fishery value of salt marsh restoration projects. Journal of Coastal Research. SI(40): 37-50.

Ruhl, J.B. and Salzman, J. 2006. The effects of wetland mitigation banking on people. National Wetlands Newsletter. 28(2): 1, 9-14.

Salo, E.O. 1991. Life history of chum salmon (Oncorhynchus keta ). In Pacific salmon life histories. Edited by C.Groot and L. Margolis. UBC Press, Vancouver, British Columbia. Pp. 233-309.

Scranton, R. 2004. The application of Geographic Information Systems for delineation and classification of tidal wetlands for resource management of Oregon's coastal watersheds. Marine Resource Management Program. College of Oceanic and Atmospheric Sciences. Oregon State University: Corvallis, OR. 88 Pp.

Sherwood, C.R., Jay, D.A., Harvey, R.B., Hamilton, P., and C.A. Simenstad. 1990. Historical changes in the Columbia river estuary. Progress in Oceanography. 25: 299-352.

Short, T.S., Burdick, D.M., Short, C.A., Davis, R.C. and P.A. Morgan. 2000. Developing success criteria for restored eelgrass, salt marsh and mud flat habitats. Ecological Engineering. 15: 239-252.

Shreffler, D.K. and K. Griffin. 2000. Ecological interactions among eelgrass, oysters, and burrowing shrimp in Tillamook Bay, Oregon. Prepared for Tillamook County Performance Partnership. 43 Pp.

Shreffler, D.K., Simenstad, C.A., and R.M. Thom.1992. Foraging by Juvenile salmon in a restored estuarine wetland. Estuaries. 15(2): 204-213.

Sigleo, A.C., Mordy, C.W., Stabeno, P., and W.E. Frick. 2005. Nitrate variability along the Oregon coast: estuarine-coastal exchange. Estuarine coastal and shelf science. 64: 211-222.

Simenstad, C.A. and J.L. Burke. In progress. Estuarine landscape classification and inventory. Wetland Ecosystem Team. School of Aquatic and Fishery Sciences. University of Washington. Seattle, WA.

Simenstad, C.A. and J.R. Cordell. 2000. Ecological assessment criteria for restoring anadromous salmonid habitat in Pacific Northwest estuaries. Ecological Engineering. 15: 283-302.

Simenstad, C.A. and K.L. Fresh. 1995. Influence of intertidal aquaculture on benthic communities on Pacific Northwest estuaries: scales of disturbance. Estuaries. 18(1A): $43-70$.

Simenstad, C.A. and R.M. Thom. 1995. Spartina alterniflora (smooth cordgrass) as an 
invasive halophyte in Pacific Northwest estuaries. Hortus Northwest 6:9-12, 3840.

Simenstad, C.A. and R.M. Thom.1996. Functional equivalency trajectories of the restored Gog-Le-Hi-Te estuarine wetland. Ecological Applications. 6(1): 38-56.

Simenstad, C.A., Tanner, C.D., Thom, R.M., and L.L. Conquest.1991. Estuarine habitat assessment protocol. Prepared for US Environmental Protection Agency. Region 10, Office of Puget Sound. Seattle, WA. 200 Pp.

Simenstad, C.A., Thom, R.M., Levy, D.A. and D.L. Bottom. 2000. Landscape structure and scale constraints on restoring estuarine wetlands for Pacific coast juvenile fishes. In Concepts and controversies in tidal marsh ecology. Edited by M.P. Weinstein and D.A. Kreeger. Kluver Academic Publishers, Dordrecht. Pp. 597630.

Simenstad, C., Tanner, C., Crandell, C., White, J., and Cordell, J. 2005. Challenges of habitat restoration in a heavily urbanized estuary: evaluating the investment. Journal of Coastal Research. SI(40): 6-23.

Smith, S.E. 1983. A mitigation plan for the Columbia river estuary. Columbia River Estuary Study Taskforce. Astoria, OR. 135 Pp.

Smith, R.D., A. Ammann, C. Bartoldus, and M.M. Brinson. 1995. An approach for assessing wetland functions using hydrogeomorphic classification, reference wetlands, and functional indices. Technical Report WRP-DE-9. U.S. Army Engineers Waterways Experiment Station, Vicksburg, MS.

Snyder, K.U., T.J. Sullivan, R.B. Raymond, J.M. Bischoff, S. White, and S.K. Binder. 2001.Miami River Watershed Assessment. E\&S Environmental Chemistry, Inc., Corvallis, OR.

Snyder, K.U., T.J. Sullivan, R.B. Raymond, E. Gilbert, and D. Moore. 2002. Necanicum River Watershed Assessment. E\&S Environmental Chemistry, Inc., Corvallis, OR.

Solazzi, M.F., Nickelson, T.E., Johnson, S.L., and J.D. Rodgers. 2000. Effects of increasing winter rearing habitat on abundance of salmonids in two coastal Oregon streams. Canadian Journal of Fisheries and Aquatic Sciences. 57: 906-914.

Spivey, M.L. and B. Ainslie. 2004. Landscape profiling and better wetland restoration: how HGM can help. $24^{\text {th }}$ Anuual ESRI User Conference Proceedings, August 913, 2004: San Diego, CA. Accessed http://gis.esri.com/library/userconf/proc04/docs/pap1193.pdf. 03/02/06.

Strittholt, J.R. and P.A. Frost. 1996. Determining abundance and distribution of eelgrass 
(Zostera spp.) in Tillamook Bay Estuary, Oregon using multispectral airborne imagery. Earth Design Consultants. Prepared for Tillamook Bay National Estuary Project. Garibaldi, OR. 10 pp.

Sullivan, T.J., Snyder, K.U., Gilbert, E., Bischoff, J.M., Wustenberg, M.,Moore, J. and D. Moore. 2005. Assessment of water quality in association with land use in the Tillamook Bay watershed, Oregon, USA. Water, Air, and Soil Pollution. 161: 323.

Sutter, L.A. 1999. Wetland mapping in coastal North Carolina. Division of Coastal Management. North Carolina Department of Environment and Natural Resources. 45 Pp.

Sutter, L.A., Stanfill, J.B., Haupt, D.M., Bruce, C.J., and J.E. Wuenscher. 1999. NCCREWS: North Carolina Coastal Region Evaluation of Wetland Significance. Division of Coastal Management. North Carolina Department of Environment and Natural Resources.

Tanner, C.D.1990. Mitigation planning on an estuary-wide scale: an alternative to caseby-case wetland mitigation policy. Institute of Marine Affairs Thesis. University of Washington.

Teal, J.M. and B.L. Howes. 2000. Salt marsh values: retrospection from the end of the century. Pp. 9-19 In Weinstein, M.P. and D.A. Kreeger. 2000. Concepts and controversies in tidal marsh ecology. Kluwer Academic Publishers: Dordrecht, The Netherlands. 875 Pp.

Thayer, G.W. and M.E. Kentula. 2005. Coastal restoration: where have we been, where are we now, and where should we be going? Journal of Coastal Research. SI(40): $1-5$.

The Conservation Foundation. 1988. Protecting America's wetlands: an action agenda. 1988. Final Report of the National Wetlands Policy Forum. Washington D.C.

The Daily Astorian. 2006. Land Use Board of Appeals will decide on LNG rezoning. Februay 15, 2006. Astoria, OR.

Thom, R.M.1987. The biological importance of Pacific Northwest estuaries. Northwest Environmental Journal . 3(1): 21-41.

Thom, R.M. 1990. A review of eelgrass (Zostera marina L.) transplanting projects in the Pacific Northwest. Northwest Environmental Journal 6:121-137.

Thom, R.M.2000. Adaptive management of coastal ecosystem restoration projects. 
Ecological Engineering. 15: 365-372.

Thom, R.M., Borde, A.B., Rumrill, S., Woodruff, D.L., Williams, G.D., Southard, J.A. and S.L. Sargeant. 2003. Factors influencing spatial and annual variability in eelgrass (Zostera marina L.) meadows in Willapa Bay, Washington and Coos, Bay, Oregon, Estuaries. Estuaries. 26(4B): 1117-1129.

Thom, R.M., Williams, G., Borde, A., Southard, J., Sargeant, S., Woodruff, D., Laufle, J.C., and S. Glasoe. 2005. Adaptively addressing uncertainty in estuarine and near coastal restoration projects. Journal of Coastal Research. SI(40): 94-108.

Thom, R.M., Zeigler, R., and A.B. Border. 2002. Floristic development patterns in a restored Elk River estuarine marsh, Grays Harbor, Washington. Restoration Ecology. 10(3): 487-496.

Thomas, D. W. 1983. Changes in Columbia River estuary habitat types over the past century. Report prepared for CREDDP. Astoria, OR. 51 Pp.

Thorson, T.D., Bryce, S.A., Lammers, D.A., Woods, A.J., Omernik, J.M., Kagan, J., Pater, D.E., and Comstock, J.A., 2003. Ecoregions of Oregon. US Geological Survey. Reston, Virginia.

Tillamook Bay National Estuary Project. 1999. "Restoring the Balance” Comprehensive Conservation and Management Plan for Tillamook Bay, Oregon. Appendix I Tidal Wetlands Study. Tillamook Bay National Estuary Project: Garibaldi, OR.

Tiner, R.W. 2005. Assessing cumulative loss of wetland functions in the Nanticoke River watershed using enhanced national wetlands inventory data. Wetlands. 25(2): 405-419.

Turner, M.G., Gardner, R.H., and R.V. O’Neill. 2001. Landscape Ecology in Theory and Practice. Springer. New York, NY. 401 Pp.

United States Army Corps of Engineers (USACE). 1987. Corps of Engineers Wetlands Delineation Manual. Environmental Laboratory, U.S. Army Engineer Waterways Experiment Station.Vicksburg, Mississippi. 32 Pp.

United States Army Corps of Engineers (USACE). 1990. Memorandum of agreement between the Environmental Protection Agency and the Department of Environmental Protection Agency and the Department of the Army concerning the determination of mitigation under the Clean Water Act Section 404(b)(1) Guidelines. February 6, 1990. Accessed at http://www.usace.army.mil/inet/functions/cw/cecwo/reg/moafe90.htm. 12/06/05.

United States Environmental Protection Agency (EPA). [2006]. An Introduction and User's Guide to Wetland Restoration, Creation, and Enhancement. Developed by 
the Interagency Workgroup on Wetland Restoration: National Oceanic and Atmospheric Administration, Environmental Protection Agency,

Army Corps of Engineers, Fish and Wildlife Service, and

Natural Resources Conservation Service. 92 Pp. Accessed at http://www.epa.gov/owow/wetlands/pdf/restdocfinal.pdf. 05/23/06.

Valiela, I., G. Tomasky, J. Hauxwell, M. L. Cole, J. Cebrian, and K. D. Kroeger. 2000. Operationalizing sustainability: Management and risk assessment of land-derived nitrogen loads to estuaries. Ecological Applications 10:1006-1023.

Van Lonkhuyzen, R.A., LaGory, K.E., and J.A. Kuiper. 2004. Modeling the suitability of potential wetland mitigation sites with a Geographic Information System. Environmental Management. 33(3): 368-375.

Washington State Department of Ecology (DOE), U.S. Army Corps of Engineers Seattle District, and U.S. Environmental Protection Agency Region 10. March 2006. Wetland Mitigation in Washington State - Part 1: Agency Policies and Guidance (Version 1).Washington State Department of Ecology Publication \#06-06-011a. Olympia, WA. Accessed at http://www.ecy.wa.gov/pubs/0606011a.pdf. 05/30/06.

Weinmann, F., M. Boule’, K. Brunner, J. Malek, and V. Yoshino. 1984. Wetland plants of the Pacific Northwest. U.S. Army Corps of Engineers, Seattle. 85pp.

Weinstein, M.P. and D.A. Kreeger. 2000. Concepts and controversies in tidal marsh ecology. Kluwer Academic Publishers: Dordrecht, The Netherlands. 875 Pp.

Weinstein, M.P., Litvin, S.Y., and V.G. Guida. 2005. Considerations of habitat linkages estuarine landscapes, and the trophic spectrum in wetland restoration design. Journal of Coastal Research. S1(40): 51-63.

West, T.L., Clough, L.M., and G.A. William. 2000. Assessment of function in an oligohaline environment: lessons learned by comparing created and natural habitats. Ecological Engineering. 15: 303-321.

Williams, K.B. 2002. The potential wetland restoration and enhancement site identification procedure: a geographic information system for targeting wetland restoration and enhancement. North Carolina Department of Environment and Natural Resources. Division of Coastal Management. 33 Pp.

Williams, P.B., M.K. Orr, and N.J. Garity. 2002. Hydraulic geometry: a geomorphic tool for salt marsh restoration design. Restoration Ecology.10(3): 527-542.

Wolanski, E., Boorman, L.A., Chicharo, L., Langlois-Saliou, E. and R. Lara. 2004. Ecohydrology as a new tool for sustainable management of estuaries and coastal waters. Wetlands Ecology and Management. 12: 235-276. 
Zedler, J.B. 1996. Coastal mitigation in southern California: the need for a regional restoration strategy. Ecological Applications. 6(1): 84-93.

Zedler, J.B. 2001. Handbook for Restoring Tidal Wetlands. CRC Press LLC: Boca Raton, F.L. 439 Pp.

Zedler , J.B. and J.C. Callaway.1999. Tracking wetland restoration: do mitigation sites follow desired trajectories? Restoration Ecology. 7(1): 69-73.

Zeff, M.L. 2002. Salt marsh tidal channel morphometry: applications for wetland creation and restoration. Restoration ecology. 7(2): 205-211. 